بدائل مقترحة لتطوير منظومة تقييم أداء الجامعات --- د/ محمد ابراهيم عبد العزيز خاطر

$$
\begin{aligned}
& \text { بدائل مقترحة لتطوير منظومة تقييم أداء الجامعات المصرية } \\
& \text { باستخدام أسلوب القياس المقارن }
\end{aligned}
$$

إعداد

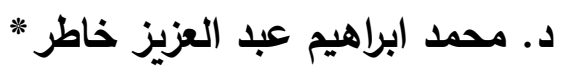

$$
\text { مقدمة: الإطار العام للارلسة:؛ }
$$

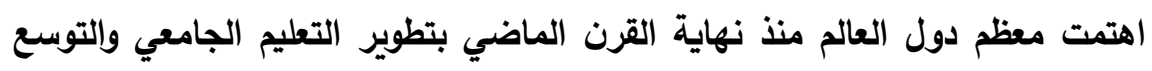

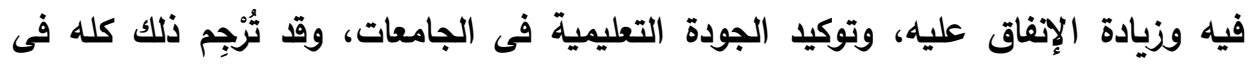

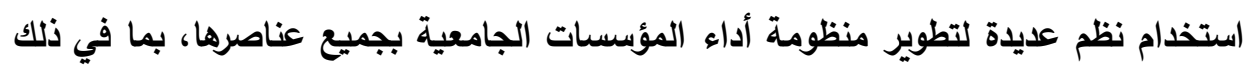

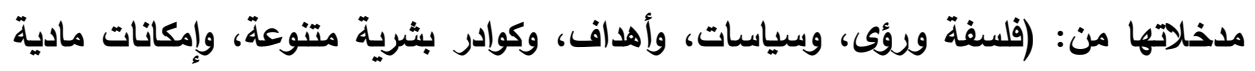

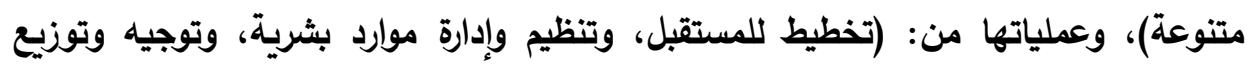

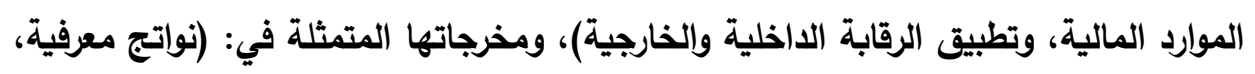

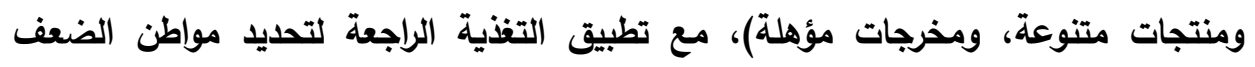

$$
\text { والسعي نحو تلافيها في المستقبل. }
$$

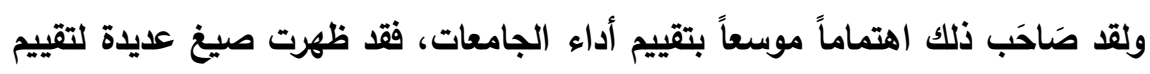

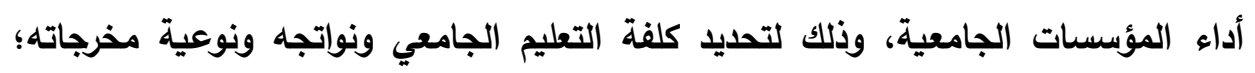

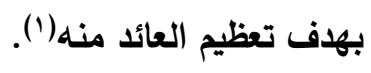

ومع ظهور حركات العولمة وتدويل التعليم، أصبحت المؤسسات الجامعية مطالبة

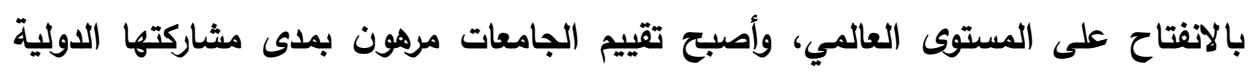

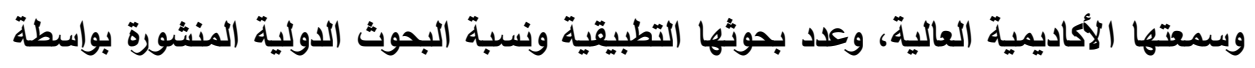

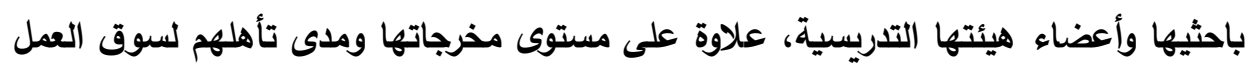

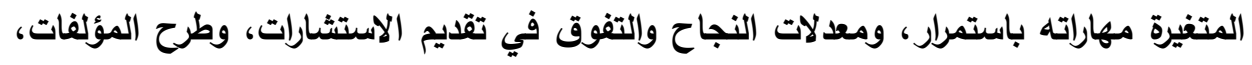

والتظلب على الأزمات والمخاطر المحتملة(؟).

* مدرس بقسم التربية المقارنة والإدارة التربوية - كلية التربية جامعة قناة السويس 
مجلة كلية التربية بالإسماعيلية - العدد الرابع والأربعون - مايو 9 م

ومن جهة أخرى فقد أصبحت التنافسية بين المؤسسات الإنتاجية والخدمية قضية حتمية

تفرضها متغيرات القرن الحالي، الأمر الأى فرض على الجامعات -باعتبارها مؤسسات إنتاجية وخدمية في الوقت ذاته- ضرورة السعي نحو تحقيق الريادة والسبق في الخدمات والمنتجات والمخرجات، وبخاصة مع ظهور منظمات دولية تجرى تصنيفات عالمية دورية للجامعات، مثل: "Academic Ranking of World Universities: التصنيف الأكاديمي لجامعات العالم "Times " والمعروف بتصنيف "ثنغهاي"- وتصنيف مجلة "التايمز" للتعليم العالى :ARWU"

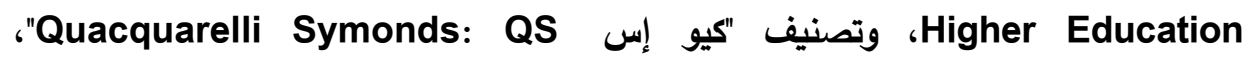
وتصنيف "الويبومتركس Webometrics"، كذلك طَرَت بعض الهيئات الدولية جوائز تميز للمؤسسات الإنتاجية والخدمية، لتحصل المؤسسات على هذه الجوائز بعد تقييمها على ضوء

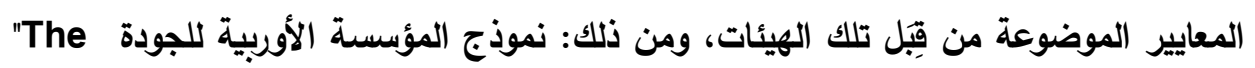
European Foundation for Quality Management: EFQM" الأمريكي، ونموذج التميز الكندي، كما ظهرت نماذج للتميز على المستوى العربى، مثل: نموذج دبى للتميز، وجائزة الملك عبد العزيز للتميز المؤسسي... وغيرها.

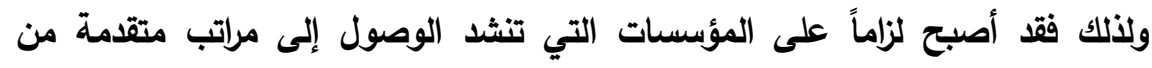
الإبداع والتميز المحلي أو العالمي أن تعمل على تحسين أدائها قياساً بأداء المنافسين

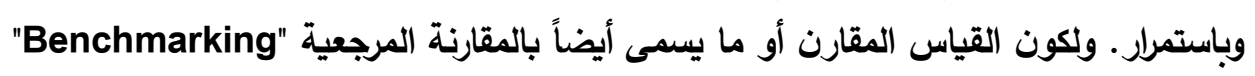
من الأساليب المتميزة التى تساعد المؤسسة على معرفة مستوى أدائها قياساً بأداء المنافسين

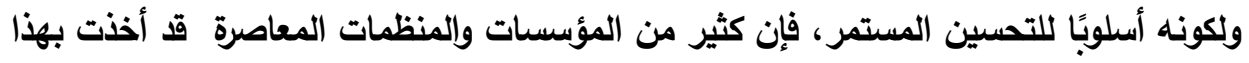

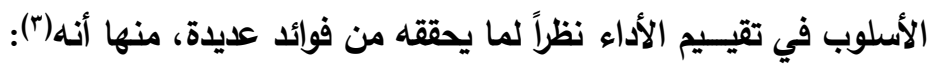

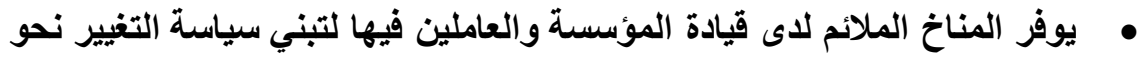
كل ما هو أفضل وجديد. • يسهم بثكل فاعل في تطوير الإبداع الفردي والجماعي.

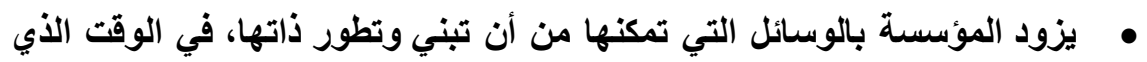
تعالج فيه نقاط الضعف والخلل. • يساعد المؤسسة في التحديد الدقيق للفجوة بين أدائها وأداء المؤسسات المتميزة الر ائدة. • يساعد على تحديد العمليات الحرجة والملحة، وإعطائها الاهتمام اللازم والأولوية في التفيذ.

• يسهم بشكل فاعل في زيادة احتمالات تحقيق منافع إضافية للمؤسسة مستقبلاً. 
بدائل مقترحة لتطوير منظومة تقييم أداء الجامعات --- د/ محمد ابراهيم عبد العزيز خاطر

وبذلك يعد أسلوب القياس المقارن، من أهم الأساليب التي تعتمد عليها المؤسسات

المعاصرة في تطوير أدائها وتحسين جودتها، فهو يتمثل فى العملية المستمرة لقياس المنتجات

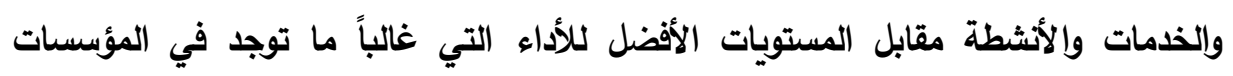
المنافسة أو مؤسسات أخرى لايها عمليات مشابهة، بما يسهم في زيادة كفاية وفاعلية مقاييس جودة الأداء الاخلية.

وبناءً على ذلك فقد تسارعت كثير من الجامعات العالمية في عملية مقارنة الأنشطة أو العمليات بالتطبيقات الأفضل لمعرفة الفجوة بين مؤسساتها وبين منافسيها من المؤسسات الأخرى، ففى الولايات المتحدة الأمريكية يرتكز التقييم التعليمي في المؤسسات الجامعية على لئل استخدام القياس المقارن فى كليات جامعات عديدة، وذلك بهدف إعداد تقارير تسهم فى لإنى تحقيق الكفاءة والفاعلية وخاصة فى الخطط والبرامج الدراسية فى هذه الكليات. ففى جامعة "هارفارد" "Harvard University" يتم استخدام النموذج الشامل للقياس المقارن الذى يقدم لمتخني القرارات ومكاتب التوظيف مخرجات فى صورة تقارير لتحسين الأداء التعليمي للجامعة، حيث إن هذا النموذج يركز على أداء الطلاب وهيئات التدريس وشروط التدريس الجيد والبرامج التعليمية واستخدام المؤشرات الخارجية الجيدة، وكذلك اقتراح مقاييس جيدة للتغيير (؛). وفى جامعة "بنسلفانيا" "Pennsylvania University" -والثهيرة بجامعة (بين

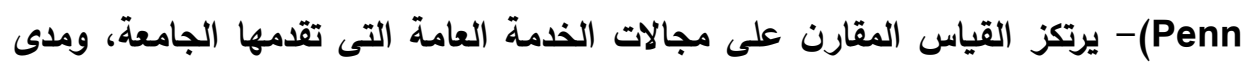
التوسع فى تكافؤ الفرص التعليمية، وتقويم أعضاء هيئة التدريس وصناعة القرار التعليمي، حيث يتم توظيف تقارير القياس المقارن لتقييم المبادرات، ونسب تدريس البرامج التنموية لوقت كامل بمشاركة الطلاب، وكذلك التركيز على أداء الخريجين حديثاً من الجامعة، وتخطيط تلفيط الموارد التعليمية والمشروعات البحثية والبرامج الخدمية؛ وذلك كله بغرض تقديم تقارير تسهر فى تحسين وزيادة كفاءة وفاعلية منظومة الأداء الجامعى ككل(ث). وفى استراليا تهتم الحكومة الاسترالية بتحقيق الكفاءة واللفاعلية في جامعاتها، وذلك بناءً

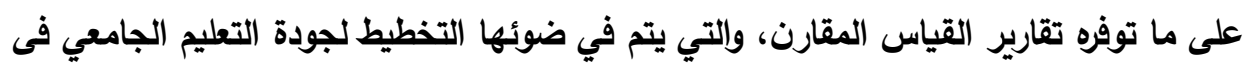

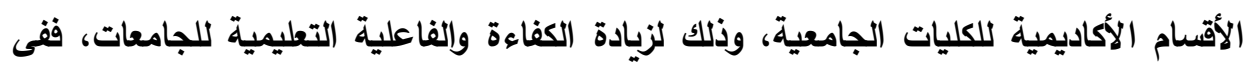

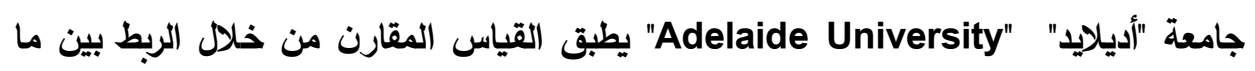

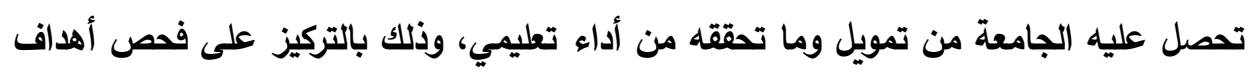

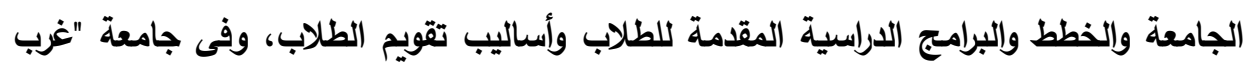
استراليا" "The University of Western Australia" يتم القياس المقارن باستخدام 
مجلة كلية التربية بالإسماعيلية - العدد الرابع والأربعون - مايو 9 م

مؤشرات عديدة منها: التقدم التكنولوجي، والعلاقات بين الأقسام الأكاديمية والجامعات الأخرى

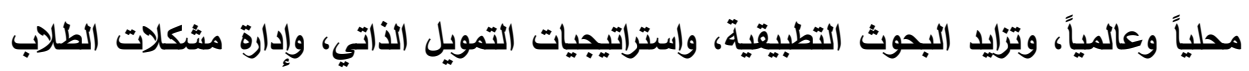

وحلها (7).

وفيما يتعلق بالجامعات المصرية فإن تقييم الأداء أو قياسه يتمثل بثكل رئيس في قيام

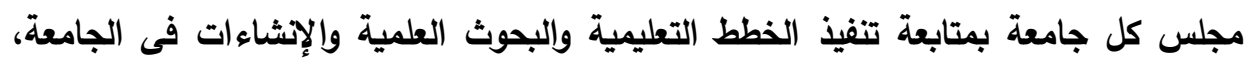
وذلك فى ضوء ما يحدد المجلس الأعلى للجامعات من سياسات عامة للتعليم الجامعي والبحث

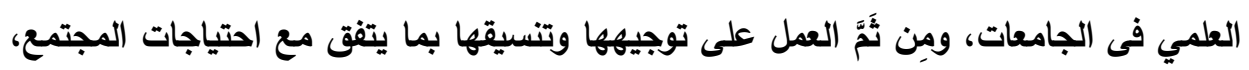
وتيسير تحقيق الأهداف القومية والاجتماعية والاقتصادية والعلمية للدولة) (v). مشكلة الاراسة وأسئلتها:

على الرغم من خضوع الجامعات المصرية لمحاولات عديدة لتقييم الأداء والمتابعة، وتطبيق أساليب معاصرة لاعم الأداء بالمؤسسات الجامعية وقياس فاعليته، مثل: الاهتمام بالتقييم الذاتي، وتطبيق معايير الاعتماد وضمان الجودة، إلا أن الجامعات المصرية لازالت تعانى من مشكلات عديدة تثير إلى ضعف في منظومة تقييم الأداء المؤسسي، وهو ما لإنائ يتضح جلياً في المشكلات التالية: • خضوع الجامعات المصرية لقانون واحد ينظم الهيكل الإداري للجامعات كافة، والعلاقات بين كل مستوى من المستويات الأفقية والرأسية وكل ما يتعلق بعناصر الإدرئ منظومة التعليم الجامعي، وهذا التميط أوجد مناخاً يفتقد محركات التجديد والمبادأة. • ضعف استجابة النظام الجامعي فى أهدافه وبرامجه وطرائقه للتغييرات الاقتصادية والتكنولوجية والعلمية والمعرفية، والحاجة إلى مراجعته من منظور الجودة التعليمية

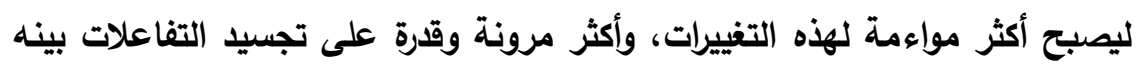

وبين قطاعات المجتمع الأخرى(^).

• قلة الضوابط والمعايير النوعية التي تضمن الوصول إلى مستويات عالية ومتميزة من الاجن الأداء البحثى فى الجامعات، كما أن كثير من تلك المعايير يفتقر إلى المرونة

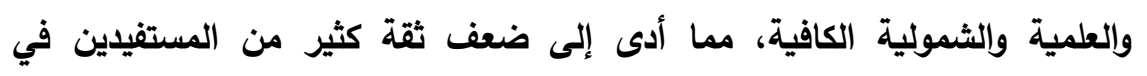
مخرجاتها البحثية(9).

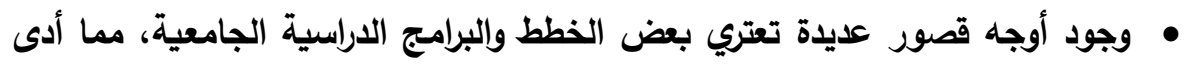
إلى ضعف قيام الجامعات بدورها فى إعداد القوى العاملة فى المجتمع، فضلاً عن الاختلا النوعي للتخصصات الاراسية وغلبة التخصصات النظرية على التخصصات 
بدائل مقترحة لتطوير منظومة تقييم أداء الجامعات --- د/ محمد ابراهيم عبد العزيز خاطر

العملية، وضعف استجابة التعليم الجامعي لمتطلبات سوق العمل المتغيرة باستمرار كماً وكيفاً.

• إن الجامعات المصرية بوضعها الحالي لم تستطع أن تحقق بكفاءة مهمة رئيسة

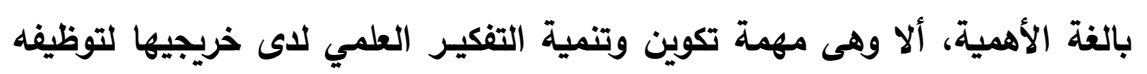

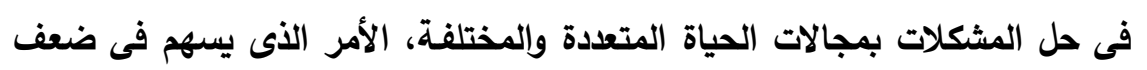

$$
\text { دورها الخدمى لمجتمعها (·) (1). }
$$

ومن منظور الجودة فإن المبادئ العامة للتوجهات المستقبلية فى التعليم الجامعى المصرى تؤكد على ضرورة توافر آليات فعالة لتقويم الأداء فى التعليم الجامعى فى إطار

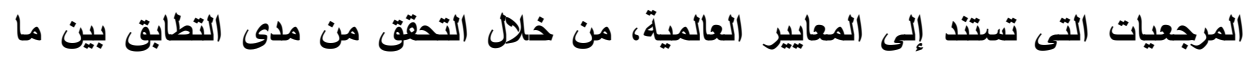

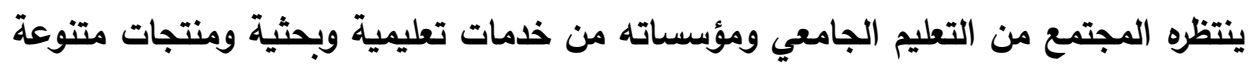
من جانب، وما تقوم به الجامعات فعلياً من جانب آخر، استناداً إلى العلاقات الوثيقة التئي ونئي تربط بين الجامعات وعالم العمل والمجتمع بفئاته المختلفة.

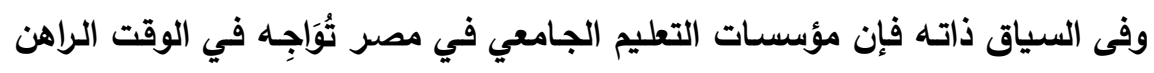
صعوبات عدة منها ما يرتبط بجودة أدائها أو التصور المعرفي حول موقعها التنافسي بالنسبة للجامعات المنافسـة الأخرى في نفس البيئة (محلياً) أو في قطاعات بيئية أخرى (عالمياً)، ولعل ذلك يرجع إلى بعض الأسباب والتي من أهمها: قلة الاهتمام بتحديد المستفيد والدراسات

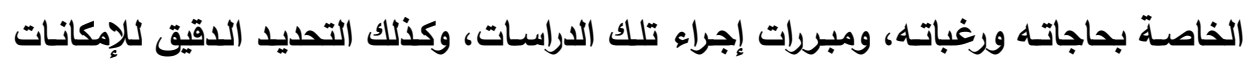

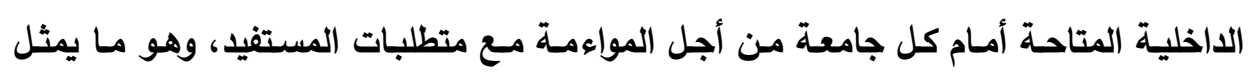
التحدي الأول الذى تواجها مؤسسات التعليم الجامعي العاملة في البيئة المحلية، أمـا التحدي الثاني فهو يتعلق بالموقع التنافسي للمؤسسة قياساً إلى باقي المؤسسات المنافسـة في البيئة

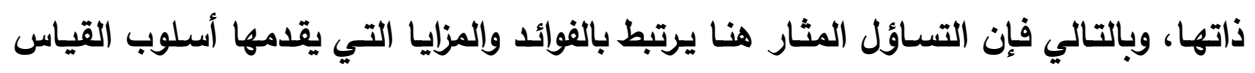
المقارن في تحديد موقع المؤسسة قياساً إلى منافسيها ('"). وفى ضوء ما سبق عرضه من مثكلات يمكن بلورة مشكلة الدراسة فى السؤال الرئيس

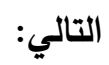
كيف يمكن تطوير منظومة تقييم أداء الجامعات المصرية باستخدام أسلوب القياس المقارن؟ ومن هذا السؤال الرئيس تتفرع الأسئلة التالية: 
مجلة كلية التربية بالإسماعيلية - العدد الرابع والأربعون - مايو 9 م ـ

1- ما الأسس النظرية لمنظومة تقييم أداء المؤسسات الجامعية؟

r - ما طبيعة أسلوب القياس المقارن في المؤسسات المعاصرة؟ r- ما أهم النماذج العالمية في توظيف أسلوب القياس المقارن لمنظومة تقييم الأداء الجامعى؟ مأو ؟ - ما البدائل المقترحة لتطوير منظومة تقييم أداء الجامعات المصرية باستخدام أسلوب

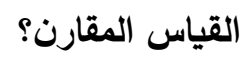
أهداف الدراسة: - 2 - 2 تسعى الدراسة إلى توظيف أسلوب القياس المقارن لتطوير منظومة تقييم الأداء الجامعية، بما تشمله من مدخلات وعمليات ومخرجات، وذلك بتقديم ثلاثة بدائل مقترحة لتطبيق هذا الأسلوب بالجامعات المصرية والمفاضلة بين هذه البدائل؛ من أجل تحديد البديل الأكثر مناسبة للسياق التشريعى والتنظيمى بالجامعات المصرية. أهمية الاراسة: تنبع أهمية الدراسة مما يلي: • أهمية قضية تقييم الأداء المؤسسى وبخاصة في المؤسسات الجامعية، وذلك لما

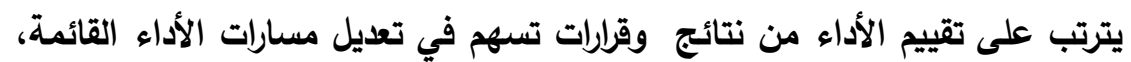

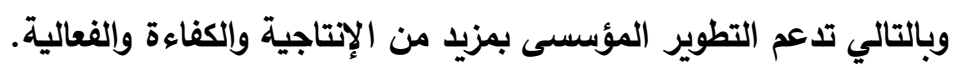
•مواكبة الدراسة للتغيرات الراهنة الحادثة على الساحة الدولية، ومنها إصدار عديد من المنظمات والهيئات تصنيفات متنوعة مثل تصنيفات الجامعات، ومؤشرات الأداء المتميز لجميع المؤسسات الإنتاجية والخدمية على السواء؛ مما جعل من المقارنة

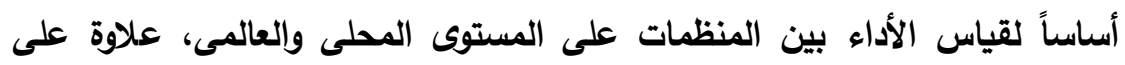
اعتبارها ضرورة حتمية تفرضها التوجهات المعاصرة في تقييم المؤسسات والمنظمات المختلفة. • توجيه نظر متخذى القرار على مستوى مؤسسات التعليم العالى، لأهمية توظيف القياس المقارن في تقييم منظومة الأداء الجامعى، وذلك من خلال بدائل مقترحة تسهم في تنفيذ عمليات القياس بما يتناسب مع طبيعة السياق الثقافى للجامعات 


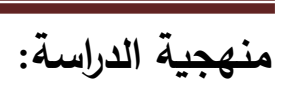

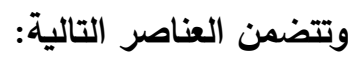

$$
\text { 1 - الأسلوب المنهجى للاراسة: }
$$

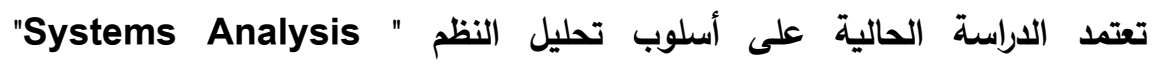
Approach

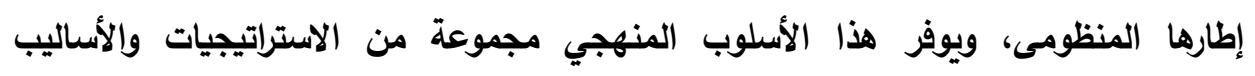

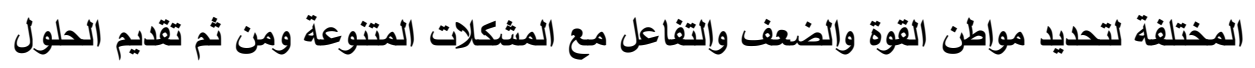

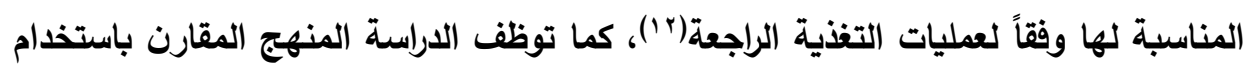

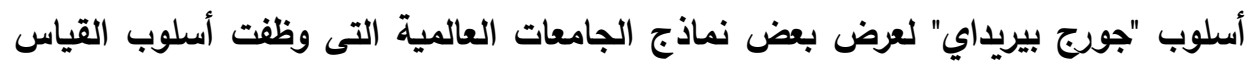

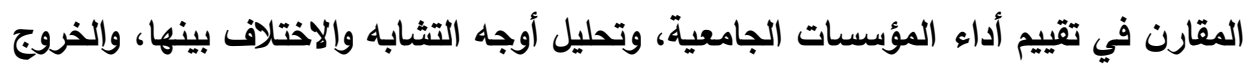

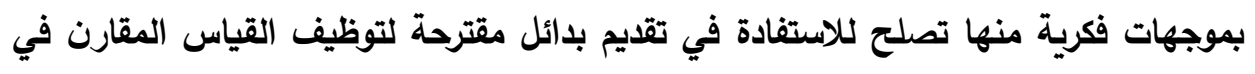
منظومة تقييم أداء الجامعات المصرية.

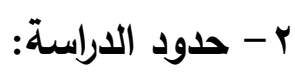

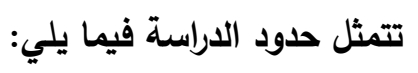
أ- الحدود الموضوعية:

تهتم الدراسة الحالية بتوظيف أسلوب القياس المقارن في تقييم الأداء الجامعى العادي

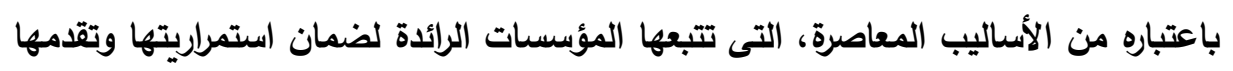

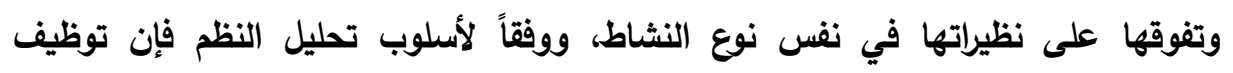

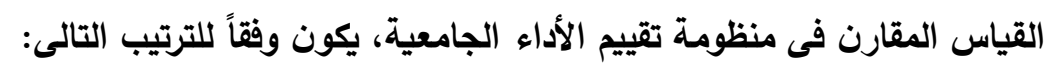

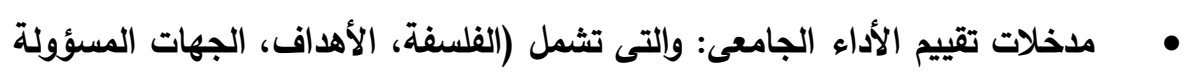

$$
\text { عن تقييم الأداء). }
$$

• عمليات تقييم الأداء الجامعى: والتى تثمل عمليات: (التخطيط لتقييم الأداء

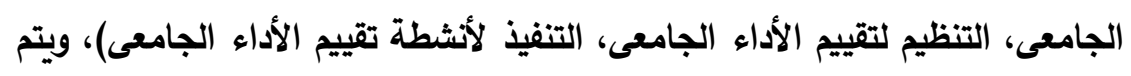

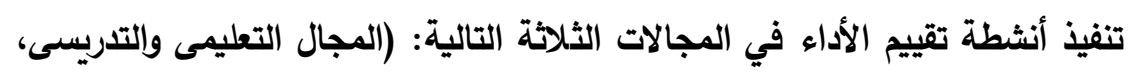
المجال البحثى، المجال المجتمعى وإلخدمى).

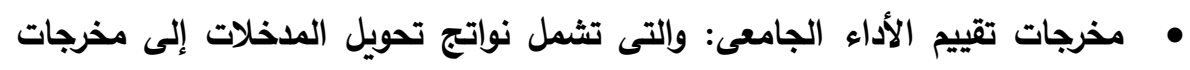

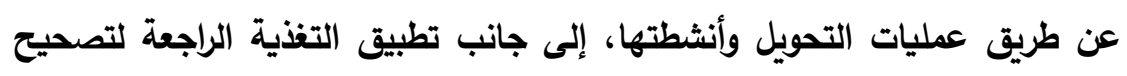

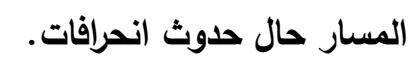


مجلة كلية التربية بالإسماعيلية - العدد الرابع والأربعون - مايو 9 م ـ

$$
\text { ب- الحدود المكانية: }
$$

تقتصر الدراسة على بعض نماذج الجامعات المتقدمة في بعض الدول، مثل نموذج

جامعة "هارفارد" "Harvard University"، وجامعة "بنسلفانيا" " University كلتا الجامعتين بتوكيد الجودة وذلك بلراسة كل جوانب الأداء التعليمى، وكذلك دراسة السياسات الجامعية والعوامل الداعمة لتنفيذها وأيضاً العوامل المعيقة لتنفيذها للتخلص لبه منها، ويتأتى ذلك من خلال دراسات التقييم الذاتى التى تنجزها كل جامعة، هذا مع مراعاة العمليات المرتبطة بتوكيد الجودة، ويأتي في مقدمتها تقارير القياس المقارن التى تتناول الأهداف التعليمية، وسياسات القبول، والخطط والبرامج الدراسية, وأساليب تقويم الطلاب، ولابل والأداء البحثى والخدمى لكل جامعة. وبناءً على تقارير القياس المقارن التى تحصل عليها كلتا الجامعتين يتم عقد اتفاقيات مع المنظمات الخارجية لإناحة فرص التدريب لطلابها ولإخضاع الخطط والبرامج الدراسية المختلفة بها للتطوير المستمر؛ وذلك كله لزيادة مستوى أداء طلابها وتحسين الإنتاجية التعليمية والبحثية والمجتمعية لها، وبذلك فإن ما تسفر عنه تقارير القياس المقارن يوضح العقبات التى تقف فى طريق تحسين الإتتاجية الجامعية في مجالات التعليم والبحث العلمى وخدمة المجتمع لكل جامعة، ومن هنا يمثل القياس المقارن وتقاريره نقطة الانطلاق الحقيقية للتطوير والتنافسية بين هاتين الجامعتين وغيرهما.

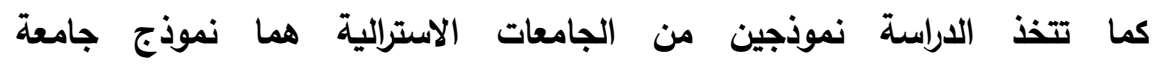
"أديلايد" "Adelaide University"، ونموذج جامعة "غرب استراليا" Western Australia" والاستفادة من تقاريره فى زيادة الكفاءة والفاعلية التعليمية مما يتيح لها المنافسة مع غيرها من الجامعات الأخرى، خاصة وأن كلتا الجامعتين تتمتعان بسمعة متميزة بين الجامعات الاسترالية وتهتم بربط أداءها الأكاديمى بما تحصل عليه من أموال ودعم مادي باعتبار ذلك لكان من عناصر المنافسة، انطلاقاً من سعيهما لتحسين الأداء الاقتصادى للمجتمع.

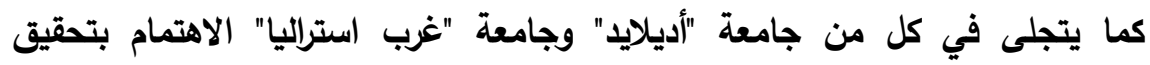
مستوى بحثي متقدم وتقديم مجموعة متنوعة من الدورات الدراسية الاحترافية للطلاب الجامعيين وطلاب الاراسات العليا والمتخصصين في مختلف المجالات، علاوة على تأسيس مليس المراكز البحثية التعاونية والتى تعمل جميعها على تعزيز البحث المشترك بين الجامعات 
بدائل مقترحة لتطوير منظومة تقييم أداء الجامعات --- د/ محمد ابراهيم عبد العزيز خاطر

والقطاع الصناعي، علاوة على اشتراك كلتا الجامعيتين في عضوية منظمة "الكومنولث"

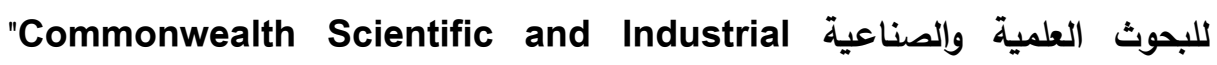
Research Organization: CSIRO" والتطوير في أستراليا، كما أنها إحدى أكبر المؤسسات البحثية على مستوى العالم، وقد نفذت هينت

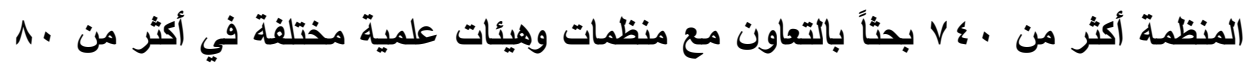
دولة، وأجرت العديد من الأبحاث في مجالات، مثل: الصحة والزراعة وتكنولوجيا المعلومات والصناعة والطاقة المستدامة والتعدين والمعادن والفضاء والبيئة والموارد الطبيعية.. وغيرها. ب - مصطلحات الاراسة: تتحدد مصطلحات الاراسة فيما يلي:

أ- منظومة تقييم الأداء System of Performance Evaluation: تقييم الأداء عبارة عن آلية لتحديد مدى تقدم المؤسسـة في مسيرة تحقيق أهدافها، وهذا التقدم يتم تحديده من خلال نظم لقياس الأداء، ويعبر عنه في شكل زيـادة في مستويات الإنتاجية(r) (1). ويُمَنِّل تقيـيم الأداء طريقـة منظمـة لتحديـد مسـتوى المسخلات والمخرجـات والعمليـات الإنتاجيـة في المنظمـات المختلفـة، ويتضـمن معـايير ومقـاييس لـلألداء للحكم على الأمسور والمواقف، وبدون مقياس واضح وقابل للاستخدام ومتفق عليه،، ستتحول الأمور إلى التدخل الشخصي الانطباعي في الحكم على الأمور وتقييمها (؛ أ).

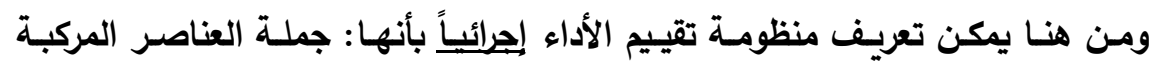

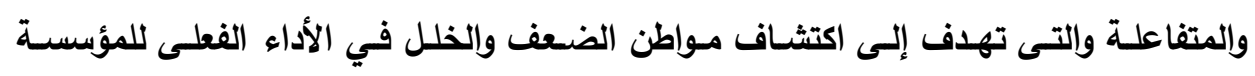

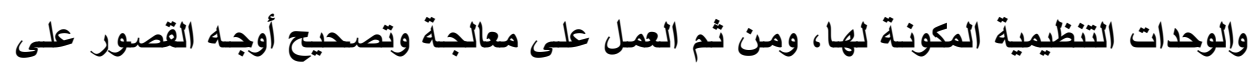

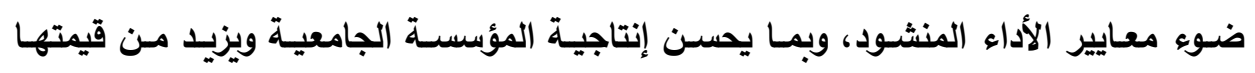
المضافة لمجتمعها.

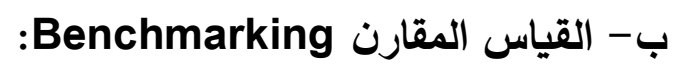
يُمَثِّل القياس المقارن أحد أهم الأساليب والمداخل المعاصرة لقياس الأداء في المؤسسات الخدمية والإنتاجية على السواء ، وتجدر الإثارة إلى ظهور مسميات علديدة لمفهوم

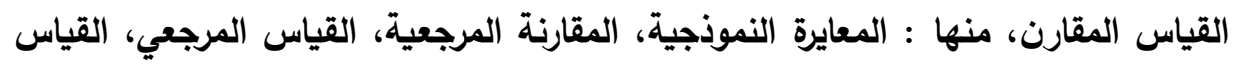
بالغير، لكنها تتفق جميعاً على مفهوم واحد وهو التحسين المستمر، والتحسين من خلال 
مجلة كلية التربية بالإسماعيلية - العدد الرابع والأربعون - مايو 9 م ـ

التعلم من الآخرين والاستفادة من كل ما هو جديد، بما يتلاءم مع ظروف وإمكانات كل مؤسسة (10).

ويمكن تعريف القياس المقارن بأنه هو الوسيلة المستخدمة من أجل الحكم على مدى

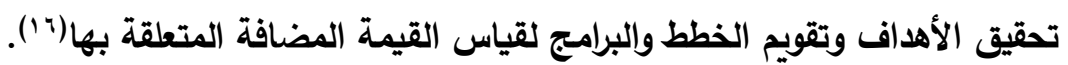

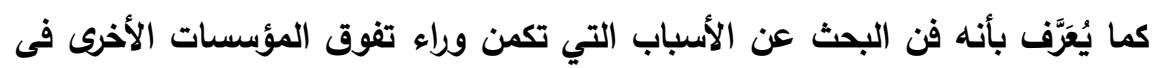
الأداء، والاسترشاد بممارستها فى تحسين أداء المؤسسة المعنية، ومحاولة إيجاد مداخل

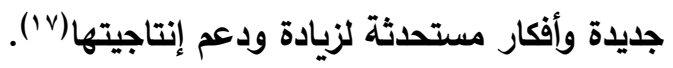
ويمكن تعريفه أيضاً بأنه أسلوب منظم للتعلم من الآخرين، من خلاد الماجيتهات الملاحظة لنماذج

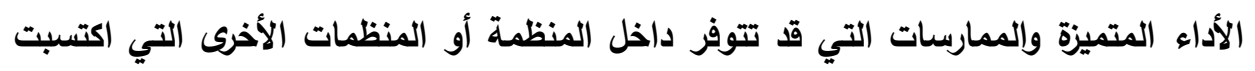

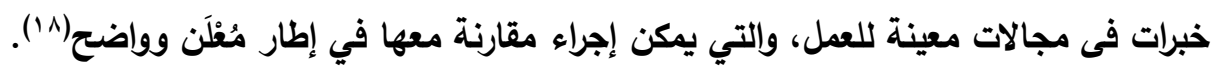

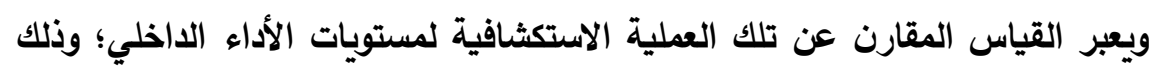
من خلال مقارنة معايير قياس أداء متعددة المستويات، داخلية وخارجية بهدف رصد الواقع، ومقارنة عمليات الأداء بنظيراتها الداخلية والخارجية في مؤسسة أخرى تتميز بمكانة

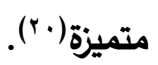

ومما سبق يمكن القول أن القياس المقارن يمثل أحد أدوات تقييم وتطوير وتحسين الأداء؛ والتي تعمل على تحديد الفجوات بين الأداء، والتعرف على أسبابها والعمل على إنى معالجتها من خلال تبني الممارسات المتميزة سواء داخل المؤسسة أو خارجها للوصول الئي أداء متميز يتوجه بالجامعة نحو مستقبل أفضل. مناتئ.

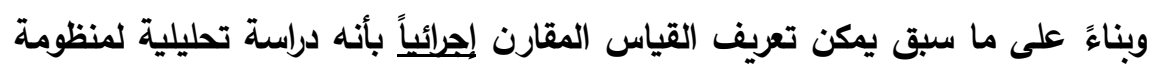

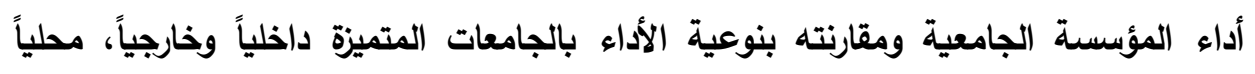

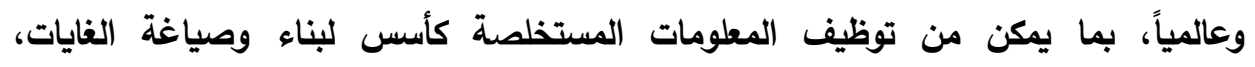
والاستراتيجيات، والممارسات التنظيمية المختلفة، وتحقيق التحسين في العمليات والخدمات والنواتج. الاراسات السابقة: من خلال الاطلاع على أدبيات الفكر التربوي الإداري المعاصر، تبين أن هناك مجموعة من الدراسات والبحوث ذات الصلة بأسلوب القياس المقارن والتي يمكن أن تفيد الدراسة

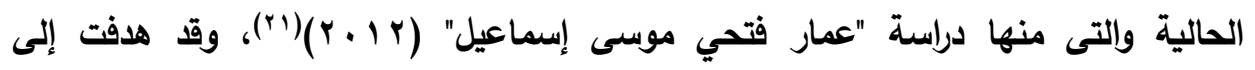
توضيح دور القياس المقارن في تعديد معوقات إدارة المعرفة بمؤسسات التعليم العالى في موسي 
بدائل مقترحة لتطوير منظومة تقييم أداء الجامعات --- د/ محمد ابراهيم عبد العزيز خاطر

مصر، إلى جانب تقييم الجودة بتلك المؤسسات، والتأكيد على أهميته في تطوير مؤسسات

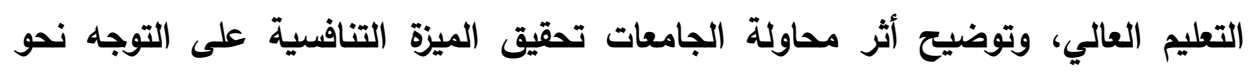
تطبيق القياس المقارن في التعليم العالي، وقد توصلت الدراسة إلى أن القياس المقارن يسهم في توفير الأدوات التي يمكن من خلالها تقييم كفاءة المؤسسات الجامعية وفعاليتها، علاوة على الخروج باستراتيجيات وأساليب التحسين المستمر ، والتعلم من الخبرات والتجارب السابقة. كما هدفت دراسة كل من "محمد الحفناوى وعلى البسطويسى ومنى قرىى Mohamed (2014) El-Hefnawy , Ali El-"Bastawissy \&Mona Kadry المقارن لمؤسسات التعليم العالى المصرى باستخدام الفهرسة المركبة، والتى تعمل على تحليل

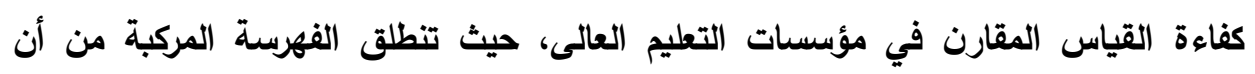

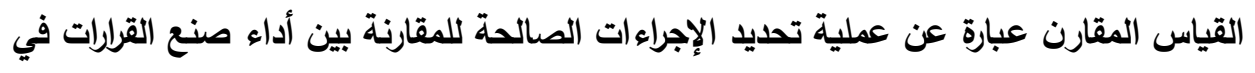
الوحدات التظيمية الجامعية واستخدامها في تحديد المواقع النسبية لصنع القرار في تلك الوحدات، وقد تم تطبيق القياس المقارن -أو ما يعرف أيضاً بالمقارنة المرجعية- للكثف عن الأخطاء الإدارية والعمل على تصحيحيها، علاوة على الوصول إلى تعلم أفضل لممارسات جيدة

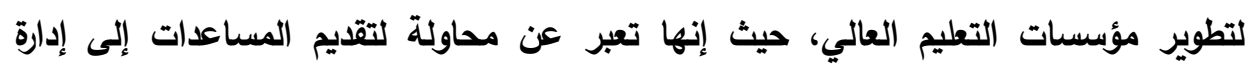

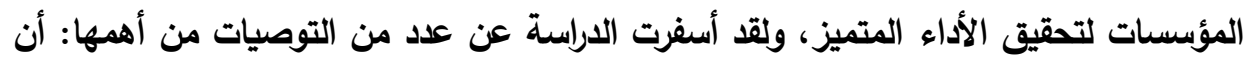
مؤسسات التعليم العالي المصرية ينبغي أن تبأ في المقارنة لقياس أنشطتها مع المؤسسات

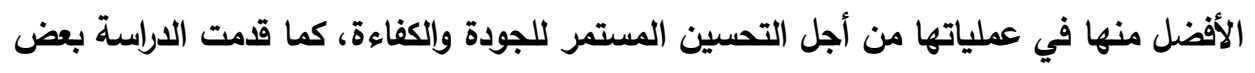
الفوائد التي تعود على المؤسسات التى تقوم بالمقارنة المرجعية بنفسها، مثل: تقاسم المعرفة، التهات تحسين جودة المؤسسة، عرض الأفكار الجيدة، توسيع آفاق التشغيل في المؤسسات، تكوين ثقافة الانفتاح على الأفكار الجديدة، كما أن هذه الدراسة أقيمت لتكون وسيلة ممكنة للتطوير بحيث تؤدي إلى إدارة جامعية مبتكرة في المستقبل.

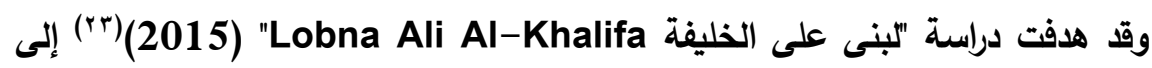
توضيح معايير الاعتماد في التعليم العالى في المنطقة العربية، وذلك من خلال عمل دراسة مقارنة باستخدام القياس المقارن، وتحليل بعض المقاييس المطبقة عالمياً، وكيفية مقارنتها بما يمكن تطبيقه على المستويات الإقليمية والمحلية، ومحاولة الربط بين واقع التطبيق الفعلي

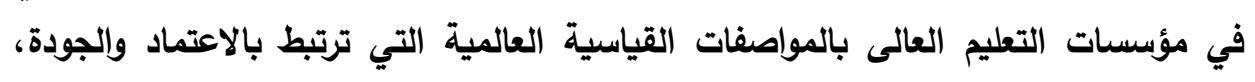

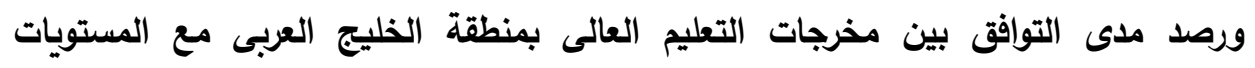


مجلة كلية التربية بالإسماعيلية - العدد الرابع والأربعون - مايو 9 م

العالمية، وقد أكدت الدراسة أن القياس المقارن يسهم في تحقيق التميز والارتقاء بالجودة التعليمية، وتحقيق كفاءة الأداء لمؤسسات التعليم الجامعي وتطويرها.

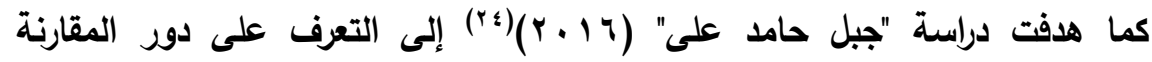
المرجعية بما تملكه من إمكانات وأنواع متعددة تعمل على جمع البيانات والمعلومات على أسس علمية وأخلاقية، والتعرف على التجارب الناجحة في صناعة قرار جامعي ناجح يعمل على تطوير مؤسسات التعليم الجامعي وتحقيق أهدافها، ومن ثم تقديم تصور مقترح لاستخدام المقارنة المرجعية كمدخل لاعم صناعة القرار الجامعي، ولتحقيق الأهداف السابقة استخدمت فوني الاراسة المنهج الوصفي، وذلك لوصف وتحليل مفهوم المقارنة المرجعية وخطوات تطبيقها والعوامل المؤثرة على نجاحها في مؤسسات التعليم الجامعي، وكذلك وصف وتحليل مفهوم صنع القرار الجامعي، ومميزاته ومعوقاته؛ وذلك للوقوف على أدوار المقارنة المرجعية في في فئي دعم صناعة القرار الجامعي، ولقد خلصت الدراسة إلي عدة نتائج من أهمها: أن المقارنة المرجعية تمتلك مميزات وامكانات وأنواع متعددة تعمل على دعم صناعة القرار الجامعي والتوجه بالجامعة نحو مستقبل أفضل، علاوة على إسهامها في تحقيق مقومات ودعائم الميزة التنافسية لها في ظل المناخ التنافسي السائد بين الجامعات، وضمان جودة التعليم الجامعي، وتحسين جودة التدريس، والبحث العلمي، وتطبيق الحوكمة المؤسسية، وتفعيل نظم وبرامج التنمية المهنية المستدامة.

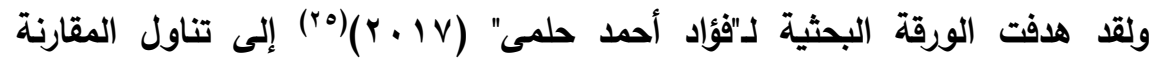
المرجعية من حيث التعريف والمفهوم وإلمصطلحات ذات الصلة، وتقييم الأداء المؤسسى من حيث الأنواع والمؤشرات وأفضل الممارسات، ثم تناولت الدراسة أنماط المقارنة المرجعية، وأثرها في تحسين أداء المؤسسات التعليمية، وأهم متطلبات تطبيق المقارنة المرجعية في المؤسسات التعليمية، وكذلك أهم مراحل وخطوات التطبيق، ولقد قدمت الورقة بعض المقترحات والتوصيات لتطبيق المقارنة المرجعية في المؤسسات التعليمية، منها ما يلى: قيام المؤسسات التعليمية بعقد دورات تدريبية للمدراء والإداريين بهدف إدراك الأساليب الإدارية

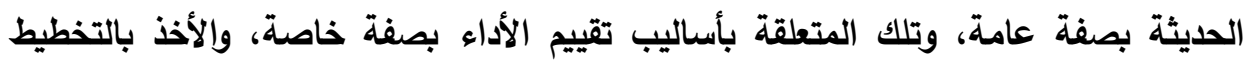
الاستراتيجى لأنه من أهم خطوات تطبيق المقارنة المرجعية كما أنه يعمل على خفض التكلفة وتحديد فجوات الأداء بثكل جيد، وتثكيل فرق عمل من المتخصصين لإجراء المقارنة المرجعية داخل المؤسسات التعليمية ومع مؤسسات أخرى خارجية وذلك بثكل دورى.

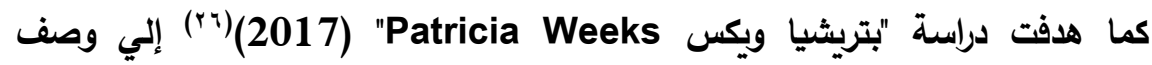
ممارسات القياس المقارن في التعليم الجامعي في استراليا، حيث طُبِقَت الدراسة على 
بدائل مقترحة لتطوير منظومة تقييم أداء الجامعات --- د/ محمد ابراهيم عبد العزيز خاطر

الجامعات الحكومية، ولتحقيق أهداف الاراسة تم استخدام المسح المقطعي لجمع البيانات من الجامعات الحكومية في الولايات الاسترالية الستة، وكانت عينة الدراسة من الإداريين وأعضاء هيئة التدربس، ولقد توصلت الدراسة إلى نتائج من أهمها ما يلى: أن أنظمة التحسين

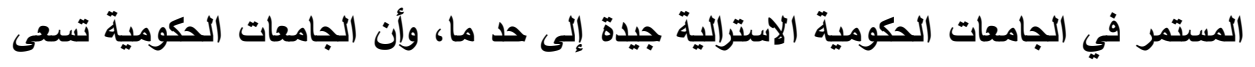
بثكل فعال وناجح نحو التحسين المستمر بتوظيف البحوث الإجرائية وتطبيق مؤشرات الأداء باعتبارهما مصادر لجمع المعلومات وحل المشكلات بثكل فورى، وفى ضوء تلك النتائج توصلت الدراسة إلى عدد من التوصيات منها: ضرورة التخطيط للاستفادة من القياس المقارن في مجالات العمل المختلفة بمؤسسات التعليم العالى، مع السعى نحو تطبيق القياس المقارن من منظور دولى، وذلك بالعمل على تهيئة الظروف المناسبة لذلك، مثل: الوقت، وتوفير الموارد المتاحة، وتحديد عناصر المقارنة.

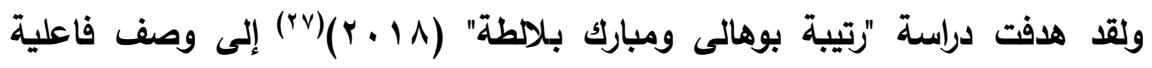
ممارسات المقارنة المرجعية في التعليم من مداخل مختلفة لتحسين الجودة، علاوة على تحليل الأعمال البحثية التي تم طرحها في مجال المقارنة المرجعية في التعليم العالي، بهدف تحديد

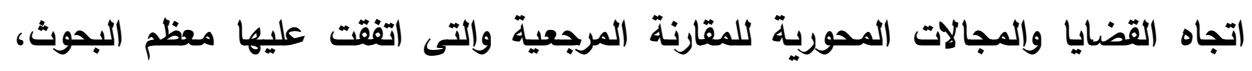
وتحديد الآثار المترتبة على الأبحاث التي أجريت وتقديم بعض الاقتراحات لتحسين الجودة في

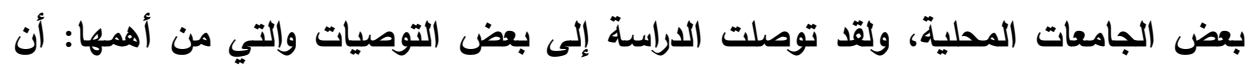
تطبيق المقارنة المرجعية الداخلية من أفضل الممارسات في الجامعة الجزائرية، كما في حالة الجامعة الأردنية، وأن المقارنة الداخلية من المقارنات المناسبة للجامعات للتطوير الداخلي بغض النظر عن غيرها من الجامعات في العالم، كما أن ممارسة المقارنة المرجعية الداخلية تساعد في التعرف على جامعات القمة من خلال أربعة معايير رئيسية لقياس الجامعات المحلية والعالمية وهي: مستوى قبول الطلاب، أداء الإداريين وأعضاء هيئة التدريس، والاستشهادات المرجعية، وأخيراً ترتيب الجامعات والتي تعتبر من الطرق الأساسية للتحسين المستمر للجامعات. ومن منظور الجودة وعلاقتها بالقياس المقارن فقد هدفت دراسة "التهامى متولي"

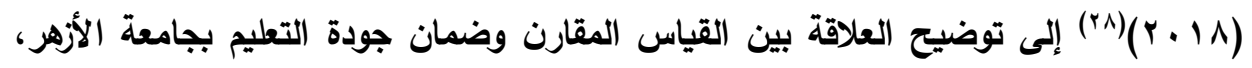
وذلك من خلا توظيف مدخل القياس المقارن لتطوير أداء مركز ضمان الجودة والتتريب بجامعة الأزهر، والكثف عن دوره في تحسين بعض مجالات العمل الجامعي كالتدريس والبحث العلمي، والممارسات الإدارية والتعليمية، وقد أكلت نتائج الاراسة أن مدخل القياس المقارن 
مجلة كلية التربية بالإسماعيلية - العدد الرابع والأربعون - مايو 9 م ـ

يسهم في تحقيق معايير الجودة القياسية التي يمكن من خلاها الحكم على مدى جودة عناصر المنظومة التعليمية، وتقييم فعاليتها، وأن مدخل القياس المقارن يقدم حلول سريعة لمعالجة ضعف الأداء بمركز ضمان الجودة والتدريب، وبذلك فهو جزء لا يتجزأ من تطوير استراتيجية

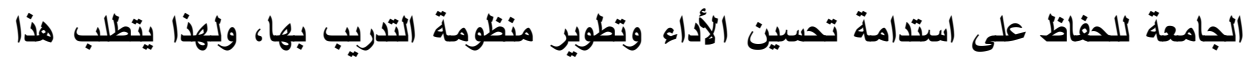
المدخل الاهتمام والاتتزام بالاستثمار في الموارد المالية والبشرية ومشاركة القيادة العليا من أجل الجل تحقيق نتائج فعالة من حيث جمع البيانات وتنفيذ النتائج في المستويات المختلفة داخل مؤسسات الجامعة؛ بما يساعد على اتخاذ القرارات المستقبلية القائمة على التبؤ بمستقبل فعاليات الجامعة.

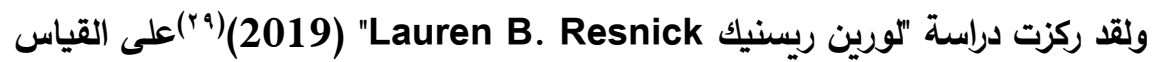
المقارن للجامعات الأمربكية من خلال الاستفادة من الخبرات والتجارب السابقة في عمل مقارنة مرجعية مع بعض الجامعات اليابانية والصينية، وتحديد المجالات التي تحتاج إلى هن تحسين وتطوير، وقد توصلت إلى أن القياس المقارن للجامعات يركز على بعض المجالات ومنها: عمليات تسجيل الطلاب، ونظام القبول، ويتم القياس من خلال مراجعة الموقف الحالي لكل جامعة، والتخطيط الاستراتيجي، وتطبيق الإجراءات، وتقييم مدى التقدم نحو تحقيق من ملى

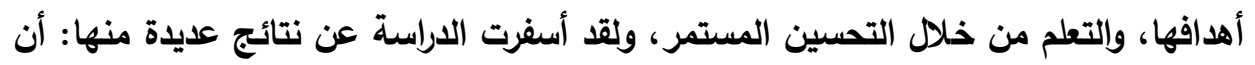
المقارنة المرجعية في التعليم الجامعى الأمريكى تعمل على التقدم وزيادة المنافسة في بيئة التعليم العالي والجامعي، كما ينظر للمقارنة المرجعية كأداة للإدارة الحديثة لدعم اتخاذ القرارات الاستراتيجية، كما أن المقارنة المرجعية عملية ديناميكية يتم من خلالها تعديد المؤشرات والمعايير ذات الصلة والتي يمكن أن تستخدم لقياس الأداء المؤسسي، فضلاً عن إسهامها

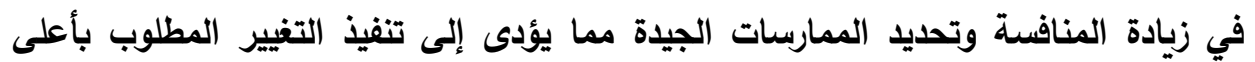
كفاءة ممكنة. التعليق على الدراسات السابقة: من خلال عرض وتحليل الاراسات والبحوث السابقة، يمكن الخروج بالاستنتاجات

• أن القياس المقارن هو عبارة عن عملية منظمة ومستمرة لتقييم أداء المؤسسة أو أحد جوانب هذا الأداء من خلال المقارنة بنموذج، سواء في داخل أو خارج هذه المؤسسة للتعرف على أسباب الفجوة والعمل على معالجتها والوصول إلى الأداء الأفضل. 
بدائل مقترحة لتطوير منظومة تقييم أداء الجامعات --- د/ محمد ابراهيم عبد العزيز خاطر

• يعتبر القياس المقارن أحد أدوات التقويم والتطوير وتحسين الأداء من خلال تحديد الفجوة فى الأداء بين الوحدات أو الأقسام الأخرى أو العمل لتعزيز النواحي التئي

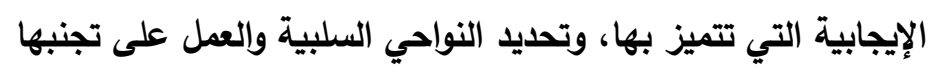
وذلك لبلوغ أفضل التطبيقات وأعلى المستويات في الأداء.

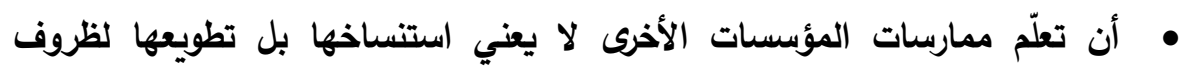
المؤسسة المعنية، هذا من جهة، ومن جهة أخرى فإن تطور المؤسسات المنافسة

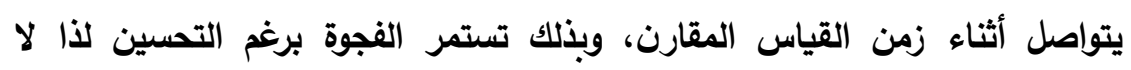
ينبغي التوقف عند مواكبة تطور الآخرين وحسب، بل استهداف التفوق عن طريق نظرة مستقبلية نحو الأفضل دائماً. • أن القياس المقارن يمثل ارتباط لكل من البحث والتطبيق اللذين يسيران بثكل مستمر بهدف استنباط وتوليد الجديد من الأفكار والممارسات والمعالجات بمقارنة

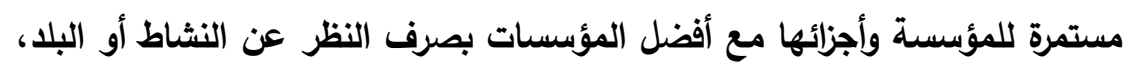

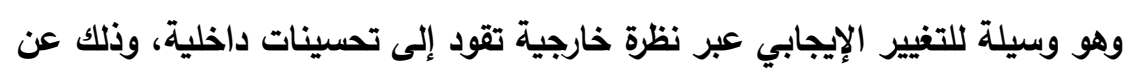

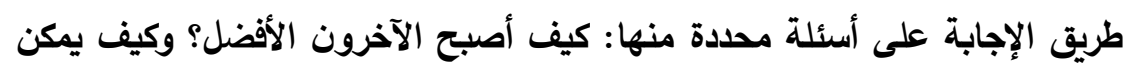

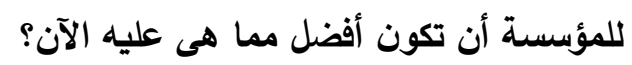
• أن القياس المقارن عبارة عن عملية مستمرة لتقييم أداء المؤسسة أو أحد أنثطتها أو خدماتها، ولا تتوقف عند حد معين، وأن عملية التقييم تتم في إطار الرؤية المقارنة لأفضل نموذج في هذا المجال أو النشاط، سواء في داخلاء وانوفل المؤسسة أو أو

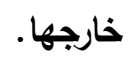
• تظهر أهمية أسلوب القياس المقارن من كونه أسلوباً للتحسين المستمر، وذلك من

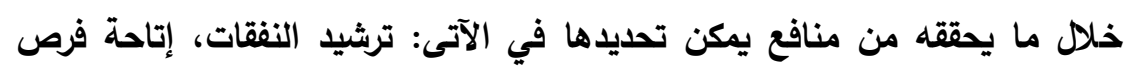

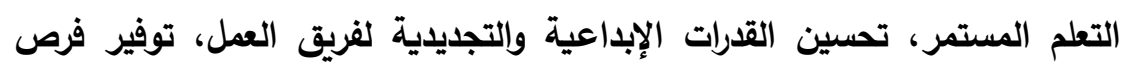
التعاون بين المنظمات أو الوحدات المحلية، تبنى ثقافة تنظيمية موجهة لحل

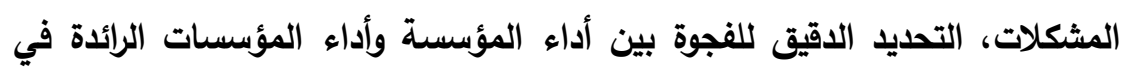
مجال عملها، توفير المناخ الملامم، تعزيز الرغبة لدى قيادة المؤسسة والعاملين فيها على تبني سياسة التغيير نحو كل ما هو أفضل وجديد، والمساعدة في تحديد

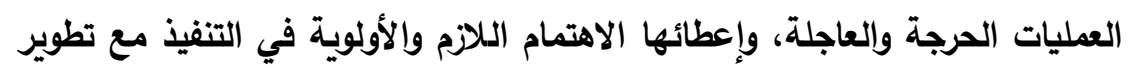
الإبداع الفردي والجماعي. 
مجلة كلية التربية بالإسماعيلية - العدد الرابع والأربعون - مايو 9 م ب r

• أن هناك ضوابط لاختيار الجامعات الأخرى للقياس المقارن، ومن أهمها: أن تقوم

الجامعات المناظرة بالوظائف الثلاث الرئيسة للجامعة، وهي البحث العلمي، والتعليم، وخدمة المجتمع، وأن تقوم بتدريس التخصصات الرئيسة نفسها في أفرع العلوم المختلفة (الطبية - التطبيقية - الإنسانية)، وأن تمنح الدرجات العلمية نفسها أو

المشابهة لها.

خطوات الاراسة: - ت ت

وفقاً للمنهجية المتبعة في الدراسة، فإن خطواتها تتمثل فيما يلي:

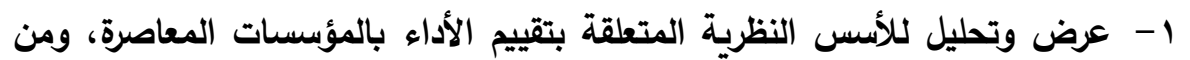
ثم منظومة تقييم الأداء الجامعى، وذلك وفقاً لـكل من: مدخلات تقييم الأداء الجامعي، عمليات تقييم الأداء الجامعي، مخرجات تقييم الأداء الجامعي. r - بيان طبيعة أسلوب القياس المقارن، من حيث أهدافه ومبررات الاهتمام به وأنماطه وخصائصه. r- عرض لبعض النماذج العالمية في توظيف أسلوب القياس المقارن لمنظومة تقييم

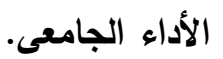
צ - تحليل مقارن لنماذج الجامعات العالمية في توظيف أسلوب القياس المقارن لمنظومة تقييم الأداء الجامعى. ه- تحليل منظومة تقييم الأداء بالجامعات المصرية (دراسة نظرية). צ- تقديم بدائل مقترحة لتطوير منظومة تقييم الأداء بالجامعات المصرية باستخدام أسلوب القياس المقارن. الإطار النظري للإسةرة: ويَََمَتَّل الإطار النظري للاراسة في "الأسس النظرية لمنظومة تقييم أداء المؤسسات الجامعية باستخدام أسلوب القياس المقارن"، ويشتمل الإطار النظري على المحاور الثلاثة التالية: المحور الأول: الأداء وتقييمه في المؤسسات التعليمية: حَظِيّ الأداء في المؤسسات المختلفة باهتمام الكثيرين من الأطراف ذات العلاقة بعملها، فهو ملخص للجهود التي بُذِْلَت، أو هو نتيجة الأنشطة وإلفعاليات التي مارستها ضمن عوامل ومحددات مختلفة، لذا ومن أجل إعطاء صورة عن طبيعة هذه الانشطة والفعاليات فقد دأبت المؤسسات على قياس أدائها من خـلال استخدام أساليب القياس 
بدائل مقترحة لتطوير منظومة تقييم أداء الجامعات --- د/ محمد ابراهيم عبد العزيز خاطر

المختلفة، حيث أصبح الأداء وتقييمه من المفاهيم الأساسية بالنسبة لمنظمات الأعمال على اختلاف أنواعها وطبيعة المهام التي تقوم بها، وخاصة في ظل عدم الاستقرار في البيئة التي

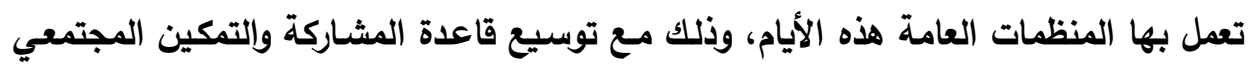
والتوجه نحو تطبيق المفاهيم الإدارية الحديثة، مثل: الثفافية والمساءلة ومراعاة الرأي العام.

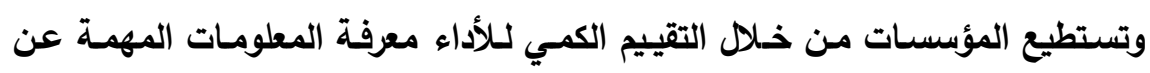
المنتجات والخدمات التي تقدمها والعمليات التي تقوم بها، فتقييم الأداء هو منهجية تساعد

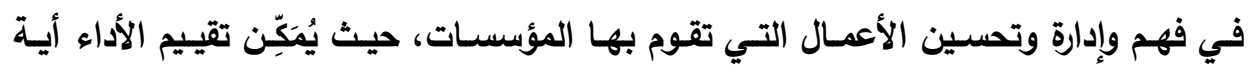
مؤسسة من معرفة الآتي (·"):

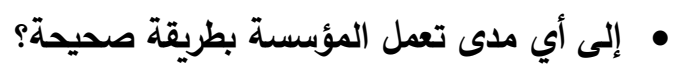
• مدى قدرة المؤسسة على تحقيق أهدافها. • مدى قدرة المؤسسة على تحقيق الرضا لعملانها. • تحديد التحسينات الضرورية التي تسعى إلى إحداثها لتطوير الأداء. وتعتبر البيانات السابقة هي المصدر الأساسي الذي تعتمد عليه المؤسسة فى اتخاذ

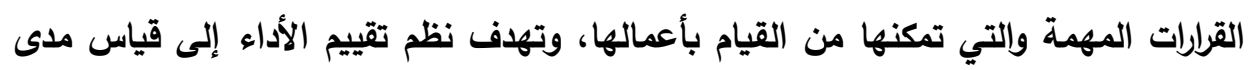

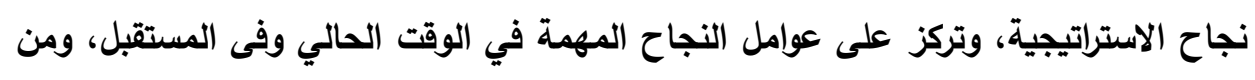
خلال تطوير هذه العوامل تستطيع المؤسسة إنجاز أهدافها.

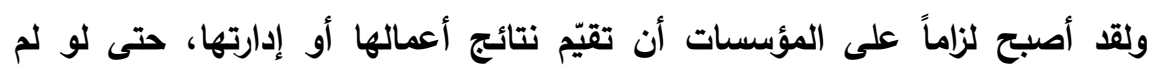
تحصل من هذه النتائج على عائد أو مكافأة، لأن المعلومات التي يتم الحصول عليها تحول أداء هذه المؤسسات إلى الأفضل، وإذا لم تستطع المؤسسة تقييم نشاطها لا يمكنها الرقابة

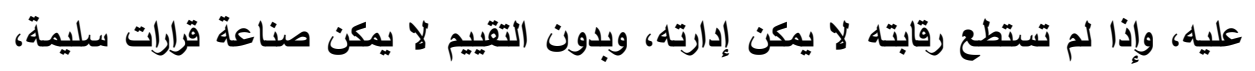

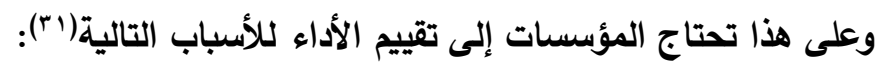
• الرقابة "Control": يساعد تقييم الأداء في تقليل الانحرافات التي تحدث أثناء العمل.

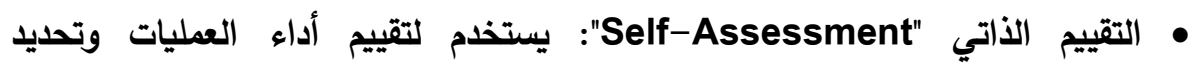
التحسينات المطلوب تنفيذها. • التحسين المستمر "Continuous Improvement": يستخدم التقييم لتحديد مصادر العيوب، واتجاهات العمليات، ومنع الأخطاء، وتعديد كفاءة وفعالية العمليات، وأيضاً فرص التحسين. 
مجلة كلية التربية بالإسماعيلية - العدد الرابع والأربعون - مايو 9 م • تقييم الإدارة "Management Assessment": بدون التقييم لا توجد طريقة للتأكد من أن المؤسسة تحقق القيمة المضافة لأهدافها أو أن المؤسسة تعمل بكفاءة وفعالية.

وتتكون نظم تقييم الأداء من معايير ومؤشرات، والتي تعد بمثابة مقاييس الأداء التى تعمل على التخطيط والملاحظة والرقابة على الموارد، بهدف تحقيق حاجـات المستفيد وإحداث التحسينات في عمليات المؤسسة وتحقيق أهدافها الاستراتيجية في ظل المنافسة التي تواجه منتجاتها وخدماتها.

ويجب أن تتصف المقاييس التي يتم تصميمها بما يلي: أن تكون نابعة من استراتيجية

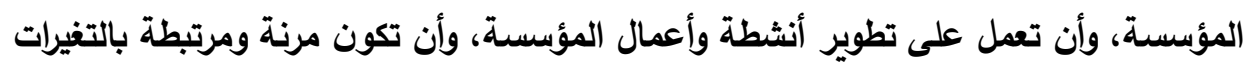

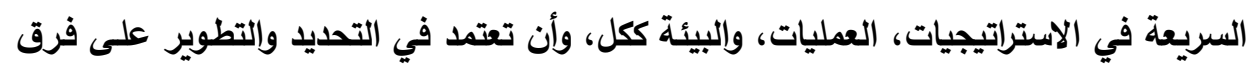

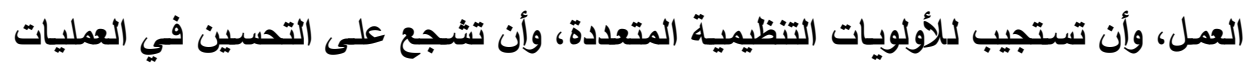
التـي تقـوم بهـا المؤسسـة، مـع إعطـاء صـورة واضـحة وكاملـة ودقيقـة وصـادقة عـن أداء المؤسسة (rr). (1)

وفى ظـل التعقيـ الـــي يواجـه إدارة المؤسســات هـذه الآونــة، يجـب علـى مـديري

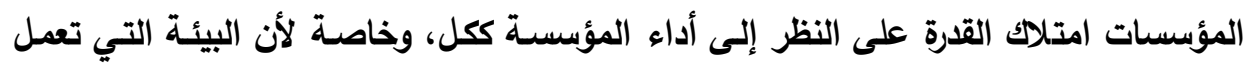
فيها المؤسسات بيئة متغيرة ونجاح المؤسسة يعتمد على قدرتها على مقابلة الحاجات المتغيرة لأصحاب المصلحة، وعلى هذا فهى بحاجة إلى تقييم الأداء من منظور خارجي، مثل الاستماع

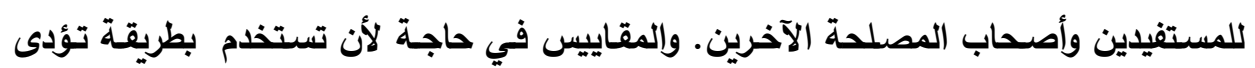

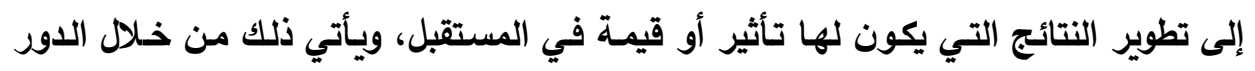
المستمر للتعلم والابتكار، وهذا هو الههف الجوهري والحقيقي لنظام تقييم الأداء الجيد.

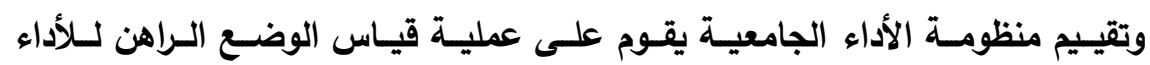
الأكاديمي والمؤسسي وتحليله للكشف عن نواحي القوة والضعف وتحديد الاتحرافات وأوجـه القصور المختلفة وتشخيص المشكلات التي تؤثر سلباً على هذا الأداء ؛ وذلك بهدف اتخاذ

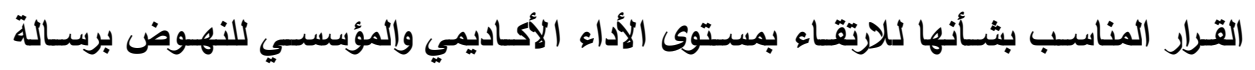
المؤسسة بفاعلية وكفاءة. وتتعدد مستويات قياس الأداء وتقييمه بالمؤسسات الجامعية، ليثمل ما يلي (rم): 
بدائل مقترحة لتطوير منظومة تقييم أداء الجامعات --- د/ محمد ابراهيم عبد العزيز خاطر

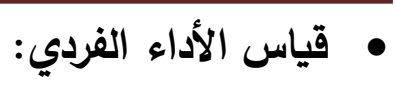

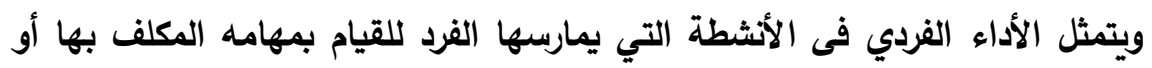
مسؤولياته التي يقوم بها في الوحدة التنظيمية؛ للإسهام في تحقيق الهاء أهدافها، ويقاس ألداء أداء

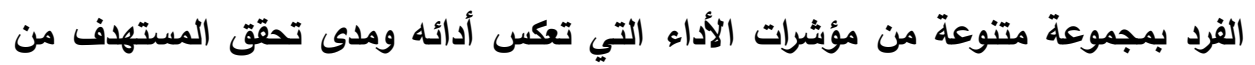
عمله أو وظيفته من حيث الكم أو الجودة المنشودة.

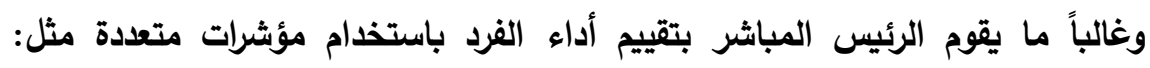

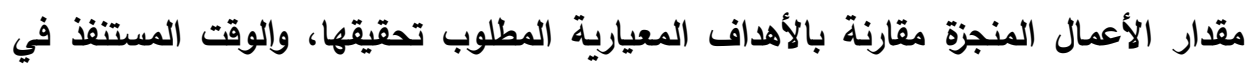

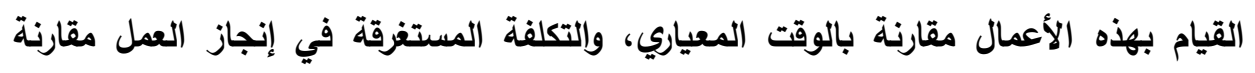

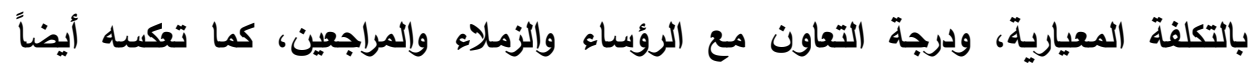

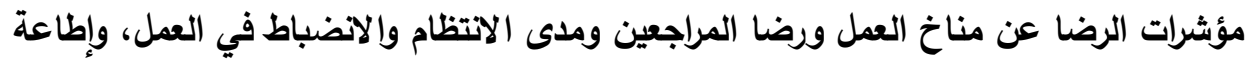

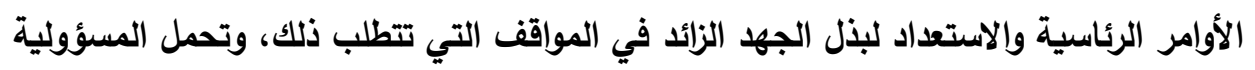

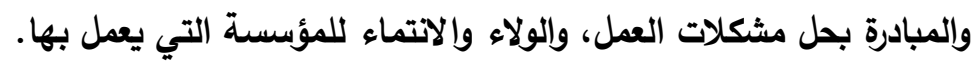
• قياس أداء الوحدات التنظيمية: إن أداء الوحدات التنظيمية هو الجهود التي تقوم بها الوحدة التنظيمية للقيام بدورها

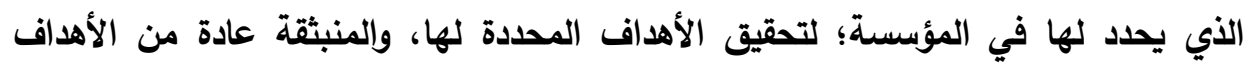
الاستراتيجية للمؤسسة وسياساتها العامة. وعادة ما تتولى الإدارة العليا في المؤسسة ووحدات التهات الجودة تقويم أداء الوحدات

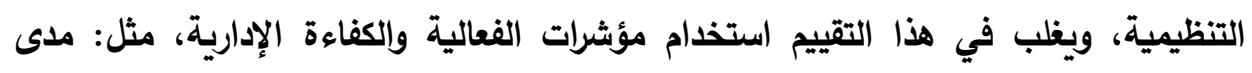

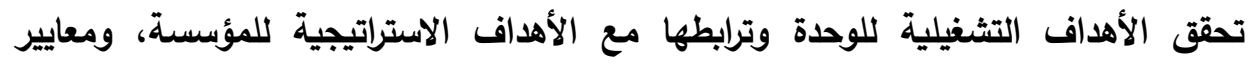

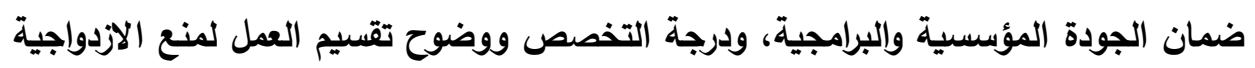

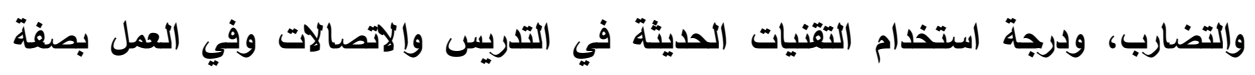

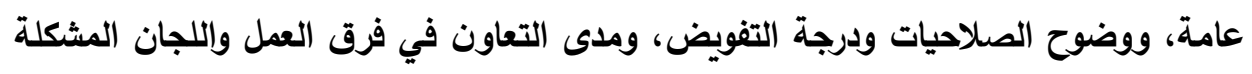

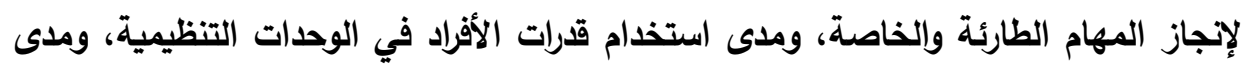

الالتزام بالتكاليف والموازنات المعيارية الموضوعة. • • قياس الأداء المؤسسي للمؤسسة كاملة:

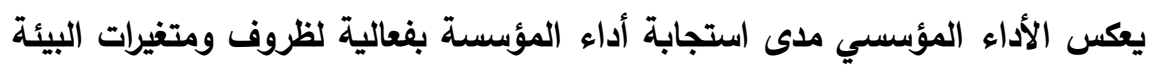

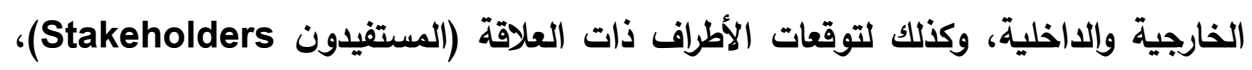
فهناك عديد من الأطراف التي تتؤثر في تحديد رؤية المؤسسة ورساتلتها وأهدافها، وتؤثثر أيضاً 
مجلة كلية التربية بالإسماعيلية - العدد الرابع والأربعون - مايو 9 م ب

في تحديد سياساتها العامة و ما هو المقبول أو غير المقبول في أساليب الأداء لتحقيق هذه الأهداف، ومن أهم الأدوات المستخدمة لتقييم أداء المؤسسات مؤشرات الأداء الخاصة بمعايير ضمان الجودة المؤسسية، وكذلك استخدام أنواع المقارنات المناسبة في هذا المجال.

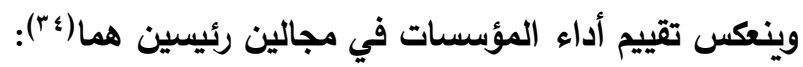
م تقييم الأداء بناءً على الأهداف الاستراتيجية للمؤسسة:

وفي هذا المجال فإن المؤسسة تضع مؤشرات خاصة بها لقياس تقدمها في تحقيق أهدافها الاستراتيجية التي تقسم أيضاً إلى عدة مستويات منها: مؤشرات لقياس الأهداف الاستراتيجية للمؤسسة، مؤشرات لقياس الأهداف التفصيلية والمبادرات في الخطة الاستراتيجية، مؤشرات لقياس المشاريع المتفرعة من المبادرات، ومؤشرات لقياس العمليات والخدمات.

م تقييم الأداء بناءً على معايير الجودة التي تقرها هيئات الاعتماد: وهذه المؤشرات خاصة بمعايير الجودة المؤسسية والبرامجية، حيث تقوم عادة الهيئات المعنية بالجودة والاعتماد بتحديد مؤشرات رئيسة لها، ويتم تبنيها من قبل المؤسسات تسهيلاً لاستخدامها وتقييم أدائها في كافة مجالات عمل هذه المؤسسات.

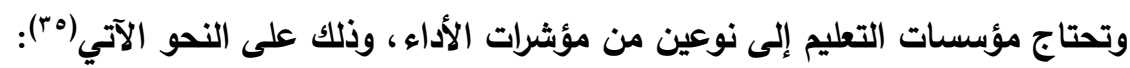
النوع الأول: المؤشرات الكمية: وتتكون من إحصائيات أو حقائق عددية، وتثثل: - مؤشرات البُعد الإنساني: مثل الإحصائيات عن أعضاء هيئة التدريس ودرجاتهم العلمية، وعدد الطلاب المسجلين في المؤسسة أو أحد برامجها، وعدد الطلاب المقبولين، وعدد الخريجين وعدد العاملين في المؤسسة. - مؤشرات بُعد المعلومات: مثل نسبة أعضاء هيئة التدريس إلى الطلاب، ونسبة الاستبقاء للطلاب ونسبة التوظيف للخريجين خلال ستة أشهر بعد التخرج. النوع الثانى: المؤشرات النوعية (الكيفية): وتكون ذات صبغة ذاتية، مثل: استقصاءات واستطلاعات الآراء والانطباعات من خلال المقابلات والبحوث المسحية، وتشمل: - مؤشرات نوعية خاصة بالطلاب، مثل: معدل رضا الطلاب عن تحصيلهم في البرامج الاراسية، ومعدل رضا الخريجين عن المهارات التي اكتسبوها خلال دراستهم، ومعدل رضا هوبا الطلاب عن البنية التحتية للمؤسسة التعليمية والخدمات المقدمة لهم. 
بدائل مقترحة لتطوير منظومة تقييم أداء الجامعات --- د/ محمد ابراهيم عبد العزيز خاطر

- مؤشرات نوعية خاصة بأعضاء هيئة التريس، مثل: معدل رضا أعضاء هيئة التدريس عن جودة البرامج الدراسية، ومعدل رضا أعضاء هيئة التدريس عن هونياء دعم المؤسسة والتسهيلات المقدمة لتشجيعهم بحثياً، ومعدل رضا أعضاء هيئة التدريس عن البنية

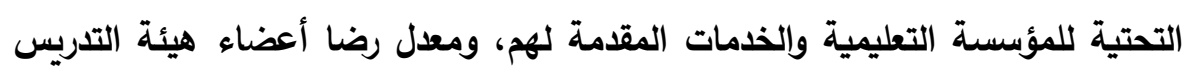
عن رؤية ورسالة المؤسسة أو البرنامج. - مؤشرات نوعية خاصة بالمجتمع، مثل: معدل رضا سوق ورئه العمل عن مهارات مخرجات

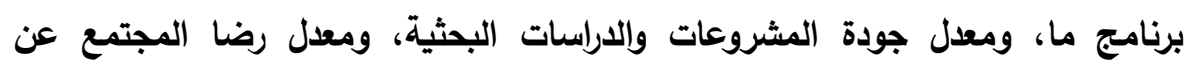
الخدمات التي تقدمها المؤسسة التعليمية لخدمة المجتمع. ويتضح مما سبق أن كل من المؤشرات الكمية، والمؤشرات النوعية تقيس أبعاداً مختلفة، وأنه من الممكن الجمع بين النوعين للحصول على منظور متوازن للأداء، كما يظهر

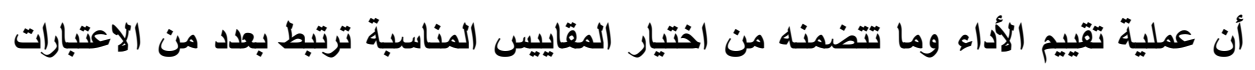

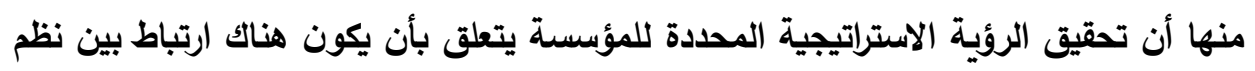
قياس الأداء في المؤسسة والتخطيط الاستراتيجي والتخطيط التثغيلي، وأن قياس الأثياء الصحيحة يفرض على المؤسسة ضرورة تحديد العمليات الرئيسة ووضعها فى خربطة التففيذ لضمان التأكد من تنفيذها بلاًا من الافتراض بفهمها، والتأكد من أن المقاييس التي تقيس فرونس نجاحها تم اختيارها بشكل صحيح، وأن القياس وسيلة وليس غاية، حيث يتم توظيف مقاييس الأداء للتأكد من تحقيق النتائج المرغوبة والتي تعتبر جوهز رؤية المؤسسة واستراتيجيتها. المحور الثانى: منظومة تقييم الأداء الجامعي وفقاً لأسلوب تحليل النظم: تتوقف قدرة الإدارة على التقييم الفعال للأداء والنتائج، بقدر امتلاك المؤسسة نظاءماء جيداً للتقييم، إذ يتوقف تحسين وتحقيق التميز في أداء المؤسسة على مدى تطوير وتنفيذ نظام تقييم الأداء، حيث يؤدى دوراً مهماً في جعل المؤسسة على علم بالعوامل الأساسية التي تحقق لها النجاح، كما يساعدها في تحديد المواطن التي تحتاج إلى تحسين وتطوير • وتنقسم

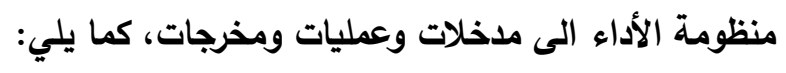

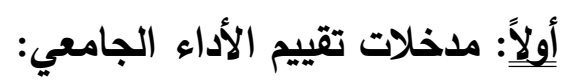
وهي تمثل مكونات النظام وتثمل كل العناصر التي تدخل المنظومة الجامعية من أجل تحقيق أهدافها وتتكون من مزيجج من الموارد البشرية والمادية والتقنية، وتتمثل المدخلات من

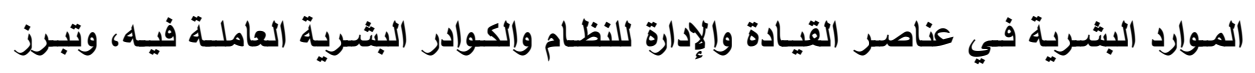
المدخلات المادية في شكل الأموال اللازمـة لتسيير العمليات الخاصـة بالنظام وكذلك المواد 
مجلة كلية التربية بالإسماعيلية - العدد الرابع والأربعون - مايو 9 م ـ

الخام والعدد والآليات المطلوبة لتحقيق وتنفيذ العمليات، كما تتمثل المدخلات التقنية في شكل المعرفة الفنية والخبرات وأساليب ومهارات العمل وتتضمن المدخلات أيضا جوانب عامـة، مثل:

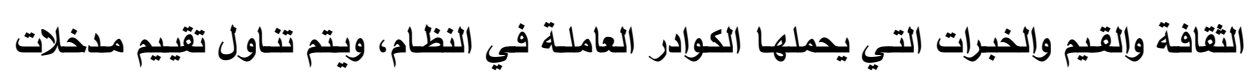
المنظومة الجامعية على النحو التالى: ا - فلسفة تقييم الأداء الجامعي وأهدافه: يُمَتُّل التعليم الجامعي الرصيد الاستراتيجي لحركة التنمية في المجتمع وتوجيه فعالياته، وإنه المدخل الرئيس للوفاء باحتياجات التنمية المستقبلية؛ ومن ثم فإن الهوية الحضارية لأئي مجتمع من المجتمعات تُبْنَى على أساس الارتقاء بالتعليم الجامعي وحسن توظيفه على المستوى

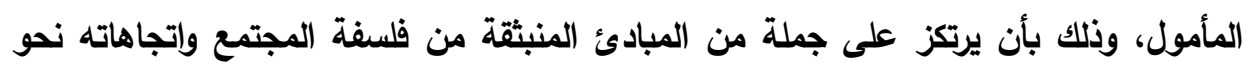
تحقيق النهضة المجتمعية الثاملة؛ بحيث يصبح الإنسان محوراً لعملية التنمية، مع المشاركة في بناء مجتمعه معرفياً واقتصادياً وثقافياً.

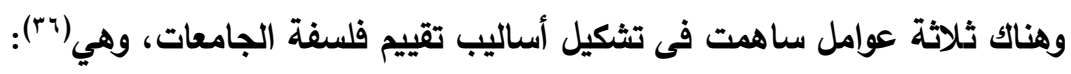

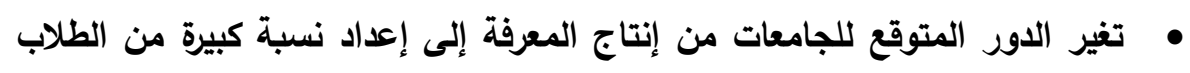

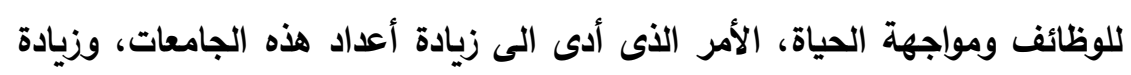
المخصصات المالية لها، ومن ثم زيادة اهتمام الرأي العام بكيفية إنفاقها للأموال التي تُخَصَّصُ لها والمردود الذى يتحقى من وراء ذلك.

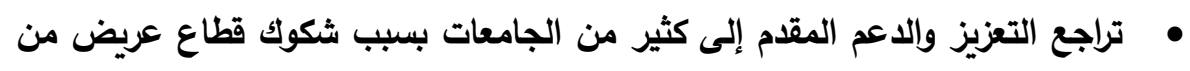

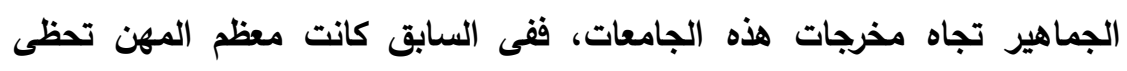

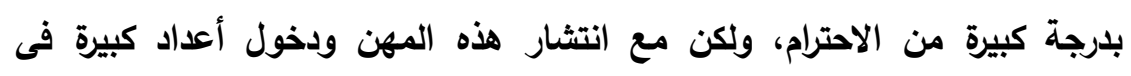
كلياتها وأقسامها وتدنى المستوى ظهرت نحوها نظرة مملوءة بالثرام، ولكن من قبل فيل الجماهير، مما أدى إلى زيادة الطلب على تقييم إنتاجية هذه الكليات والأقسام وبالتالي الجامعات فى ضوء الاعم المالي المقدم لها. • تزايد الاهتمام الثعبي بضرورة تقييم الأداء التعليمي للجامعة فى ضوء الفاعلية التعليمية لها. ومن ناحية أخرى فإن تقييم أداء الجامعات يقوم على عدة مبادئ، تمثل فلسفة هذا النظام وينبغي مراعاتها حتى يكون فعال ويؤدى إلى اتخاذ قرارات صائبة، ومن تلك المبادئ ما • تحديد ما يراد تقييمه، وتحديد الغرض من التقييم. 
بدائل مقترحة لتطوير منظومة تقييم أداء الجامعات --- د/ محمد ابراهيم عبد العزيز خاطر

$$
\text { • الاهتمام باختيار وتطوير أدوات القياس المناسبة للغرض من إجرائه. }
$$

• الوعى بخصائص القياس بالآخرين، ومن أهم هذه الخصير التصائص الثمولية

والتوازن والتنوع والاستمرارية.

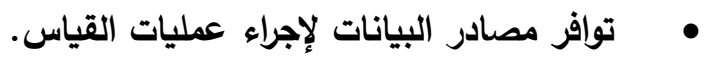

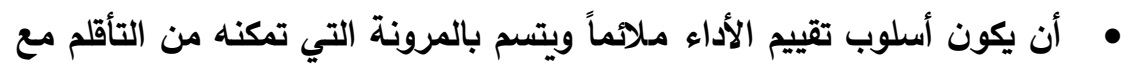

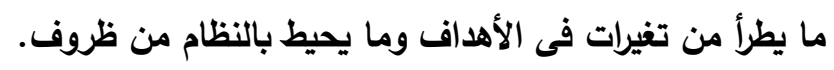

ونظراً لارتباط تقييم الأداء الجامعى بوجود أهداف يراد تحقيقها، فإن تقييم أهداف

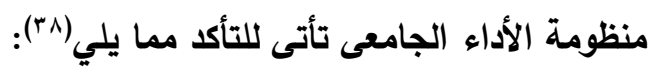

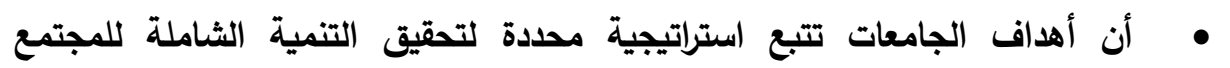

$$
\text { وتحقيق متطلبات السوق. }
$$

• أن أهداف الجامعات قابلة للقياس مما يسمح بتحليل الأهداف التعليمية إلى أهداف

خاصة، ووضعها وفقاً لنظام معين ليسهل نشر النتائج، وذلك خلال فترة زمنية محدة. • أن أهداف الجامعة تحدد نوع الخريج المطلوب، والمهارات التي ينبغي أن تتوافر لايه

حتى يستطيع العمل بكفاءة فى مؤسسات المجتمع.

أن أهداف الجامعة توجه مؤسساتها إلى تغيير طريقة عملها، بحيث يقود العمل ويقلل

الفاقد الاقتصادي المعقد ويصبح مقبول اجتماعياً ويحقق التطورات المرغوبة.

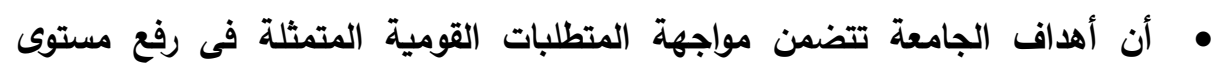

$$
\text { الطلاب وإعادة الثقة فى التعليم الجامعي. }
$$

إن وجود أهداف واضحة ومحددة تعبر عن وظيفة الجامعة فى نطاق بيئتها له أهمية قصوى؛ لأنه يوجه العمل بثكل منتظم ومنظم، وتتحدد كفاءة الأداء فى أي جامعة بناءً على

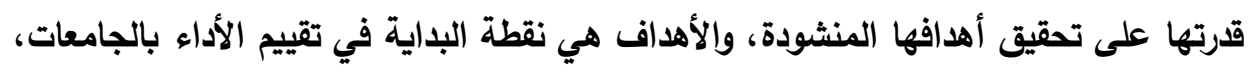
إذ تبين مدى كفاءة الجامعة فى تحقيق أهدافها الموضحة، في ضوي أداء ونتائج نظيراتها. r - الجهات المسؤولة عن تقييم الأداء الجامعي: يمكن تحديد أهم الجهات المسئولة عن تقييم الأداء الجامعى والتي تقع خارج الجامعة الجداء

$$
\text { أو داخلها وتقوم على تقييم الأداء، فيما يلي: }
$$$$
\text { أ- الجهات الخارجية: }
$$

وتضم كافة جهات المجتمع الخارجي المعنية بتقييم أداء الجامعات، وذلك من أجل التأكد من قيام الجامعات بمقابلة الحاجات الخاصة بالمجتمع ومؤسساته، ويتم فى أغلب 
مجلة كلية التربية بالإسماعيلية - العدد الرابع والأربعون - مايو 9 م

الجامعات وضع آراء المؤسسات المجتمعية المختلفة فى الاعتبار عند إجراء التقييم والقياس لمنظومة الأداء الجامعي، وذلك من خلال طلابها بحيث يتم التحقق من أن المناهج الجامعية أكثر تكيفاً مع احتياجاتهم الخاصة، وأن خريجي الجامعات الراغبين فى العمل فى تلك مأك المؤسسات المجتمعية يمتلكون المواصفات والمهارات والقدرات التي تمكنهم من العمل بكفاءة. وعلى ذلك فإن تقييم أداء الجامعات عن طريق الجهات الخارجية يتم بغرض تحديد إنجازاتها، ثم تتم المقارنة بين بعضها البعض بهدف التحسين المستمر والمشاركة في الاستفادة(9").

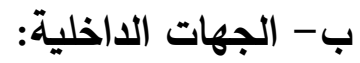

وهى جهات تابعة للجامعات، وبالتالي فإنها تقوم بعمليات التقييم من أجل تحسين الأداء الجامعي في مختلف مجالاته وتحقيق رضا جميع المنتمين للمؤسسة الجامعية، وفيما يلى بعض هذه الجهات الاخلية(·؛): • مجلس الجامعة: لعل مجلس الجامعة وما ينبثق عنه من لجان مختلفة من أهم الجهات داخل الجامعة التي تمارس التقييم فى الجامعات، كَوْنَه مسؤولاً عن أمور عديدة، منها: توجيه الاستراتيجية الجامعية والإشراف على تنفيذ السياسات العامة، وتوفير المناخ الإباعي داخل الجامعة والتجاوب مع البيئة الخارجية والمجتمع المحلى والمستفيدين، وضمان الاستثمار الأمثل للموارد المتاحة داخل الجامعة وفى بيئتها المحيطة.. الخ. • مجلس الكلية: ويشارك فى تقييم الأداء كَوْنَه مسؤولاً عن تسيير أمور الكلية، ولهه الحق فى اقتراح أمور تتعلق بمجلس الجامعة ولجانه المختلفة، وكذلك تقديم تقرير

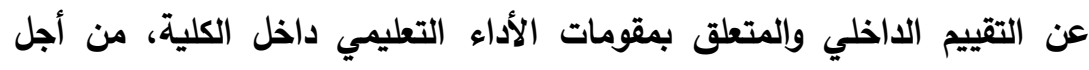
توكيا الجودة وزيادة الكفاءة والفاعلية التعليمية بالكلية. • مجلس القسم: إن مجلس القسم له دور مهم فى تقييم الأداء وخاصة فيما يتعلق باده بالخطط والبرامج الدراسية، وبالتالي يعمل التقييم على تحسين الإنتاجية التعليمية،

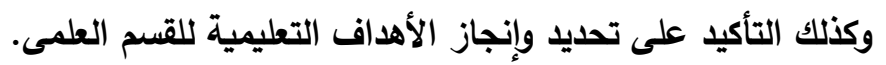

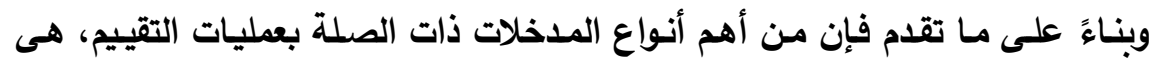

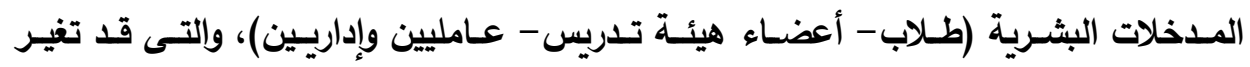

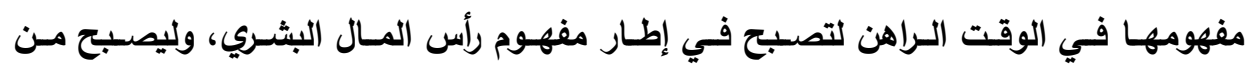

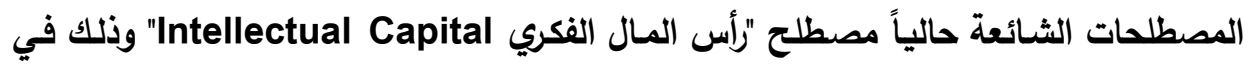
إطار ظهور مجتمعات واقتصاديات المعرفة، ويقوم تقدّم المؤسسات بصفة عامـة والجامعات 
بدائل مقترحة لتطوير منظومة تقييم أداء الجامعات --- د/ محمد ابراهيم عبد العزيز خاطر

بصفة خاصة على تركيزها على تَحَوُل قسط كبير من مواردها البشرية وتنميتها وفقاً لمفهوم

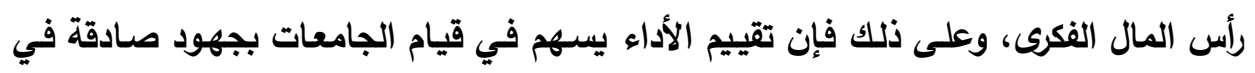

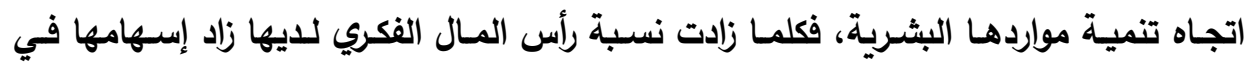

التطوير المبدع والمستمر . أنمان.

ثانياً: عمليات تقييم الأداء الجامعيز

وهـى المرحلـة التحى يـتم خلالها تحويـل المــخلات إلـى مخرجـات، وتضــم العمليـات

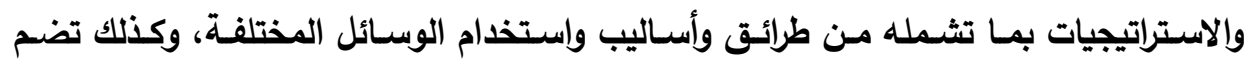

العلاقات المتبادلة والمتفاعلة بين مدخلات النظام كالتفاعل بين المتعلمين والأساتذة والإداريين

والمستفيدين لتحويل مدخلات النظام إلى مخرجات، وبمعنى آخر تحقيق أهداف المنظومة. وتتمثل أهم عمليات وأنشطة منظومة الأداء الجامعى، فيما يلي:

1 - التخطيط لتقييم الأداء الجامعي:

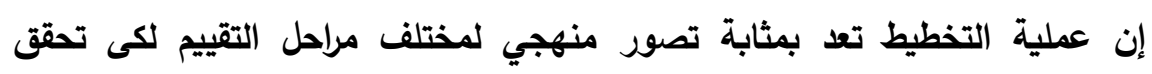
أغراضها المرجوة على المدى القصير أو فى المستقبل البعيد، والتخطيط لتقييم الأداء يعنى الإعداد لإجرائه بجمع البيانات عن الجانب المراد قياسده أو دراسته مع استخدام مقاييس ومؤشرات مناسبة فى ذلك، ويُرَاعَى فى عملية التخطيط تحديد ما يجب قياسه، وتحديد

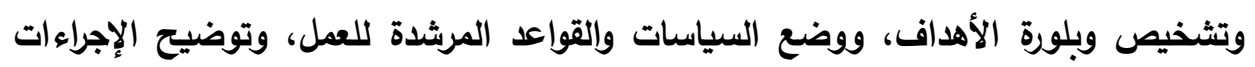

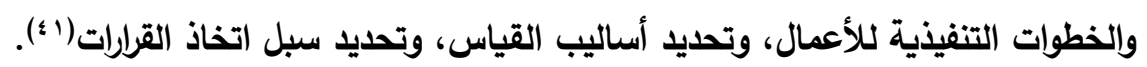

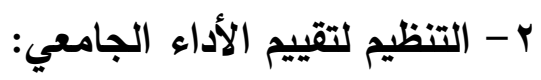

إن التظيم هو تحديد أوجه النشاط اللازمة لتحقيق أي هدف، وترتيبها فى هـ

مجموعات ليسهل تنفيذ ما تم تخطيطه، ويتم فى هذه العملية التركيز على ما يلى (rأ):

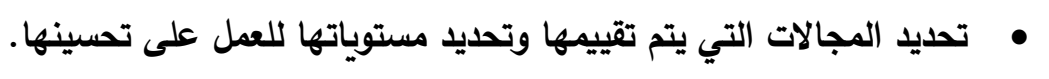

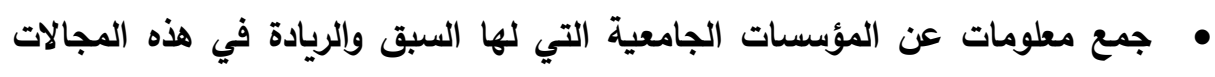

$$
\text { وغيرها. }
$$

تحديد المدة الزمنية للقياس وعدد الفريق حسب حجم الجامعة، وتحديد مهام الفريق

ومهماته.

تحديد وقت البدء فى تطبيق المقاييس والمؤشرات وجمع المعلومات والبيانات عن طريق فحص السجلات، والملاحظة، والمناقثة مع هيئة التدريس وكل المهتمين. تحديد طريقة رصد الملاحظات والبيانات المختلفة وتقييمها. 
مجلة كلية التربية بالإسماعيلية - العدد الرابع والأربعون - مايو 9 م ـ

• تحديد محاور تقرير التقييم مع تحديد جوانب القوة وجواتب الضعف مع توضيح الأدلة

التي تثبت صحة ذلك.

ب- تنفيذ أنشطة تقييم الأداء الجامعي:

يعبر تنفيذ الأنشطة الخاصة بالأداء الجامعى عن جملة الفعاليات والإجراءات المتبعة

لتقييم الأداء في مجالاته المختلفة، والتي تتمثل فيما يلي:

أ- المجال الأول: الاور التعليمى والتدريسى للمؤسسات الجامعية:

ويتمثل الجانب التعليمى وإلتدريسى فيما يلي:

• الأهداف التعليمية:

تُعَبِّر الأهداف التعليمية عن المدخل المعرفى الأى يستند إلى فلسفة المجتمع وغايته

من المؤسسة التعليمية، علاوة على أن الأهداف تعد بمثابة الموجه الفكرى للعناصر البشرية وهى المحدد لكافة الأساليب والطرق التى يتم اتباعها، بالإضافة إلى ارتباط تقييم الأداء

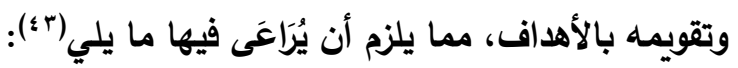

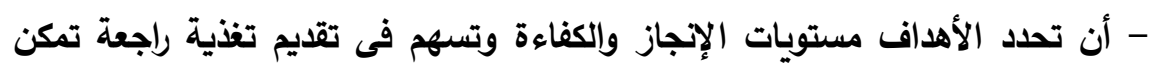
الجامعة من توكيد الجودة وتحسين الإنتاجية التعليمية وزيادة الكفاءة والفاعلية

التعليمية لها.

- أن يتوفز فيها من المرونة ما يضمن تخطيط وإدارة وتنظيم الأنشطة الجامعية المتعددة والمتابعة المستمرة للتمكن من اتخاذ القرارات المصححة للمسار التعليمي فى التوقيت المناسب.

- أن تحدد المؤشرات الخاصة بالأداء التعليمي للجامعات، مع تمكين المسئولين من إصدار أنواع محددة من القرارات النوعية التي يعتمدها لتحسين مستويات أداء الجامعات، وكذلك بيان التسلسل الرتبي للجامعات والأقسام المتناظرة.

$$
\text { سياسة القبول: }
$$

تشير سياسات الالتحاق بمؤسسات التعليم الجامعي إلى النهج العام الذي تتبعه دولـة ما نحو إعداد طلابها، ممن تتوافر فيهم مجموعة من المتطلبات والشروط، حيث تترجم إلى بـى إلى

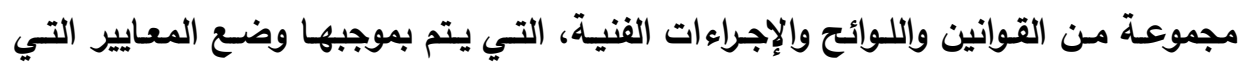

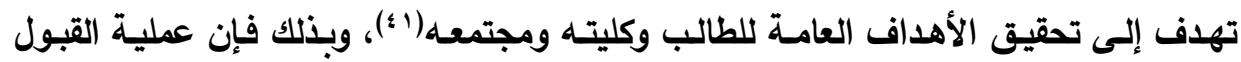
تمس رغبة كثير من أفراد المجتمع، ويقصد منها عادة وضـع الطالب المناسب في التخصص 
بدائل مقترحة لتطوير منظومة تقييم أداء الجامعات --- د/ محمد ابراهيم عبد العزيز خاطر

المناسـب، وعلى هذا فبإن كل جامعة تضـع لنفسها أسـلوباً في القبـول يعتمــ على مقـاييس ومعايير علمية يمكن بواسطتها الحكم على قدرات وميول الطالب في الإنتاج والإبداع.

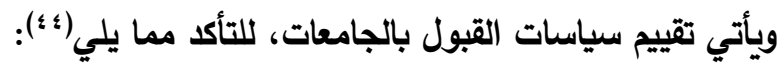

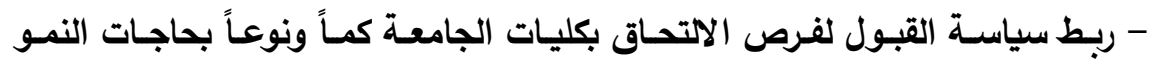
الاقتصـادي، من أجل توفر المتخصصين الأكفاء لتلبية احتياجـات كافة القطاعات المجتمعية تحقيقًا للتنمية الثاملة. - إسـهامها في التظلب على مشكلات الكفـاءة الداخليـة والخارجيـة لمنظومـة الأداء الجامعي، وكذلك تحقيق التوازن بين العرض والطلب من القوى العاملة.

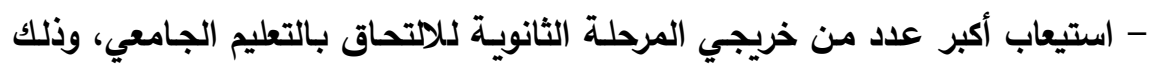

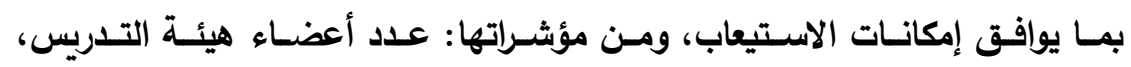

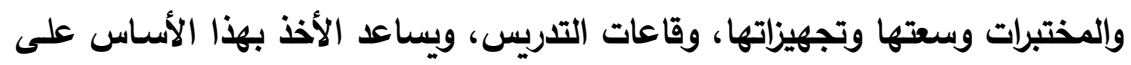
تحديد الطاقة الاستيعابية لكليات الجامعة. - مراعاة رغبات الطلاب المتقدمين وقدراتهم، ويترجم هذا الأسـاس من خلال السماح للراغبين بالاتحاق بتحديد أكثر من رغبة، مع مراعاة الانتقاء على أساس القدرات.

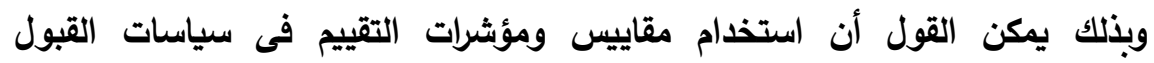
بالجامعات، يتم فى إطار من احتياجات المجتمع وسوق العمل، والمواصفات والثروط التي يطلبها هذا التعليم فى الطالب ليستوفى صلاحية الانخراط فيه، وميول الطلاب وقدراتهم، وأن يراعى نظام القبول إمكانات تلك المؤسسات من حيث أعضاء هيئة التدريس والإداريين والفنيين ومدى توفير المعامل والمختبرات والورش ونحوها، وأن يتم تقييم سياسات القبول

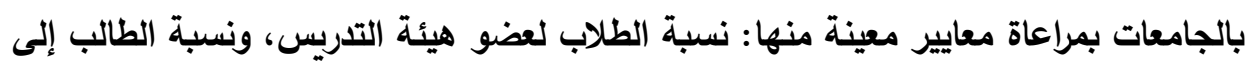
المقعد فى المكتبة والطالب إلى الكتاب والدوريسة، ونسبة الطالب إلى المساحة، وإلى استخدام المختبرات وساعات استخدام القاعات، علاوة على الطاقة الاستيعابية للأقسام من الطلاب. • الخطط والبرامج الاراسية: إن الخطط والبرامج الدراسية هي متطلبات التخرج وبإكمالها يُمنتح الطالب الدرجة العلمية وهذه المتطلبات تشمل: متطلبات المعرفة العامة، ومتطلبات التخصص، والمتطلبات الاختيارية، وترتبط زيادة كفاءة التعليم الجامعي وتحسين إنتاجية الجامعة من خلال التركيز على الخطط والبرامج الاراسية، بما يحقق الإنتاجية التعليمية للجامعات، ويمكن للجامعات تقييم أداء مؤسساتها فيما يتعلق بالخطط والبرامج الدراسية للتأكد من الآتي(ه ؛): 
مجلة كلية التربية بالإسماعيلية - العدد الرابع والأربعون - مايو 9 م ـ

- التنوع وحرية الاختيار وبيئة التنفيذ من حجم القاعات وحجم حجرات الدراسة.

- مستوى حداثة ومعاصرة الخطط والبرامج الدراسية للتطورات العلمية السريعة وحنم والمتجددة.

- مدى توافر توثيق رسمى واضح ومتكامل ومطبوع للخطط والبرامج الدراسية لكى يساعد على ضبط الأداء فى العملية التعليمية.

- مدى وجود نظام يحمم البرامج الدراسية بثكل يؤدى إلى إحداث التكامل المعرفي لمحتوياتها.

- درجة جودة المصادر العلمية التي يعتمد عليها فى تثغيل الخطط والبرامج الدراسية أثناء العملية التعليمية والتي تتمثل أساساً فى الكتب الدراسية الدماسية. - مدى وجود تكرار أو تداخل بين الخطط والبرامج الدراسية، وتأثيره على تكامل الجوانب المعرفية المقدمة للطلاب.

تقويم المخرجات التعليمية:

تأتى عملية تقويم المخرجات التعليمية لتؤكد على المواءمة بين الخطط والبرامج الاراسية الجامعية وبين متطلبات التنمية، حيث تتبع بعض الجامعات أساليب مختلفة لربط لتبط خططها وبرامجها الدراسية باحتياجات المجتمع، إذ تنظم بعض الجامعات دورات تدرببية

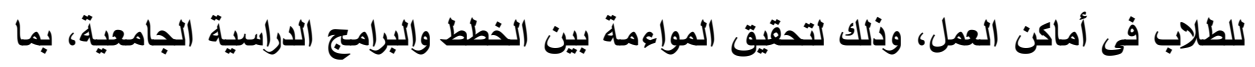
يسهم فى الاتصال بين مستويات المهارة المهنية والصناعية ومستويات تعليم الطلاب والقدرة على التطبيق(1) ؛ (1).

ب- المجال الثاني: الدور البحثي للمؤسسات الجامعية: يمثل البحث العلمي البُعد النوعي فى رسالة أي جامعة لحل مشكلات مجتمعها المتجددة؛

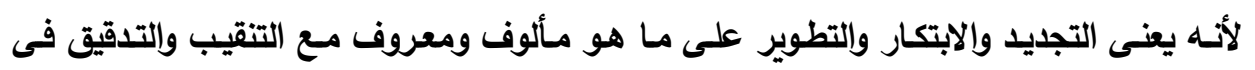
أصول المشكلات، وإعادة النظر فى النتائج وتحكيم العقل فى معانيها بهدف تطوير الواقع الذي هي نعيثه، ويتم إجراء عمليات التقييم في مجال البحوث العلمية للجامعات للتأكد مما يلي( (v)؛ • مدى تمكين الباحثين من التعامل مع مثكلات واقعية ومحاولة إيجاد حلول لها.

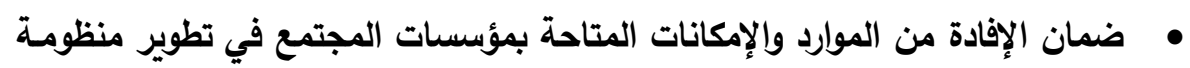

$$
\text { البحث العلمي. }
$$

• نشر ثقافة التميز البحثي والمؤسسي للجامعات بالمجتمع باعتبارها سبيلاً لا بديل

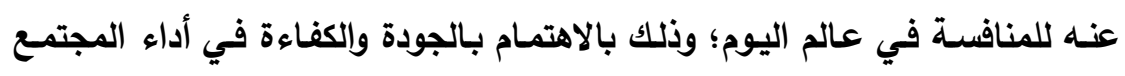


بدائل مقترحة لتطوير منظومة تقييم أداء الجامعات --- د/ محمد ابراهيم عبد العزيز خاطر

الأكاديمي والثقافي والعلمي، وباتباع أنماط جديدة متطورة من نظم التعليم والبحث

العلمي.

• فاعليـة شـراكة الجامعة مـع الهيئـات العلميـة والبحثية الدوليـة، تعظيم القدرة على

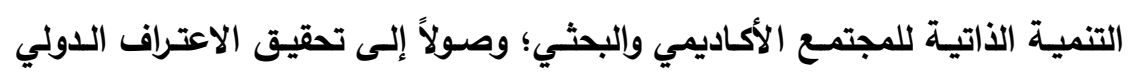

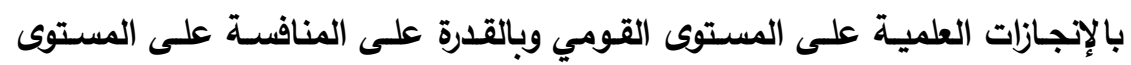

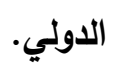

•مدى تنـوع الصيخ البحثية التي تتبناهـا الجامعات مـع مؤسسـات المجتمـع، بحيث

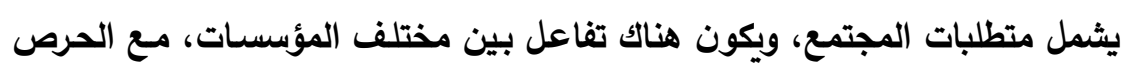

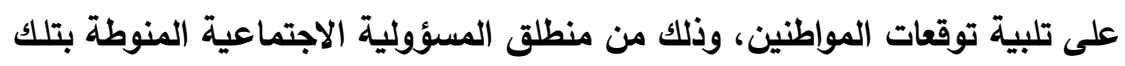

المؤسسات.

• تطبيق المؤسسـات الجامعية للصيغة التعاقية في البحوث، حيث يمكن من خـلال

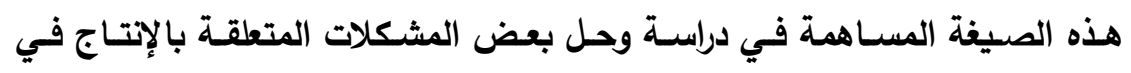

الصناعات المختلفة، وكذلك تقديم الدراسات التطبيقية التي تخدم الإنتاج.

وبذلك يظهر دور التقييم في الجوانب البحثية داخل الجامعات في تأكيده على اضطلاع

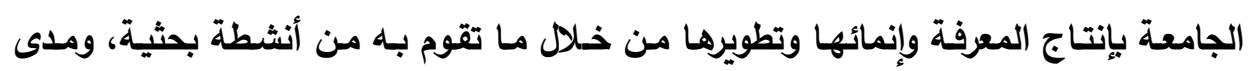

حرصها على تثجيع أعضاء هيئة التدربس وطلبة الدراسـات العليا بها على إجراء الأبحاث

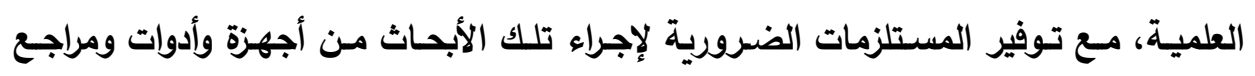

علمية وغيرها.

ج- المجال الثالث: الدور المجتمعي للمؤسسات الجامعية: إن العلاقة بين الجامعة والمجتمع علاقة عضوية لها أبعاد كثيرة، فهى علاقة تتأثر

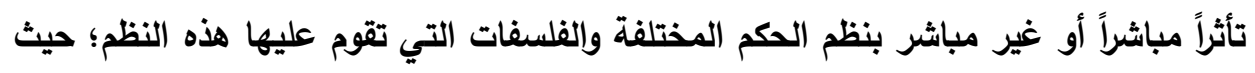
إن كل تغيير يطرأ على المجتمع إنما ينعكس على الجامعة، كما أن كل تطور يصيب الجامعة

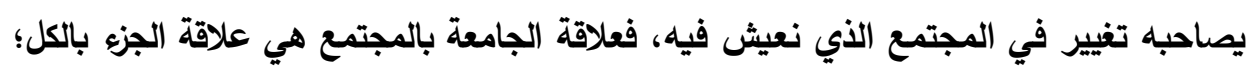
فلا توجد الجامعة أبداً من فراغ، بل لكل جامعة بيئة محيطة بها تؤثر بطرق مباشرة وغير مباشرة فئي

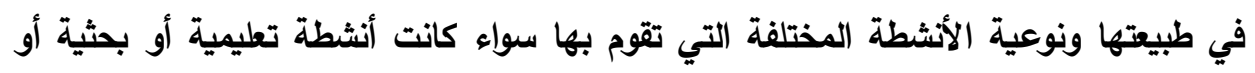

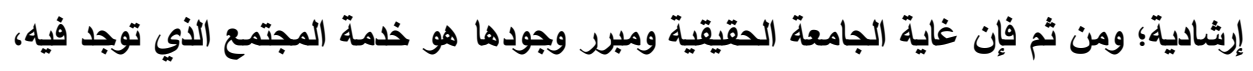

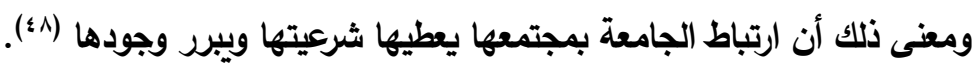


مجلة كلية التربية بالإسماعيلية - العدد الرابع والأربعون - مايو 9 م ـ

وتظهر خدمة المجتمع في أى نثاط تقوم به الجامعة لحل مشكلات المجتمع، أو

لتحقيق التنمية الثاملة في المجالات المتعددة وذلك من خلال ما تقدمه كليات الجامعة ومراكزها من أنشطة وخدمات، تتوجه بها إلى غير طلابها النظاميين أو أعضاء هيئة التدريس بها، وإنما تقدم إلى أفراد المجتمع ومؤسساته بهدف إحداث تغييرات سلوكية وتنموية في البيئة المحيطة.

ومما سبق ينبغى التأكيد على ضرورة أن تكون الجامعات في مجتمعاتها المحلية مراكز

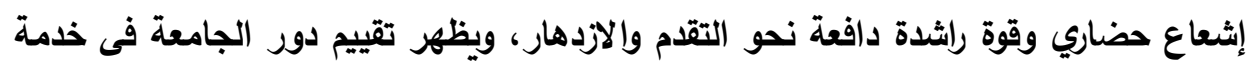
مجتمعها، فى تحديد ما يلي(9) ؛ ؛ ):

• مدى تنوع مجالات خدمة المجتمع وتعددها بما توفره من مناخ يتيح ممارسة الايمقراطية، والمشاركة الفعالة في الرأي والعمل، مع تنمية قدرة طلابها وتعا على المشاركة والإسهام في بناء المجتمع وحل مشكلاته، وكذلك تنمية الرغبة الجادة في البحث عن المعرفة في إطار منهج علمي دقيق، يراعى الظروف الاجتماعية والاقتصادية وإلسياسية ولية ولئه

للمجتمع.

• إعداد الطلاب للقيام بالأعمال التي يتطلبها سوق العمل، مع إكسابهم الاتجاهات

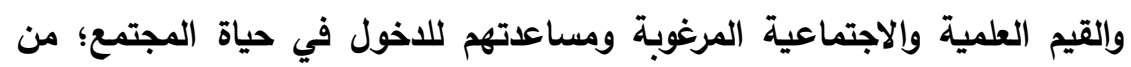
أجل تطويره والنهوض به، والتركيز علي تنمية المهارات وروح الابتكار لدي الطلبة، وطرح نماذج جديدة للتعليم والبحث العلمي بما يلانم واقع وحاجة المجتمع. • نشر العلم بين أبناء المجتمع المحلى، من خلال الندوات والمحاضرات وبرامج التعليم المستمر ، وحركات النقد الاجتماعي البنّاء .... وغيرها.

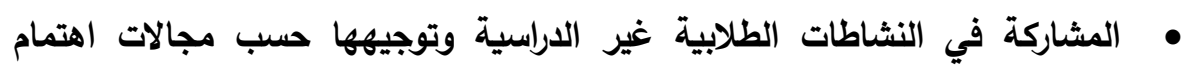
عضو هيئة التدريس؛ في الثئون الثقافية والاجتماعية أو الرياضية أو الفنية وغير ذلك، أو ما يقام من معسكرات للخدمة موجهة للبيئة المحلية.

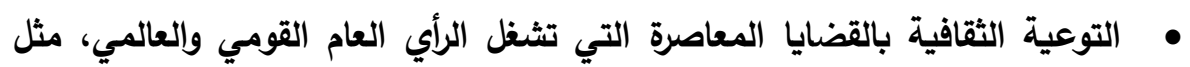
قضايا الانفجار السكاني، والمعرفي، وثورة المعلومات والاتصالات؛ وتغير المناخ وقضايا حقوق الإنسان ونثر السلام ورعاية ذوى الاحتياجات الخاصة بالمجتمع. وبذلك تظهر أهمية تقييم الدور الخدمى للجامعات تجاه مجتمعها والذى يظهر في الخدمات الامتدادية "Outreach Services" والتى تتضمن كل شيء يمكن أن تقدمه الجامعة لتنمية المجتمع المحيط بعيداً عن أدوارها التقليدية في التدريس والبحث العلمي، مثل: 
بدائل مقترحة لتطوير منظومة تقييم أداء الجامعات --- د/ محمد ابراهيم عبد العزيز خاطر

الاستشارات العلمية التي تقدمها الجامعة لمؤسسات المجتمع وأفراده، والبحث التطبيقي الذي يسعى إلى دراسة المشكلات والعمل على حلها، ونقل نتائج البحوث والاكتشافات الجديدة إلى المى المجتمع المحلى والقومي، وتأليف الكتب العلمية للطلاب ولغيرهم من المعنيين بحقول المعرفة

ثالثاً: مخرجات تقييم الأداء الجامعي:

تمثل المخرجـات المرحلـة الأخيرة مـن محصلة العمليات التحويلية وهـي النتائج النهائيـة

للنظام وهي تمثل مؤشر لنجاح أو ضعف النظام، ويمكن تقسيمها إلى: مخرجات كمية، مثل: أعداد

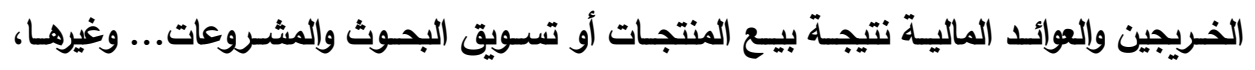

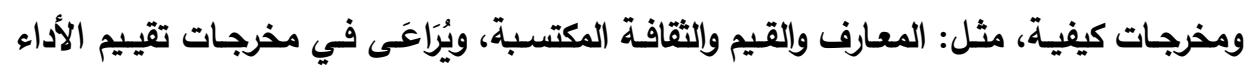
الجامعى بعض الاعتبارات، يتمثل أبرزها فيما يلي (••):

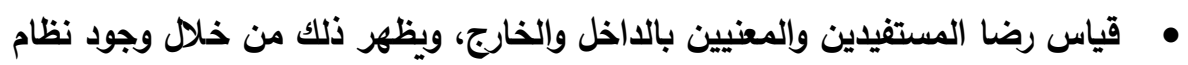

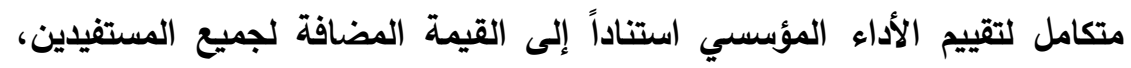
والتقييم وفق مؤشرات السوق بما يضمن رضا المستفيد عن جودة الخدمة، وسرعة الادئ تقديمها والحصول عليها في الوقت المناسب، وبالتكلفة المناسبة، وبالتنوع الذي وني يرغبه.

قياس أنثطة التثغيل الداخلية لتحديد مستويات الجودة والتكلفة والقيمة المضافة من تحويل المدخلات إلى مخرجات، ووجود مؤشرات دقيقة للمعاملات المالية لقياس أداء المؤسسة فيما يتعلق بمعدلات الإنفاق، وكلفة العمليات. • تحديد فجوات الأداء، ويظهر ذلك من خلاء مراجعة البيانات ومؤشرات الأداء الرئيسة، والتقارير السنوية التي تحدد نقاط القوة، وفرص التحسين، وتباينات الأداء

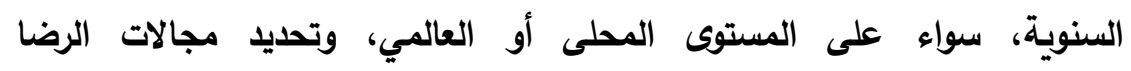
للمستفيدين ودلالتها التظيمية، ومشاركة العاملين في جوائز التميز المحلية والإقليمية، ومشاركة الطلاب في المسابقات والمحافل الدولية.

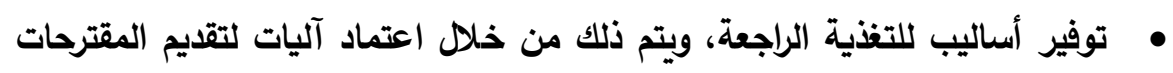

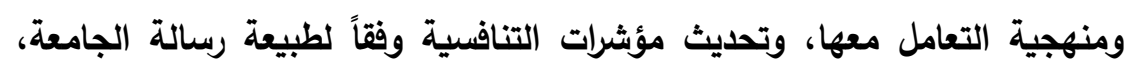
بحيث تقوم بتحديث منافسيها دورياً، وتدرس مدى جودة منتجاتهم ورضا المستفيدين

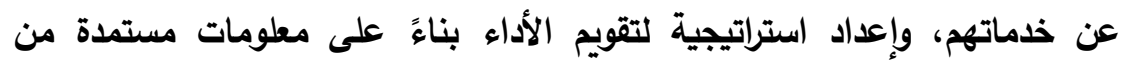


مجلة كلية التربية بالإسماعيلية - العدد الرابع والأربعون - مايو 9 م ـ

مقاييس الأداء المقارنة، وتبنى نماذج عالمية للتميز الإداري، والعمل وفقاً لمكوناتها

$$
\text { ومقاييس تقويمها. }
$$

واستناداً إلى ما تقدم، وبتحليل منظومة تقييم الأداء الجامعى بمدخلاتها وعملياتها

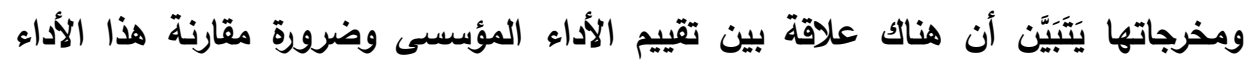
بمؤسسات أخرى؛ إذ يساعد ذلك المؤسسةَ على تحديد ما إذا كانت ممارساتها ونواتجها

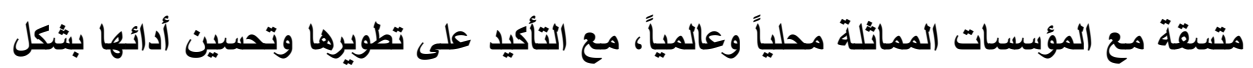
تصاعدى من عام لآخر .

المحور الثالث: طبيعة أسلوب القياس المقارن بالمؤسسات المعاصرة: ينطلق القياس المقارن من مناظرة المؤسسة بمؤسسات أخرى في ميادين معينة من أجل التعلم منها والتفوق عليها في الميدان أو الميادين محل المقارنة، عن طريق تحسين وتطوير الأداء والإنتاجية وأساليب خدمة المستفيدين، وإذا إِنتُخْدِم أسلوب القياس المقارن بثكل صحيح فإنه يمد بالحقائق اللازمة لتخطيط وتنفيذ الاستراتيجيات التي تخدم متطلبات المستفيدين والمعنيين وأصحاب المصالح، حيث يعمل القياس المقارن على مساعدة المؤسسات في تقييم منافسيها وذاتها واستخدام المعلومات الناتجة عن المقارنة في تصميم خطة عملية لتحقيق التفوق في سوق العمل، والههف هو التصميم على أن تصبح المؤسسة في وضع أفضل من وضعها القائم. وتُبْنَّى فكرة القياس المقارن على ما يسمى بـ "دورة القياس المقارن" التي تتكون من خمسة أنشطة متتالية، وتتضح -على الترتيب- في الثكل التالي(10):

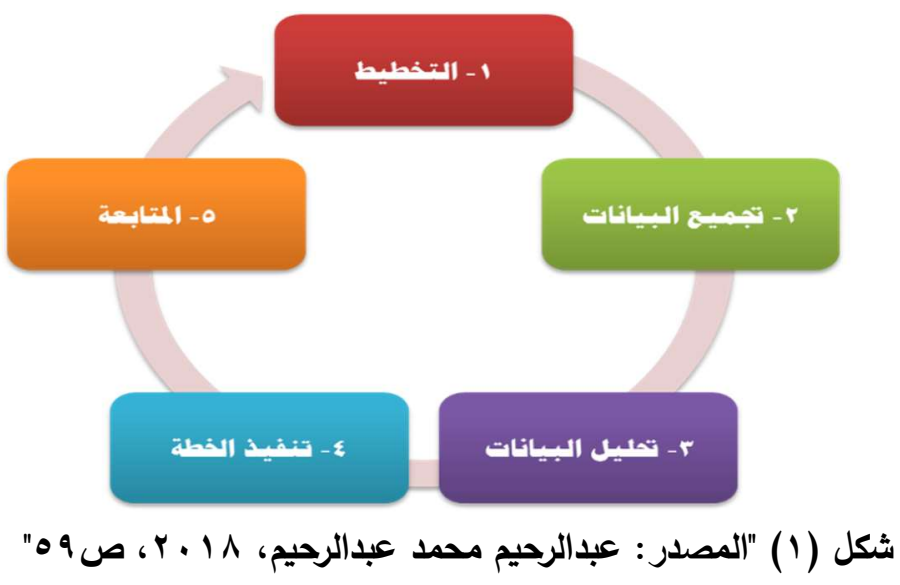


بدائل مقترحة لتطوير منظومة تقييم أداء الجامعات --- د/ محمد ابراهيم عبد العزيز خاطر

ويتضح من الثكل السابق خطوات دورة القياس المقارن، وهى: رسم خطة وبرنامج

لتحقيق أفضل الأهداف مقارنة بالقائم في السوق بما يجعل المؤسسة تتفوق على الأفضل بين منافسيها، ثم تجميع البيانات وتحديد العناصر المؤثرة في النجاح، وتحليل أفضل بلهيل المؤسسات المنافسة في الميدان وفقاً للبيانات المجموعة، ومِنْ ثم تنفيذ الخطة المرسومة، ثم وفي يلي ذلك متابعة دورة قياس الأداء وقياس التقدم والتأكد من أن الدورة تعيد نفسها بما يضمن استمرارية التحسين. وبذلك فإن أسلوب القياس المقارن يمكن أن يساعد في تصميم استراتيجيات التحسين، ولتهن وفي التطوير التظيمي وزيادة كفاءة الأداء، وتحسين التدريب، والحد من التكاليف، وفي تمكين الأفراد من التعلم حول الطرق الجديدة في أداء العمل، وتحسين طرق الاتصال الاخلي.... - اخيرها. ويتم تناول المحور المتعلق بالقياس المقارن وطبيعته في المؤسسات التعليمية وفقاً للعناصر التالية: أولاً: نشأة القياس المقارن وأهدافه: يعتبر مفهوم القياس المقارن أحد المفاهيم الحديثة التي ظهرت خلال نهايات القرن

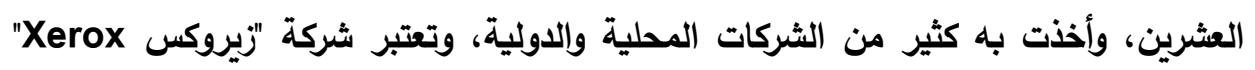

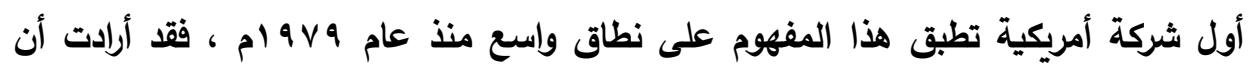
تدرس أسباب تفوق المنافسين اليابانيين عليها فى إنتاج آلات تصوير المستندات بجودة أعلى ملى فئ وبأسعار أقل من تكلفة إنتاجها بشركة "زيروكس"، فقامت بثراء الآلات اليابانية وتفكيكها ودراستها ومعرفة سر قوتها وإنخفاض تكاليفها واستفادت بذلك في تحسين آلاتها بلرجة

وبالرغم من أن هذه العملية ركزت فى البداية على دراسة المنتجات المنافسة إلا أنها امتدت إلى دراسة إجراءات العمل ووظائف العاملين والأداء التنظيمي، كما شملت دراسات زيادة الإتتاجية ورفع قيمة العمل ككل، وهكا فإن البحث وراء الأساليب الأفضل لا ينحصر في إنى نشاط معين بل يشمل كل الأنشطة بما فى ذلك النشاط التسويقي. وتعتبر شركة "فورد Ford" من الشركات الرائدة فى هذا المجال فى الوقت الحاضر ،

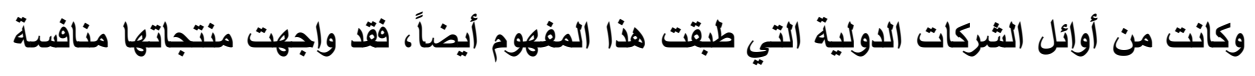
شديدة من جانب السيارات الأوروبية واليابانية، مما جعلها تتبع أسلوباً جديداً فى إنتاج الئه سياراتها الجديدة، حيث كَوَّنَت فريقاً من المتخصصين العاملين فى جميع المجالات الوظيفية 
مجلة كلية التربية بالإسماعيلية - العدد الرابع والأربعون - مايو 9 1 ـ r

ضمت ممثلين عن المستهلكين وأيضاً ممثلين عن الموزعين، وقام الفريق بدراسة أحسن الخصائص التي يرغبها المستهلكون فى كل السيارات المنتجة فى العالم ثم جلبت منها إلى

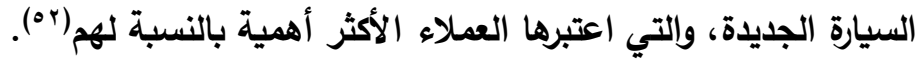

وفى الآونة الأخيرة تستخدم عديد من المنظمات والوحدات الإدارية حول العالم مفهوم

الاسترشاد بالممارسات الأفضل وبصورة عميقة؛ وذلك لتحقيق مجموعة من الأهداف، تتمثل

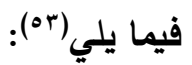

التركيز على تحديد فجوة الأداء، أي الفروق الجوهرية بين المؤسسة والمؤسسات

$$
\text { الأخرى المُنَافِسَة الأكثر تقدماً فى السوق. }
$$

• اقتباس الأفكار الناجحة من المؤسسات التي حققت مستوى تنافسي متقدم باستخدام مقاييس، مثل: (جودة المنتج، ومعدل الإقبال عليه، والتوسع فى ملى (السوق، وإرضاء المستفيدين). • ترشيد النفقات وتخفيض تكاليف الإنتاج أو الخدمات التي تكون مرتفعة، حيث تلجأ المنظمات الإدارية إلى البحث عن المنظمات التي تقوم بتأدية نفس النشاط أو الخدمة بتكلفة أقل. • توفير فرص التعاون بين المنظمات وتشجيع المنافسة فيما بينها على تحسين الأداء وإدخال أليات السوق ضمن استراتيجيات العمل، مما يتيح فرص التعلم المستمر، ونقل الخبرات والمعارف من المنظمات الأخرى بهدف تغيير نظم وأساليب العمل التقليدية. • إتاحة الفرصة للمؤسسة للتوجه نحو النماذج الأفضل للأداء والجودة، التي توفر لها فرص تحقيق رضا المستفيدين. تغيير ثقافة المؤسسة بحيث تصبح موجهة لحل المشاكل والأداء، والتركيز على تحقيق الأهداف والأولويات، ويتفق القياس المقارن مع الجودة فى أنهما يهدفان إلى التحسين المستمر. • تحسين القدرات الإبداعية والتجديدية لفريق العمل المسؤول عن تحسين الأداء

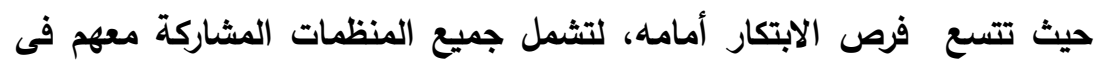
عملية القياس المقارن. وبناءً على ما تقدم يمكن استنباط أن لأسلوب القياس المقارن عديد من المبررات التي فرضت تطبيقه في المؤسسات المعاصرة ومنها المؤسسات التعليمية، ومن تلك المبررات ما 
بدائل مقترحة لتطوير منظومة تقييم أداء الجامعات --- د/ محمد ابراهيم عبد العزيز خاطر

• أنه يعد طريقة فعالة لإدخال التحسينات، حيث يستطيع المدراء تطبيق العمليات

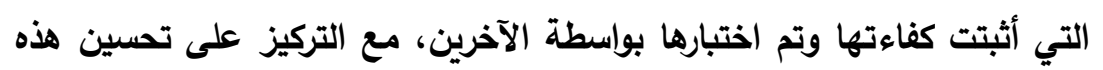

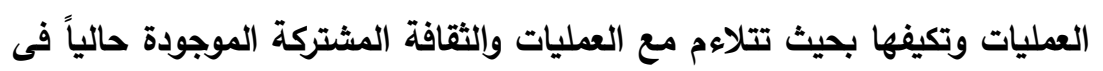

مؤسستهم.

• أنه يساعد المؤسسات فو إدخال التحسينات بسرعة أكبر، مما يسهم فى الاستفادة

الجيدة من إمكانيات طريقة القياس المقارن للمضي قدماً فى إحداث التحسينات

بصورة أسرع وأكثر كفاءة.

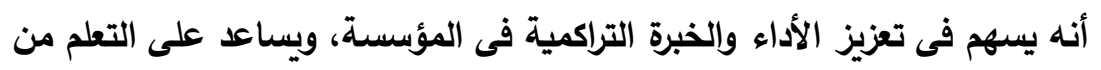

$$
\text { الآخرين، والسعي نحو التفوق عليهم. }
$$

• يعد أداة لتحقيق النتائج والأهداف التنافسية، ومن ثم يعد من الأدوات الفاعلة

عندما يستخدم بطريقة صحيحة ويتماشى مع استراتيجية المؤسسة.

ثانياً: أنماط القياس المقارن بالمؤسسات المعاصرة:

للقياس المقارن ثلاثة أنماط متعددة حسب الغرض والههف المنشود منها، ولكل

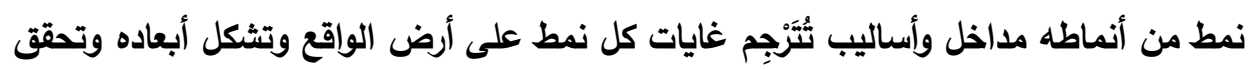

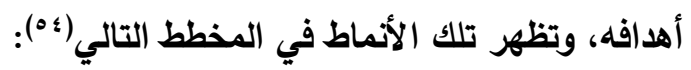

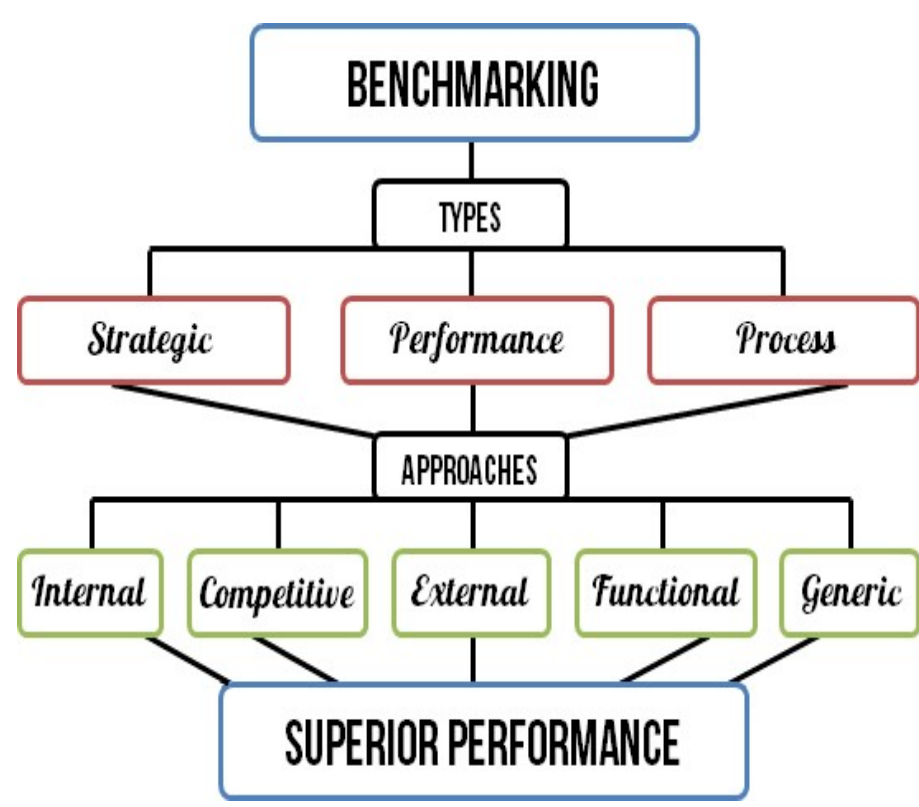

شكل (ץ) المصدر:"Kovacic, A., 2017, p.503" 
مجلة كلية التربية بالإسماعيلية - العدد الرابع والأربعون - مايو 9 م ـ

وبناءً على المخطط السابق فإن أنماط القياس المقارن، تتمثل فيما يلي(ه0):

1- القياس المقارن الاستراتيجي (Strategic Benchmarking): يستخدم القياس

المقارن من منظور استراتيجي عندما تبحث المنظمات عن سبل تحسين مجموع أعمالها،

من خلال دراسة الاستراتيجيات طويلة الأجل والمداخل التي أدت إلى نجاح المنظمات الأخرى فى هذه المجالات، ويترتب على القياس المقارن الاستراتيجي إحداث نقلة كبيرة فى مجال التركيز الكلى للمؤسسة بحيث تتم إعادة تحديد الأهداف وإعادة هندسة إجراءات الاتسيري العمل وتحديد الالتزامات التنافسية للمؤسسة، حيث يتفص هذا الأسلوب الاستراتيجيات الناجحة التي قادت إلى ميزة تنافسية ونجاح أكاديمي مستهدفة تشخيص مناطق قوة وضعف جهة المقارنة أو من يعمل في النشاط نفسه، كخطوة مهمة في ترتيب أولويات مجالات التحسين والتعرف على أفكار جديدة تسهم في بناء استراتيجية ناجحة. ץ- القياس المقارن الأدائي أو التطبيقي (Performance Benchmarking)، حيث يقسم القياس المقارن إلى قياس فى المجال التطبيقي وقياس مقارن فى المجال النظري، وعلى هذا الأساس تكون مقارنة نقاط التقدم فى مستويات الأداء المستخدمة فى عملية

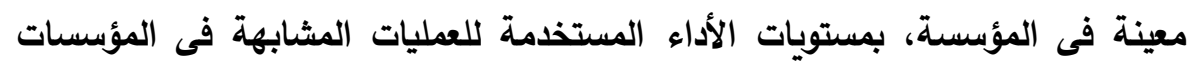
الأخرى.

ب- القياس المقارن العملياتى(Process Benchmarking): ويتم هذا النمط من خلا الشراكة مع المؤسسات التي تعمل فى نفس النشاط بهدف تحسين الوظائف المماثلة وخطوات العمل التي تتماثل لبعض الأعمال، وتؤدى إلى التعرف على الطرق المبتكرة

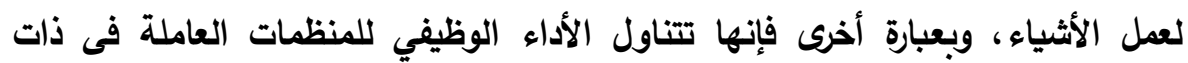
المجال بصورة شاملة تغطى المجال الأى تعمل فيه المؤسسة، ومن أمثلة ذلك أن يتم

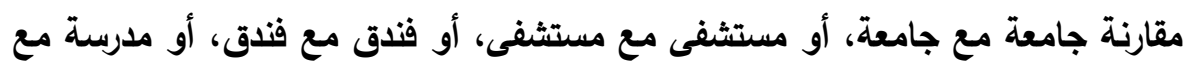
مدرسة أخرى داخل الدولة أو خارجها. وبناءً على الأنماط الثلاثة السابقة تأتى مداخل تطبيق القياس المقارن في المؤسسات المختلفة، وذلك وفقاً للأنواع التالية(† ه): • القياس المقارن الداخلي (Internal): القياس المقارن الاخلي هو الذى يتم داخل المنظمات التي لها عدة فروع ووحدات إدارية، وهنا يمكن مقارنة أداء مدير أو إدارة بأداء مدير أو إدارة أخرى فى نفس المؤسسة، كما يشمل القياس المقارن الداخلى أن تقارن المؤسسة أداءها الحالي بأدائها في الأعوام السابقة، وتفيد هذه النوعية 
بائل مقترحة لتطوير منظومة تقييم أداء الجامعات --- د/ محمد ابراهيم عبد العزيز خاطر

من المقارنات في معرفة مستوى الأداء، وما إذا كان في تحسن وتطور أو أنه يسوء أو في حالة ثبات.

القياس المقارن التنافسي (Competitive): يختص هذا النمط بإجراء القياس بين المنافسين ليس فقط من ناحية نوعية الخدمات والمنتجات، ولكن من ناحية فهم

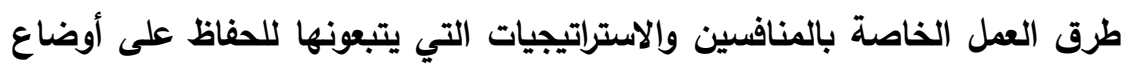
المنافسة، وتكون المقارنة هنا بين مؤسسات التعليم العالي وغيرها من المؤسسات

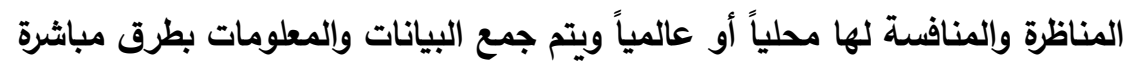
عن طريق عقد الاتفاقيات مع المؤسسات المناظرة أو بطرق غير مباشرة، وذلك من خلال المواقع الإكترونية أو وسائل الإعلام... وغيرها. • القياس المقارن الخارجي (External): وهو الإنى يتم بين المؤسسات وبعضها البعض حيث تتم مقارنة وقياس أداء مؤسسة ما بمؤسسة أخرى متماثلة أو غير متماثلة معها فى النشاط، وقت تقتصر المقارنة على أحد أنشطة أو خدمات المؤسسة بنشاط أو خدمة فى مؤسسة أخرى، وقد تمتد المقارنة إلى مؤسسات خارج الدولة

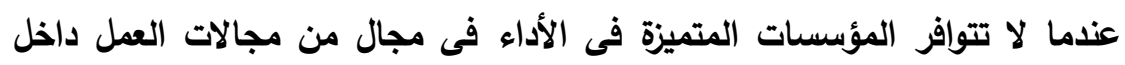
الدولة. • القياس المقارن الوظيفى أو التثغيلي (Functional): يتم الاتفاق في هذا النمط على مقارنة العمليات التى تحقق عوائد أسرع في تحسين الأداء، كما تتم المقارنة بين الوظائف أو العمليات الإدارية ذات الطبيعة الواحدة. وبذلك يمكن أنوائه أن تقوم المؤسسة الجامعية بمقارنة وظائف تقوم بها مثل: التدريس أو البحث العلمي أو الو الواته خدمة المجتمع بالوظائف ذاتها في مؤسسات التعليم العالي المناظرة والمتميزة إقليمياً أو دولياً؛ بهاف الارتقاء بهذه الوظائف وتحسينها، ويلخل ضمن هذا هابس النوع مقارنة

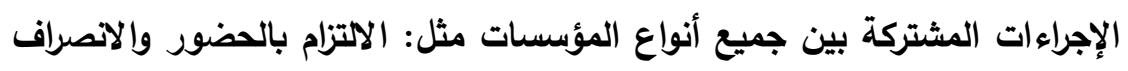
ونظام العمل والأجور واستخدام التقنيات الحديثة وغيرها من الجواتب الأخرى.

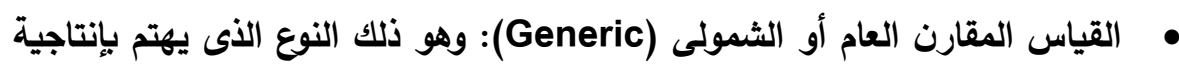
المؤسسة بشكل كلى، حيث يركز على تحديد مستوى الجودة، من جميع النواحي

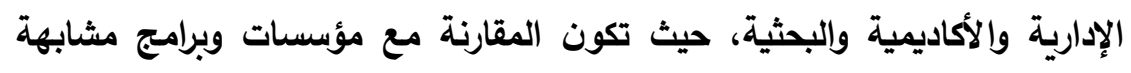

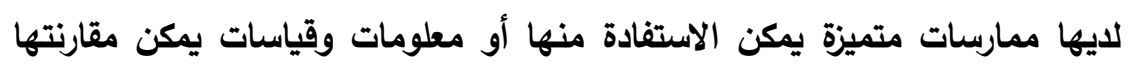
مع هذه الجهات للحكم على الأداء. 
مجلة كلية التربية بالإسماعيلية - العدد الرابع والأربعون - مايو 9 م

ومن جهة أخرى فهناك من ذهب إلى أن أسلوب القياس المقارن يشتمل على أنواع

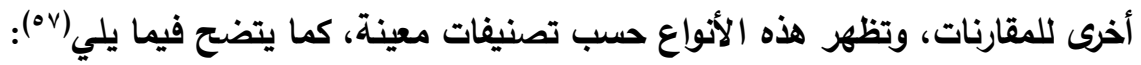

• القياس المقارن من حيث مجال المقارنة: وعلى هذا الأساس تكون نقاط التقدم إما ليا

داخلية أو خارجية، فإذا كان مجال القياس داخلياً فيكون القياس المقارن داخلياً،

أي مقارنة عملية مع عملية أخرى داخل المؤسسة، أما إذا كان مجال القياس

خارجياً فيكون القياس خارجياً، أي مقارنة عملية ما في مؤسسة ما مع عملية أخرى

في مؤسسة أخرى.

هالقياس المقارن من حيث مجال المنافسة: وعلى هذا الأساس يتم تقسيم القياس

حسب وجود منافسة أم لا، فإذا كان القياس المقارن مع مؤسسات منافسة (نفس ولف

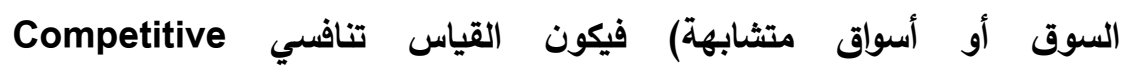
"Benchmarking" أما إذا كان القياس مع مؤسسات غير منافسة (تعمل فى مئوئ

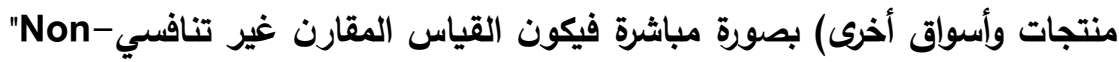

.competitive Benchmarking"

ومن ناحية أخرى فإن هناك ثلاثة أنواع من المشاركين أو الأقران الذين يمكن إجراء

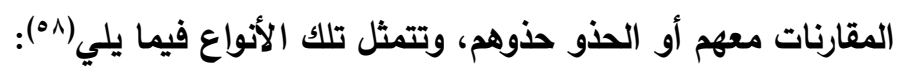
• الأقران المماثلون Peers: هي المؤسسات أو البرامج التي تشترك في خصائص التص ومصالح مماثلة، لها خصائصها التي تشمل أوجه التشابه، مثل: التأسيس والثقافة ونظام العمل، ولكى تتم الاستفادة من المقارنة معها يجب أن يكون لايها نظم لإدارة الجودة، وتكون حاصلة على الاعتماد أو على وشك أن تحصل عليه، وذلك للتأكد من أن ممارساتها ونواتجها على مستوى جيد. • الأقران المتطلع الوصول إليهم Aspiration: وهي المؤسسات أو البرامج المتميزة التي تتفوق على الجامعة أو البرنامج، وتكون للجامعة خطط مستقبلية لتحقيق رؤيتها في الوصول إلى مستوى قريب من هذه المؤسسات أو البرامج، ولا يشترط في هذه الحالة أن تتشابه مع المؤسسة أو البرنامج في الكثير من المميزات والظروف؛ فتقوم المؤسسة أو البرنامج بعمل مقارنة مرجعية تعاونية مع هذه الجهات؛ لتبادل الخبرات واكتساب الممارسات للتطوير . التعلم من الممارسات المثلى Best practices: وفي هذه الحالة تقوم المؤسسة بالاقتداء ببعض المؤسسات أو البرامج التي لايها بعض الممارسات المميزة التي تجد الجامعة أو البرنامج أنه من المفيد لها تطبيق هذه الممارسات، حتى لو كانت 
بدائل مقترحة لتطوير منظومة تقييم أداء الجامعات --- د/ محمد ابراهيم عبد العزيز خاطر

أنشطة هذه المؤسسة ليست مماثلة، مثل استحداث طرق لتنويع مصادر التمويل

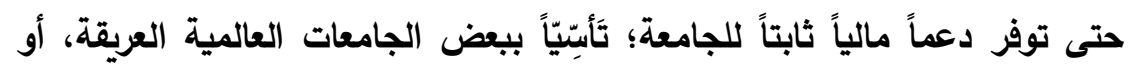

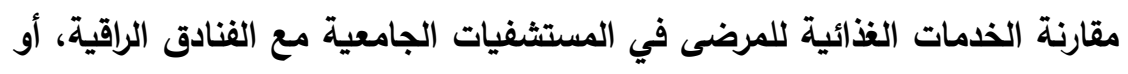
مقارنة نظم الحوكمة والإدارة وأساليب تنمية الموارد البشرية..... إلخ. ثالثاً: مراحل تنفيذ القياس المقارن بالمؤسسات المعاصرة : يتطلب التطبيق العملي للقياس المقارن اتخاذ الخطوات التالية(90):

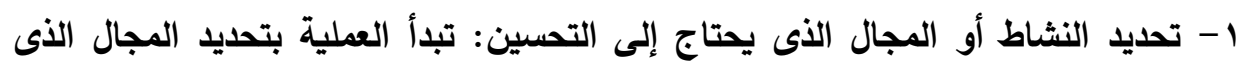
يلاحظ تراجع المؤسسة الجامعية فى أدائه عن المنافسين، وبذلك فإنها تحدا إلى مواطن الضعف التي تحتاج إلى إصلاح، وتعتبر هذه الخطوة من أهم الخطوات؛ لأن كل الجهود

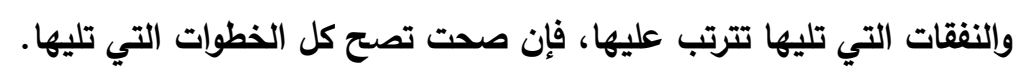
ץ- تحديد معايير الأداء الممتاز: ويراعى أن تكون هذه المعايير قابلة للقياس حتى تتم المقارنة بين أداء المؤسسة الجامعية موضع الدراسة وأداء المؤسسة الجامعية الأفضل بطريقة موضوعية، مثل: معدل الإنتاجية والقدرات التسويقية وعدد المستفيدين والسمعة الأكاديمية... وغيرها. r- تحديد المؤسسات ذات الأداء الأفضل: حيث يتم البحث عن المنافس الذى يتميز بالأداء

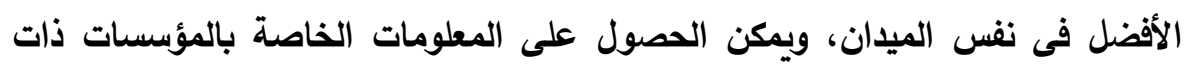
الأداء الأفضل بالاستعانة بعدد من المؤشرات، والتي من أمثلتها:

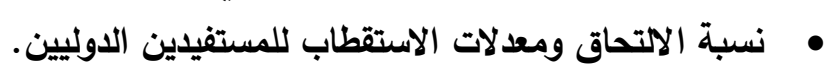

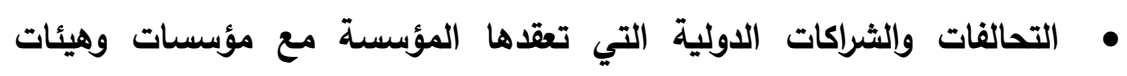
مناظرة. • ترتيب المؤسسة في المسابقات والتصنيفات الدولية التي تجرى سنوياً من قبل منظمات وهيئات دولية.

צ- جمع البيانات اللازمة: تتركز الجهود هنا فى جمع البيانات حول العمليات المطبقة

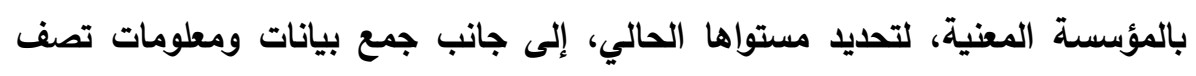

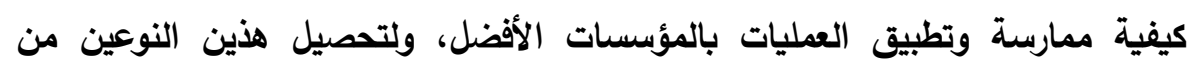
المعلومات يمكن الاعتماد على الأساليب التالية(·"):

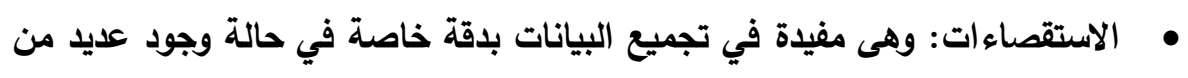
المصادر الخارجية المتباعدة، وفي هذه الحالة يمكن الحصول على على البيانات من 
مجلة كلية التربية بالإسماعيلية - العدد الرابع والأربعون - مايو 9 م

المنظمات عن طريق البريد أو التليفون، أو عن طريق المستقصين، هذا بجانب إمكانية قيام الاستقصاء بتمهيد الطريقة أمام الزيارات الميدانية بعد ذلك أو فرئ

استخدامها لتدعيم نتائج تلك الزيارات ومتابعة ما توصلت إليه.

• الزيارات: تمد الزيارات المؤسسة بفرصة مشاهدة العمليات وجه لوجه على الواقع

العملي، ويتم التخطيط لها بين المؤسسة والمنظمات التي سيتم زيارتها، بحيث يتم تخصيص الوقت المناسب للزيارة وتحديد الأطراف التي سيتم مقابلتها والبيانات والمعلومات المطلوبة والمتاحة للنشر، كما يجب أن يحدد الفريق بدقة قبل الزبارة ما

الأي يود معرفته أو رؤيته ويوضح ذلك للمسئولين بالمؤسسة التي يتم زيارتها. • المجموعات ذات الاهتمام: وتتمثل فى مجموعات الأفراد الذين لهم علاقة مباشرة بأنشطة وعمليات القياس المقارن ومن هذه الفئات أو المجموعات: المستفيدين، أو الو أعضاء وممثلي المنظمات المتخصصة، مثل: منظمات الجودة. • مسـح السـوق أو عمل لقاءات مـع المستفيدين، ثم حصر المنافسين ووضـع أوزان نسبية محتملة لهم، وذلك من خلال تحديد محاور التقييم كالسعر وتقسيم السوق بالنسبة للنواتج النهائية ثم تقييم هذه العمليات وبـذلك يتم تحديد المنتج وضـمان موثوقيته . باته • دراسة المشكلات عن طريق شكاوى المستفيدين؛ لتحديد المواطن التي تحتاج إلى تحسين. ه - تحديد الفجوة بين المؤسسة المعينة والمؤسسة الأفضل: عند مقارنة أداء المؤسسة المعينة بأداء المؤسسات الأفضل يتم تحيد الفجوة بين الإنثين، وقد تكون الفجوة موجبة (أداء المؤسسة يتفوق على أداء المنافسين) أو سالبة (هناك قصور فى الأداء تعانى منه

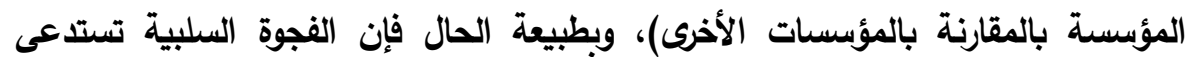
التخخل بغرض الإصلاح. צ- تصميم البرنامج المناسب لسد الفجوة بين أداء المؤسسة المعنية وأداء المؤسسة الأفضل: وفى هذه المرحلة يتجمع لاى المسؤولين كل المعلومات الخاصة بالوضع الحالي واللوضع المرغوب فيه فيقومون بوضع البرنامج الانى يعاونهم فى تحقيق الوضع الأفضل، غير أن تصميم البرنامج المناسب يحتاج إلى وضع بعض الافتراضات حول المستقبل وتكوين عدد من السيناريوهات البديلة بما يتفق مع التغييرات المطلوب إجراؤها. - تنفيذ البرنامج ومتابعة النتائج: بحيث يمكن اتخاذ الإجراءات التصحيحية فى حالة الخطأ

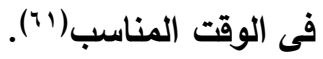


بدائل مقترحة لتطوير منظومة تقييم أداء الجامعات --- د/ محمد ابراهيم عبد العزيز خاطر

وبناءً على ما تقدم يمكن استخلاص خطوات تطبيق القياس المقارن في منظومـة أداء

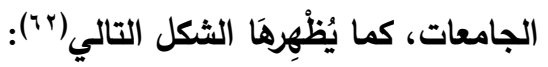

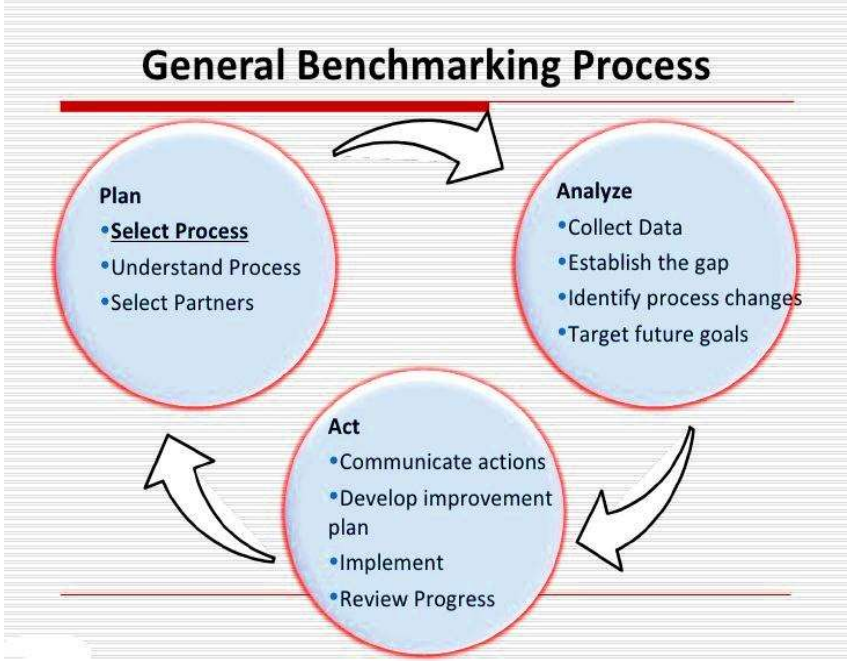

شكل (ץ): المصدر: "Lobna Ali Al-Khalifa 2015, p.315"

ويلاحظ من الثكل السابق، أن مراحل القياس المقارن، يمكن إجمالها في ثلاثة مراحل

$$
\text { تفاعلية، وذلك على النحو التالي: }
$$

مرحلة التخطيط: وهي تلك المرحلة التى يتم خلالها تحديد العمليات وإدراكها بثكل

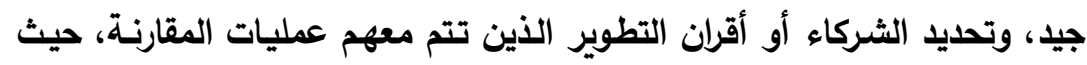

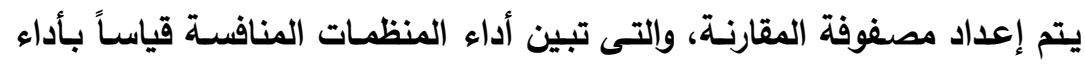
المؤسسة الحالية، إذ يقوم فريق العمل بملء مصفوفة المقارنة أي مستوى الناتج النهائي مقارنة بما تنتجه المؤسسات المنافسة. مرحلة التحليل: وهي التى تتضمن تجميع البيانـات، وتحديد الفجوة فـى الأداء، ، والتعرف على عمليـات التغيير، وصـياغة الأهداف المستقبلية، وتتضـمن هذه

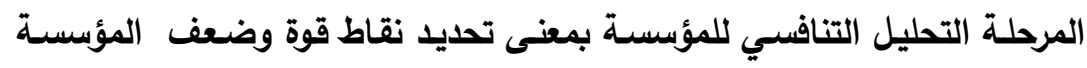
في البيئة التي تعمل بها، ويتطلب ذلك إجراء دراسـات تحليل البيئة من خـلال

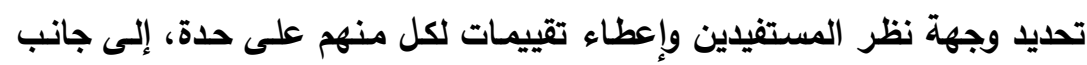

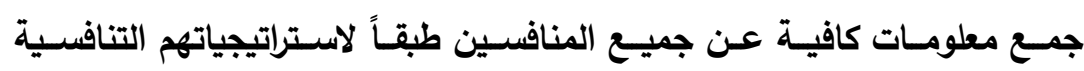
المختلفـة، وذلك بالتركيز على أسباب نجاح هذه المؤسسـات التعليمية وأسباب

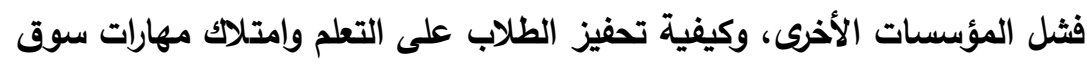
العمل المتجددة، والكلفة الكلية للعملية التعليمية، وديناميكية بيئة التعليم. 
مجلة كلية التربية بالإسماعيلية - العدد الرابع والأربعون - مايو 9 م ـ r

• مرحلة التنفيذ: وهي التى تتضمن إجراءات الاتصالات وتطوير الخطة، والعمل

على تنفيذها، ومراجعة التقدم الحادث بثكل دورى، مع استدامة دراسة المقترحات والآراء الابتكارية لتحديد فرص التحسين وتحقيق المركز الإيجابى الأفضل والحرص على تنميته والاستثمار فيه.

رابعاً: عيوب القياس المقارن بالمؤسسات المعاصرة وسبل التغلب عليها:

تأتي الاتتقادات الموجهة لأسلوب القياس المقارن من كَوْنَه فكرة تعتمد على ما

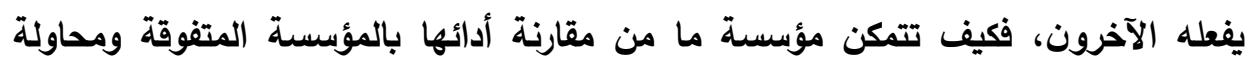

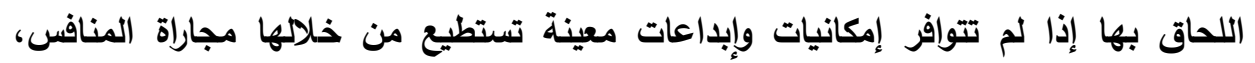
وتتمثل أهم عيوب هذا الأسلوب فيما يلى (سॅ):

ا - إن قوة أسلوب القياس المقارن وفائدته للمؤسسة تكمن فى وضع الغايات والأهداف اعتماداً على الظروف والواقع الخارجي، وعلى ذلك ينبغي مراعاة أن نتائج الأمس ونس

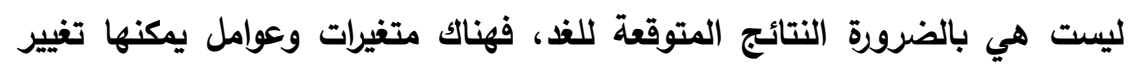
المعاييز ودقة أو سرعة الأداء. r - إن أسلوب القياس المقارن ليس بديلاً للإبداع والابتكار، إنه فقط مصدر للأفكار من خارج المؤسسة، فالنجاح فى إدارة أعمال المؤسسة يعتمد على صياغة وتحقيق لائل مجموعة من الغايات والأهداف التظظيمية. r- يترتب على تطبيق مبدأ الاسترشاد بالممارسات الأفضل إعاقة الابتكارية والتفكير

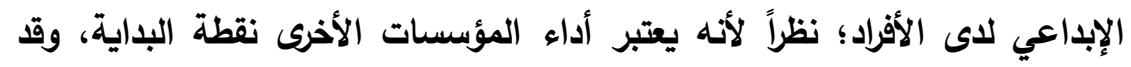

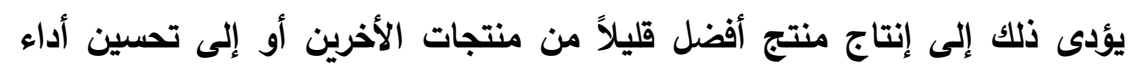

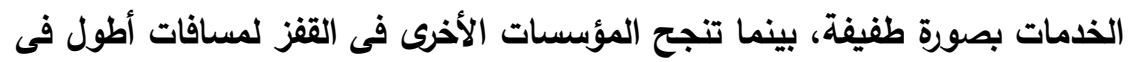
سباق التفوق. ع - تحتاج الدراسات التي تجرى لتحديد الممارسات الأفضل فى العمليات والأنشطة إلى وقت طويل، وحينما تبدأ المؤسسة فى تطبيق تلك الممارسات، ربما تكون ممارسات أخرى أفضل قد ظهرت لاى بعض المؤسسات الأخرى. ه - يؤدى الأخذ بهذا المبدأ إلى التركيز على المنافسين بصفة أساسية بينما تفقد

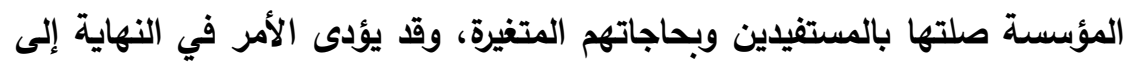

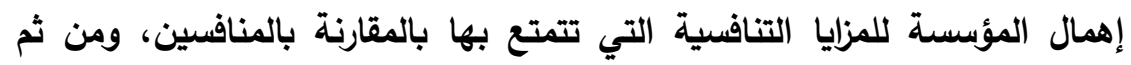
تُهْمِل إجراء التحسينات اللازمة فى تلك المزايا بغرض الحفاظ عليها. 
بدائل مقترحة لتطوير منظومة تقييم أداء الجامعات --- د/ محمد ابراهيم عبد العزيز خاطر

هذا ويمكن التظلب على المعوقات السابقة، بتوافر عدة مقومات، تساعد على نجاح

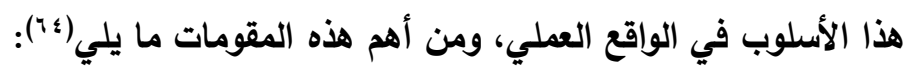

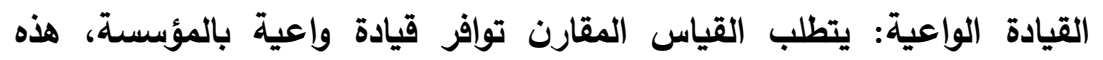

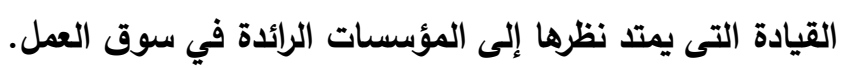

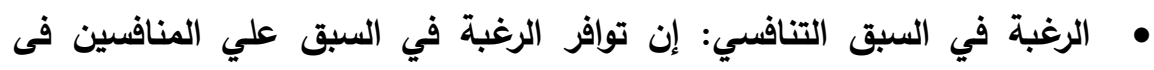

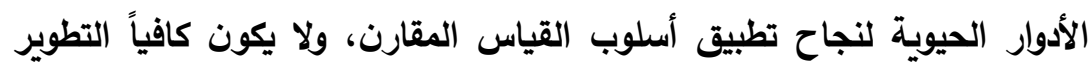

العادي بل يمتد إلى الرغبة في السبق عن المنافسين.

القدرة على السبق التنافسي: بمعنى امتلاك القدرة على تطبيق أسلوب القيات القياس

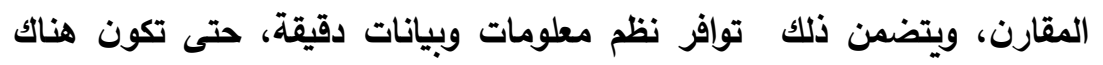

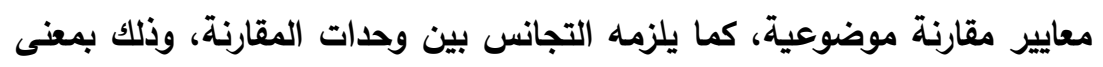

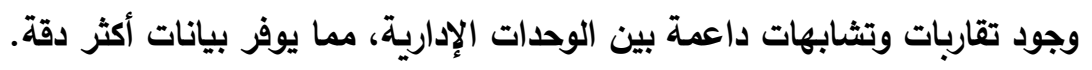

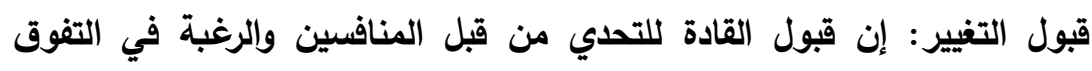

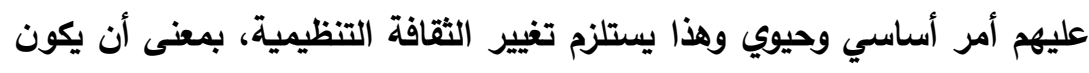

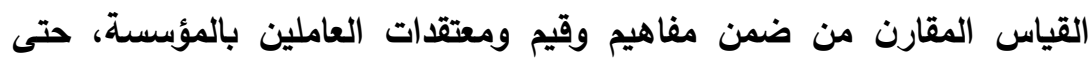

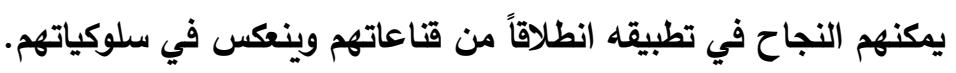

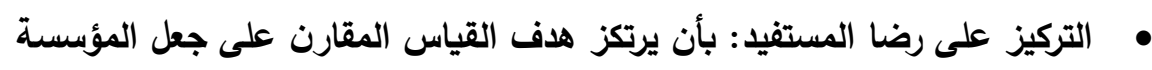

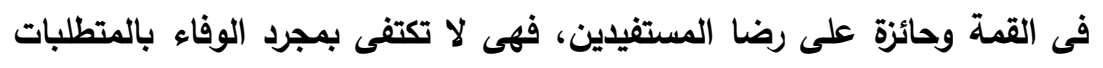

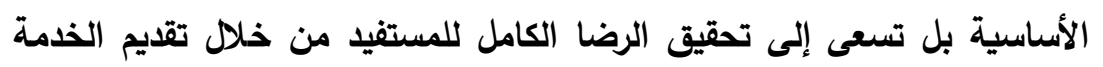
بأقل تكلفة وأعلى جودة. وبناءً على ما تقدم في المحور الثالث، المتعلق بأسلوب القياس المقارن وتطبيقه

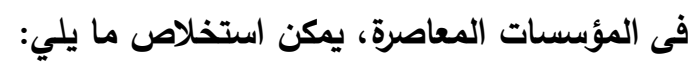

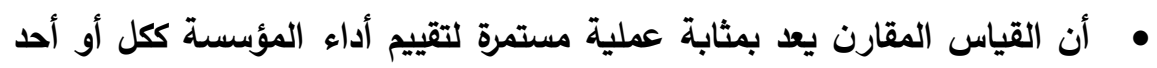

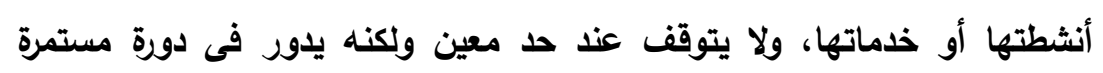

$$
\text { هافها تحسين الأداء. }
$$

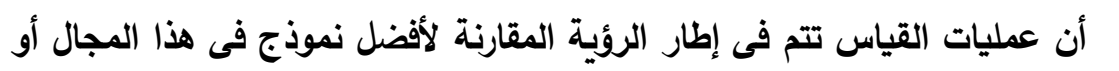
الخدمة سواء فى داخل المؤسسة أو خارجها.

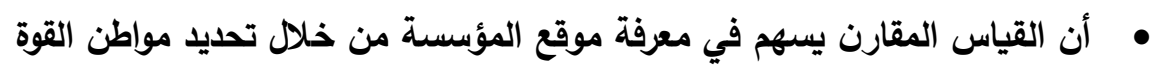
ومواطن الضعف في استراتيجيتها فيما يخص المنافسين. 
مجلة كلية التربية بالإسماعيلية - العدد الرابع والأربعون - مايو 9 م ـ

• يتطلب أسلوب القياس المقارن أن يدرك المديرون لماذا يختلف أداؤهم عن

غيرهم، ومن ثم على مصمي أسلوب القياس المقارن أن يطوروا باستمرار

معارفهم عن كل من العمليات التي تتم فى منظماتهم.

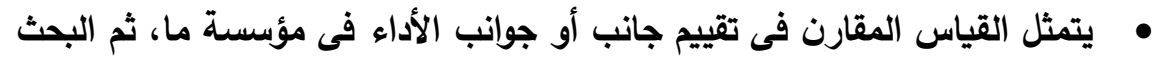

عن نموذج أو قيمة مرجعية متميزة، وعقد مقارنة بينهما، والتعرف على أسباب

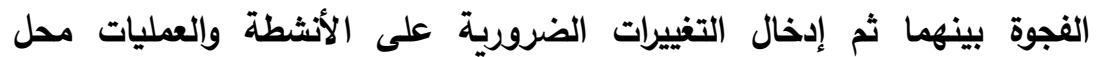

الدراسة، مع الأخذ فى الاعتبار تكييفها للظروف الداخلية للمؤسسة.

إن إدراك وفهم الاختلافات يسمح للمديرين بتنظيم وتنمية الجهود المبذولة للتحسين والتطوير المستمر لتحقيق الأهداف المنشودة.

• أن توافر مقومات التطبيق لأسلوب القياس المقارن ليس كافياً بدون مجموعة من الافئن

المهارات في طريقة تطبيق هذا الأسلوب، ومن بين أهم هذه المهارات: مهارة

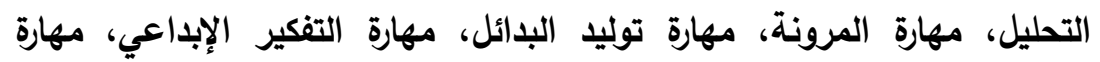

الاستقراء المستقبلي).

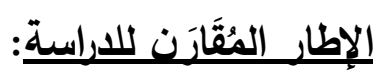

ويَتَمَتَّل الإطار المقارن للاراسة في عَرْض "'نماذج عالمية لمنظومة تقييم الأداء الجامعي

باستخدام أسلوب القياس المقارن"، ويشتمل الإطار المقارن على المحاور الأربعة التالية: المحور الأول: القياس المقارن لمنظومة تقييم الأداء بجامعات الولايات المتحدة

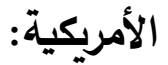

توجد فى الولايات المتحدة الأمريكية ثلاثة أنواع من الجامعات، جامعات حكومية

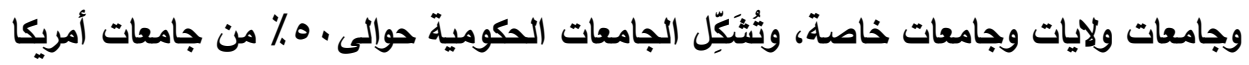
بصفة عامة، وتراعى هذه الجامعات البُعد الاقتصادي فى تخطيط التعليم، وتمولها الحكومة بثكل كبير، ويختلف الأمر فى الجامعات الأخرى؛ إذ أن جامعات الولاية تُمَوَّل من قبل الولاية ونهات بثكل محدود، وتثكل مصروفات الطلاب العنصر الأساسي فى التمويل، بينما تُمَوَّل الجامعات

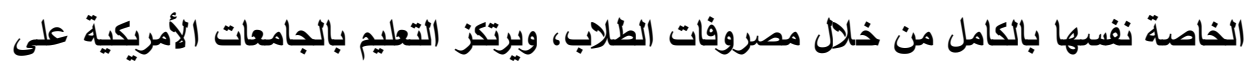

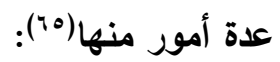
• اعداد الطلاب للحياة والعمل فى المجتمع العالمي التنافسي. • الاهتمام بإعداد الطلاب المؤهلين سواء للدراسة أو العمل بعد التخرج. • تقديم البرامج المهنية المختارة التى تؤهل الطلاب ليصبحوا جزء من العمالة. 
بدائل مقترحة لتطوير منظومة تقييم أداء الجامعات --- د/ محمد ابراهيم عبد العزيز خاطر

$$
\text { • تمكين الطلاب من فهم العادات الاجتماعية والعلمية والسياسية فى ثقافات عديدة. }
$$

وتعد الولايات المتحدة الامريكية من أكثر الدول التي تتم فيها عمليات التقويم والمتابعة

لتحقيق ضمان الجودة والاعتماد المؤسسي للتعليم، حيث وضعت الجامعات الامريكية الآليات المناسبة لكي تتابع جودة التعليم الجامعي تأكيداً على متطلبات سوق العمل، وتحقيقاً لضمان الاني الجودة واعتماد مؤسسات التعليم الجامعي ومن قبيل الاهتمام بالعولمة وتداعياتها، والحراك الاولي للطلاب، والتسويق العالمي لنظم التعليم الجامعي، والتزايد والتوسع المستمر للتوجه نحو تدويل التعليم الجامعي.

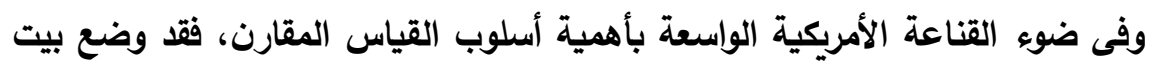
الخبرة الأمريكي للمقارنة المرجعية مجموعة من المبادي التي تنظم أخلاقيات تلك العملية وكذلك إجراءاتها، وتتمثل هذه المبادئ في النقاط التالية(ب7):

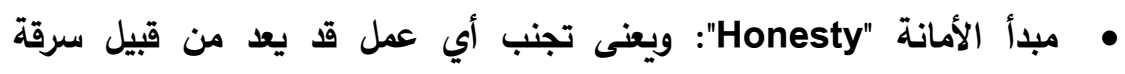
مجهودات الأخرين، أو معرفة أسرار لا يرغب الآخرون فى كشفها، أو استخدام البيانات والمعلومات التي تحصل عليها المؤسسة فى إضرار الأخرين.

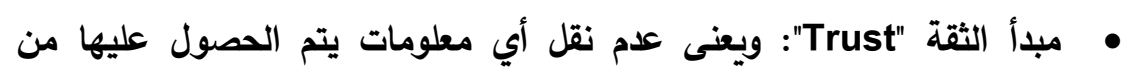
الثركاء فى عملية المقارنة إلى طرف أخر إلا بموافقة هؤلاء الثركاء.

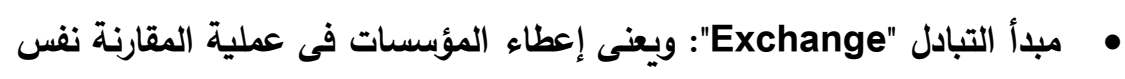
القدر من المعلومات من نفس النوع، ومن الأفضل توضيح هذا الاستعداد لتبادل المعلومات. • مبدأ الاستخدام "Usage": ويعنى تجنب استخدام المعلومات التي يتم الحصول

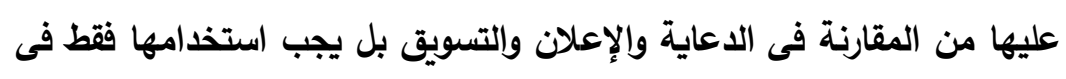
تحسين العمليات. • مبدأ الاتصال "Communication": ويعنى تجنب الاتصال مباشرة بالوحدة أو

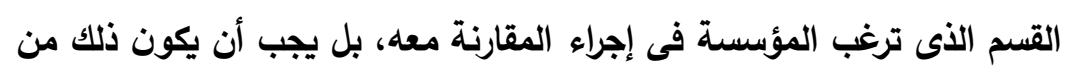
خلال المديرين المسئولين. وفيما يلى عرض لنموذجين من الجامعات الامريكية في توظيف أسلوب القياس المقارن لمنظومة تقييم أداء المؤسسات الجامعية: 
مجلة كلية التربية بالإسماعيلية - العدد الرابع والأربعون - مايو 9 م

النموذج الأول: جامعة هارفارد Harvard University:

تُعَّ جامعة "هارفارد" واحدة من أعرق وأقدام الجامعات الأمريكية، ومن أفضل جامعات

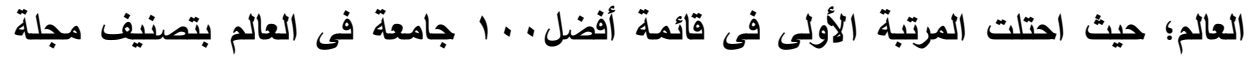

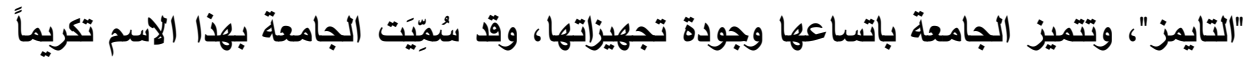

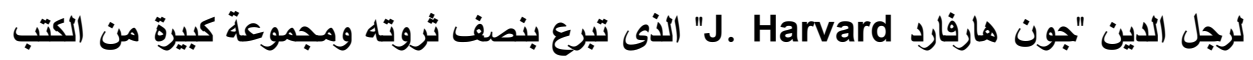

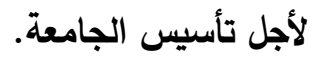

وتؤكد رسالة الجامعة على دعم التدريس والبحث العلمى من خلال توفير مجموعة واسعة من الخدمات لمجتمع "هارفارد"، وتثمل صيانة المرافق، وإنتاج الطاقة والمشتريات،

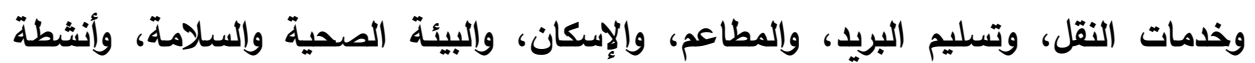

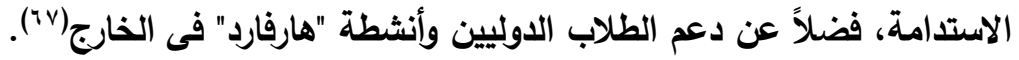

أولِاً: مدخلات القياس المقارن لتقييم الأداء بجامعة هارفارد:

تتميز جامعة "هارفارد" باستجابتها للمطالب المتفيرة للجمهور والمستفيدين وأصحاب

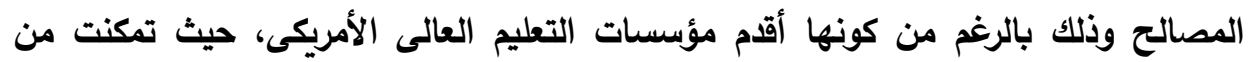

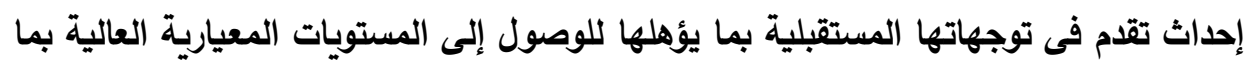

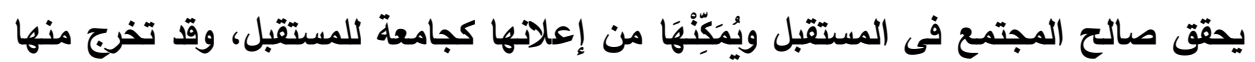

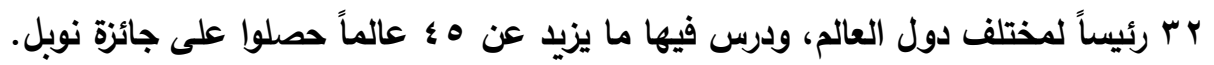

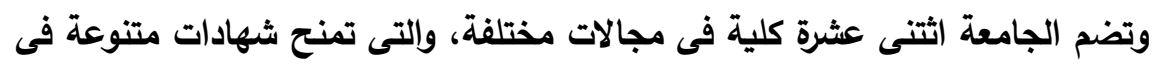
الارجة الجامعية الأولى إلى جانب شهادات الدراسات العليا، وأيضاً الدرجات الجامعية المهنية

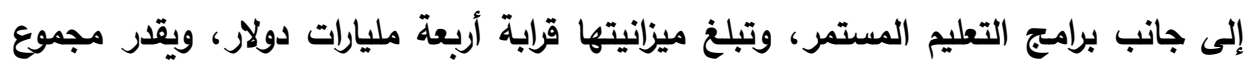

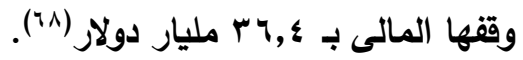

وتثمل مدخلات القياس المقارن لتقييم الأداء في الجامعة العناصر الآتية: 1 - فلسفة القياس المقارن بجامعة هارفارد وأهدافه:

تنظق فلسفة قياس الأداء فى جامعة "هارفارد" من أمور عديدة من بينها (19):

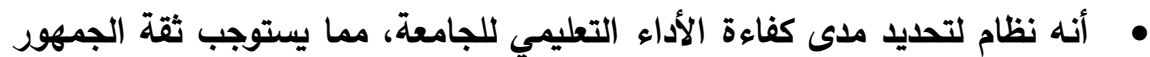

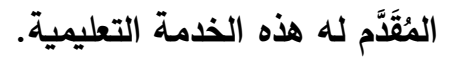

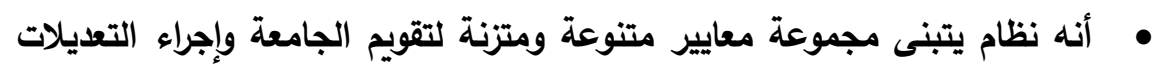
اللازمة لإحراز التقدم المطلوب لتحقيق فعالية الجامعات. 
بدائل مقترحة لتطوير منظومة تقييم أداء الجامعات --- د/ محمد ابراهيم عبد العزيز خاطر

• أنه نظام يتيح التعاون بالطرق المناسبة بين الجامعات التي تتفق فى سياساتها

سواء على مستوى الولاية الواحدة أو كل الولايات.

وتهتم جامعة "هارفارد" بتقويم ذاتها، وتقوم رابطة الاعتماد بعملية مراجعة دورية للأداء

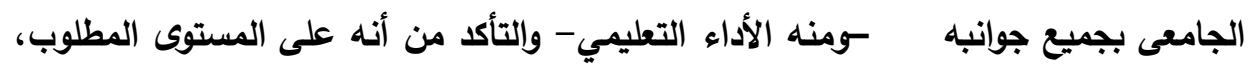

ويتم ذلك من خلال نظم محددة لتقويم الأداء، ومنها أسلوب القياس المقارن؛ وذلك لاستمرار

الاعتراف بالجامعة، واعتمـاد الخطط والبرامج الدراسية التي تقدمها، وكذلك الفحص المستمر

للأهداف التعليمية وسياسات القبول وسياسات تقويم الطلاب، وتتحدد أهداف القياس المقارن

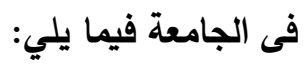

• تطوير الأداء التعليمى للجامعة من خلال تقويم الأداء والإششاد مع التركيز على

أهداف الجامعة وإلنتائج التى حققتها.

• نشر نتائج الأداء المتعلقة بالجامعة وبما يتفق مع المعايير التى تتبناها.

• تقديم معلومات تفيد فى إجراء المقارنات بين الجامعات وغيرها.

r - الجهات المسؤولة عن القياس المقارن لتقييم الأداء بجامعة هارفارد:

لمجلس الولاية للتعليم العالى فى جامعة هارفارد ومجلس الجامعة ومجلس الكلية وكذلك مجلس القسم أدواراً قوية فى قياس أداء الجامعة، وذلك من خلال قيامهم بعمليات التقييم والإشراف والرقابة الجامعية باستمرار، وذلك من خلال السلطة المُخَوَّلَة لهذه المجالس على فيلى السياسات التعليمية، ويأتي دور الحكومة بعد ذلك؛ حيث يقتصر دورها على وضع آليات الجودة وتقييمها من خلال المؤشرات القومية، وبالتالى يمكن القول أن الحكومة لا تتلخل فى التشريعات أو الرقابة، بل تتيح الفرصة للاستقلالية وتعمل كمشرف فقط على الجامعة بطريقة غير مباشرة؛ لضمان المساهمة فى تحقيق الأهداف القومية وتدعو الجامعات للتظيم الذاتي وتحقيق الجودة في الأداء، هذا ويمكن تقسيم الجهات المسؤولة عن تقييم الأداء بجامعة "هارفارد" إلى جهات داخلية وخارجية، كما يتضح فيما يلي: الئرئ

$$
\text { أ- الجهات الخارجية: }
$$

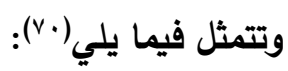

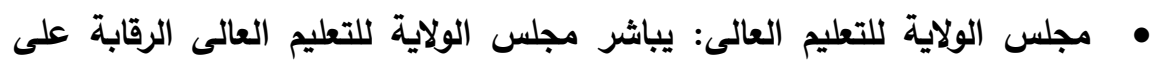

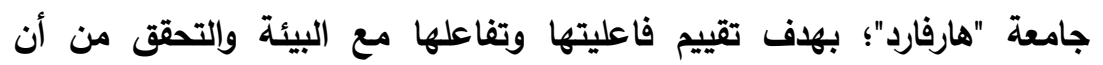
الجامعة تلبى احتياجات المجتمع، ويتعاون مع مجلس الولاية المكتب العام

للمحاسبات، وهو مكتب يعمل تحت رئاسة المراقب العام للولايات المتحدة 
مجلة كلية التربية بالإسماعيلية - العدد الرابع والأربعون - مايو 9 م

الأمريكية، وينقسم إلى عدة إدارات تختص إحداها بمراجعة حسابات الجامعات

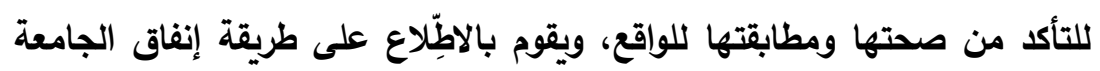
للمخصصات المالية التي تحصل عليها، وتنتهى تلك المحاسبة المالية بتقديم تقرير من المراقب العام يتم فيه تحديد المخالفات المالية وأسبابها والمقترحات لتلافى ذلك.

"The National Education المجلس القومي لمعايير التعليم وتطويره Standards and Improvement Council (NESIC)" المجلس بالجامعات المعتمدة وما تحققه من أدوار قومية واتجاهاتها نحو تحقيق الأهداف التعليمية، كما يقدم تقارير أداء تتعلق بتحقيق الأهداف القومية، علماً بأن هذه التقارير تسهم فى تطوير الأداء التعليمى حتى تتصف الجامعة بالعالمية، ويقدم أيضاً مقاييس ومؤشرات للقياس المقارن وهى تساعد الطلاب على الادئ آتيار الجامعة والتخصص المرغوب، وتمكن الجامعة أيضاً من تحسين عملياتها.

$$
\text { ب- الجهات الداخلية: }
$$

• مجلس الجامعة: تتضمن جامعة "هارفارد" هيكل تنظيمى يطبق مستويات عالية من اللامركزية، ويظهر ذلك من خلا تفويض قرارات التخطيط الهامة للكليات والوحدات المختلفة مثل: قرارات تعيين أعضاء هيئة التدريس، والبرامج، والموارد المالية ... وغيرها، وتضم مجالس إدارة الجامعة مجلسين هما:

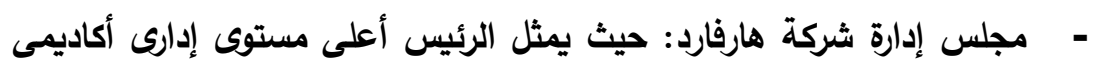
فى الإدارة المركزية، ويتبعه نائب الرئيس التنفيذى والذى يمثل المسؤول الإدارى الثانى. - - مجلس المراقبين: ويمثله مكتب رئيس المجلس، وتتمثل مسؤولياته في: (تقديم المشورة للقيادة الجامعية حول الأولويات والخطط، كما أنه يملك سلطة الموافقة على إجراءات معينة للمؤسسة، ودعم المشروعات الفنية

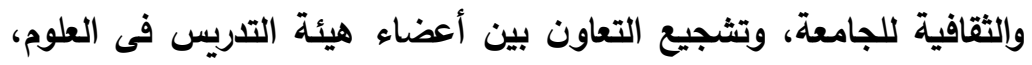
والعلوم الاجتماعية، والإنسانيات، وتوجيه مبادرات أكاديمية وتوثيق التعاون البحثى مع الصناعة، والارتقاء بمداخل موسعة خاصة بالسياسة البحثية وتنسيق الأنشطة (لاولية)، ويتألف مجلس المراقبين من ثلاثين عضواً مُنْتَخَبَاً 
بدائل مقترحة لتطوير منظومة تقييم أداء الجامعات --- د/ محمد ابراهيم عبد العزيز خاطر

بما فيه الرئيس وأمين الصندوق، يتم انتخابهر من قبل خريجى جامعة

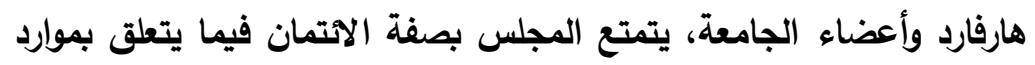

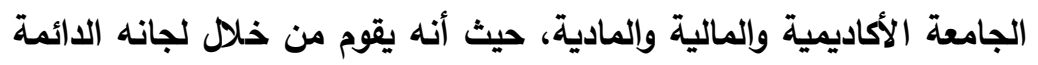

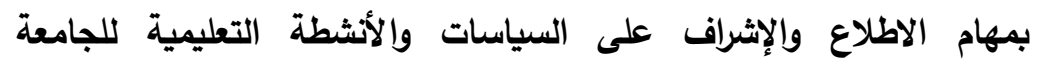
والموافقة على الإجراءات الهامة للجامعة بعد دراستها بثكل متعمق.

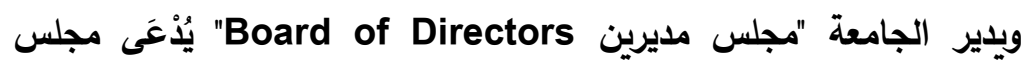
تسيير شركة هارفارد "Harvard Management Company"، وهو مجلس "هائس منتخب من قبل شركة "هارفارد"، ويقوم مجلس تسيير شركة "هارفارد" بمهامه من

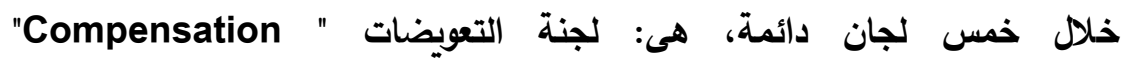
committee Investment Governance Committee" "Avaluation ولجنة القياس المقارن والتقويم 'Advisory Committee" .and Benchmarking Committee"

• جلس الكلية: ويهتم هذا المجلس بدعم الكيانات والمشروعات الثقافية والفنية، ومراقبة وتنسيق الأنثطة الجامعة الدولية، ودعم الطلاب وأعضاء هيئة التدريس

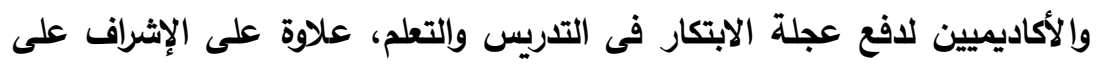

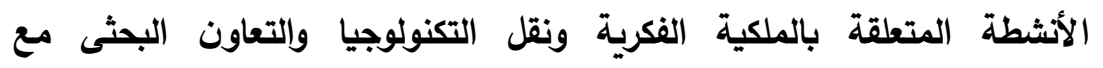

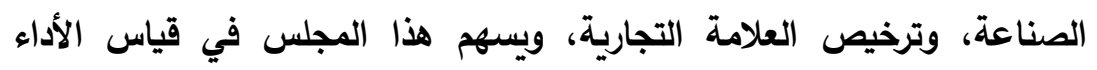
الجامعى من خلال قيامه بمتابعة الأداء التعليمى للكلية للأقسام العلمية وكذلك فلكائ

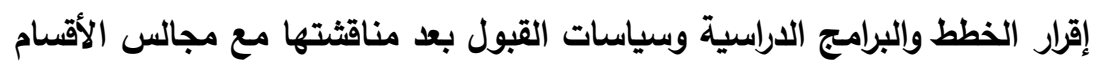

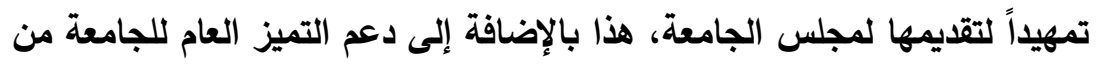

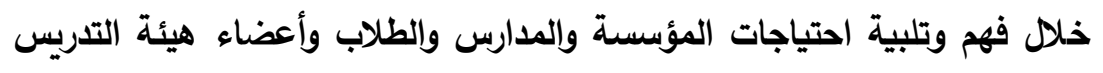

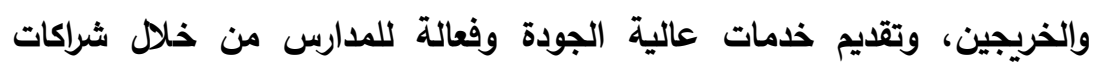
ديناميكية وتعاونية. • مجلس القسم: ويسهر هذا المجلس في قياس الأداء الجامعى، من خلا استخدام

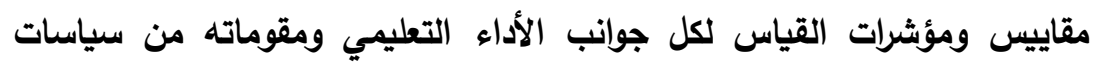
للقبول والخطط والبرامج الدراسية وسياسات تقويم الطلاب، ويتم إعداد تقارير يتم 
مجلة كلية التربية بالإسماعيلية - العدد الرابع والأربعون - مايو 9 م ـ

فى ضوئها تقديم جوائز لأعضاء هيئة التدريس، وكذلك تحديد نقاط الضعف فى لإنى

الأداء التعليمي للجامعة ومقترحات التطوير .

ثانياً: عمليات القياس المقارن لتقييم الأداء بجامعة هارفارد:

تُمَارِس الجهات المسئولة عن القياس المقارن بالجامعة العمليات التالية:

1- تخطيط القياس المقارن لتقييم الأداء الجامعي:

يتم تخطيط القياس المقارن لتقييم الأداء فى جامعة "هارفارد" وفقاً للمراحل التالية(Vr):

• التحديد الدقيق والواضح لمقومات الأداء التعليمى للجامعة من أهداف وسياسات

قبول، وخطط وبرامج دراسية، وسياسات تقويم الطلاب، وبرامج وخدمات ممتدة،

وبحوث ومشروعات علمية.

• تحديد مهام كل مجموعة من مجموعات القياس المقارن، وتحديد زمن مناسب

لإتمام كل مهمة من المهام المكلفين بها.

• إطلاع كل مجموعة فرعية على مبررات القياس لمقومات الأداء التعليمى

ومناقشتها.

• وضع خطوات تنظيمية لإجراء القياس داخل الجامعة، ثم القيام بزيارة الجامعة

الأخرى لإتمام القياس المقارن.

r - تنظيم القياس المقارن لتقييم الأداء الجامعي:

يتم ترتيب وتنظيم عمليات القياس المقارن من خلال الخطوات التالية(rrV):

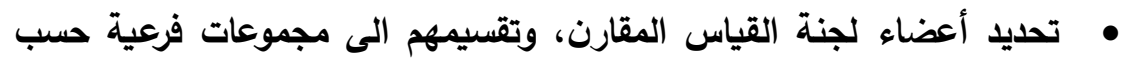

مقومات الأداء الجامعى المختلفة.

• التحقق من تقارير القياس الداخلي لمجالات أداء الجامعة.

• قيام أعضاء فريق القياس المقارن بزيارة الجامعة المستهدفة للإطلاع على

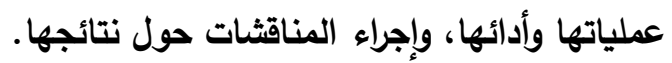

• إعاد تقرير نهائي يتم تقديمه للمهتمين بالأداء التعليمى للجامعة.

r- تنفيذ أنشطة القياس المقارن لتقييم الأداء الجامعي:

ويتم تنفيذ أنشطة القياس المقارن في مجالات الأداء التالية:

أ- المجال الأول: الاور التعليمى والتدريسى للمؤسسات الجامعية:

ويشتمل على ما يلي (؛) 
بدائل مقترحة لتطوير منظومة تقييم أداء الجامعات --- د/ محمد ابراهيم عبد العزيز خاطر

• الأهداف التعليمية: تهدف الجامعة إلى تثقيف المواطنين حتى يصبحوا قادة

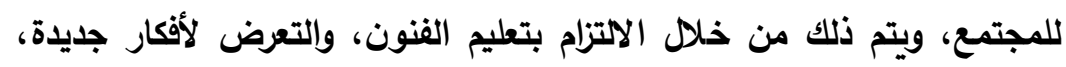

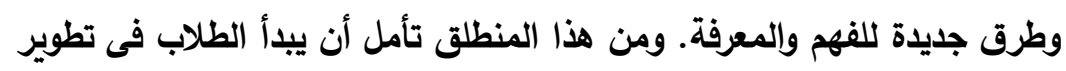

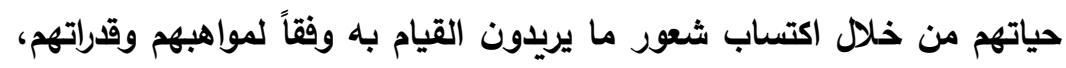
مع السعى الدائم لتسهيل عملية التعليم والبحث والتعلم من خلال الإل الاستخدام الفعال لتكنولوجيا المعلومات، ويهتم القياس المقارن بوجود أهداف تعليمية طويلة المدى وقصيرة المدى، والتأكد من وضوح الأهداف وتحديدها وسهولة

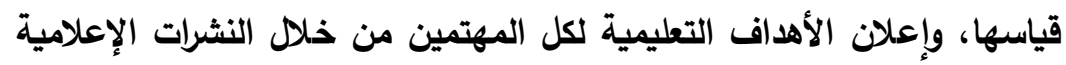
للجامعة ومن خلا كتيبات وأدلة الجامعة، ودعم حرية التعليم والحرية الأكاديمية للطلاب.

• سياسات القبول: تُعد جامعة "هارفارد" من أصعب جامعات العالم فى قبول الطلاب،

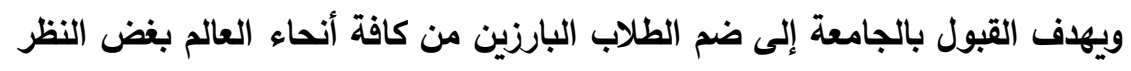

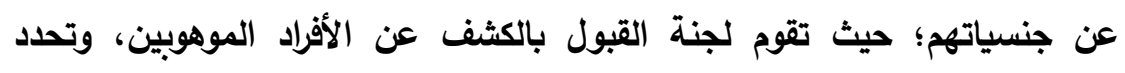
الجامعة تلك الموهبة فى القيادة الفعالة والطموح والثخصية القوية. ويهتم القياس المقارن بالتأكد من اجتياز الطلاب اختبار قبول كل كلية، وتراعى هذه الاختبارات طبيعة الدراسة وحقل التخصص المراد الالتحاق به، هذا بالإضافة إلى أن الجامعة الطئي

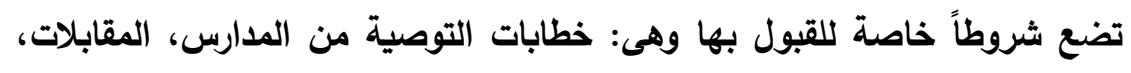
الصفات الثخصية، تقرير الحالة الصحية والنفسية، الإقامة بالولاية، كما أن جهات مختلفة، مثل: (رابطة الطب الامريكية، والمجلس القومي لتقويم واعتماد إعداد المعلم) تؤكد على الحيادية وعدم التمييز فى سياسات قبول الطلاب، وتنوع وتعدد القائمين على رسم وتحديد تلك السياسات. • الخطط والبرامج الدراسية: يتسم التعليم والتعلم بالجامعة، بالتركيز على الأشطة

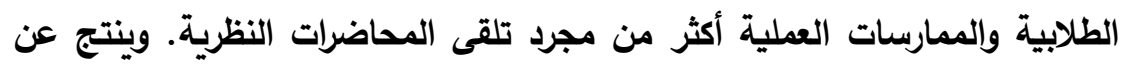
ذلك إعداد أفراد قادرين على قيادة البلاد وباحثين مميزين. ويتم القياس المقارن للبرامج الدراسية والخطط التعليمية على مستوى كل مؤسسة جامعية للتأكد مما يلى: القدرة على الاستجابة السربعة للمتغيرات المحلية والعالمية، والقدرة على الاستجابة السريعة للاحتياجات المتغيرة للطلاب، والتأكيا على التميز والتنوع فى الخطوط الاطيه 
مجلة كلية التربية بالإسماعيلية - العدد الرابع والأربعون - مايو 9 م

والبرامج الدراسية حب طبيعة التخصص وحرية الاختيار فى الخطط والبرامج الدراسية، وكذلك التأكيد على أهداف الخطط والبرامج الدراسية وتعددها. • تقويم المخرجات التعليمية: نظراً لأهمية تقويم الطلاب فإن جهات عديدة تسهم فى وفئ وضع مؤشرات النجاح وذلك للحكم على نتيجة التقويم، ومن هذه الجهات: الكلية،

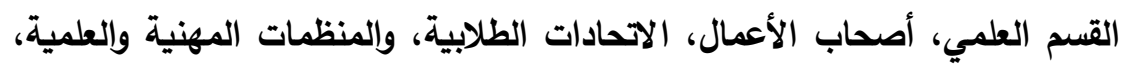
هذا بجانب اللجنة الخاصة بأساليب التقويم بالجامعة والتي تقوم بالتنسيق بين كل

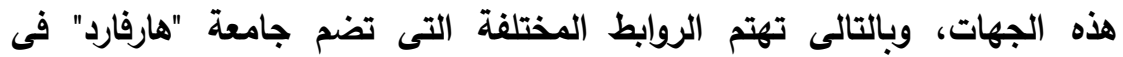
عضويتها بضرورة تقديم أدلة عن تقويم الطلاب فى التخصصات المختلفة وذلك لمواصلة الاعتماد أو الاعتراف بالجامعة وتخصصاتها والخطط والبرامج الدراسية فيها.

ويتم تقويم الطلاب بجامعة "هارفارد" استناداً إلى رضا الخريجين والمنافسة وكذلك رضا الطلاب عن دراستهم وعن التقويم التعليمى لهم من حيث تنوعه وشموله واستمراريته، وتتخذ الجامعة تقويم الطلاب كعامل هام للقياس التعليمى من خلال

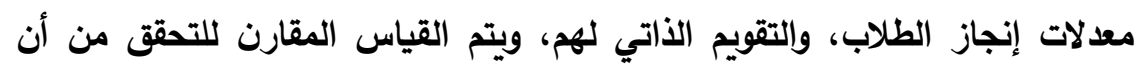
تقويم الطلاب يحدد ما تعلمه الطلاب، وأنه يحدد الكفاية والفاعلية فى الأداء التعليمي، ويقسم الطلاب الى نوعيات مختلفة، كما يترتب على عمليات التقويم الحكم على الخطط والبرامج الدراسية، وأنه يحدد مسؤولية الطلاب عن اختيارهم للخطط والبرامج الدراسية، علاوة على التأكيد على شمولية أساليب تقويم الطلاب المتبعة لكل جوانب شخصية الطالب وكذلك استمراريتها وتتوعها، وتُسْتَخََْم نتائج التقويم كتغذية راجعة لتطوير الأداء التعليمى للجامعة. ب- المجال الثانى: الدور البحثى للمؤسسات الجامعية: بدأ نجاح جامعة "هارفارد" فى البحث العلمي من وضـع خطة بحثية متكاملة وإدارتها

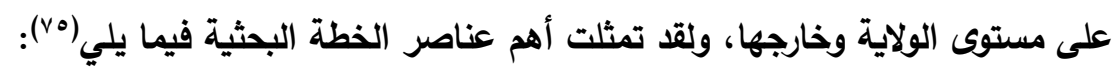
• تحديد الأولويات البحثية للولاية: حيث يقوم بوضع هذه الخطة فرق من الخبراء

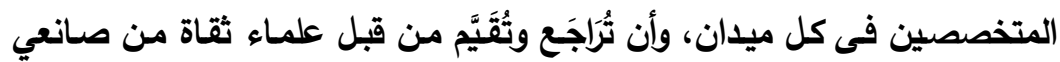
القرار، وأن تقسم إلى مراحل قريبة المدى وبعيدة المدى، ثم تُصَنَّف إلى بحوث مرثي

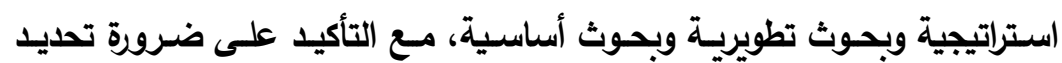
الأولوبات البحثية وفقاً 
بدائل مقترحة لتطوير منظومة تقييم أداء الجامعات --- د/ محمد ابراهيم عبد العزيز خاطر

لاحتياجات المجتمع التنموية بثكل يضمن الاستثمار الأمثل للموارد المتاحة.

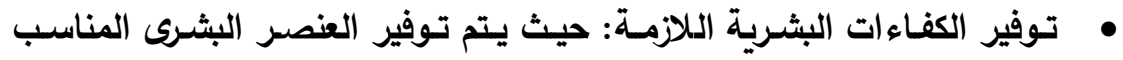

تأهيلاً وخبرة للقيام بتنفيذ البحوث العلمية؛ ضماءناً للاستفادة من كافة الموارد المتاحة بثكل أمثل، ويتمثل العنصر البشرى فى: (العلماء الباحثين، الباحثين

المساعدين، طلاب الدراسات العليا).

• تـوفير الظـروف المناسـبة للبـاحثين: حيث يـتم تـوفير المنــاخ الملائـم لإجـراء

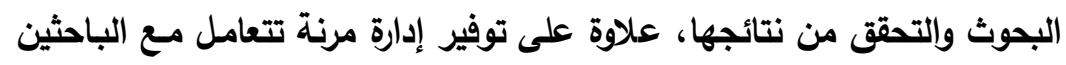
فى إطار من العلاقات الإنسانية الجيدة بما يحقق روح معنوية عالية. • تسويق نتائج البحوث وتعميمها: حيث تحرص الجامعة على وجود آليات لتعميم ونشر البحوث بنتائجها وتسويقها، وذلك في ضوء العلاقة الوثيقة بين المراكز البحثية والمؤسسات والثركات ذات العلاقة بتلك البحوث. ج- المجال الثالث: الاور المجتمعى للمؤسسات الجامعية: يتوجـه القيـاس المقـارن في مجـال خدمـة الجامعـة للمجتمع والخـمات الامتداديـة التـى

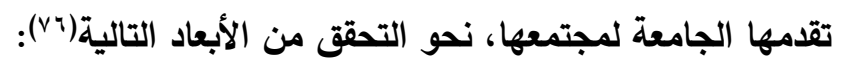
• بُعد الأهمية "Significance": ويختبر مدى الهمية أهمية وجدية القضايا التي يعالجها مشروع الامتداد الجامعي لكل من المجتمع الأكاديمي وأصحاب ولهي المصلحة في المجتمع المحلي. • بُعد السياق "Context": ويختبر مدى اتساق مشروع الامتداد مع رسائة الكلية

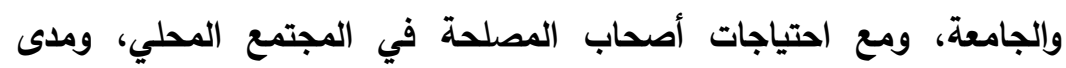
مناسبة كل من المنهجية المستخدمة والموارد المتاحة والخبرات المتوفرة لإنجاز المشروع بنجاح.

• ُعد المنح الاراسية "Scholarship": ويختبر ما إذا كان مشروع الامتداد يثجع على توليد ونقل وتطبيق المعارف العلمية ومدى الاستفادة منها في المحيط الاجتماعي، ويؤكد على ضرورة توثيق النتائج التي حققها المشروع.

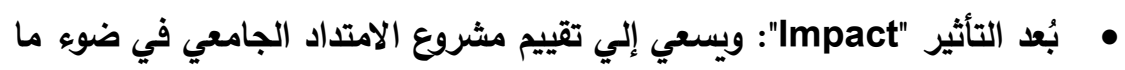
تحقق من نتائج، وفي ضوء مدى تأثيره على القضايا التي يسعى لمعالجتها وعلى أفراد ومؤسسات المجتمع المحلي. 
مجلة كلية التربية بالإسماعيلية - العدد الرابع والأربعون - مايو 9 م ـ r

ثالثاً: مخرجات القياس المقارن لتقييم الأداء بجامعة هارفارد:

تنتهى عمليات قياس الأداء الجامعى بإصدار تقارير بعد تحليل نتائج القياس المقارن،

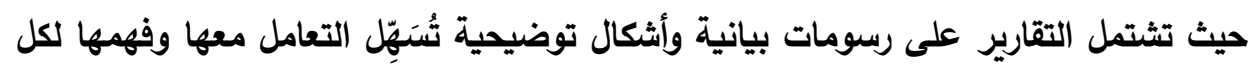
المهتمين بالأداء التعليمى للجامعة، وتوضح التقارير الأداء التعليمى للجامعة والمقترحات والتوصيات لتطوير هذا الأداء، ويقوم أعضاء فريق القياس المقارن بإعداد تقارير يتم تقديمها لإناء للجهات الخارجية فى حالة رغبة هذه الجهات فى الاطلاع عليها، وكذلك تقديم صورة من هذه التقارير للمهتمين بتقييم أداء الجامعة ذاتها للاستفادة منها فى إجراء التقييم للمنظومة الجامعية في المرات القادمة. وتؤكد تقارير القياس المقارن على ما يلي(vv):

• التزام إدارة الجامعة بالدقة فى التعامل مع المهتمين بعمليات القياس، والاهتمام

بنتائجها فى عمليات التطوير.

• سعي الجامعة المستمر فى تطوير نظام قياس الأداء لتلبية رغبات كافة المهتمين بالأداء التعليمى للجامعة.

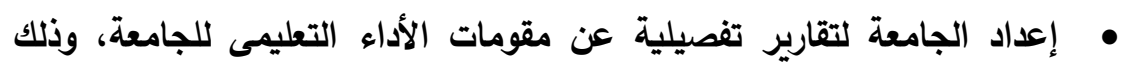
لاتخاذ القرارات التعليمية وكذلك المقارنة بينها وبين الجامعات المختلفة.

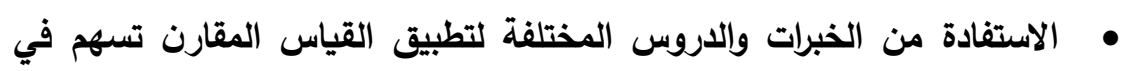
تحقيق الكفاءة والفاعلية بالمؤسسات الجامعية، وتدعم الخبرات الخاصة بتطوير الخطط والبرامج الدراسية، وتوفر التغذية الراجعة الناتجة عن تقويم الطلاب. وفى ضوء عرض ملامح القياس المقارن بجامعة "هارفارد"، يمكن استخلاص عدد من

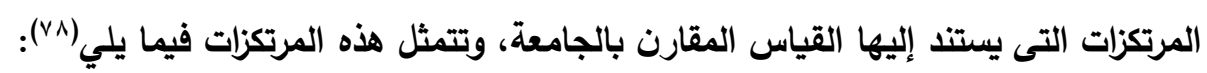

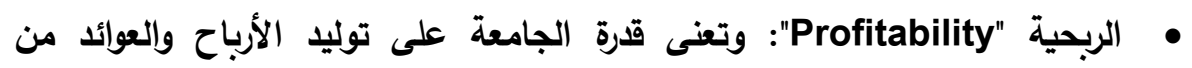

استثمار مرافقها وبيع منتجاتها.

• قيادة المنتجات "Product Leadership": يركز هذا المجال على قيام الإدارات الرئيسة في المؤسسة الجامعية بتقييم التكاليف والجودة للمنتجات الجامعية الحالية والمنتجات المخطط لها في المستقبل.

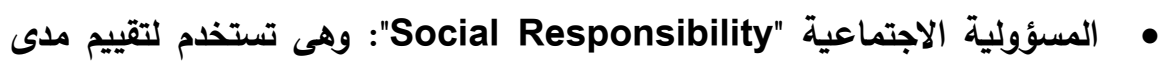
النجاح الذي حققته الجامعة ومؤسساتها في تحمل المسئوليات تجاه العاملين والمجتمع بصفة عامة. 
بدائل مقترحة لتطوير منظومة تقييم أداء الجامعات --- د/ محمد ابراهيم عبد العزيز خاطر

• • الإتتاجية "Productivity": يثير مفهوم الإتاجية إلى العلاقة بين مخرجات

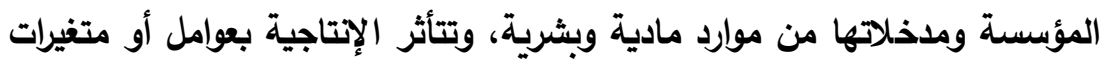

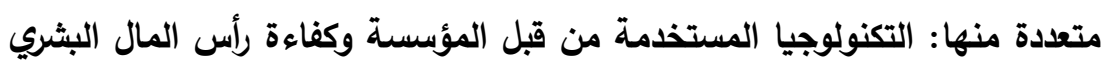

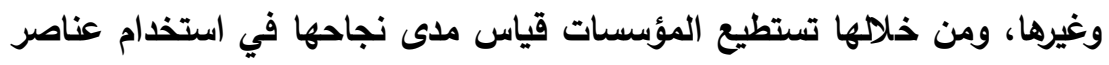

الإنتاج المادية والبثرية المتاحة لها بما يضمن تحقيق ما ترمى إليه من أهداف.

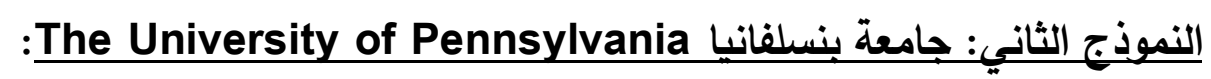

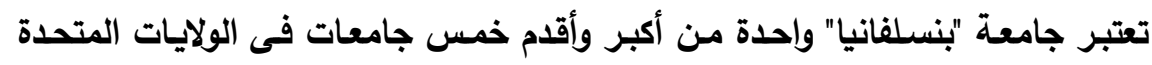

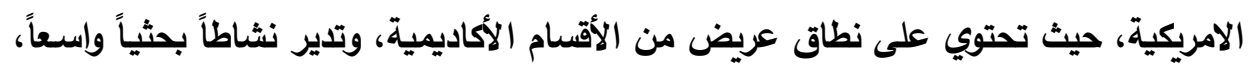

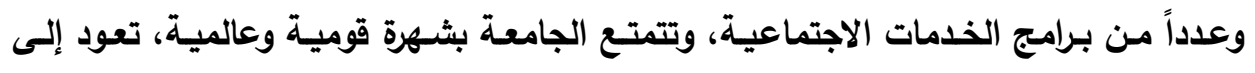

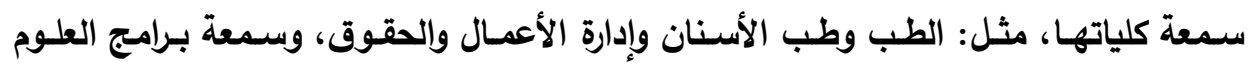

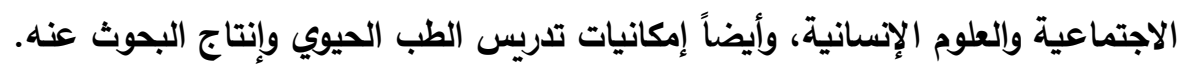

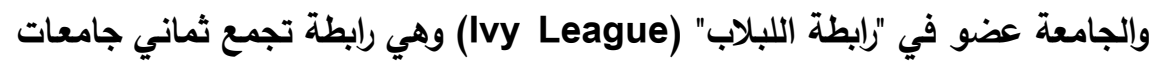

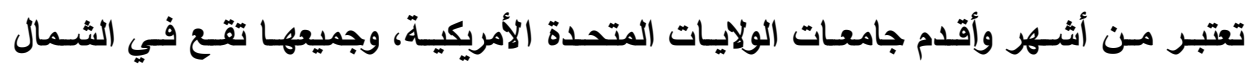

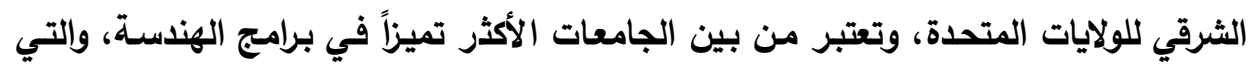
يتصدرها معهة ماساتثوسيتس للتقنية وتليه فيها جامعة ستانفورد (va). أولاًا: مدخلات القياس المقارن لتقييم الأداء بجامعة بنسلفانيا:

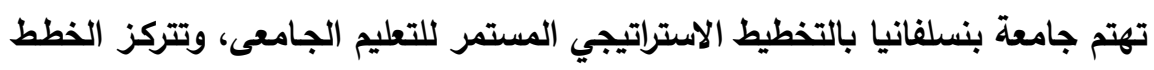

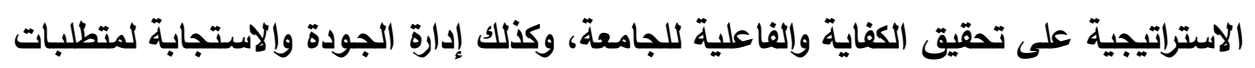

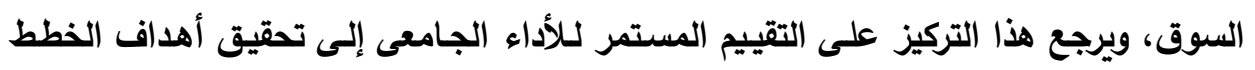

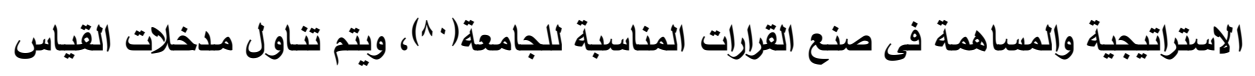
المقارن لتقييم الأداء بجامعة "بنسلفانيا" تفصيلياً وفقاً للعناصر التالية: 1 - فلسفة القياس المقارن بجامعة بنسلفانيا وأهدافهـ:

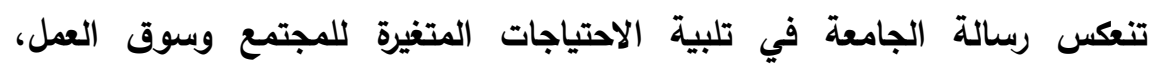

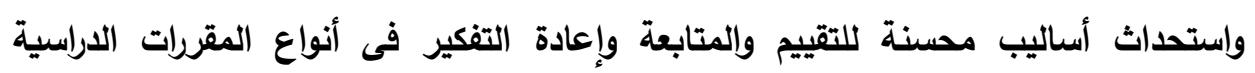

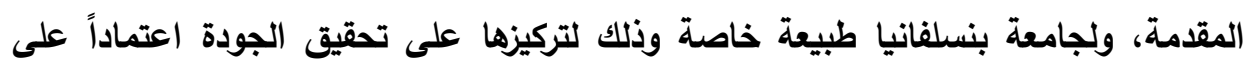

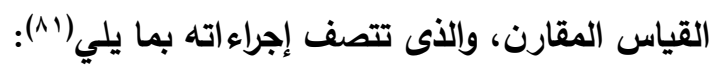

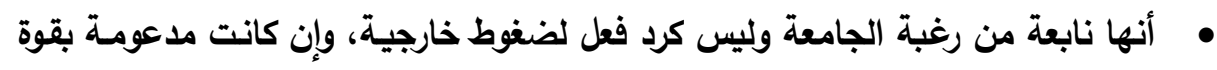
من اتجاه الجامعة للتركيز على الجودة والتخطيط. 
مجلة كلية التربية بالإسماعيلية - العدد الرابع والأربعون - مايو 9 م

• أن يُلائم تخطيط وتنظيم عمليات القياس ظروف وطبيعة الجامعة، ويتوافر لها مراكز متخصصة لاتخاذ القرارات.

• أن قيـاس الأداء تسـهم فيهـا جهات عديـدة مـن المهتمسين بجوانـب ومقومـات الأداء التعليمى للجامعة، وينتج عنها تقارير تسـهم فى أغراض التقيـيم الداخلى والخـارجى لالجامعة. وبـلك فإن الهـدف الرئيس مـن القياس المقـارن بالجامعـة يتمثل في فحص الأداء بالمؤسسات الجامعية، لتحديد نقاط القوة والضعف، مـع إعداد تقارير قياس لها الدور القوى فى توكيد الجودة ورفع كفاءة وفاعلية الأداء التعليمى وتحسين الإنتاجية التعليمية للجامعة. r - الجهات المسؤولة عن القياس المقارن لتقييم الأداء بجامعة بنسلفانيا: وتتمثل تلك الجهات فيما يلي: أ- الجهات الخارجية: تتميز جامعة بنسلفانيا بعضويتها لعديد من الروابط، منها(^^):

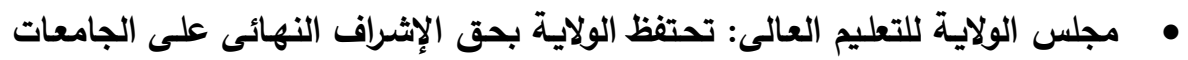

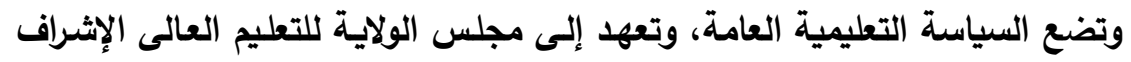
على الجامعـات ويترك التففيذ المباشـر للجامعـات، فتضـع كـل جامعـة سياسـتها

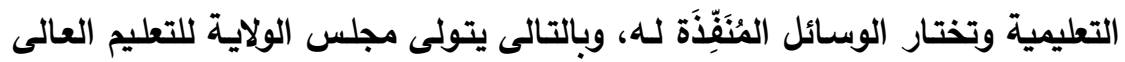

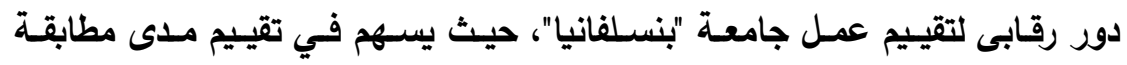

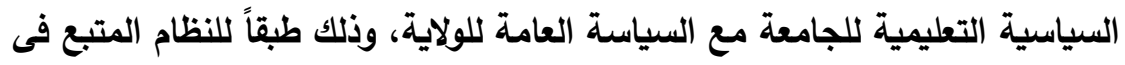
الاعتماد ومراجعة الاعتماد للجامعة. •مجس الاعتمـاد للتعليم العـالى: يحدد هذا المجلس معـايير الاعتمـاد الاختيـاري

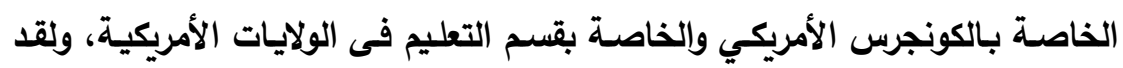

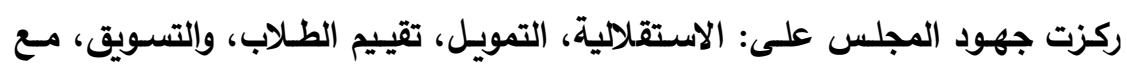

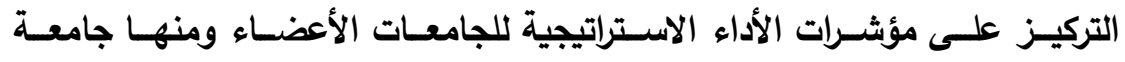
"بنسلفانيا".

• عضوية اللجـان: تتمتع جامعة بنسلفانيا بالعضويـة فى لجنـة إقليمية تسمى "لجنـة

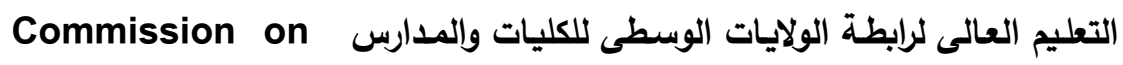
Higher Education Middle States Association of Colleges and Schools" 
بدائل مقترحة لتطوير منظومة تقييم أداء الجامعات --- د/ محمد ابراهيم عبد العزيز خاطر

وإعطاء التراخيص للجامعات، ولهذه اللجنة الحق فى إلغاء اعتمـاد أو إغلاق أي

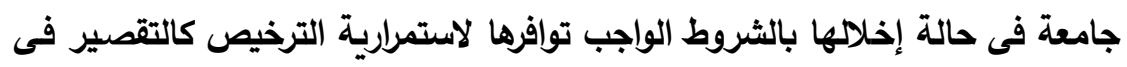
مسـتوى معين مـن الخـدمات، أو انخفـاض نتـائج الطـلاب، أو التقصسير فـى الأداء التعليمى وكل جوانبه ومقوماته.

• المجلس القومي لمستويات التعليم والإنجـاز : ويركز هذا المجلس على القيساس

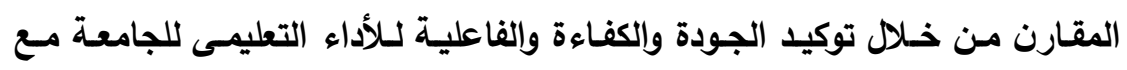

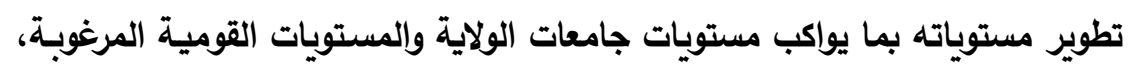

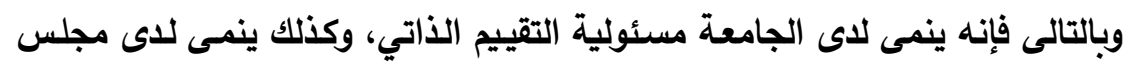

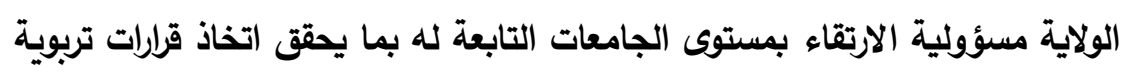
وفهم العمل المشترك والمنافسة.

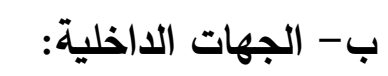

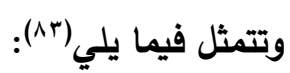

• مجلس الجامعة: لمجلس الجامعة دور قوى في تطوير أداء الجامعة والتأكيد على الجى اتفاقيـات تحسين جـودة الأداء الجـامعى ككل، حيث يتعـاون المجلس مـع مجلس

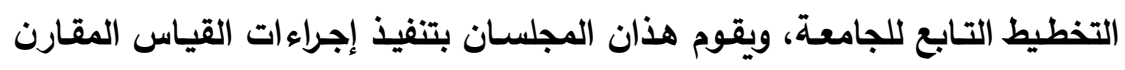
للتركيز على تقويم الأداء وتوكيد الجودة بكافة مؤسسـات الجامعة ومراكزها البحثية الجية

$$
\text { والخدمية. }
$$

•مجلس الكلية: ويسهم هذا المجلس بلدور بارز فى القياس المقارن لـلأداء من خـلال

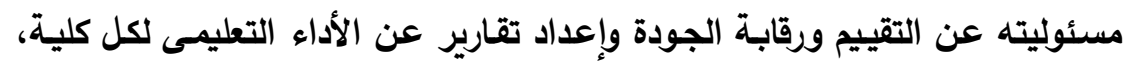
وإسهاماته فى التخطيط الأكاديمي مع الأقسام، وعقد الاجتماعات مع رؤسئه إعاء الأقسام العلمية لمناقشة الأمور العلمية التي تعدها الأقسام تمهيداً لعمل تقرير لتقييم الأداء يتم تقديمه من الكلية إلى مجلس الجامعة. • مجلس القسم: ويسهم هذا المجلس فى قياس الأداء الجامعى من خلال اختصاصاته

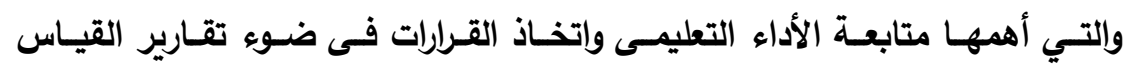
المقارن، مع متابعة ما أسفرت عنه تقارير القياس السابقة.

ثانياً: عمليات القياس المقارن لتقييم الأداء بجامعة بنسلفانيا: يظهر نموذج عمليات ومراحل القياس المقارن بالجامعة في الثكل التالي(ء^): 
مجلة كلية التربية بالإسماعيلية - العدد الرابع والأربعون - مايو 9 ب.

\section{Benchmarking Model}

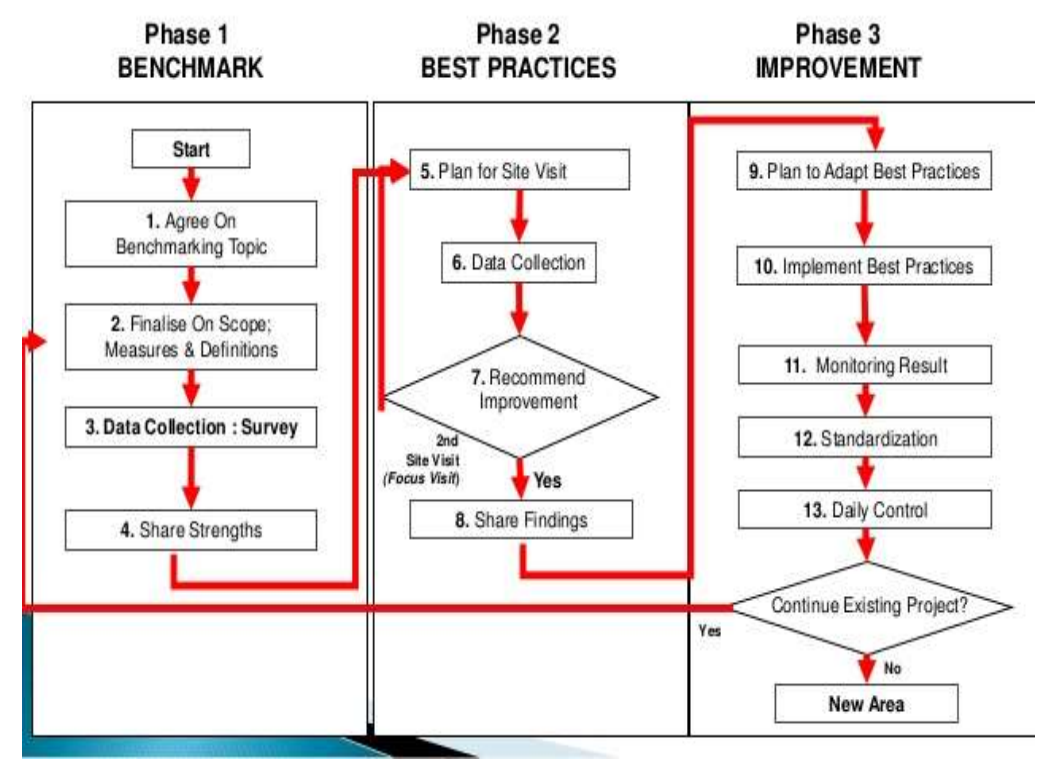

شكل (؛) المصدر: "Timothy O., Daniel W.M., 2019, p.1215"

يتبين من الثكل السابق أن القياس المقارن يتكون من ثلاث مراحل، تتمثل فيما يلي: • المرحلة الأولى: مرحلة القياس ووضع المؤشر : وتتضمن خطوات عليدة منها (البداء

والتجهيز لعمليات القياس، وتحديد موضوع القياس وقضيته، والاتتهاء من تحديد المفاهيم والتعريفات والمقاييس اللازمة للقياس، ثم إجراء الدارسة المسحية وتجميع البيانات، وتحديد مواطن القوة وإعلانها ومثاركتها للجميع).

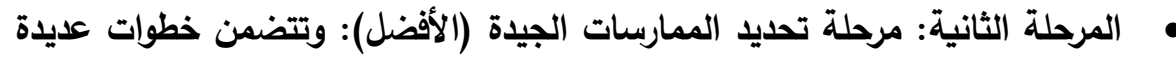

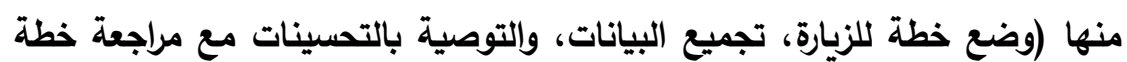
زيارة المؤسسة موضع المقارنة، ثم تتتهى هذه المرحلة بإعلان نتائج خطة الزيارة

$$
\text { وأوجه الاستفادة). }
$$

• المرحلة الثالثة: مرحلة إذخال التحسينات: وتتضمن الخطوات التالية: (التخطيط للتكيف مع الممارسات الجيدة وإدخالها، تطبيق الممارسات الجيدة، ومتابعة نتائج التطبيق، الوصول للأداء القياسى، والتحكم المستمر، وفى الخطوة التالية يكون إما الاستمرار فى مشروع التطوير والتحسين بحماس وشغف، وإما العودة للحاولة

$$
\text { التركيز على مقاييس أخرى). }
$$


بدائل مقترحة لتطوير منظومة تقييم أداء الجامعات --- د/ محمد ابراهيم عبد العزيز خاطر

وتتضح عمليات القياس المقارن بالجامعة فيما يلى:

ا - تخطيط القياس المقارن لتقييم الأداء الجامعي:

يتم التخطيط لقياس الأداء الجامعى، وفقاً لمراحل محدة هي(ه)؛

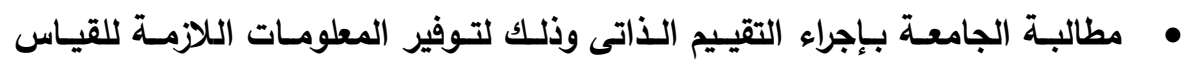

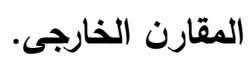

• قيام الفريق المكلف بالقياس المقارن بزيارة الجامعة وذلك لفحص المعلومـات الواردة فى التقييم الذاتى، واستكمال الجوانب الأخرى للقياس الخـارجى المقارن من عمل بـل مقابلات وإستبيانات للحصول على بيانات أخرى.

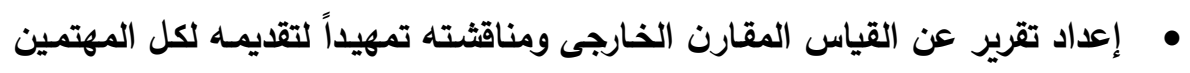
بالأداء التعليمى للجامعة. r - تنظيم القياس المقارن لتقيم الأداء الجامعي: يتم ترتيب وتنظيم عمليات القياس المقارن من خلال الخطوات التالية(^^): • مرحلـة التقييم الذاتي (Self- Evaluation): وفيها تقوم الجامعـة بمؤسسـاتها المختلفة بتطبيق المقاييس والأدوات المختلفة لتقييم أنشطتها وعملياتها ومخرجاتها. • مرحلة الزيـارة (Site Visit): وفيها يقوم الفريق المكلف بالقياس المقارن التابع

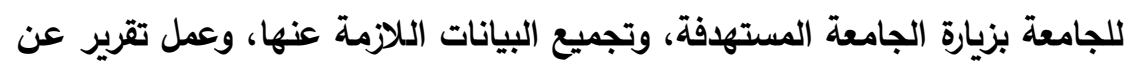

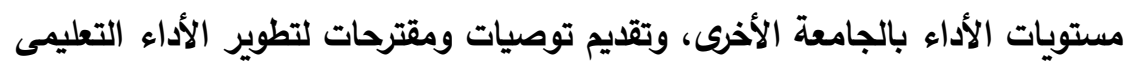
للجامعة. • مرحلة المراجعة (Review): وفيها تـتم المراجعة لتقـارير التقيـيم الذاتي وتقـارير القياس المقارن للجنة الزائرة، ويمكن إجراء تعديلات للتوافق بين التقريرين. • المرحلـة النهائية (Final Report) فيها يتم إعداد تقرير ختـامي عن الأداء التعليمى للجامعة ومتطلبات تطويره. r- تنفيذ أنثطة القياس المقارن لتقييم الأداء الجامعي: ويتم تنفيذ أنشطة القياس المقارن في مجالات الأداء التالية: أ- المجال الأول: الاور التعليمى والتدربسى للمؤسسات الجامعية: ويمكن تناول هذا المجال من خلال العناصر التالية(^v): • الأهداف التعليمية: يتم التأكيد على وضوح وتحديد الأهداف التعليمية وكذلك سهولة التهاولة قياسها، وذلك عن طريق فحص الوظيفة التعليمية للجامعة للتأكد من تحديدها فى الاهي 
مجلة كلية التربية بالإسماعيلية - العدد الرابع والأربعون - مايو 9 م

عبارات واضحة ليسهل قياسـها، وفحص تدرج أهداف الجامعة بين أهداف قصيرة

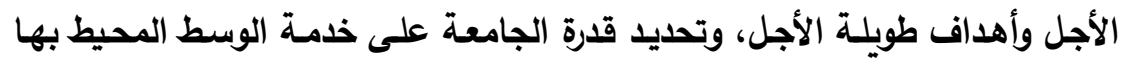
وارتباطها بجميـع قطاعـات المجتمـع، ومــى تأكيد الأهـداف علـى إعـداد الطـلاب للمستقبل المهني أو الحرفي، وتطوير أو إنجاز مهارات العمالة وتحسين قدرة الطلاب على التفكير، والتنمية الشخصية للطلاب وتطوير قدراتهم. سياسات القبول: تهتم جامعة بنسلفانيا بالقياس المقارن لشروط القبول وقد ترتب على ذلك أن بعض أنواع التخصصات فى الجامعة تشترط نوعاً من الخبرة العملية: مثل: انتظام طلاب هذه التخصصات قبل قبولهم أو أثناء دراستهم فى العمل الإنتاجي

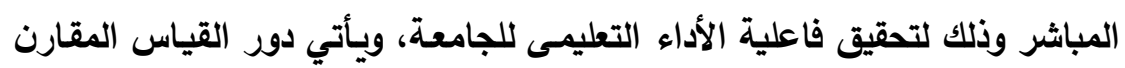
في التأكيا على تنوع متطلبات القبول بالجامعة ما بين المتطلبات العامـة، ودراسـة

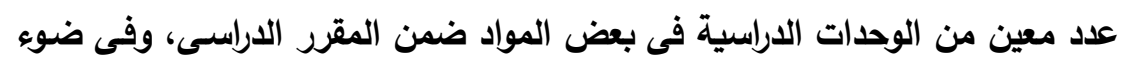

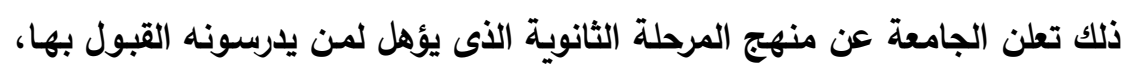

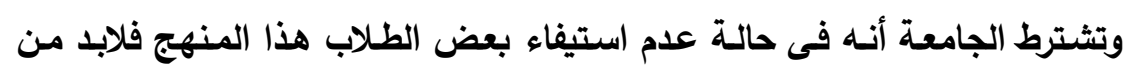

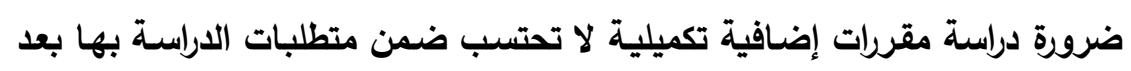

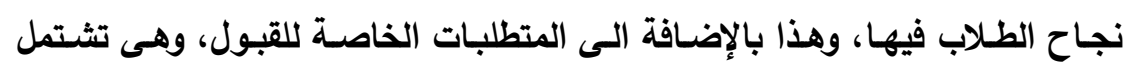

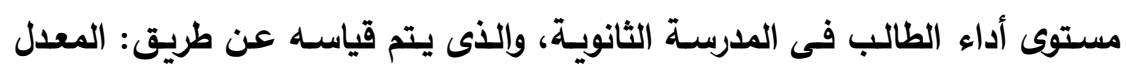
التراكمي للطالب، ترتيب الطالب بين أقرانه، واختبارات القبول المعياريـة (الاستعداد ولئه الاراسى (SAT) واختبار الكلية)، وتؤكد الجامعة على التوجيه المهني للطلاب، والكربط بين التعليم

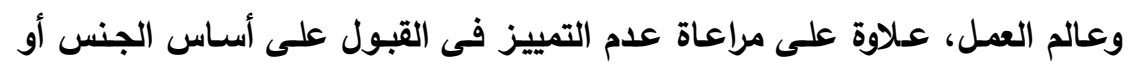
اللون، وتوجيه سياسات القبول للتفوق العلمي. الخطط والبرامج الدراسية: تقوم جامعة بنسلفانيا بخدمة r مليون فرد كل عام من

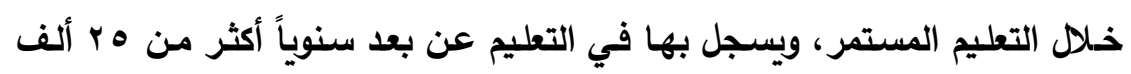

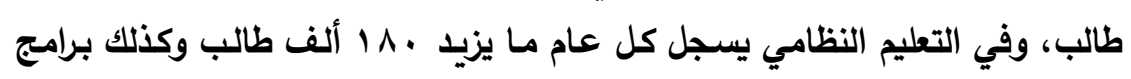

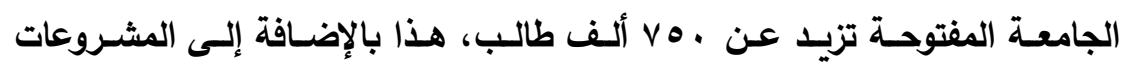

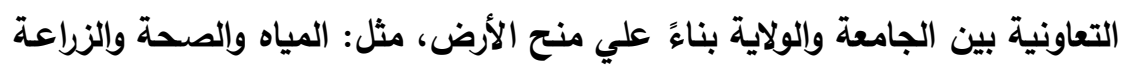

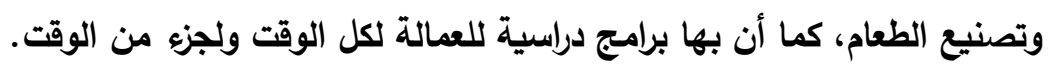

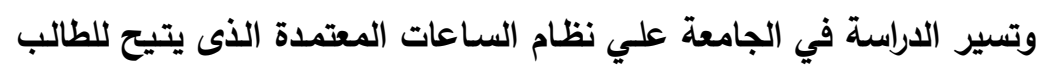
اختيـار المقـررات التـي تناسـبه والتخصـص الـذى يرغبـه، ويمكن للطالب أن يغيـر 
بدائل مقترحة لتطوير منظومة تقييم أداء الجامعات --- د/ محمد ابراهيم عبد العزيز خاطر

التخصص، ويدرس الطالب مقررات حرة (متطلبات جامعية)، بالإضـافة إلى مقررات

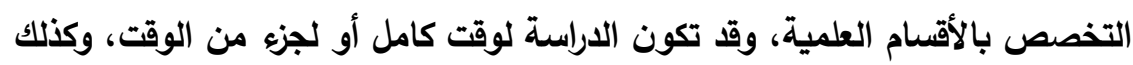
تهتم جامعـة "بنسـفانيا" بتقديم دراسـات متداخلـة "بينيـة" لتربط كلياتها ومدارسـها المختلفة بتخصصاتهم العلمية المختلفــة.

والجدير بالذكر أن الخطط والبـرامج الدراسـية التي تثبـت عدم كفاءتها ولا

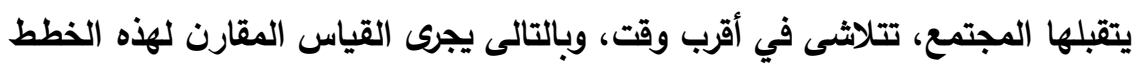

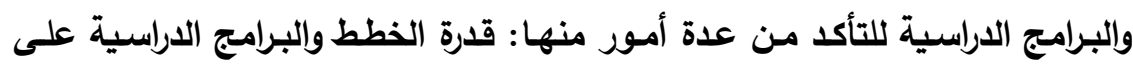

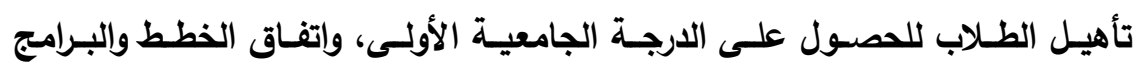
الدراسية ومحتوياتها مع أهداف الجامعة ووضع هذه الخطط والبرامج الدراسية على أساس مجالات متخصصة من الاراسة فى مستوى التعليم الجامعى، واتصاف الخطط

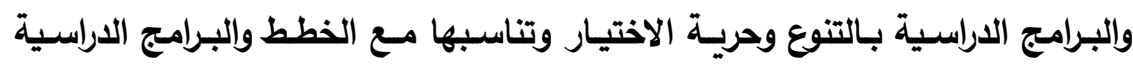
للجامعات الأخرى من حيث الطول والمحتوى الدراسى، وإثتمال الخطط والبرامج على الاحسي متطلبات مترابطة متسقة تتفق وأهداف الجامعة وتؤكد على عمق المعرفة المقدمـة، فضلاً عن التكامل فى إعداد الطلاب من خلال تقديم برامج دراسية تربط بين العلوم الأساسية وإلتطبيقات العملية والقضايا الاجتماعية والصناعية. • تقويم المخرجات التعليمية: يتم تقويم الطالب من خلال مشروعات البحوث التي يقوم

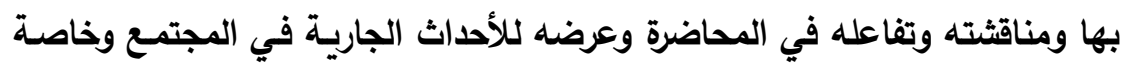
التحى ترتبط بالموضسوع (المحاضرة أو المقرر الدراسسي)، بالإضـافة إلى أوراق العمل التى يقوم بإعدادها، والتقويم مستمر لكل الأعمال التى يعرضها الطلاب أولاً بأول. ويؤكد القياس المقارن للمخرجات التعليمية على جدية أساليب التقويم، وتنوعها، وشمولها لكل جوانب شخصية الطالب، وكذلك على استمرارية هذه الأساليب، كما يؤكد على مدى التكامل والتناغم فى أساليب التقويم، وشمولها لجميع الجوانب التطبيقية والفنية والعقلية، علاوة على شمول أساليب التقويم لقياس مختلف قدرات الطلاب. ب- المجال الثانى: الدور البحثى للمؤسسات الجامعية: تثتهر الجامعة بتقدم تسهيلات عديدة وفزص مختلفة لطلاب الدراسات العليا للاراسة

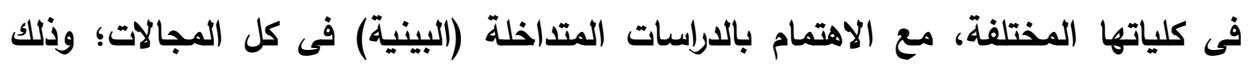
لاهتمامها بالتكنولوجيا المستخدمة وإعداد باحثين مزودين بالجوانب النظرية والعملية في آن واحد، مع استهاف الحصول على مراكز متقدمة في التمويل البحثى من خلال الشراكات 
مجلة كلية التربية بالإسماعيلية - العدد الرابع والأربعون - مايو 9 م ـ

والمشروعات البحثية الممولة، وبالتالي يؤكد القياس المقارن في مجال البحث العلمي

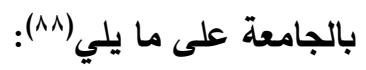

• توفير التمويل اللازم للبحوث (Research Fund): فالتمويل يؤدى دوراً حاسماً

فى تنفيذ خطة البحث، وبدون توفره يصع تنفيذ أي مشروع بحثي؛ نظراً لأن

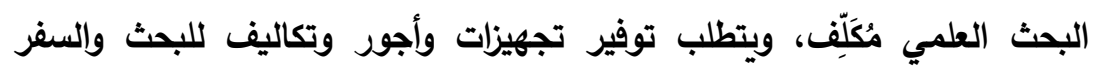

ولحضـور المؤتمرات وشراء المطبوعات وإلنشرات العلمية.

• التدريب والتأهيل (Training): حيث يتطلب البحث العلمي توافر بنـاء تراكمي من

الخبرات السـابقة فى إجراء البحوث، ولا يتأتى ذلك إلا من خـلال زيـادة فرص التبادل

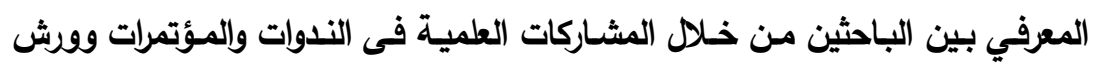

العمل وتبادل الزيارات فيما بين الجامعات.

إنثاء المراكز المتخصصة في البحث العلمي (Research Centers): وحرصاً من الجامعة على تنفيذ الخطط البحثية الموضوعة بأعلى قدر من الكفاءة؛ فلقد

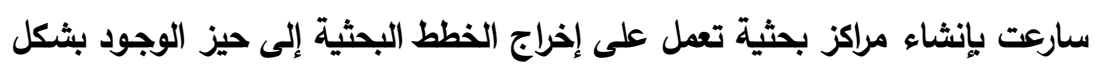

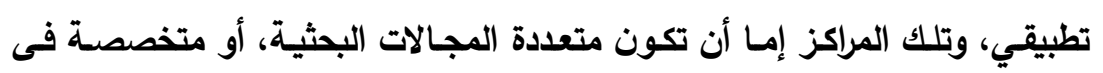

$$
\text { إنتاج أنواع معينة من البحوث. واتل }
$$

ج- المجال الثالث: الاور المجتمعى للمؤسسات الجامعية:

تتعدد صيغ الخدمات التي يمكن أن تقدمها الجامعة لمجتمعها المحلي، من خلا

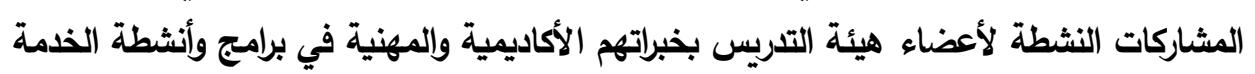
(العامة، والتي من بينها(^ه):

" إجراء البحوث العلمية القابلة للتوظيف في معالجة قضايا مهنية وتطبيقية محددة.

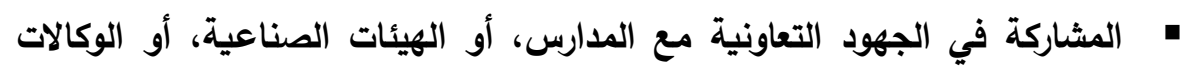
المدنية. • تقديم المشورة المطلوبة للمؤسسات وليلأفراد والجماعات في المجتمع المحلي. • إجراء دراسات عن المشكلات المحدة التي تُعرض عليهم من قبل الأفراد أو الهيئات

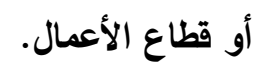

إعداد العنصر البشرى القادر على إحداث التنميـة المنشودة، من خـلال إعداد القوى العاملة القادرة على مواجهة التغيرات العلمية والتكنولوجية في العالم المعاصر. • القيام بالبحوث التي تسهم في تنمية المجتمع وحل مشكلاته. 
بدائل مقترحة لتطوير منظومة تقييم أداء الجامعات --- د/ محمد ابراهيم عبد العزيز خاطر

$$
\text { • الاستشارات العلمية التي تقدمها الجامعة لمؤسسات المجتمع. }
$$

• نشر المعرفة بين أبناء المجتمع المحلى، من خلال الندوات التي تساعدهم على حل

$$
\text { مشكلاتهم والتكيف مع مجتمعهم. }
$$

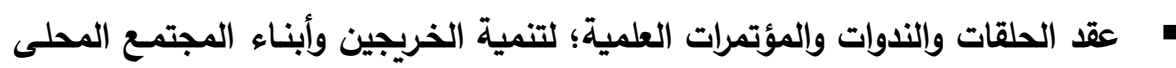

$$
\text { كل في مهنته وتخصصه. }
$$

ثالثًاً: مخرجات القياس المقارن لتقييم الأداء بجامعة بنسلفانيا:

تهـتم جامعـة بنســفانيا بتقـارير القيـاس المقــارن باعتبارهـا تتضــن معلومـات عـن

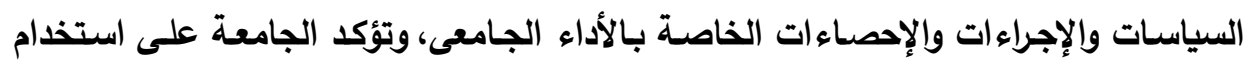

تقـارير القيـاس المقـارن فـى التخطيط الاسـتراتيجي للجامعـة وخاصـة مـا يتعلق بالمعلومـات

- أعداد الطلاب المقيدين بالجامعة.

- معدلات الطلاب لهيئة التدريس بكل كلية.

- متوسط عدد الطلاب المتخرجين كل عام.

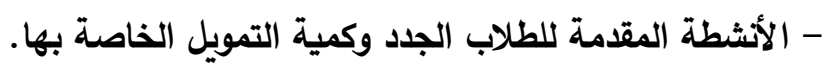
- البرامج الدراسية لكل الوقت ولجزء من الوقت.

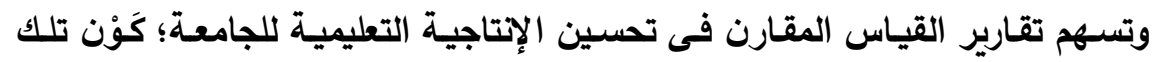
التقـارير تسـاعد على تلبيـة رغبـات المستفيدين، وتقدم اقتراحـات لتطوير البرامج الدراسـية

وتحسين سياسات القبول وتقويم الطلاب، وذلك بمراعاة ما يلى: م نشر تقارير القياس المقارن لكل المهتمين بالأداء التعليمى للجامعة. م الاعتماد على رؤية واضحة للأهداف التعليمية للجامعة. م تعظيم التفوق العلمي وذلك من خلال الاعتماد على الجودة العالية للتدريس والتعليم

$$
\text { والبحث العلمي. }
$$

م تعظيم الخبرة التعليمية لكل طلاب ولاية "بنسلفانيا".

م تقديم أفضل الخدمات للمجتمع المدني.

المحور الثانى: القياس المقارن لمنظومة تقييم الأداء بجامعات استراليا: تعد استراليا من أولى دول العالم التي اتجهت نحو تبني مفهوم الجودة في المؤسسات التعليمية بعد انتقاله من مجال الصناعة، حيث بدأت تنتشر مفاهيم الجودة وآلياتها في معظم الأجزاء التي حاولت تطبيق مدخل ضمان الجودة، حيث طبقت بعض مؤسسات التعليم 
مجلة كلية التربية بالإسماعيلية - العدد الرابع والأربعون - مايو 9 م ـ

الجامعي هذه المداخل بُغْيَة تحسين الأداء بها، وتحسين العملية التعليمية، والخدمة التعليمية المقدمة للطالب، وتحقيق الميزة التنافسية في السوق التعليمي، وق ساعد على ذلك التطور الهائل في تكنولوجيا المعلومات والتعليم، والتزايد المستمر في عدد الطلبة وفي مؤسسات التعليم الجامعي.

ولقد أصبح القياس المقارن بالأفضل ذا أهمية كبيرة في التعليم الجامعي الاسترالي عندما قدمت الحكومة آليات تقييم جودة التعليم، وتوفير مصادر جديدة لتمويل التعليم الجامعي، كما أصبحت الجامعات الاسترالية تسعى إلى ترشيد الإنفاق، وتقليل تكلفة تقديم خدمة تعليمية متميزة مقارنة بجامعات الدول المتقدمة، والتي تحقق التعليم الجيد بأقل تكلفة ممكنة. وفيما يلى عرض لنموذجين من الجامعات الاسترالية في توظيف أسلوب القياس المقارن لتقييم أداء المؤسسات الجامعية:

النموذج الأول: حامعة أديـلايد Adelaide University: هي جامعة عامة مقرها مدينة "أديلايد" بولاية استراليا الجنوبية، تأسست سنة

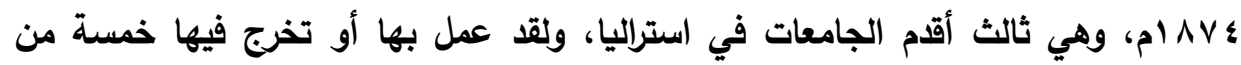
حاملي جائزة نوبل، وهي جامعة عضو في ما يسمى "مجموعة الثمانية" للجامعات الاسترالية، كما أنها إحدى الجامعات المسماة في استراليا بجامعات "الحجر الرملي"، في إثارة إلى قدم تأسيسها. وتمتلك الجامعة خمسة مقرات موزعة على مدن ولاية استراليا الجنوبية، إلى جانب إنب إنسات مقر سادس هو مركز "نجي آن - أديليد" التعليمي، وتضم الجامعة خمس كليات هى: كلية الهندسة وعلوم الحاسب والرياضيات، وكلية علوم الصحة، وكلية الإنسانيات والعلوم الاجتماعية، وكلية المهن، وكلية العلوم، والجدير بالذكر أن كل كلية من الكليات الخمس ولهابه

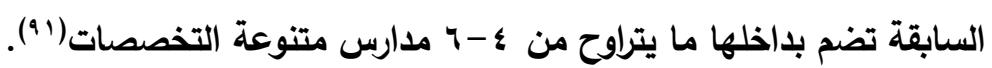
أولاً: مدخلات القياس المقارن لتقييم الأداء بجامعة أديلايد: تتمثل رؤية الجامعة في تعظيم دورها كمركز تعليم وتثقيف وتنوير تثع مساهتها العلمية والفكرية على العالم، مع أهمية تطوير المنظومة التعليمية والبرامج الدراسية، بما يضمن زيادة الحراك الطلابى وزيادة الطلاب الوافدين حول العالم. وتتمثل مدخلات القياس المقارن للجامعة في العناصر التالية: 
بدائل مقترحة لتطوير منظومة تقييم أداء الجامعات --- د/ محمد ابراهيم عبد العزيز خاطر

$$
\text { 1 - فلسفة القياس المقارن بجامعة أديلايد وأهدافه: }
$$

تتمتع الجامعة بالحرية المرتبطة بعملية التقويم وقياس العائد ومراقبة وظائف الجامعة،

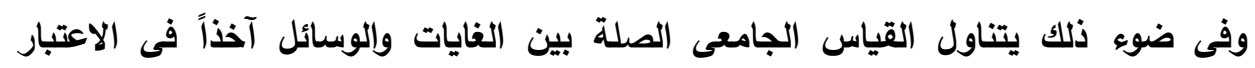
متطلبات المجتمع والجامعة، وتركز الجامعة على تقارير قياس الأداء لكل المهتمين بالأداء

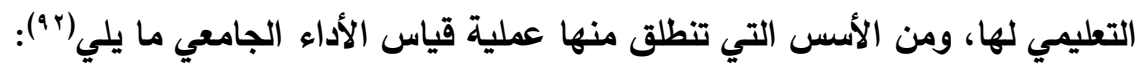

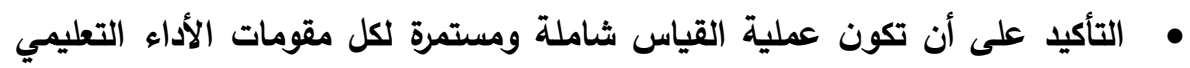
فى الجامعة والعوامل الخارجية المؤثرة فيها. • أن القياس المقارن أساس جوهرى لضمان جودة الأداء التعليمى للجامعة، وتحقيق قدر معقول من الكفاءة والفاعلية.

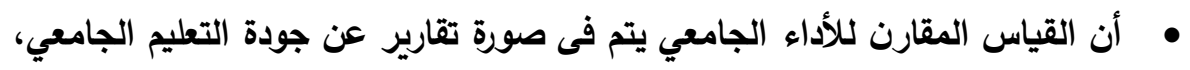

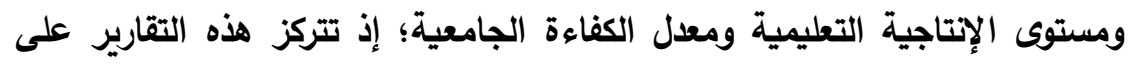

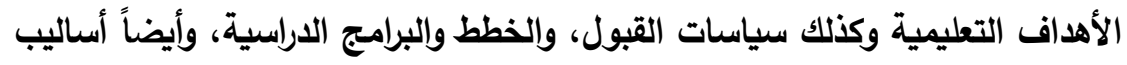

$$
\text { تقويم الطلاب فى الجامعة. }
$$

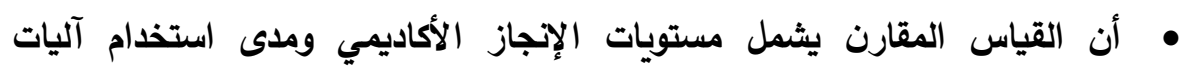

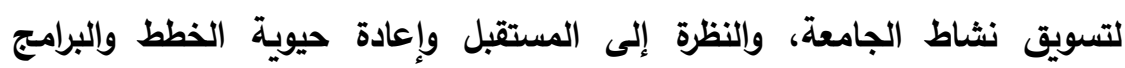

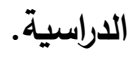

r - الجهات المسؤولة عن القياس المقارن لتقييم الأداء بجامعة أديلايد: تتنوع الجهات التي تجرى عمليات القياس لتقييم الأداء الجامعي، ومن هذه الجاء لجامعهاء الجهات:

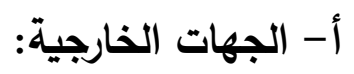

تخضع الجامعة للتقييم والمراجعة من منظمات أو سُلْطَات خاصة للإجازة والمصادقة، وهى تمثل روابط أو هيئات تطوعية غير حكومية، أو هيئات مهنية تضع معايير للحكم وتنظم

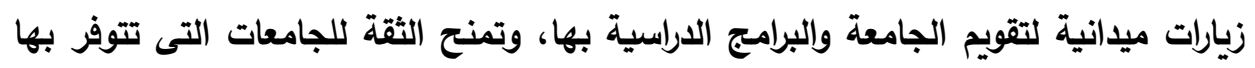

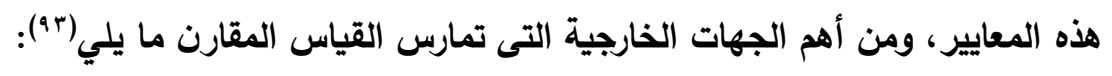

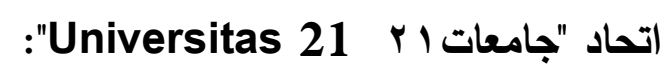

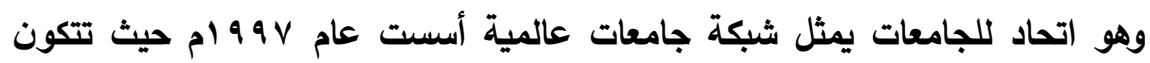

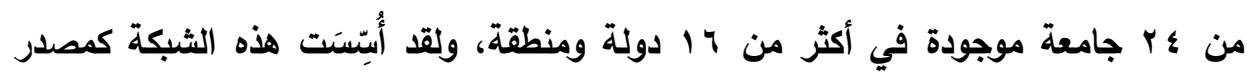

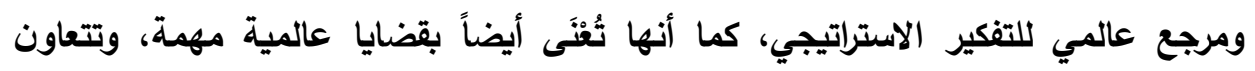

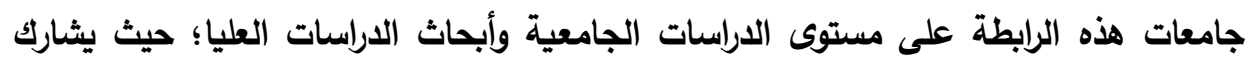


مجلة كلية التربية بالإسماعيلية - العدد الرابع والأربعون - مايو 9 م ـ

مئات الطلبة سنوياً في برنامج التبادل الطلابي، وتدخل جامعة "أديلايد" فى هذا الاتحاد علاوة على أنها تأخذ -مثل غيرها من الجامعات الاسترالية- بنظام الاعتماد الخارجى وفيه يتم الاعتماد والاعتراف بالجامعة أو الكلية أو البرنامج طبقاً لمعايير محدة وفقاً لنتائج عمليات التقويم الذاتي للجامعة وإلفحص من قبل هيئات الاعتماد الجامعى، وقد تبنت الجامعة -مثل

بقية الجامعات الاسترالية- فلسفة الجودة باعتبار أن التعليم يوجد فى بيئة تنافسية عالية.

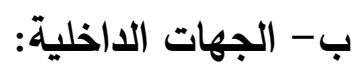

يشترك في قياس أداء الجامعة مستويات متعددة من الجهات الداخلية، ويسمى القياس

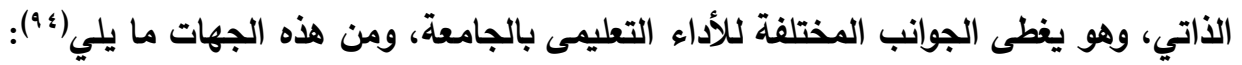

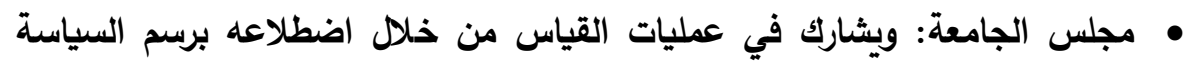

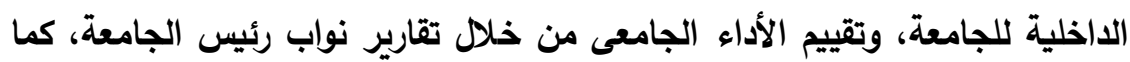

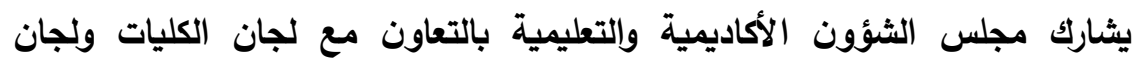
الأقسام فى الرقابة واستخدام مقاييس كمية ونوعية لقياس الأداء التعليمي، ومتابعة لإنة السياسة التعليمية وجميع مقومات الأداء التعليمى للجامعة من تقييم الأهداف، وسياسات القبول، وإقرار ومتابعة الخطط والبرامج الدراسية وأساليب تقويم الطلاب. • المراكز العلمية المتخصصة: وهى المراكز التى تعمل على استمرارية الأداء التعليمى

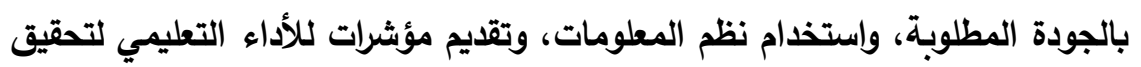
الجودة والتركيز على الإنجاز الأكاديمي. • مجس الكلية: ويشارك في عمليات القياس من خلال وضع اللانحة التنفيذية للكلية، وإقرار الخطط والبرامج الدراسية، والعمل على تحقيق الأهداف العامة للجامعة والأهداف الخاصة بالكلية من خلال التقييم والمراقبة المستمرة، علاوة على مناقشة أساليب تقويم الطلاب للعمل على تطويرها وذلك فى ضوء نتائج الجامعات الأخرى. • مجلس القسم: ويشارك في عمليات القياس من خلال قيامه بأمور عدة منها: إقرار الخطط والبرامج الدراسية، ومتابعتها وتقييمها باستمرار لتطويرها، ووضع الخطط العامة لشروط القبول بالقسم وتنويعها أمام الطلاب. ثانياً: عمليات القياس المقارن لتقييم الأداء بجامعة أديلايد: تتبع الجامعة نموذج القياس المقارن الذى يظهر في الثكل التالي(ه9): 
بدائل مقترحة لتطوير منظومة تقييم أداء الجامعات --- د/ محمد ابراهيم عبد العزيز خاطر

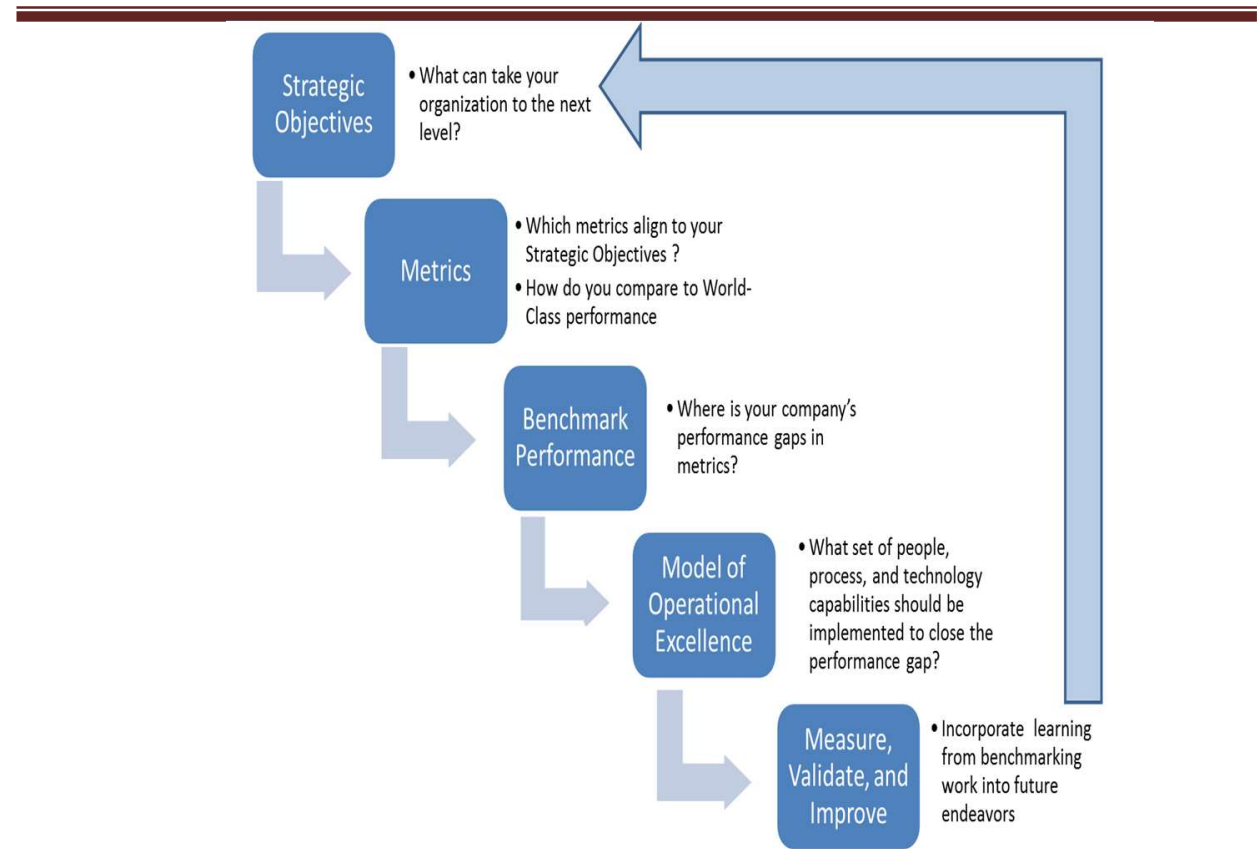

شكل (•): المصدر: Department of Education, Training and Youth"

Affairs, 2012, p.124."

ويتبين من الثكل السابق أن الجامعة تطبق هذا النموذج والذى يصلح للمؤسسات الإنتاجية والربحية، مثل الثركات، حيث يظهر هذا النموذج أن عمليات القياس المقارن تتضمن مراحل متتالية تظهر في شكل دائرى مستمر، وذلك كما يلي:

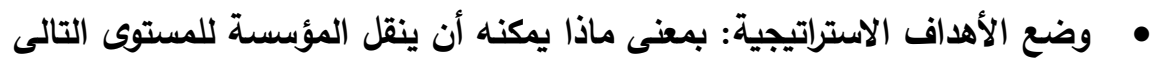
الجديد؟

• عديد مصفوفة الأداء: بمعنى أى مصفوفة تصلح لترتيب الأهداف الاستراتيجية؟

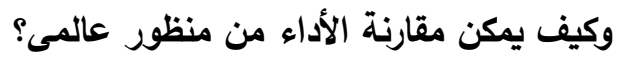

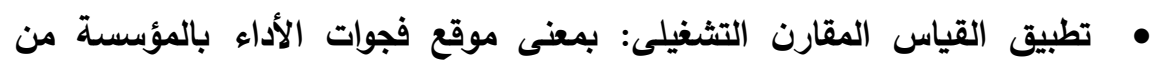
مصفوفة الأداء. تحديد نموذج التميز في العمليات: بمعنى ما الاور التنفيذى للأفراد، والعمليات والتكنولوجيا والإمكانات من أجل سد فجوة الأداء؟ • الوصول إلى القياس والمصداقية والتحسين: بمعنى التعلم من نتائج القياس

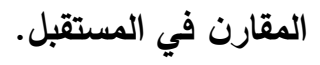


مجلة كلية التربية بالإسماعيلية - العدد الرابع والأربعون - مايو 9 م ـ وبناءً على ما تقدم، فإن الجهات المسئولة عن القياس المقارن بالجامعة، تؤدى

العمليات التالية:

ا - تخطيط القياس المقارن لتقييم الأداء الجامعي:

يعتمد القياس المقارن بالجامعة على مجموعات عمل فرعية تهتم بدراسة مقومات

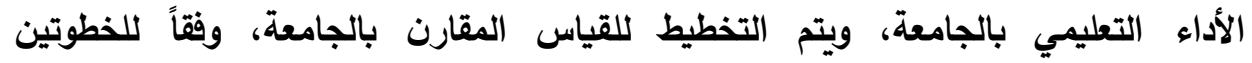

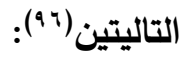

• الإعداد والتجهيز، وتثمل هذه المرحلة تحديد أعضاء لجنة القياس المقارن ووضع

$$
\text { قائمة باحتياجاتهم. }
$$

• تحديد الأدوار والمسئوليات، وتثمل هذه المرحلة توجيه مجموعات العمل إلى

إيجاد آليات الاتصال والتنسيق بين الوحدات الموجودة داخل الجامعة وبعضها، وبينها وبين الجهات الخارجية وتحديد الجدول الزمنى لإنهاء عمليات القياس

$$
\text { الجامعي. }
$$

r - تنظيم القياس المقارن لتقييم الأداء الجامعي:

تهتم لجان ومجموعات القياس المقارن بزيادة الجامعة وزيادة كل الأقسام العلمية

وذلك لمدة ثلاثة شهور، وتحليل تقارير الأقسام ونتائج الطلاب ثم عمل تقرير عن الزيادة يشتمل على استراتيجيات للتوجيه الخارجي والداخلي عن الجامعة، ويتم ذلك وفقاً للخطوات

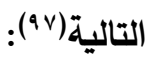

• عديد مندوب للتنسيق بين الجامعة والجامعة أو الجامعات الأخرى، وغالباً ما

$$
\text { يكون أحد عمداء كليات الجامعة. }
$$

تحديد موعد الزيارة لفريق القياس المقارن، وكذلك تثكيل الفريق وتحديد مهامه

$$
\text { المختلفة. }
$$

• قيام الجامعة جهة المقارنة برفع تقريرها عن مقومات الأداء التعليمي بداخلها.

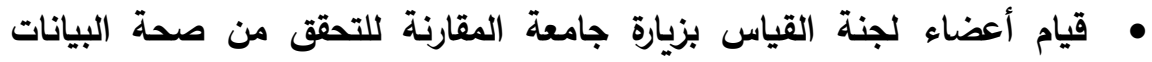
المقدمة من أعضاء هيئة التدريس، وفحص دقة البيانات عن مقومات جاءم الأداء

$$
\text { التعليمي للجامعة. }
$$

• تجهيز البيانات اللازمة مصحوبة برسومات وأثكال وإحصاءات تسهل على مستخدميها التعرف عليها واستخدامها، ويتم جمعها من خلال المستويات المنشورة والمعلنة من الروابط المختلفة ومجلس الولاية للتعليم العالى، مع عمل 
بدائل مقترحة لتطوير منظومة تقييم أداء الجامعات --- د/ محمد ابراهيم عبد العزيز خاطر

مقابلات مع بعض مسؤولي الجامعة وإجراء حوار بين كل المهتمين بالأداء

التعليمي للجامعة.

r- تنفيذ أنثطة القياس المقارن لتقييم الأداء الجامعي:

ويتم تنفيذ أنثطة القياس المقارن في مجالات الأداء التالية:

أ- المجال الأول: الدور التعليمى والتدربسى للمؤسسات الجامعية:

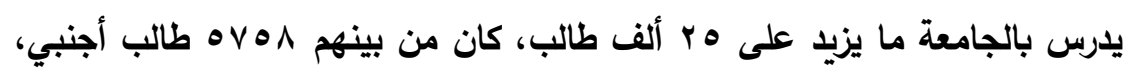

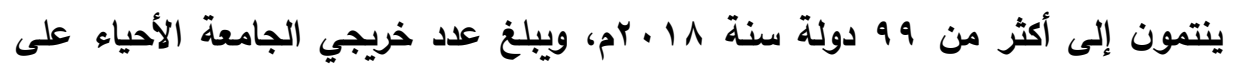

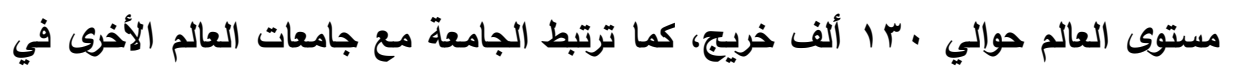

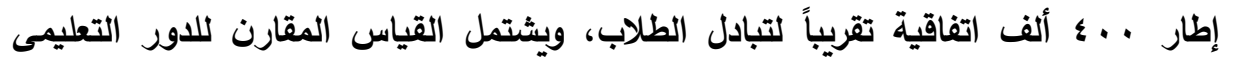

$$
\text { والتدريسى على العناصر الآتية(9^): }
$$

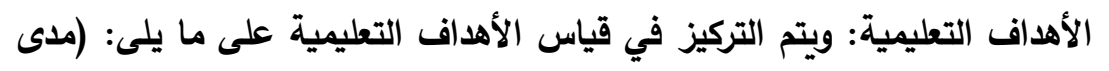

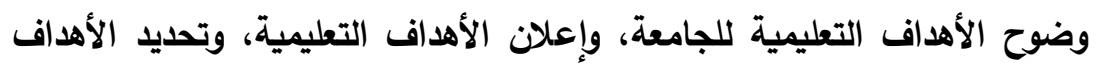

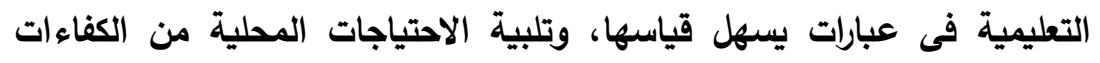

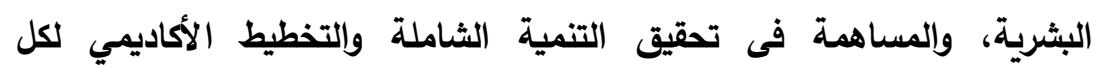

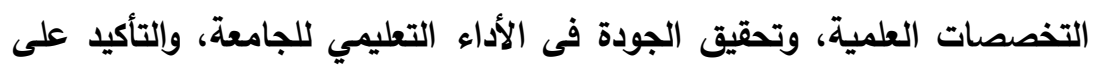

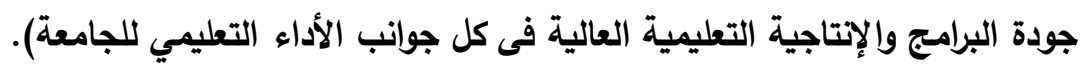

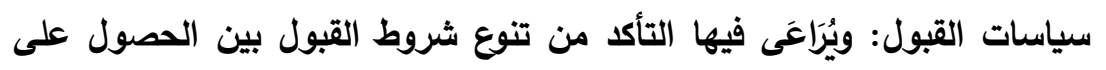

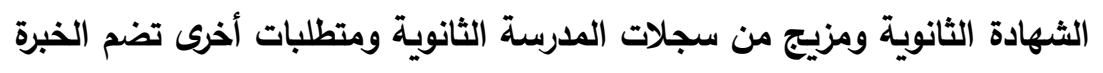

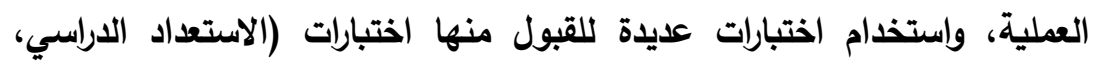

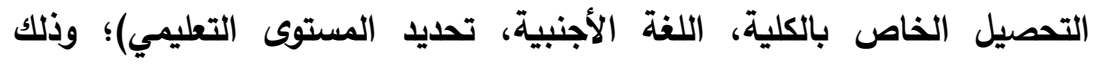

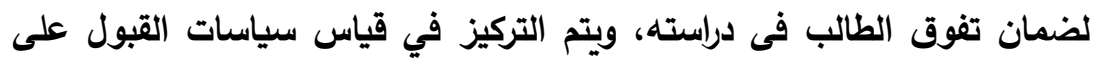

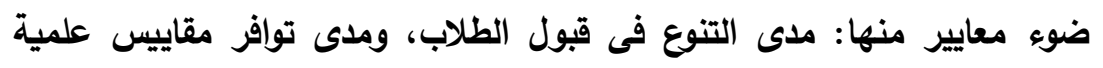

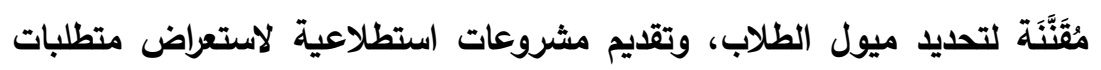

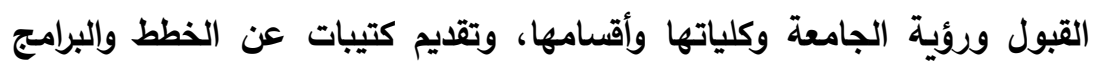

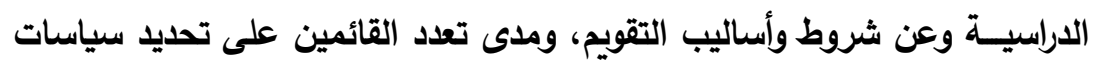
قبول الطلاب بالجامعة.

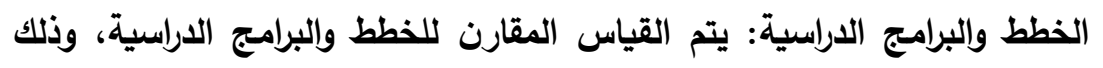
لتستجيب الجامعة لاحتياجات المجتمع، وعلى ذلك يتم تركيز الأقسام العلمية 
مجلة كلية التربية بالإسماعيلية - العدد الرابع والأربعون - مايو 9 م

المختلفة بالجامعة على ما يلى: (توافر الثروط الأكاديمية فى الخطط والبرامج الدراسية المختلفة واختلافها باختلاف مجالات التخصص الاراسية، ومعرفة مدى تحقق الأهداف المُحََّدَة سلفاً للخطط والبرامج الدراسية سواء فى شقها النظري أو العملي التطبيقي، والتأكد من التنوع وحرية الاختيار فى الخطط والبرامج الاراسية، ومواءمة أهداف الخطط والبرامج الدراسية مع أهداف الجامعة، ومعدلات تسجيل الطلاب فى الخطط والبرامج الدراسية، وكذلك آرائهم بثأن هذه الخطط والبرامج الاراسية، والتنوع وحرية الاختيار فى الخطط والبرامج الدراسية بما يتيح تحقيق

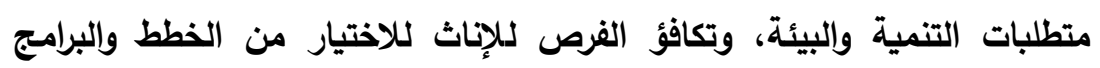

$$
\text { الاراسية التي يتم تقديمها فحى كليات الجامعة). }
$$

تقويم المخرجات التعليمية: يتم التركيز في قياس مستويات الطلاب والخريجين على ما يلى: (مدى التكامل فى أساليب التقويم، مدى استمرارية أساليب تقويم الطلاب، مدى شمول أساليب تقويم الطلاب واهتمامها بالجوانب التطبيقية

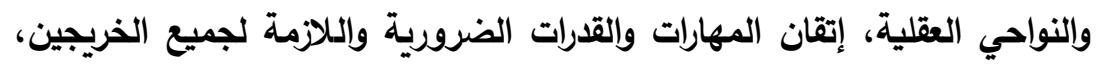
إتقان المستوى المعرفي المناسب لمنح الدرجة الجامعية، ومدى تتبنى الجامعة

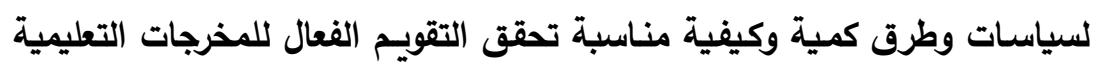
والخطط والبرامج الدراسية، وربط نتائج التقويم بأداء الجامعة التعليمي ونشر النتائج، وتقديم نماذج مخططة لتقويم الطلاب والتفذية الراجعة بما يحقق تطوير الأداء التعليمي للجامعة ككل). ب- المجال الثانى: الاور البحثى للمؤسسات الجامعية: تعد الجامعة واحدة من أكثر الجامعات الأسترالية نشاطاً في مجال البحث العلمي، ويتسم باحثو الجامعة بالتميز الملحوظ، وبصفة خاصة في أبحاث علوم الزراعة، وعلوم

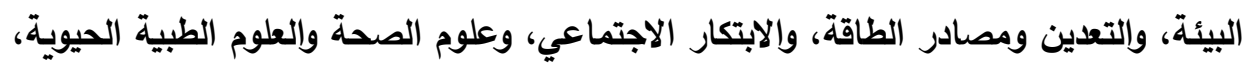
والاستشعار عن بعد وعلوم الحاسب، وبناء على ذلك يتوجه القياس المقارن في مجال البحث

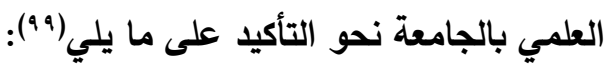
• إجراء البحوث ذات الصلة الوثيقة باحتياجات المجتمع. - تقديم الاستثارات البحثية العلمية للمؤسسات الخدمية. • حث أعضاء هيئة التدريس على بحث مشكلات المجتمع. 
بدائل مقترحة لتطوير منظومة تقييم أداء الجامعات --- د/ محمد ابراهيم عبد العزيز خاطر

• نشر نتائج البحوث التي يتم التوصل إليها، مـع تقديم برامج للتدريب على مهارات

$$
\text { البحث العلمي. }
$$

ـ قيام أعضاء هيئة التدريس بنشر أبحاثهم في مجلات عالمية في التخصص.

• إتاحة الفرصة للمؤسسات الأخرى للمشاركة في تمويل البحث العلمي.

• امتلاك آليات متنوعة لتسويق بحوثها العلمية.

• حرص إدارة الجامعة على تطوير وتدعيم آليات ونظم البحث العلمي.

• امتلاك خطة بحثية على مستوى الأقسام العلمية، بكل كلية من كليات الجامعة.

ج- المجال الثالث: الاور المجتمعى للمؤسسات الجامعية:

يتوجـه القياس المقارن في مجال تفاعل الجامعة مـع مجتمعها المحلى والعالمي نحو

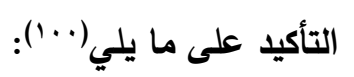

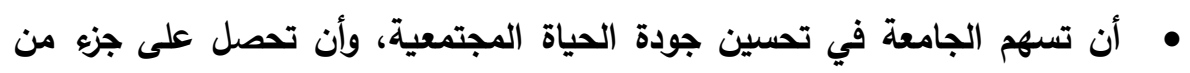

مواردها من مؤسسات المجتمع.

• أن تلبي متطلبات سوق العمل من التخصصات الجديدة، وأن تسهر الأبحاث العلمية

للجامعة في حل مشكلات المجتمع.

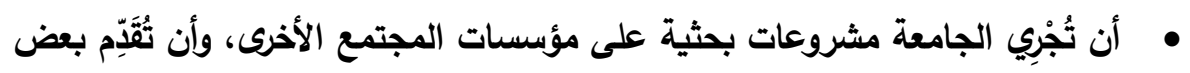

$$
\text { الاستشارات العلمية لمؤسسات المجتمع. }
$$

• أن تحرص على تناول مشكلات المجتمع في مؤتمراتها، وأن توجد قنوات اتصال

مفتوحة بين الجامعة والمجتمع.

• أن تقدم دورات تدريبية للعاملين بمؤسسات المجتمع، وأن يوجد بها بهات وحدات ذات

طابع خاص وذات إنتاجية متميزة.

ثالثاً: مخرجات القياس المقارن لتقييم الأداء بجامعة أديلايد:

تنتهى عمليات القياس المقارن بإصدار تقارير تمثل مخرجات هذه المنظومة، وتأتى

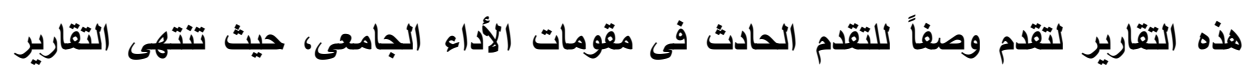
بتحديد ما يلي (1) - (1):

• فعالية التكلفة (Cost Effectiveness): وتثير إلى كيفية إدارة التكلفة بشكل جيد،

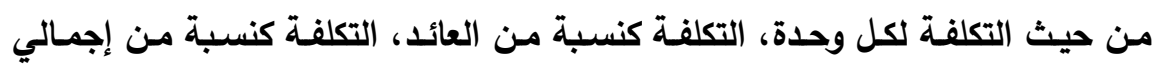

الموازنة الجامعية، والتكلفة الفعلية إلى تكلفة الموازنة الجامعية لعام دراسى ما. 
مجلة كلية التربية بالإسماعيلية - العدد الرابع والأربعون - مايو 9 ـ

إنتاجية العاملين (Staff Productivity): وهى تشير إلى مخرجات العاملين فى

وقت محدد، ويتضمن ذلك عدد المستفيدين الذين تم خدمتهم لفترة محددة، وعادة ما

تركز على العوامل التي تـؤثر على إنتاجيـة العـاملين، مثل: سـاعات التـريب لفترة

محددة، والقيم التظيمية السائدة .. وغيرها.

كفـاءة العمليـات (Processes Efficiency): تثـير إلـى كيفيـة عمـل الـنظم

والإجراءات في دعم العمليات، كما تتضمن معدل الخطأ، معدلات الدقة، وتهتم أيضاً بالعوامل المؤثرة على كفاءة العمليات، مثل: ميكنة العمليات.

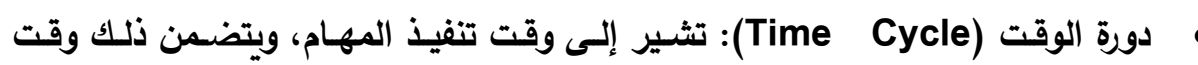

التشغيل والوقت اللازم للرد على استفسارات العملاء وحل مشاكلهم... وغيرها.

وفى ضوء نتائج تلك التقارير يتم اتخاذ اجراءات التغذية الراجعة والمرتبطة، بما يلي:

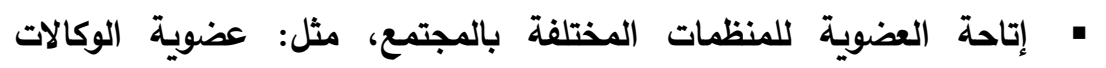

الخاصة بالتجارة والعمالة.

• تقديم قيمة الأموال التى تحصل عليها الجامعة من المجتمع سواء المحلى أو

القومي، وما تقدمه من خدمات.

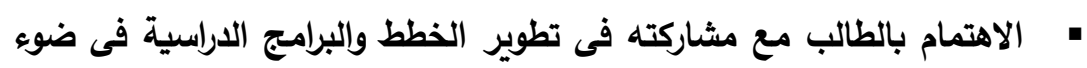

شعوره بالراحة فيما يتعلق بوقت البرنامج ومحتواه وتكاليفه.

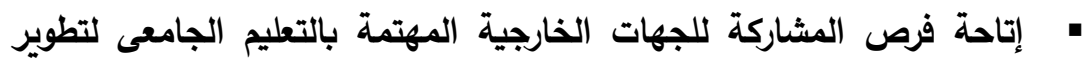

الخطط والبرامج الدراسية.

The University of Western النموذج الثاني: جامعة غرب استراليا

:Australia

تُعَ الجامعة واحدة من الجامعات الرائدة في استراليا، كما أن لها سمعة دولية متميزة

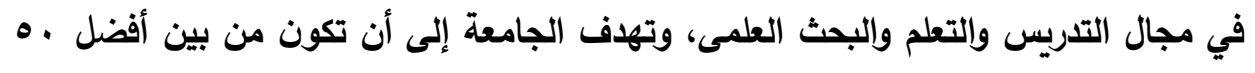

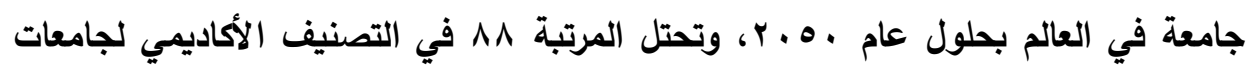

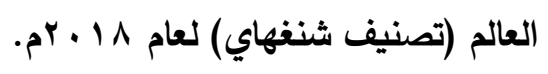

وتطبق الجامعة نظاماً متميزاً للقياس المقارن لتحقيق جودة مؤسسات التعليم الجامعي، كما أنه يقدم رؤية واضحة عن العلاقة بين تغيير سياسات الجودة والتغيرات والتطورات التي قد تطرأ على الجامعات الاسترالية بصفة عامة، والتي بدورها تحاول التكيف

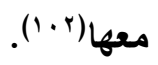


بدائل مقترحة لتطوير منظومة تقييم أداء الجامعات --- د/ محمد ابراهيم عبد العزيز خاطر أولاً: مدخلات القياس المقارن لتقييم الأداء بجامعة غرب استراليا:

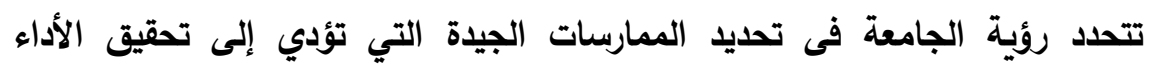

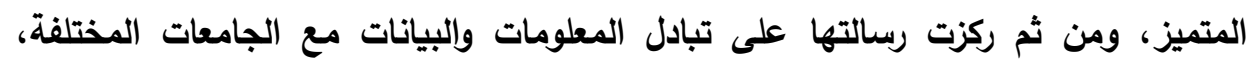

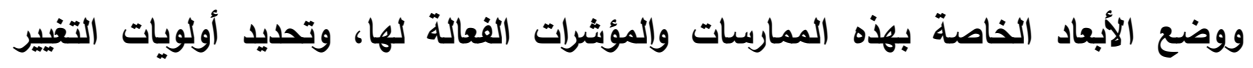

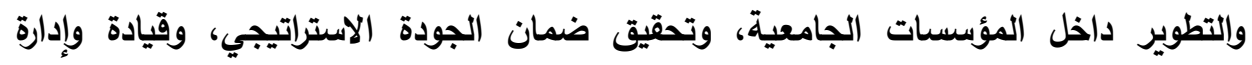

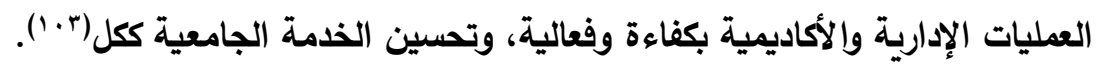
1 - فلسفة القياس المقارن بجامعة غرب استراليا وأهدافهه:

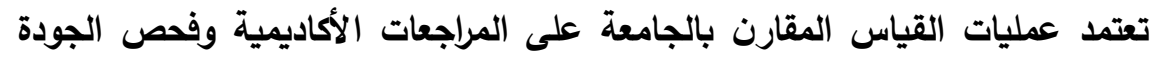
لمؤسسات التعليم الجامعي، وتقييم أنثطتها المختلفة، وتركز على المقارنة المرجعية القائمة المعاديا

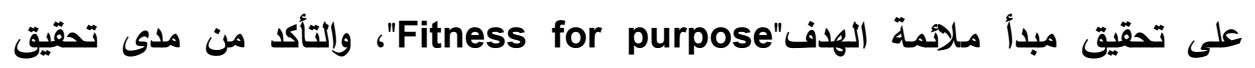

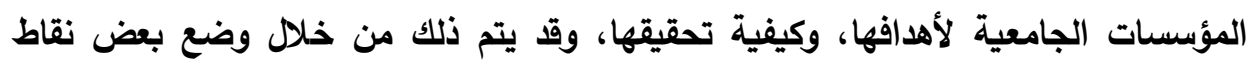

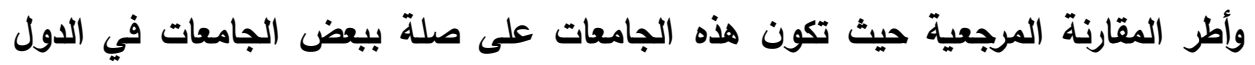

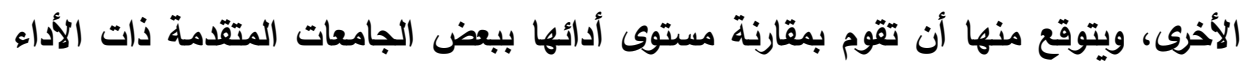
المتميز (؛ + ().

ويعتمد القياس المقارن على مبدأ رئيس هو منظومة القياس، والمقارنة بين عمليات

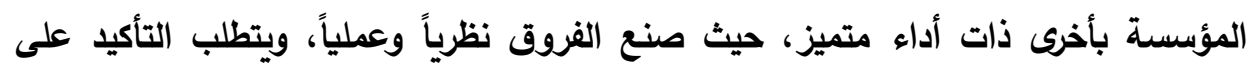

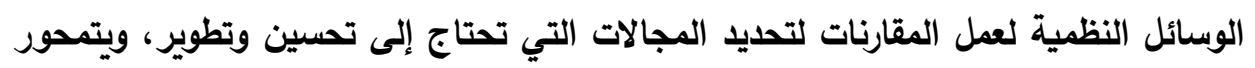

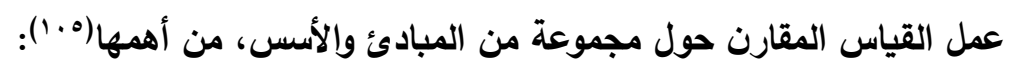
$\checkmark$ إعطاء أولوية لتكوين مجموعة من النظراء من المؤسسات الجامعية بهاف القياس الهاس

$$
\text { المقارن للأداء الاستراتيجي. }
$$

ل تطوير استراتيجية للشراكة من أجل تطبيق القياس المقارن بين الجامعات الاسترالية.

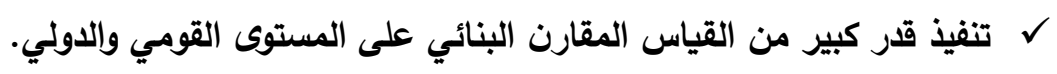

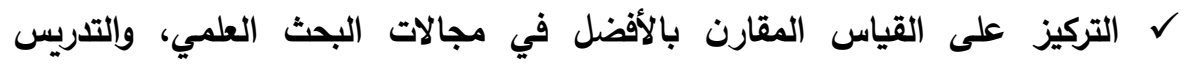
الجامعي.

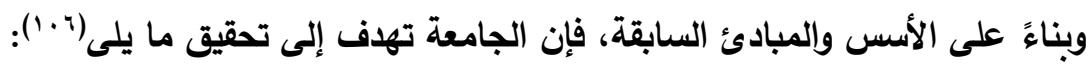

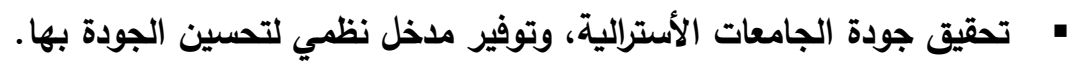

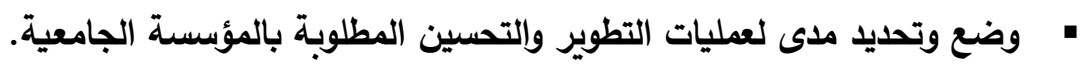
• توفير قاعدة أساسية لعمليات التحسين وتطوير مقاييس أداء المؤسسات الجامعية. 
مجلة كلية التربية بالإسماعيلية - العدد الرابع والأربعون - مايو 9 م ـ

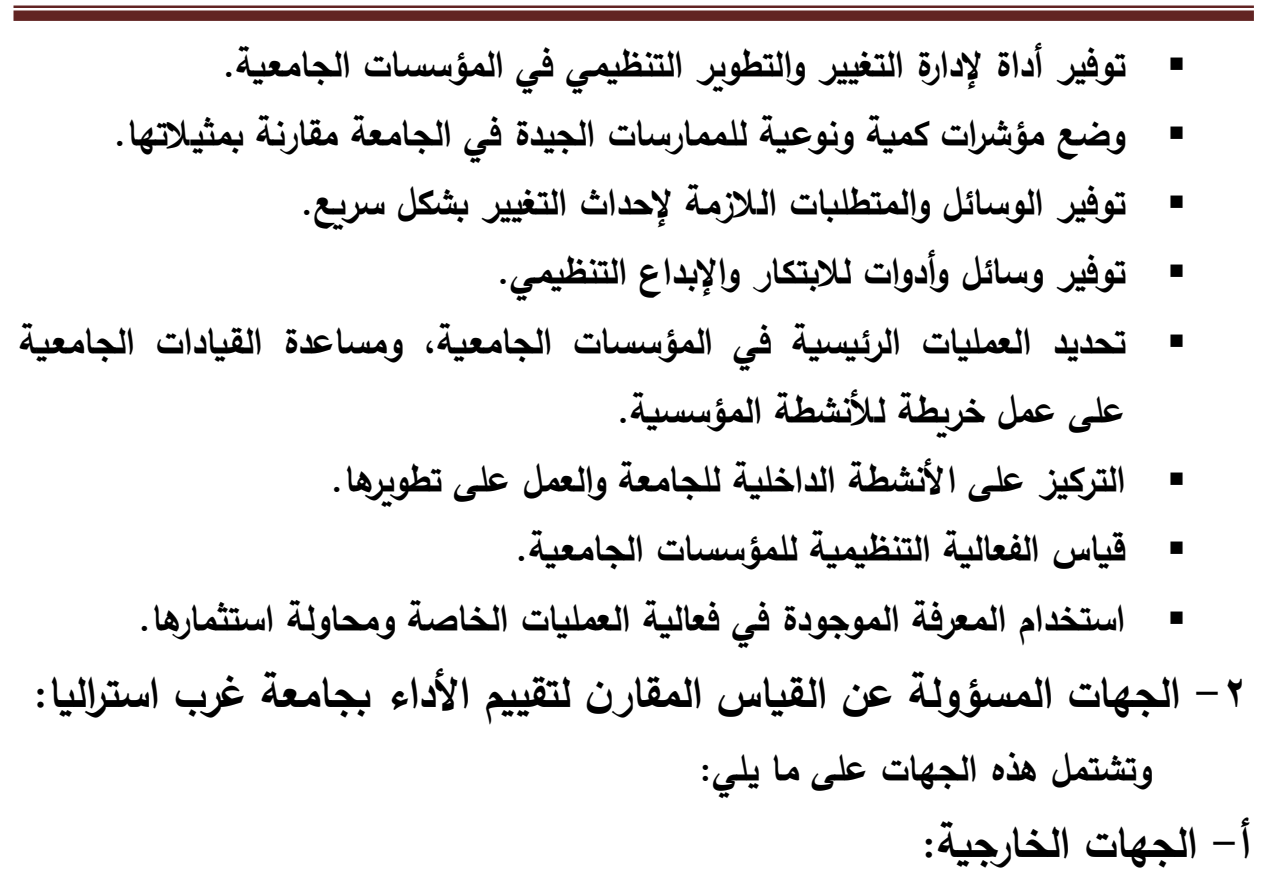

تخضـع الجامعة لتقييم أدائها من جهات عديدة، وذلك لعمل تقـارير عن الجامعة

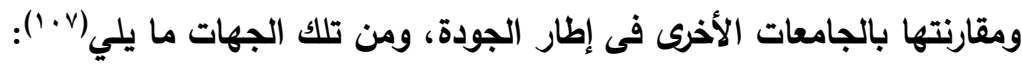

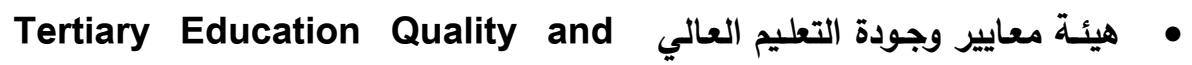
: تهتم الهيئة بتظيم وضمان جودة قطاع : Standards Agency (TEQSA) التعليم العالي في استراليا ككل، وتلتزم الهيئة بعمل تقييمات لنظم الجودة وذلك بزيـارة الجامعة لفحص الجودة وتوكيدها، ويتم التأكيد على تحقيق الكفاءة والتركيز على لحئ

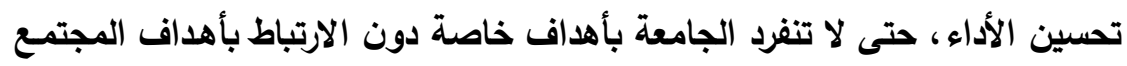
كله. • وحدة الفحص الأكاديمي "Academic Examination Unit" : تسـهم هذه الوحدة بقياس الأداء من خلال اهتمامها بتقويم الجودة فى الجامعة، وذلك بالتركيز على الخطط والبرامج الدراسية، وكذلك وضع أحكام للجودة التعليمية فى الجامعة من

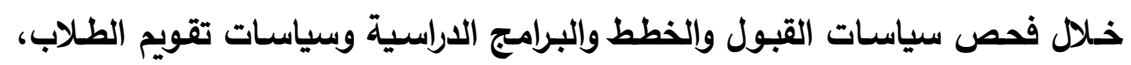
وكذلك تصنيف الجامعات؛ وذلك لعدل المقارنـة بين الجامعة والجامعات الأخرى،

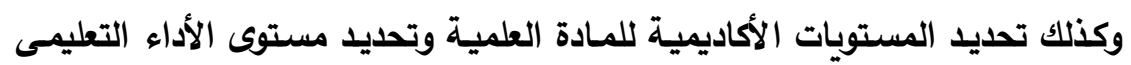
للجامعة ككل. 
بائل مقترحة لتطوير منظومة تقييم أداء الجامعات --- د/ محمد ابراهيم عبد العزيز خاطر

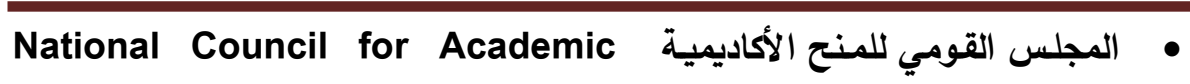

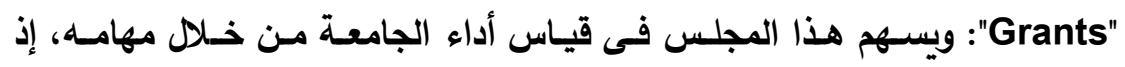
يستخدم المقاييس القومية للرقابة على الخطط والبرامج الدراسية، ويستخدم مستوبات إنجاز الطلاب للحكم على الجودة التعليمية للجامعة، وكذلك فإنـه يستخدم مقاييس عديدة لسياسـات القبول، ويؤكد المجلس على الوظائف الأكاديمية للجامعات وفى لهـ نفس الوقت فإنـه يتبنى مدخل إدارة الجودة لفحص أنثطة الطلاب وتقويمهم مـع

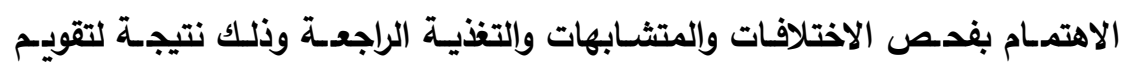
الطـلاب. ويركـز المجلس علـى الفلسـفة والهـــف مـن الخطط والبـرامج الدراسـية وخصائصها الرئيسة والمتطلبات المستقبلية لتطويرها، وكذلك نشر هذه الاهتمامـات فى صـورة خطوط ومحاور عامـة على المستوى القومي ووضـع توصيات لكيفيـة التطبيق والالتزام بها، وبالتالى فإن هذا المجلس يتيح المنافسـة بين الجامعـات، وبعضها البعض من خلال تقارير كفاءة الأداء التعليمى التى يقدمها. ب- الجهات الا|خلية:

يتم القياس المقارن بناءً على الوثائق والبيانات التى تقوم الجامعة بإعدادها، ولكى

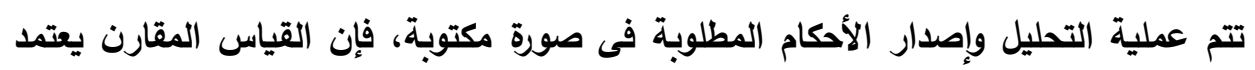
على أدوات عديدة كالاستبيانات، والمقابلات الثخصية، وإستطلاع رأى الطلاب وأعضاء هيئات التدريس؛ وذلك لتجميع أكبر قر من البيانات عن الجانب المراد قياسده، وتتمثل الجهات

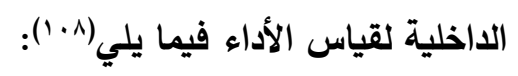

• مجلس الجامعة: لمجلس الجامعة أدواراً مختلفة فى قياس الأداء، من أهمها ضمان انفاق الميزانية المخصصة للجامعة فى أغراضها وبما يتفق مع القانون وأهداف الجامعة، وضمان سلامة التظظيمات الفعالة، والضبط الاقتصادي من خلال الإدارة الفعالة لموارد الجامعة، وتلزم الإثارة في هذا الموضع إلى أن الجامعة لها مجالس

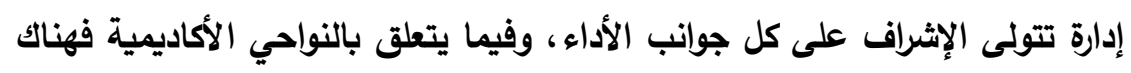

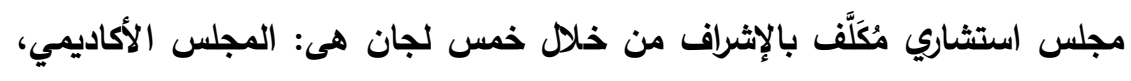
المجلس الطلابي، مجلس الاراسات الخارجية، مجلس اختبارات المدرسة ودخول الجامعة، وتسهم هذه الجهات فى القياس المقارن من خلال مناقثتها لكل ما يتعلق بالجامعة وإصدار ما يلزم من قرارات لتنفيذها. 
مجلة كلية التربية بالإسماعيلية - العدد الرابع والأربعون - مايو 9 م

• مجلس الكلية: ويسهم هذا المجلس في قياس الأداء المقارن من خلال مهامه ومسؤولياته عن تسيير أمور الكلية واقتراح أي أمور تتعلق بالأقسام العلمية، على فئ اعتبار أن العميد عضو فى المجلس الأكاديمي ومجلس الجامعة ويرأس مجالس

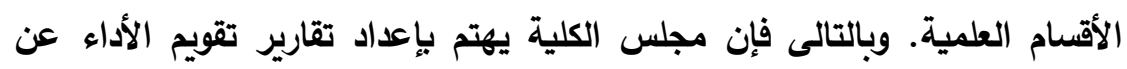
الكلية وأقسامها مما يحقق التقييم الذاتي للأداء، وفى نفس الوقت يسهم في القياس المقارن مع الجامعات والمؤسسات الجامعية المناظرة في نوع العمليات والأنثطة. • مجلس القسم: يقرر مجلس القسم سياسة القبول وشروطها ومتطلباتها الخاصة الواجب توافرها فى الطلاب الجدد الراغبين فى الاتحاق بهذا القسم، حيث يوجد بكل

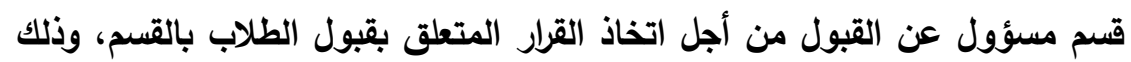
وفقاً للأماكن الخالية وطبقاً للشروط والمتطلبات الخاصة التى يثترطها القسم لهم لهن للالحاق به، ويلاحظ أن الشروط والمتطلبات الخاصة للقسم العلمي الواحد تختلف من قسم لآخر، ويسهم رؤساء الأقسام فى قياس الأداء من خلال اختصاصاتهم ومسؤولياتهم عن الاستثمار فى الموارد والتطبيق الناجح لاستراتيجيات وخطط العمل ومتابعته ووضع محتويات الخطط والبرامج الدراسية والاهتمام بأساليب تقويم الطلاب. • مركز تطوير التعليم: وهو مركز ملحق بالجامعة، ويسهم في تقييم الأداء والقياس المقارن، من خلال اهتمامه بتقييم الخطط والبرامج الدراسية بالأقسام المختلفة بالجامعة كل عام وذلك لتحقيق الانتفاع الكامل من التسهيلات التعليمية المتاحة للجامعة من خلال ارتباط الجامعة بروابط مهنية وتكنولوجية، ودراسة سياسات القبول وأثرها فى أداء الطلاب، والاهتمام بنتائج تقويم الطلاب واستخدامها كتغذية راجعة لتطوير مقومات الأداء التعليمى. ثانياً: عمليات القياس المقارن لتقيم الأداء بجامعة غرب استراليا: وتتمثل أهم هذه العمليات فيما يلي: ا - تخطيط القياس المقارن لتقييم الأداء الجامعي: تـتم عمليـة القيـاس المقـارن في الجامعـة بواسـطة الجامعـة نفسـها، عـلاوة على

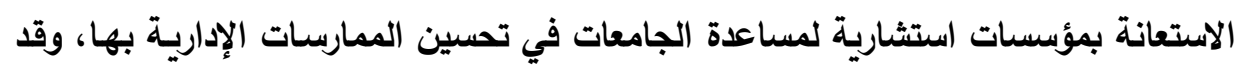

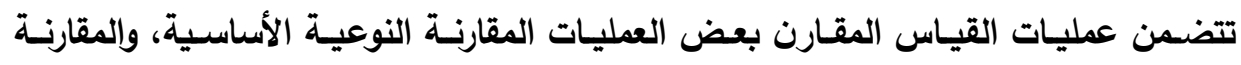

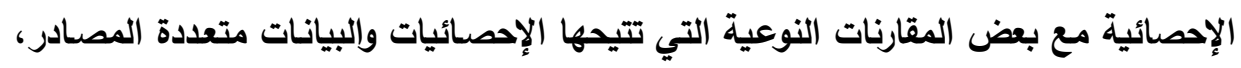


بدائل مقترحة لتطوير منظومة تقييم أداء الجامعات --- د/ محمد ابراهيم عبد العزيز خاطر

كمـا يتم تحديـ أي الممارسـات التربويـة والأكاديميـة أقل تكلفـة عن مثيلاتها في الجامعات الأخرى ذات الأداء المتميز.

ويتم توجيه القياس المقارن بالجامعة نحو اختيار وتطوير وسـائل المنافسـة وتحديد مصادر الأخطاء المحتملة وتطوير الأداء التعليمى للجامعة، وذلك من خلاله (9. 1):

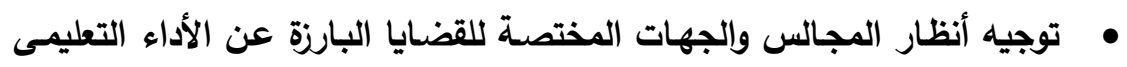
لاجامعة. • الإثبـات الرســـى لمؤشـرات الأداء المشـتركة، والمؤشـرات التـى تصـلح لتحقيـق فعالية الأداء التعليمى للجامعة. • تقييم عمليـات التطوير لمقومـات الأداء التعليمى للجامعـة وتقديم تقـارير عن الأداء التعليمى للجامعة، وذلك لتوكيد الجودة التعليمية، وتقديم معلومات تفيد

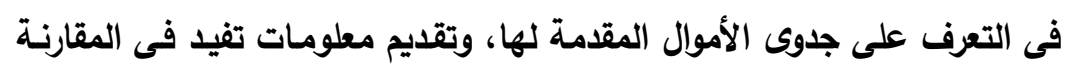
مع الجامعات الأخرى. • تشيط وتحفيز الاتجاه نحو تجويد التعليم الجامعى ومقوماته المختلفة.

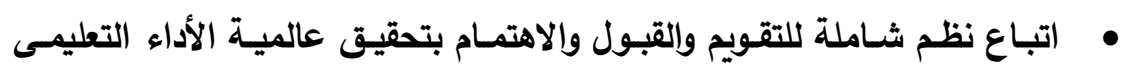
للجامعة.

• وضع إطار عمل منظم للأداء والتوجيه الأكاديمي وإتسامه بالثمول والتوازن. • جودة المكتبة وإلتسهيلات التكنولوجية مع جودة استخدام الموارد. وبناءً على ذلك فإن التخطيط للقياس المقارن يرتكز على التحليل المستمر للبيانات التي يتم جمعها حول فعاليات المؤسسة الجامعية ومخرجاتها والمجالات التي تحتاج إلى يلى التحسين، علاوة على الالتزام بعمليات القياس المقارن بالأفضل وتنفيذ آلياته، وتحديد

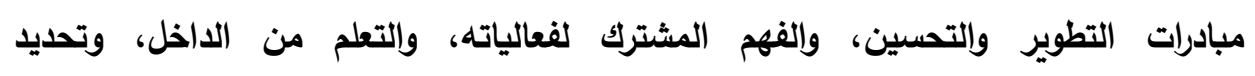

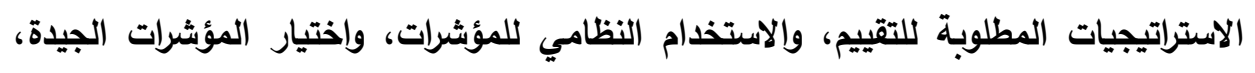
وضمان جودة البيانات، والتنسيق والتكامل. r - تتظيم القياس المقارن لتقييم الأداء الجامعي: تتضمن عمليات القياس المقارن عديد من المجالات منها: الميزانيات المخصصة للتعليم

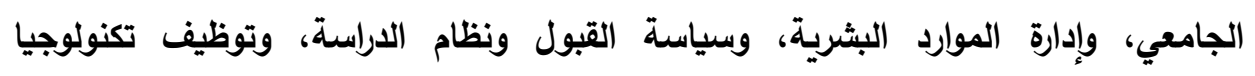

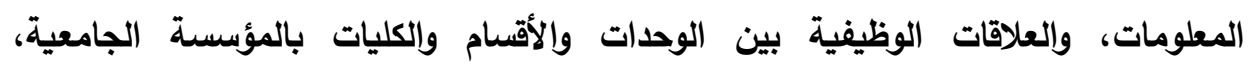

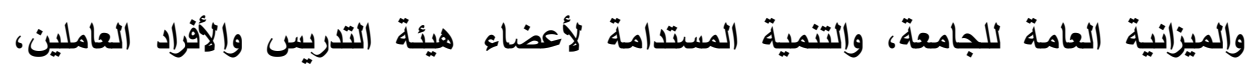


مجلة كلية التربية بالإسماعيلية - العدد الرابع والأربعون - مايو 9 ا ب r

والتسهيلات المؤسسية، والخدمات الصحية المقدمة للطلاب، ومؤشرات الأداء المؤسسي ومعد لاته، وتتمثل أنشطة تنظيم القياس المقارن

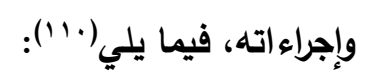

• المشاركة في ورش جمع البيانات التي يتم تصميمها لتحسين فهم المؤسسة الجامعية لعمليات القياس المقارن، ومساعدتها في تفسير البيانات وتحليلها، ومساعدة المؤسسة الجامعية على تنظيم هذه البيانات، وتحليل نتائج عملية المقارنة

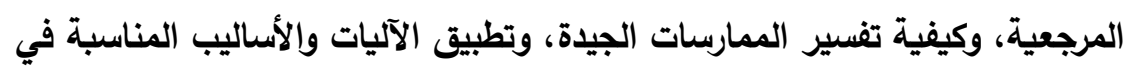
إعادة هندسة العمليات الإدارية والتنظيمية بالمؤسسة الجامعية.

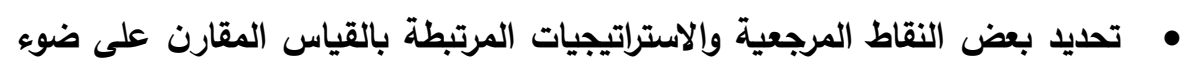

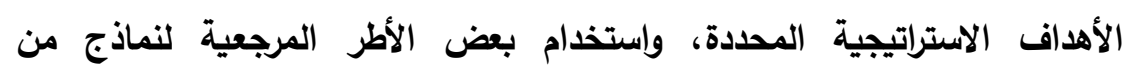
القطاعات المختلفة، وتطوير الهياكل التنظيمية، وكذلك تحديد الممارسات الجيدة في عدة مجالات مختارة، من خلال تفسيرات مختلفة تثكل في مجموعها القياس المقارن لأفضل الممارسات، والتي تتضمن الفهم التام للأساسيات التي تقود إلى فئ فئل النجاح المؤسسي، ويتم تضمين القياس المقارن في عمليات أخرى داخل المؤسسة

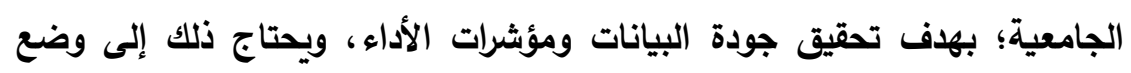
الخطط اللازمة لتوجيه أنثطة المؤسسة الجامعية. • الحصول على الوثائق عن مقومات الأداء التعليمى للجامعة، وعمل مقابلات مع رؤساء الأقسام والبعض من هيئات التدريس والطلاب، حيث يقوم الفريق المكلف هوماتف

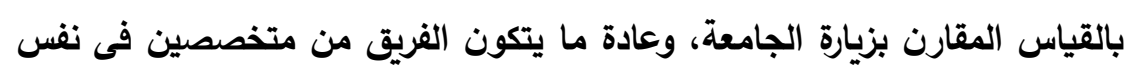

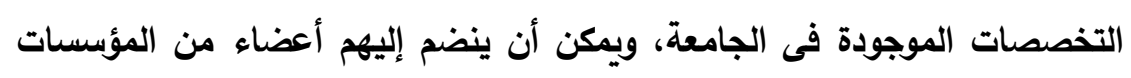
الصناعية أو التجارية، ويقوموا بالزيارة وكتابة التقرير عن كل مقومات الأداء

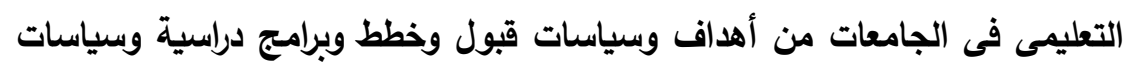

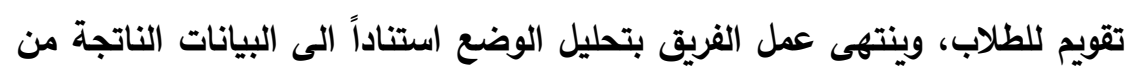
الزيارة تمهيداً لإصدار الأحكام. r- تنفيذ أنشطة القياس المقارن لتقييم الأداء الجامعي: ويتم تنفيذ أنشطة القياس المقارن في مجالات الأداء التالية: أ- المجال الأول: الاور التعليمى والتدربسى للمؤسسات الجامعية: 
بدائل مقترحة لتطوير منظومة تقييم أداء الجامعات --- د/ محمد ابراهيم عبد العزيز خاطر

صُنِّفَت جامعة "غرب استراليا" على أنها الجامعة الأولى في استراليا التي تعتمد على الَّل المقاييس الأساسية الموجودة في دليل أفضل الجامعات، وذلك فيما يتعلق بنتائج المسوح

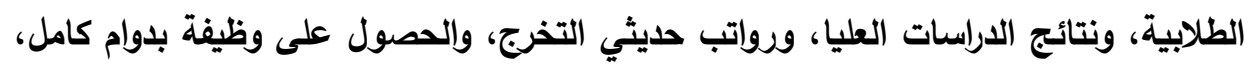

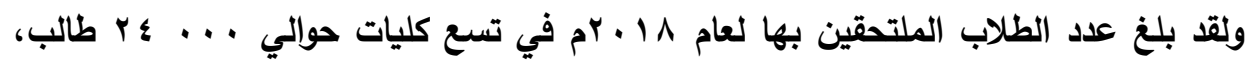

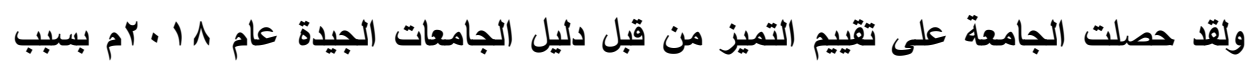
انخفاض نسبة الطلاب إلى المعلمين، مما يُمَكِن الطلاب من الحصول على الدعم التعليمي دئي

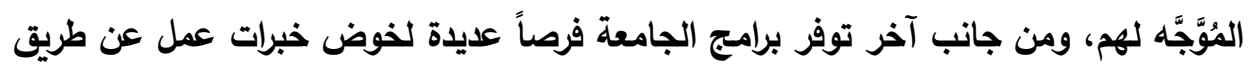
الشراكات الصناعية القوية للجامعة. وتثتهر الجامعة بتقديم خمات مهنية محورية ومُكَثَّفة؛ حيث يستطيع الطلاب الحصول على المعلومات حول التوظيف والمناسبات المهنية وورش العمل، كما يمكن الحصول على

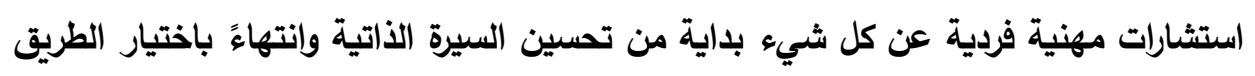

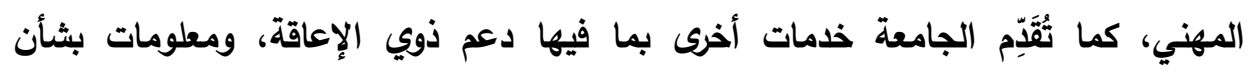

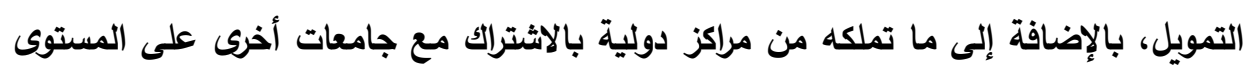
الاولى.

ويتضمن القياس المقارن للدور التعليمى والتدريسى بالجامعة للمجالات الفرعية

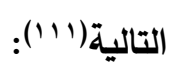

• الأهداف التعليمية: يتم القياس المقارن للأهداف التعليمية في ضوء أمور عديدة

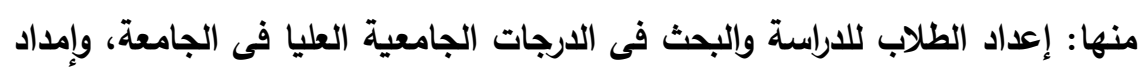
المجتمع بمتطلباته اللازمة من العمالة، وتقديم تدريب متقدم ليس فقط للطلاب ولكن أيضاً للقوى العاملة، والتأكيد على استمرارية تقديم التعليم والبحث العلمي للطلاب،

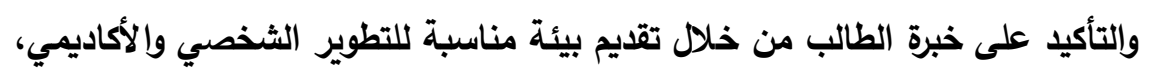
وتطوير المهارات الثخصية والمهنية للطالب. • سياسات القبول: لما كانت الجامعة تهتم بسياسة القبول بمعناها الثامل، فإنها تؤكد على تحقيق تكافؤ الفرص بين الطلاب، كما تهتم بالتميز بين الطلاب بناءً على إجراء

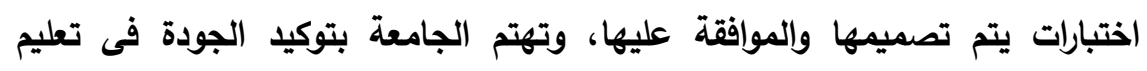
الطلاب، ولذلك فإنها تراعى الاتجاهات والمهارات والقرارات التى لها علاقة بالبرنامج الذى يرغب الطالب الدراسة فيه، كذلك تهتم الجامعة -استناداً الى القياس المقارنبتنوع شروط القبول، فهى تُركّز على الاختبارات التى تهتم بالنواحي النظرية والعملية 
مجلة كلية التربية بالإسماعيلية - العدد الرابع والأربعون - مايو 9 م ـ

معاً، واختبارات القدرات ومقاييس الثخصية والدافعية والمقاييس البذنية والصحة

النفسية والمقابلات الشخصية، وذلك للإلمام بكافة جوانب شخصية الطالب وضمان

فاعليته فى الاراسة الجامعية، علاوة على مراعاة الحيادية والتنوع، وتوافر الجهات المساندة فى رسم وتنفيذ سياسات قبول الطلاب.

• الخطط والبرامج الدراسية: تهتم الجامعة بتحقيق الجودة فى الخطط والبرامج الدراسية، ويتم تطبيق القياس المقارن للتأكيد على عمل اتفاقيات مع المنظمات الخارجية لإتاحة فرص التدربب للطلاب وذلك لتحقيق الاستجابة المستمرة لطلبات المجتمع مما يعنى المواءمة بين الخطط والبرامج الدراسية ومتطلبات التنمية، وإعداد توصيف لمجالات الموضوعات التى يدرسها الطلاب وتحديد ما هو إجباري وما هو اختياري وتحديد متطلبات القبول، وعمل برامج للتوجيه المهني لتثجيع الطلاب على اختيار الخطط والبرامج الدراسية التى تناسبهم وتتفق مع خبراتهم وقدراتهم الذهنية وإبراز مهاراتهم النوعية التى لها علاقة بمجال التخصص، وتمتلك الجامعة نقابة للطلاب تدير أكثر من · ؛ 1 من النوادي، بما يمكن من ممارسة الطلاب للعديد من الأنثطة الاجتماعية والتى تثمل الرحلات البعيدة، المهرجانات، أسواق الطعام وأسبوع الكهرباء .... وغيرها. • تقويم المخرجات التعليمية: يسهم القياس المقارن فيما يتعلق بتقويم الطلاب بالتركيز

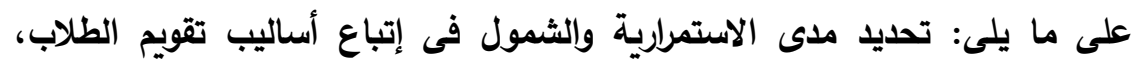
ومدى الاستعانة بممثلين عن بعض الجهات الصناعية والتجارية مع هيئات التهاع التدريس للحكم على أدائهم، علاوة على مدى الاعتماد على التقويم المستمر، ومدي التنوع في سياسات تقويم الطلاب لتثمل اختبارات تحريرية ومقالات ومشروعات عمل الفريق التمادي

$$
\text { والمقابلات والتقارير والاختبارات الإكلينيكية. }
$$

ب- المجال الثانى: الدور البحثى للمؤسسات الجامعية: تُعْتَبَ جامعة "غرب استراليا" من مؤسسات البحث الدولية الرائدة، نظراً لوجود شراكات صناعية قوية مع عديد من المنظمات، وإعطاء طلاب الدراسات العليا تجارب عملية في العالم الحقيقي جنباً إلى جنب مع التعليم النظري القوي، فضلاً عن فرص التواصل المهني القَيّمَة، وبناءً على ذلك يتوجه القياس المقارن في مجال البحث العلمي بالجامعة نحو التأكيد على ما 
بدائل مقترحة لتطوير منظومة تقييم أداء الجامعات --- د/ محمد ابراهيم عبد العزيز خاطر

• امتلاك كل مؤسسة جامعية لخطة استراتيجية لمنظومة البحث العلمي تنبع من رؤيتها ورسالتها، وتوجهاتها المستقبلية ويتوافق مع توجهات الجامعة والمجتمع ككل. • تطبيق المشروعات البحثية التطبيقية الموسعة تلبية لاحتياجات المجتمع ومتطلباته

وتطلعاته المستقبلية.

• كفاية ميزانيات البحث العلمي بكل مؤسسة جامعية لتغطية تكاليف مشروعات البحوث العلمية المتنوعة، بما يتطلبه ذلك من تطبيق آليات محددة لتنمية موارد التمويل الأتي للبحوث العلمية الجامعية. • دعم إسهام الثركات والمؤسسات الخاصة في تمويل مشروعات البحوث العلمية، وتثجيع رجال الأعمال على الاستثمار في البحوث العلمية بصفة مستمرة. • تهيئة الظروف الملانمة لنجاح المخططات البثثية الفردية والمشروعات البحثية الجماعية، وذلك بتوفير التجهيزات اللازمة للعمل، مثل: عقد اجتماع مع الجهات المعاونة، وتوفير متطلبات المخططات البحثية المادية والبشرية، وتحديد مواقع التطبيق. • تسويق نتائج المخططات والمشروعات البحثية، من خلال نشر البحوث العلمية في مجلات متخصصة محلية أو عالمية، إلى جانب تطبيق استراتيجيات التسويق الإكتروني للمخططات والمشروعات البحثية وعوائدها. • تفعيل أدوار مراكز التميز البحثي وحاضنات الأعمال فى الإطارين المحلى والدولي. جـ- المجال الثالث: الاور المجتمعى للمؤسسات الجامعية: تسعى الجامعة إلى خدمة وتنمية المجتمع المحلي من خلال برامج ونشاطات تقدمها الكلية أو الوحدات ذات الطابع الخاص التابعة لها، من أجل الارتقاء بالمجتمع وتنمية بيئته

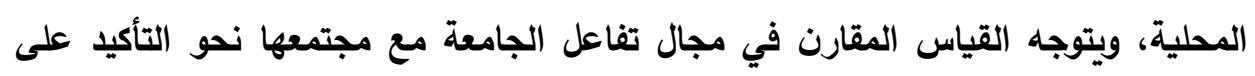

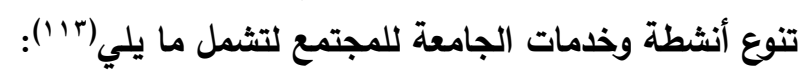
• الأنشة الثقافية: من خلاع الندوات العامة التي تعقد بلداخل الجامعة وخارجها ويشارك فيها أعضاء هيئة التدريس بالكلية والخبراء على المستوى القومي، من خلال المحاضرات واللقاءات والمؤتمرات التي تنظمها الكليات الجامعية لمناقشة القضايا المجتمعية والعمل على تنمية الوعي الجماهيري بها. 
مجلة كلية التربية بالإسماعيلية - العدد الرابع والأربعون - مايو 9 م

• الاستشارات: وهي نشاطات أو خدمات اعتيادية يقدمها أعضاء هيئة التدريس كل في

مجال اختصاصه لمؤسسات المجتمع المحلي الحكومية أو الخاصة، وكذلك لأفراد

المجتمع الذين يشعرون بالحاجة إلى مثل هذه الاستشارات.

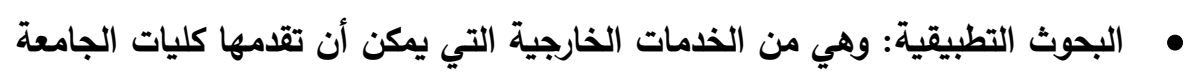

للمجتمع المحلي، حيث توجه الكلية هذه البحوث مباشرة لحل مشكلات المجتمع في

عديد من مجالات وجوانب الحياة الاقتصادية والاجتماعية.

• التدريب والتعليم المستمر: حيث يتم توجيه تلك الخدمات لكل قطاعات المجتمع

وتستجيب لحاجاتهم التعليمية والتدرببية بأساليب مختلفة تناسب ظروفهم الخاصة

وقراتهم وإمكاناتهم.

ثالثًاً: مخرجات القياس المقارن لتقييم الأداء بجامعة غرب استراليا :

تأتى هذه المخرجات فى صورة تقارير تتضمن معلومات وأثكال ومخططات

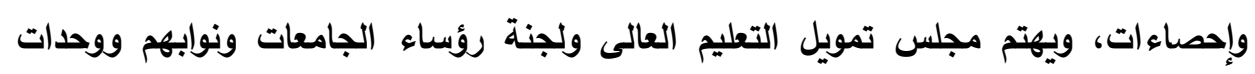

الفحص الأكاديمى بنشر أدلة عن الجامعات، تتضمن نشر تقارير القياس عن كل مقومات

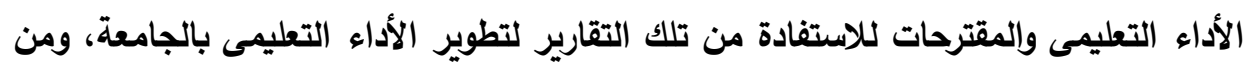

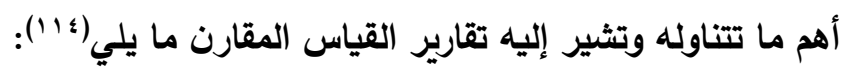

• وصف للعمليات المختلفة لتقويم الأداء التعليمى وعلاقة ذلك بالجودة.

• أن الجامعة تتبنى فلسفة واضحة للتقييم الذاتى ولديها قناعة بالقياس المقارن

الخارجى دون أن يؤثر ذلك على استقلاليتها أو حريتها الأكاديمية.

• تعاون الجامعة مع الجهات الخارجية التى تمارس تقييم الأداء الجامعى.

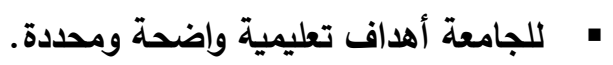

• إن الأداء التعليمى للجامعة يتفق مع ما تحدده المجالس المختلفة المهتمة بالتعليم

الجامعى.

• سياسات القبول المُتَّبَعة، وتعدد القائمين على رسمها وتنفيذها، لأن تمويل للجامعة

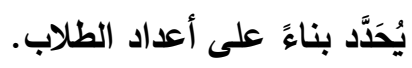

• اهتمام الجامعة بمقاييس ومؤشرات القياس المقارن فى الخطط والبرامج الدراسية وبالتالى فإنها تتيع حرية الاختيار والتنوع فى الخطط والبرامج الدارية وماتية.

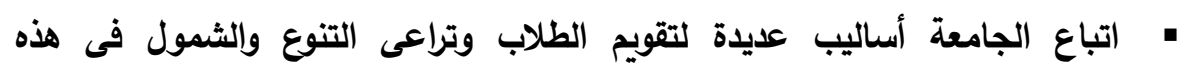


بدائل مقترحة لتطوير منظومة تقييم أداء الجامعات --- د/ محمد ابراهيم عبد العزيز خاطر

المحور الثالث: تحليل مقارن لمنظومة تقييم أداء المؤسسات الجامعية بين

$$
\text { نماذج الجامعات العالمية (جامعات المقارنة): }
$$

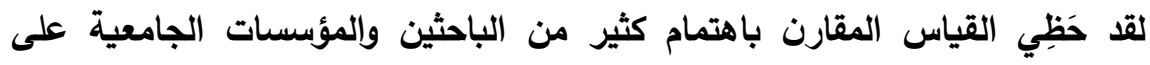

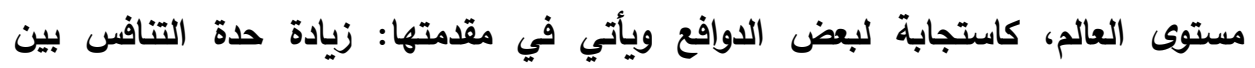

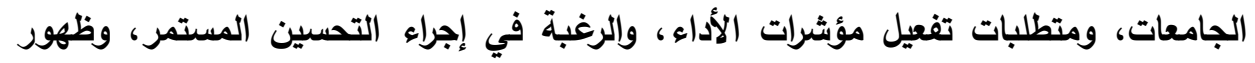

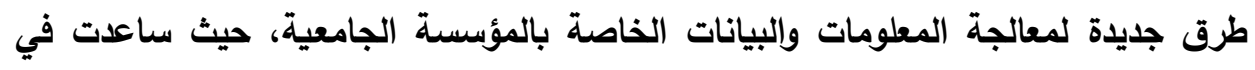

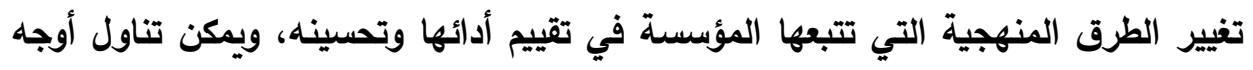

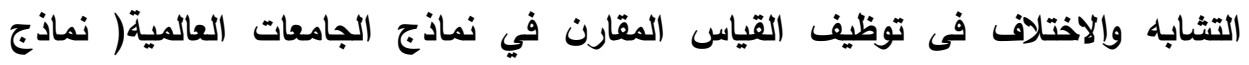

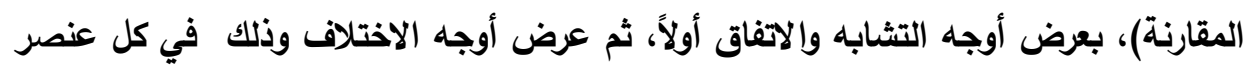

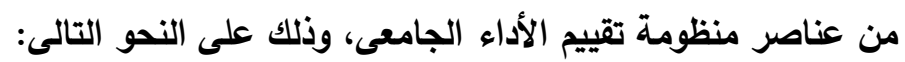

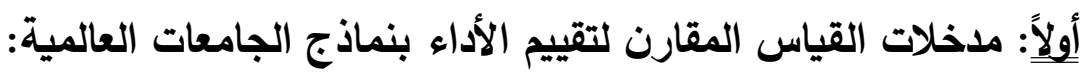
ويسير التحليل المقارن للمدخلات وفقاً للعناصر الفرعية الآتية: 1 - فلسفة القياس المقارن وأهدافه بنماذج الجامعات العالمية: ويتمثل ذلك فيما يلي: أمياس المعارن

أ- أوجه التثابه والاتفاق في فلسفة القياس المقارن وأهدافه بنماذج الجامعات العالمية: - إجها

اتفق نموذجا الجامعات الأمريكية مع نموذجى الجامعات الاسترالية فيما يتعق بفلسفة

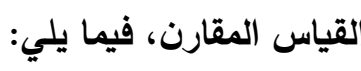
(1) أن فلسفة القياس المقارن بنموذجى الجامعات الأمريكية، ونموذجى الجامعات الاسترالية، قد انطلقت مما يلى: • تفضيل أصحاب العمل خريجي الجامعات التى تخضع لتقييم الأداء الجامعى؛ لتهاء ليضمنوا كفاءة خريجي هذه الجامعات.

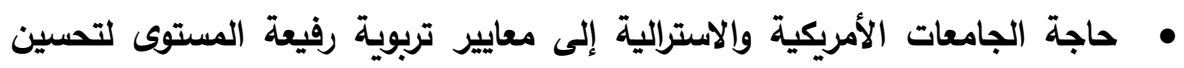

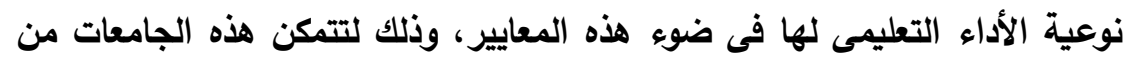

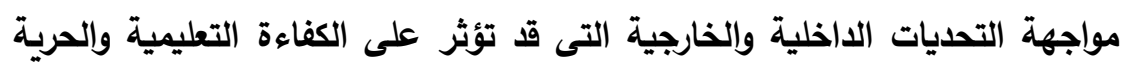

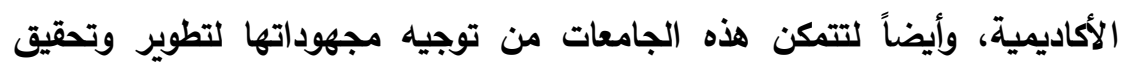
الأهداف التعليمية للمؤسسة الجامعية. 
مجلة كلية التربية بالإسماعيلية - العدد الرابع والأربعون - مايو 9 م ـ

• إن نظام الاعتماد يواجه عيوباً منها تزايد التكلفة الإدارية وتضخم الأمور وسوء

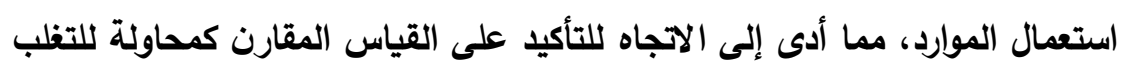

$$
\text { على هذه العيوب، كما أنه يسهم في ضمان استمرارية الاعتماد. }
$$

• تزايد الضغوط لتوسيع خدمات الجامعات، وكذلك تزايد التمويل المقدم للجامعات، كلها

أمور جعلت المسؤولين عن الجامعات يتحملون المسؤولية لتقديم مبررات التمويل وابتكار أنظمة للتقييم وذلك لمراقبة وتقييم فعالية المؤسسة لتحديد إنتاجية أدائها، مثل هذه المبادرات جعلت الحكومات تبحث فى سبل يمكن أن تقيم وتقارن أداء الكليات والجامعات، لتحقيق مستويات الأداء الأفضل.

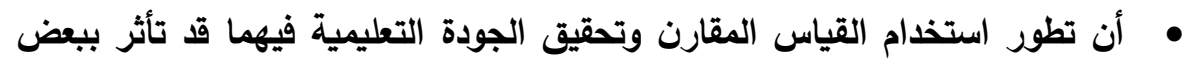
القوى والعوامل الثقافية ومنها العامل السياسي، والعامل الاقتصادي، والعامل الاجتماعي، والعامل الثقافي، كما أن هنائ اتفاقاً واضحاً على أن القياس المقارن

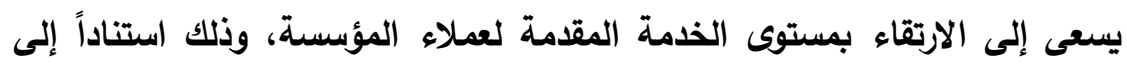
المقارنة بجامعات متميزة، علاوة على تطبيق مجموعة من الأسس والمبادئ، والتي

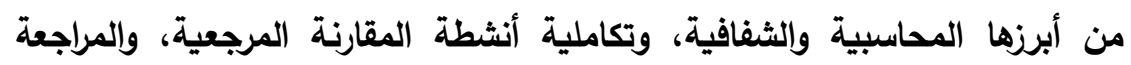

الأكاديمية للممارسات التعليمية والبحثية والخدمية. (r) أن فلسفة القياس المقارن بنموذجى الجامعات الامريكية ونموذجى الجامعات الاسترالية، قد استقرت بثكل تدريجى، وذلك كما يلي: • لم يكُن ظهور القياس المقارن في نماذج الجامعات الأمريكية والاسترالية فُجَائبِياً، بل كان نتيجة مجموعة من السياسات التي بدأت مع منتصف ثمانينات القرن الماضي واستهدفت تطوير التعليم، وحاولت توفير التمويل اللازم للجامعات، وتوفير نوع من التقييم الذاتي داخلها، وتثجيع المؤسسات الجامعية على تحسين إنتاجيتها

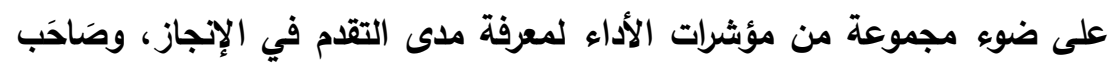
ذلك تطبيق بعض القيم العددية في قياس جودة الجامعات كبديل للإحصائيات

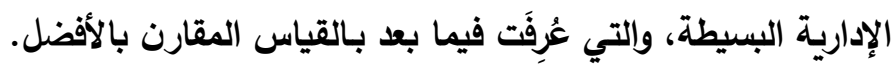

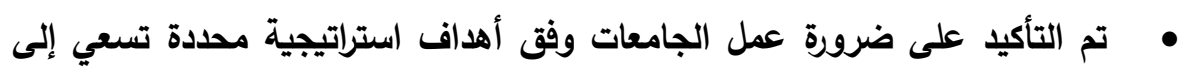
تحقيقها، وأهمية سعيها لتحقيق قيمة مضافة "Value Added"، وتحديد مؤشرات لتقييم أدائها، كما تم وضع مجموعة من المعايير الأكاديمية للتأكيد على جودة البرامج التعليمية التي تقدمها. 
بدائل مقترحة لتطوير منظومة تقييم أداء الجامعات --- د/ محمد ابراهيم عبد العزيز خاطر

• استحدثت النماذج العالمية مراكز للمراجعة الأكاديمية بواسطة الجامعات بهدف تقييم الجودة داخلها، وق استندت طرق التقييم فيها على نموذج للمراجعة المالية،

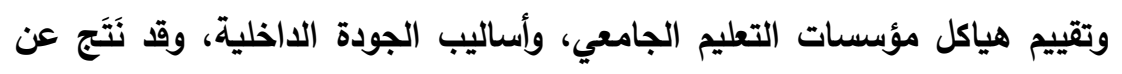
هذا تنفيذ عديد من مشروعات القياس المقارن في مجال تمويل عمليات تطوير

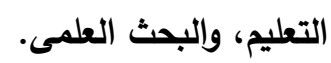
تم تنفيذ آليات القياس المقارن بتطبيق التقويم الذاتي، وتَقَاسُم المعلومات وتبادلها بين الجامعات ومراجعة النظراء، بهدف تحديد وتطوير الممارسات الجيدة، ووضع

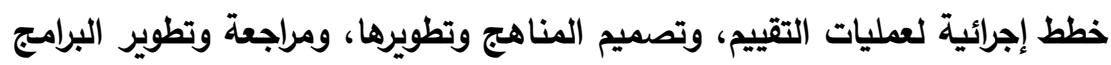
الإدارية، والتوجيه والإرشاد الأكاديمي للطلاب، ووضع المعايير القياسية، ونظم

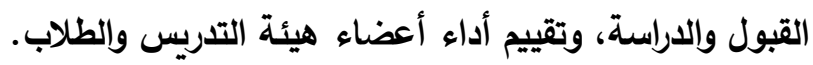
(r) أن هناك اتفاقاً في أهداف القياس المقارن بنموذجى الجامعات الأمريكية ونموذجى

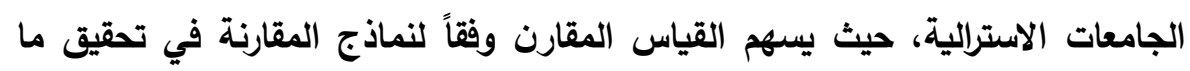
يلى على المستوى الخارجى للمؤسسات الجامعية: حيث تمثلت الأهداف الخاصة بهذا المستوى في: السعي لتحقيق التفاهم الدولي والتعاون العالمي، وتكوين وضع أفضل لفهم المنافسين وتغييرات مؤسسات التعليم العالي، ومراعاة احتياجات أصحاب

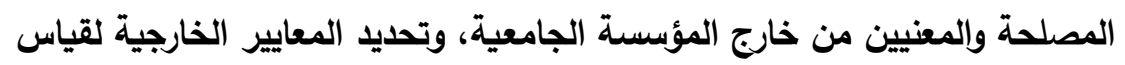
الأنشطة الجامعية، ومن ثم تحديد أين تكمن فرص التطوير والتحسين.

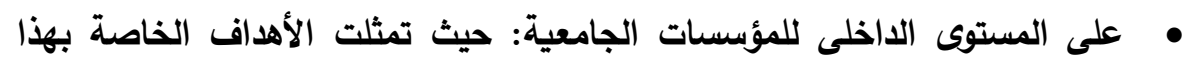
المستوى في: تحديد أهداف فعالة وإجراءات إنتاجية، والعمل على تحقيق التميز، والتفكير المتعمق في المعرفة والابتكار، وتحديد نقاط الضعف ونقاط القوة كأساس ولتهيل للتحسين الذاتي، وذلك من خلال المقارنة بين خدمات المؤسسة ومنتجاتها، وعملياتها مع مؤسسة أخرى ذات أداء متميز، وتوفير الثعور بالحاجة الملحة لتحسين أساليب العمل، مع تضمين أفضل الممارسات في إجراءات العمل، والتطوير التظيمى داخل المؤسسة، حيث يساعدها على التخطيط والتتبؤ بالمستقبل. 
مجلة كلية التربية بالإسماعيلية - العدد الرابع والأربعون - مايو 9 م ـ

ب- أوجه الاختلاف في فلسفة القياس المقارن وأهدافه بنماذج الجامعات

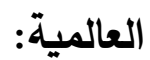

(1) أن هناك اختلافاً في معدل انتشار فلسفة وفكر القياس المقارن بنموذجى الجامعات

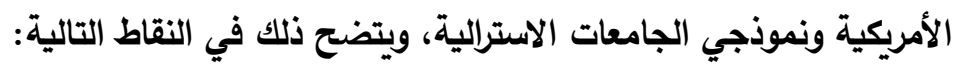

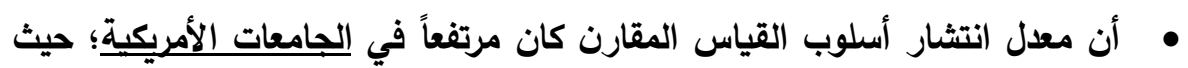

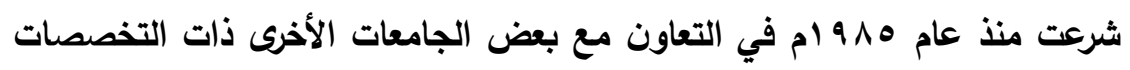

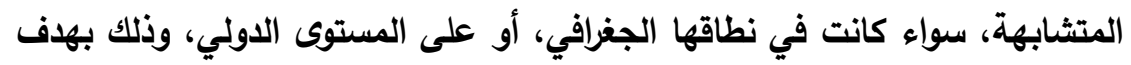

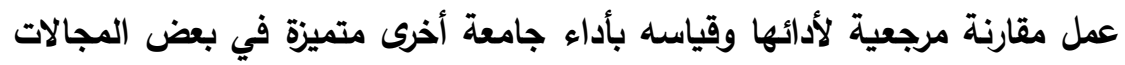

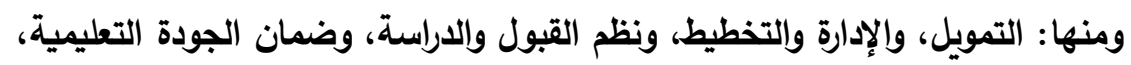

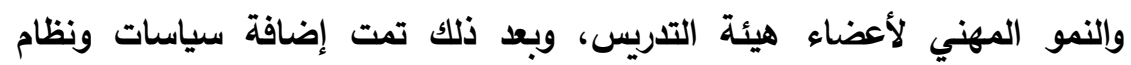

القبول، وتسويق البحوث العلمية، والذدمات الطلابية، والحراك الطلابي وتدويل

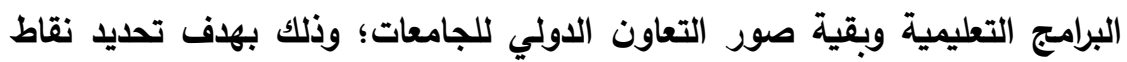

القوة والضعف بها، ومقارنة مؤشرات الأداء ومعدلاته في المؤسسات الجامعية

الثلاثة، وركز هذا المشروع على ثقافة المعايير وتطبيقات جودة التعليم، وبناء

الهيكل الأساسي للمعايير، والاستفادة من خبرات الجامعات الأخرى، لتحقيق التحسين

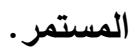

• أن معدل انتثار أسلوب القياس المقارن في الجامعات الاسترالية كان محدوداً في العيات

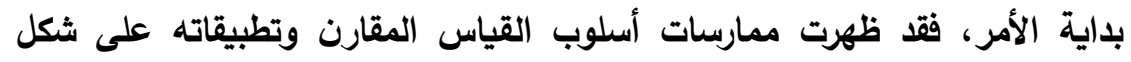

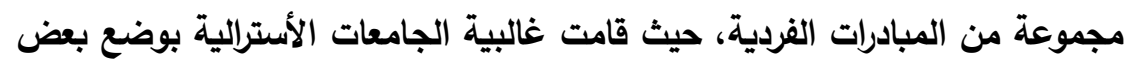

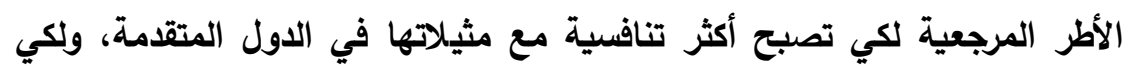

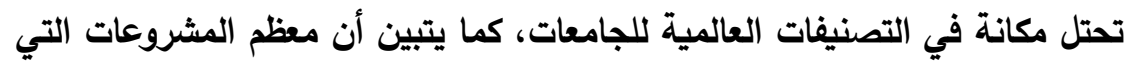

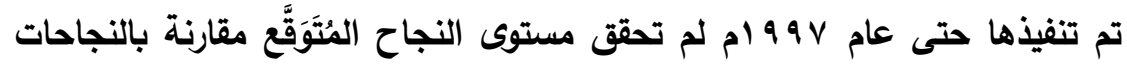

التي حققها القياس المقارن في جامعات الولايات المتحدة الأمريكية.

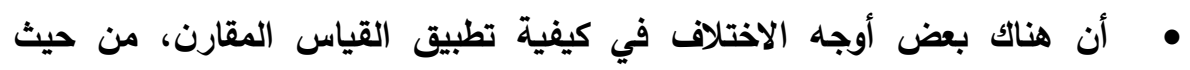

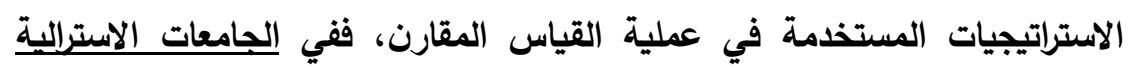

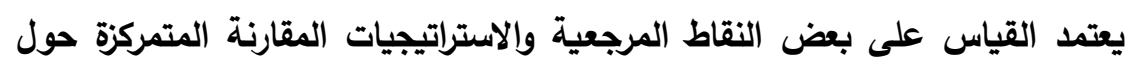

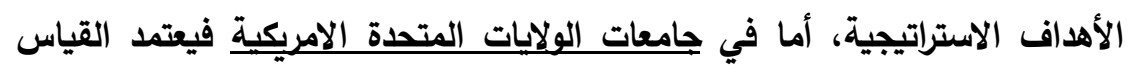


بدائل مقترحة لتطوير منظومة تقييم أداء الجامعات --- د/ محمد ابراهيم عبد العزيز خاطر

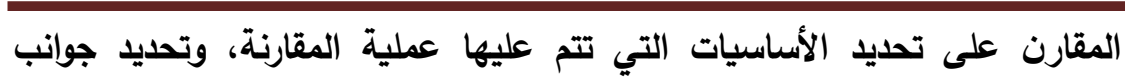

المقارنة، ووضع معايير المقارنة المرجعية، وتطبيق الأطر والمؤشرات المرجعية.

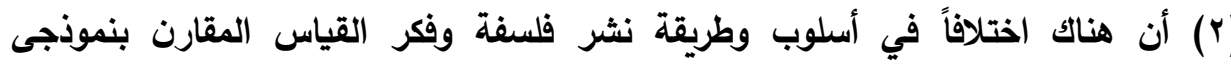

الجامعات الأمريكية ونمونجى الجامعات الاسترالية، وذلك كما يلي:

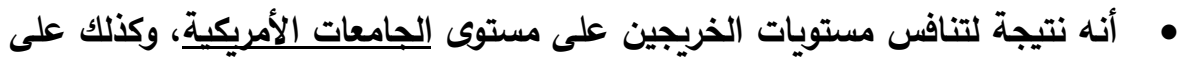

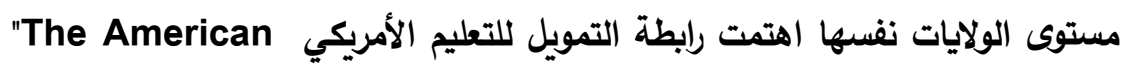
Education Finance Association"

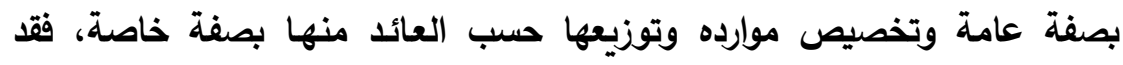

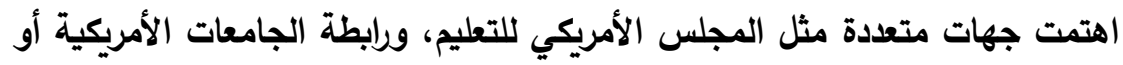

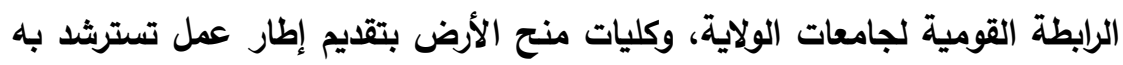

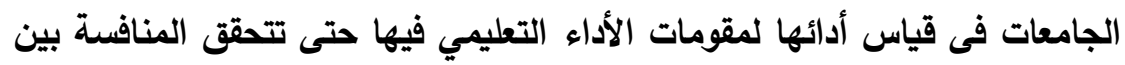

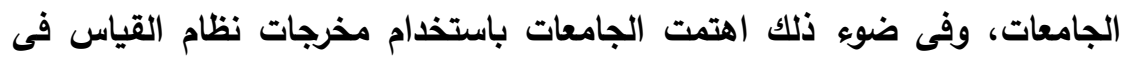

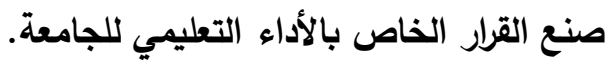

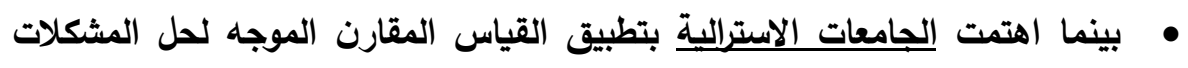
المؤسسية، على اعتبار أن القياس المقارن حيث كان أكثر جدوى عن القياس المئيف

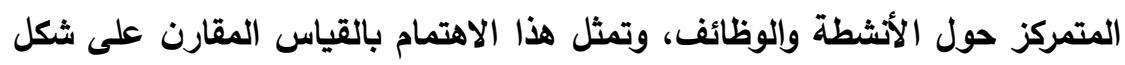

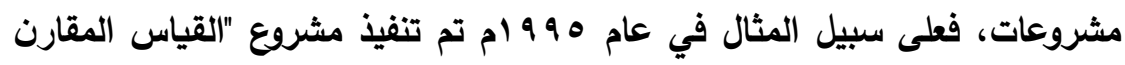

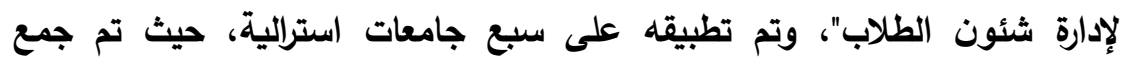
البيانات عن موعد الاتحاق بالجامعة، ومعدل التخرج، ونتائج تقييم الطلاب، وقدات

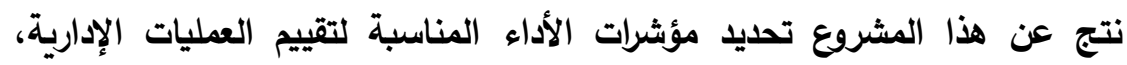

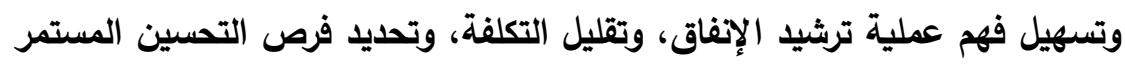

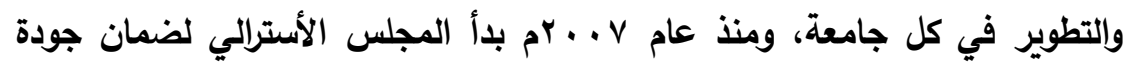

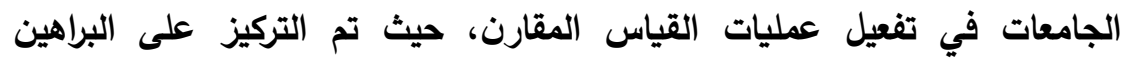

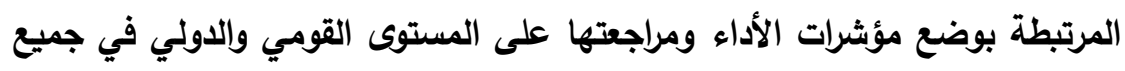

$$
\text { الجامعات الاسترالية(1') - (1'). }
$$

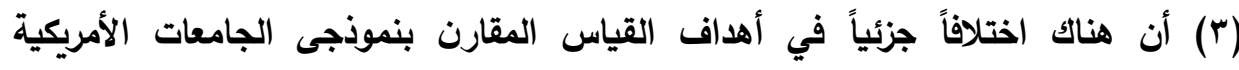
ونموذجى الجامعات الاسترالية، وذلك كما يلي: الهئ 
مجلة كلية التربية بالإسماعيلية - العدد الرابع والأربعون - مايو 9 م

• أن أهداف القياس المقارن بالجامعات الأمريكية تضمنت بشكل واضح إمداد القيادات

الإدارية والأكاديمية ببعض المعايير القياسية الخارجية لتقييم الأنشطة الداخلية،

وتدعيم التزام الجامعات بتحقيق الجودة، وتفعيل عملية التقويم المؤسسي، والتقويم

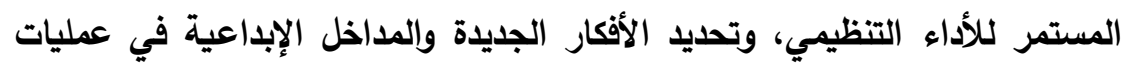
التطوير، وتوفير إطار مرجعي للتغيير، وتطوير الممارسات الجيدة والتطبيقات المتميزة في الجامعة، ومساعدة الجامعات على التحول نحو نموذج المنظمة المتعلمة، والاستفادة من الخبرات والتجارب السابقة في التدريس والتعلم. • بينما ركزت أهداف القياس المقارن بنموذجى الجامعات الاسترالية على تحديد المعايير القياسية لجودة التعليم مع نشر جميع التقارير الخاصة بها متضمنة مراجعة للموضوعات والقضايا التي تطرقت لها عملية التقييم، مثل: القضايا الإدارية، وقضايا التمويل الجامعي، ومقارنة جميع عمليات الاعتماد المتفق عليها في مقابل العمليات التي يستخدمها مجلس اعتماد الجامعات باستراليا. • أن الجامعات الأمريكية تسعى دائماً لتكون مؤسسات للامتياز والتفوق وتستجيب

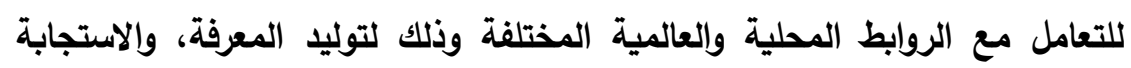
للحاجات الاجتماعية والثقافية فى كل المجتمعات وبذلك فهى تطبق القياس المقارن

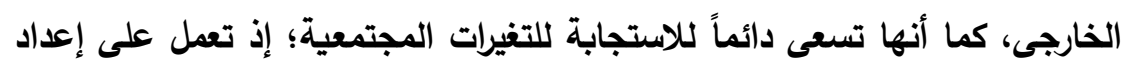
القوى العاملة اللازمة لتحقيق التطور الاجتماعي والاقتصادي، وفى كل ذلك فهي

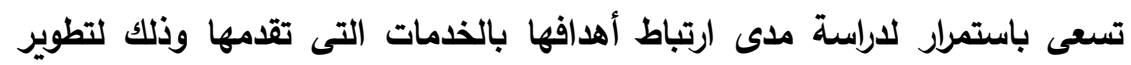
أدائها فى ضوء المعايير التى تعدها الروابط واللجان المختلفة، أى أنها تهتم بتقويم أدائها التعليمى وترجمة نتيجة ذلك إلى أولويات للتطوير . اتجهت عملية القياس المقارن في نموذجى الجامعات الاسترالية إلى القياس المقارن الاخلى، حيث اهتمت بالجوانب الاخلية لعمل المؤسسات الجامعية، ومنها: حل المشكلات المؤسسية، وتقييم الأداء الفردي والمؤسسي ككل، وتحليل الأنثطة والخدمات الأكاديمية، والتسهيلات والخدمات الجامعية، ثم حاولت بعض الجامعات الاسترالية تطبيق القياس المقارن لتصسين جودة العملية التعليمية بها، حيث قامت جامعة "أديلايد Adelaide" في عمل مشروع "التخطيط المؤسسي وجودة الأداء" بهاف التعرف على الممارسة الجيدة في الجامعات الأخرى، والاستفادة منها، والربط

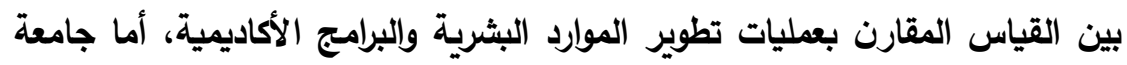
"غرب استراليا" فقد تضمنت القياس المقارن في جميع سياساتها كأداة هامة في صنع 
بدائل مقترحة لتطوير منظومة تقييم أداء الجامعات --- د/ محمد ابراهيم عبد العزيز خاطر

القرارات المرتبطة بجودة التعليم، وتحديد المجالات التي تحتاج إلى التطوير،

$$
\text { والممارسات الجيدة في الجامعة. }
$$

r- الجهات المسؤولة عن القياس المقارن لتقييم الأداء بنماذج الجامعات العالمية:

أ- اتفق نموذجا الجامعات الأمريكية مع نموذجى الجامعات الاسترالية فيما يتعلق بالجهات المسؤولة عن القياس المقارن بمنظومة الأداء الجامعي، على أنها تتمثل في الجهات

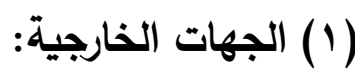

• جالس وهيئات جودة التعليم وروابط الاعتماد والروابط المهنية الموجودة بالمجتمع.

• المجالس الأكاديمية ومجالس تقويم الإنجاز على مستوى كل ولاية من الولايات.

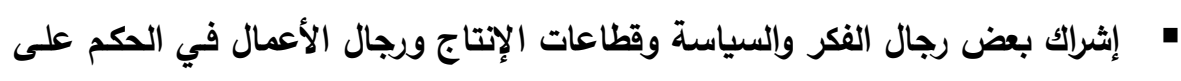

مستويات الأداء وجودة المخرجات التعليمية.

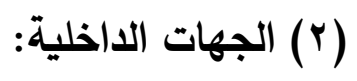

• مجالس الجامعات ومجالس الكليات ومجالس الأقسام، وذلك بعد إدراج مهمة القياس

الأتى والمقارن ضمن اختصاصاتها.

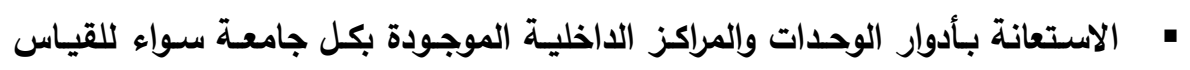

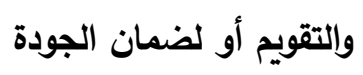

• الاستعانة بآراء بعض الطلاب فيما يقدم لهم من مقومات أداء تعليمى.

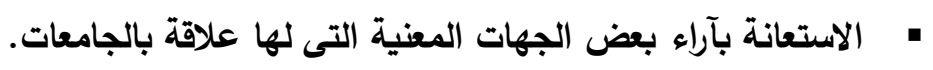

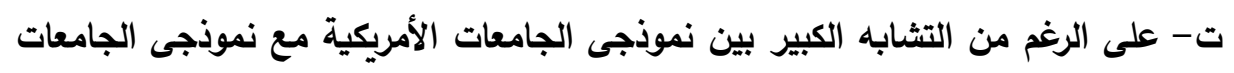

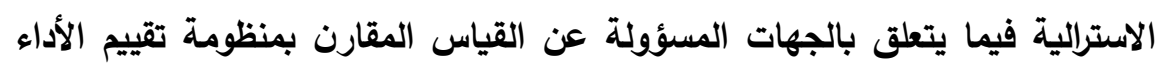
الجامعي، إلا أن الجامعات الاسترالية تميزت بتأكيدها على أن يكون هناك تكامل بين

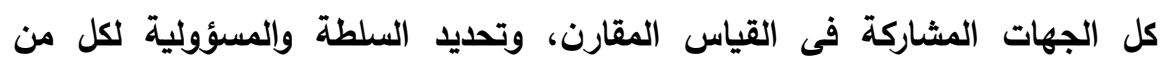
المشاركين فى القياس المقارن، وتفويض السلطة بين الجهات المشاركة في القياس

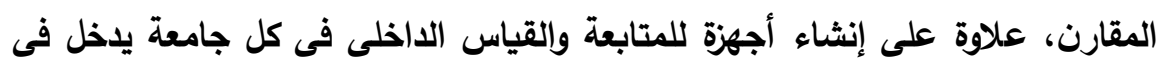
تخصصها قياس مدى ما حققته الجامعة من أداء تعليمى، مع العناية بتقارير المراكز المتخصصة لضمان الجودة وتقويم التعليم بالمؤسسات الجامعية. 
مجلة كلية التربية بالإسماعيلية - العدد الرابع والأربعون - مايو 9 م

ثانياً: عمليات القياس المقارن لتقييم الأداء بنماذج الجامعات العالمية:

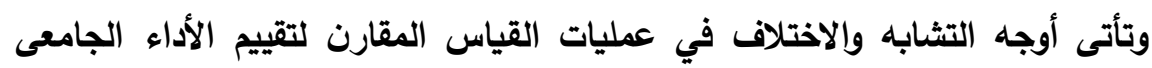
بنماذج الجامعات العالمية وفقاً للعناصر التالية:

ا - تخطيط القياس المقارن لتقييم الأداء الجامعي:

أ- اتفق نموذجا الجامعات الأمريكية مع نموذجى الجامعات الاسترالية فيما يتعلق بالتخطيط

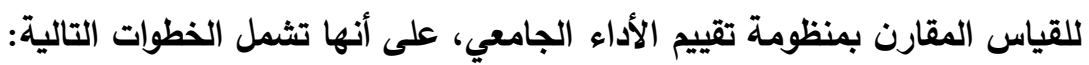

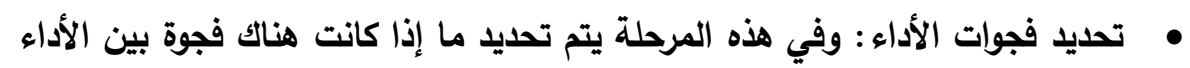

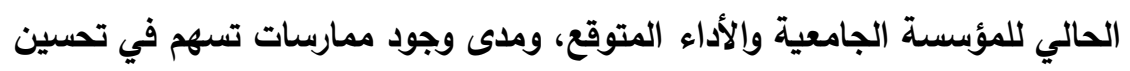

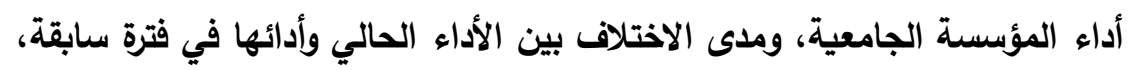

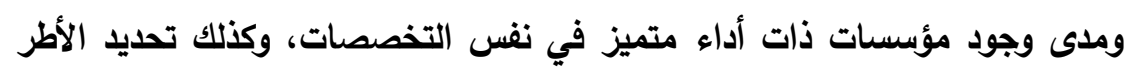

$$
\text { المرجعية التي يمكن استخدامها في التقييم المؤسسي. }
$$

• تحديد جوانب القياس المقارن: ويتم في هذه المرحلة تخطيط العمليات الإدارية

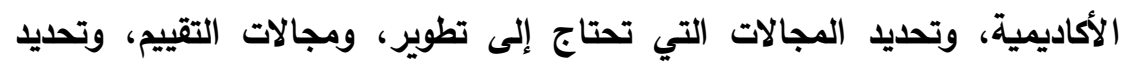

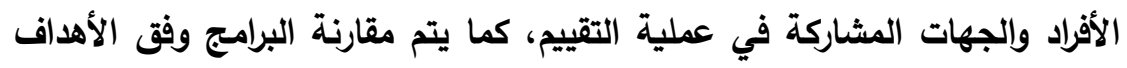
والأغراض المحددة سلفاً، ومراجعة وإعادة تصميم البرامج، والتغذية الزراجعة لها، والتعاون بين النظراء الأكاديميين.

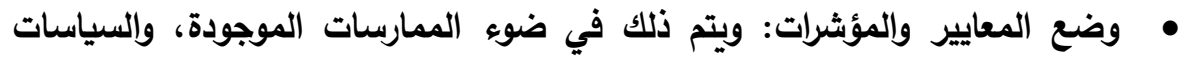
المتفق عليها، وتحديد بعض المعايير والمؤشرات التي يتم على ضوئها تقييم أداء

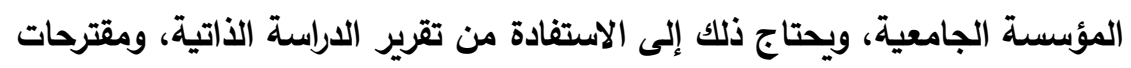

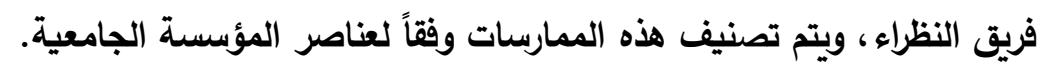

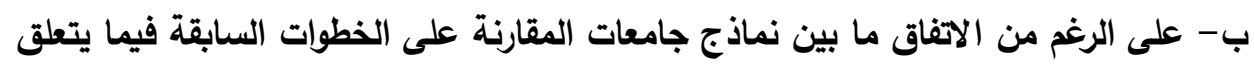

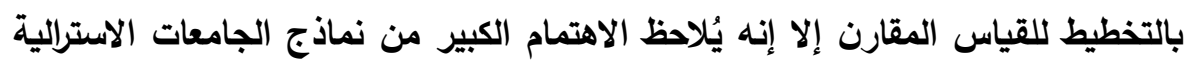

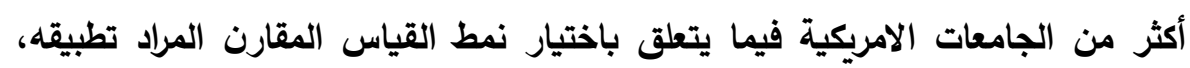

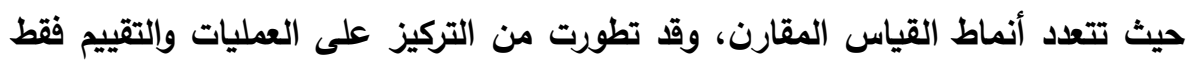

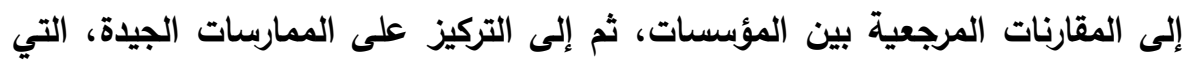

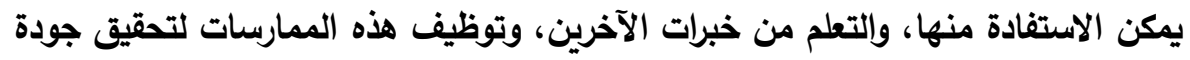

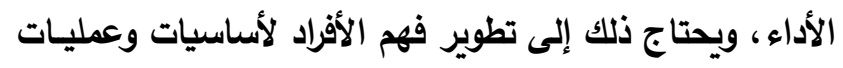


بدائل مقترحة لتطوير منظومة تقييم أداء الجامعات --- د/ محمد ابراهيم عبد العزيز خاطر

القياس المقارن، والتركيز على عمليات التحسين المستمر، وإدارة عمليات التغيير

التظظيمي، وسد الفجوة التنظيمية.

r - تتظيم القياس المقارن لتقييم الأداء الجامعي:

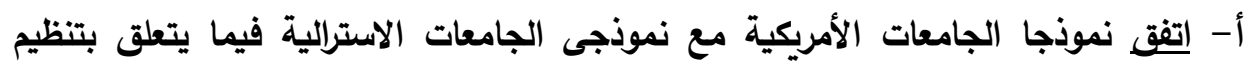

عمليات للقياس المقارن بمنظومة الأداء الجامعي، على أنها تشمل الخطوات التالية:

• الإعداد والتجهيز لأنشطة القياس المقارن "Preparation"، وتحديد المنهجية التي

يتطلب استخدامها وتحديد المشاركين في عملية القياس المقارن.

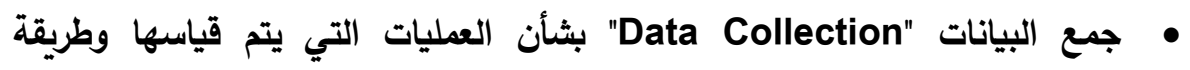

قياسها، وفي هذه المرحلة أيضاً يتم تحديد البيانات التي سيتم جمعها كما يتم تحديد

الوسيلة المناسبة لجمع البيانات.

• تحليل البيانات "Data Analysis" والتحقق من مصداقيتها وتبويبها وتصنيفها،

بثكل يُمَكَّنُ من الاستفادة منها لإجراء عمليات مقارنة الأداء.

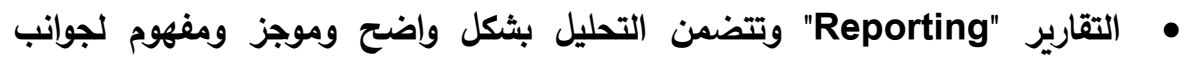

الأداء التى تم قياسها من منظور مقارن.

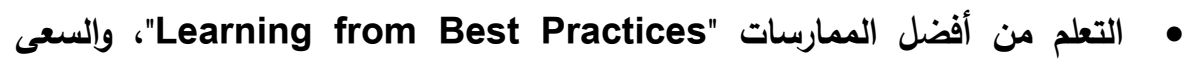

نحو مشاركتها والأخذ بها.

• تفيذ عمليات التحسين "Implementing Improvement" وذلك بطرح خطة

عمل للتغيرات التي تهدف إلى تحقيق التحسين ووضع نقاط التعلم المفيدة وتنفيذها

مستقبلاً.

ب- على الرغم من الاتفاق بين نماذج جامعات المقارنة على الخطوات السابقة فيما يتعلق

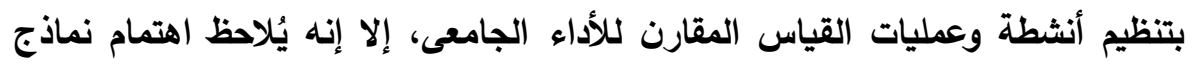
الجامعات الاسترالية أكثر من الجامعات الأمريكية في إضفاء الطابع المؤسسي للتعلم "Institutionalizing Learning" المكتسبة وأن تحسينات الأداء قد تحققت لتكون جزءً لا يتجزأ من المؤسسة الجامعية، ولهي وعليه يمكن إجراء القياس المقارن علي المؤسسة الجامعية ككل أو العمليات التثغيلية أو مستويات المؤسسة المختلفة.

r- تنفيذ أنثطة القياس المقارن لتقييم الأداء الجامعي: ويتمثل تنفيذ أنثطة القياس المقارن للأداء الجامعى في المجالات التالية: 
مجلة كلية التربية بالإسماعيلية - العدد الرابع والأربعون - مايو 9 م ـ

$$
\text { أ- المجال الأول: الاور التعليمى والتدريسى للمؤسسات الجامعية: }
$$

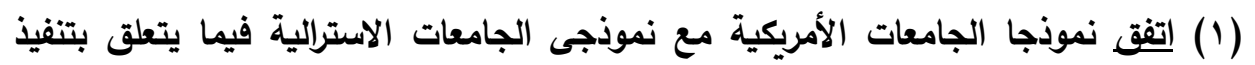

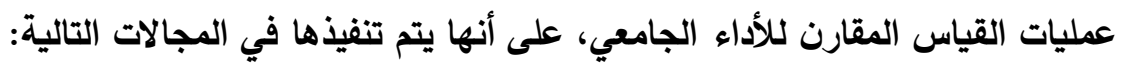

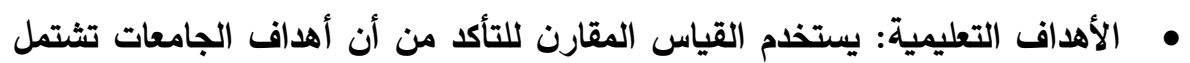

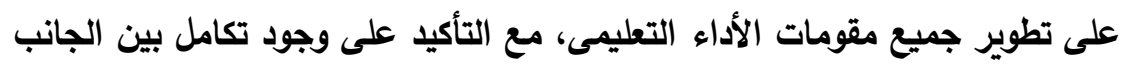

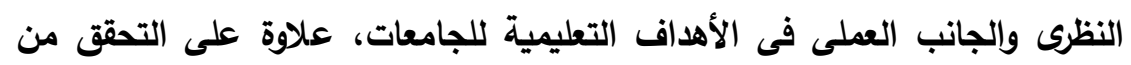

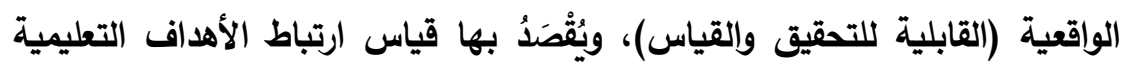
للجامعات بالواقع وقابليتها للتحقيق وكنلك قابليتها للقياس.

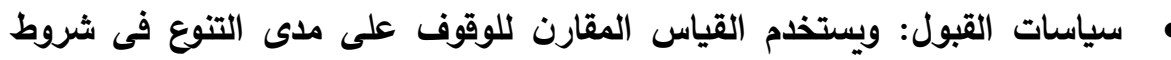

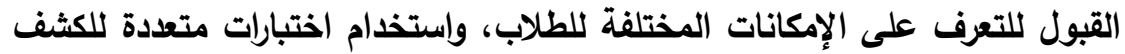

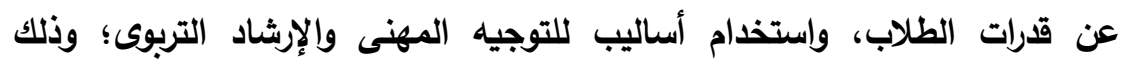

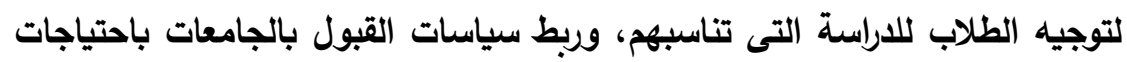
المجتمع فى كافة القطاعات فى السنوات القادمة وكذلك بالموارد الطبيعية.

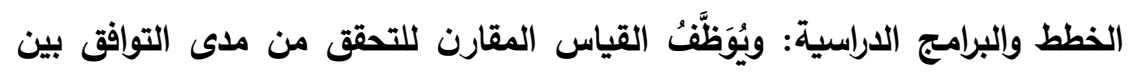
الخطط والبرامج الدراسية الجامعية وبين متطلبات التنمية، ومدى التكامل بين الخطط

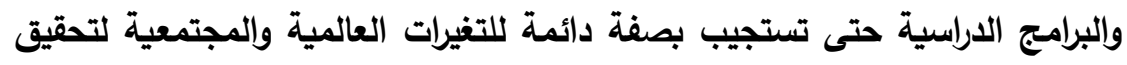
أهدافها، ومستوى التنوع وحرية الاختيار فى الخطط والبرامج الدارسية وفقاً لميول

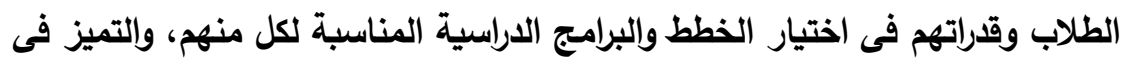

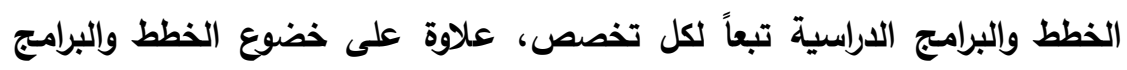
الدراسية للتطوير والمراجعة بصفة دورية كجزء من التخطيط العام بالجامعة لزيادة

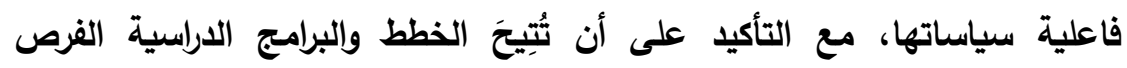

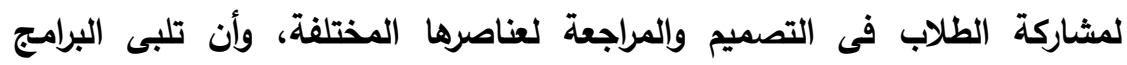

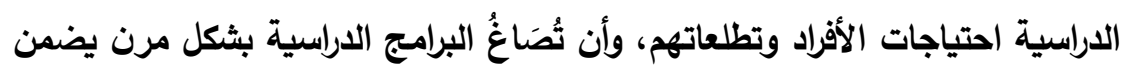

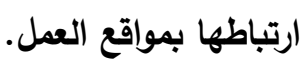

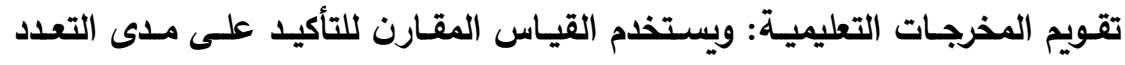

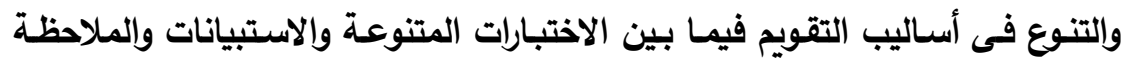

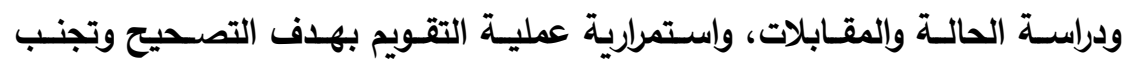

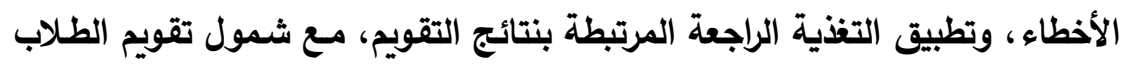


بدائل مقترحة لتطوير منظومة تقييم أداء الجامعات --- د/ محمد ابراهيم عبد العزيز خاطر

لكي يتضـمن النـواحى التحصيلية والوجدانيـة والمهاريـة، فضـلاً عن تَكَامُـل أسـاليب

التقويم واتسامها بالموضوعية.

(Y) على الرغم من الاتفاق بين نماذج الجامعات العالمية على الخطوات السابقة فيما يتعلق

بالمجال التعليمى والتدريسى بالمؤسسات الجامعية إلا إنه يُلاحَظ ما يلي: لئي

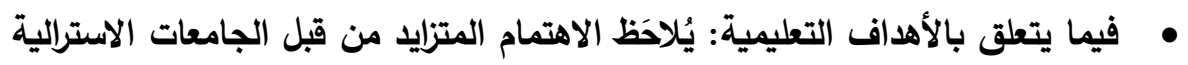

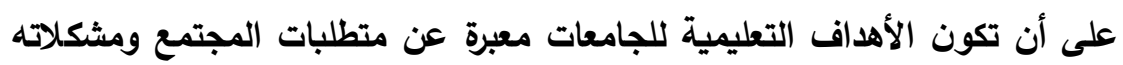

$$
\text { والتحديات التى تحيط به. }
$$

• فيما يتعلق بسياسات القبول: يُلاحَظ اهتمام الجامعات الأمريكية باتباع الديمقراطية

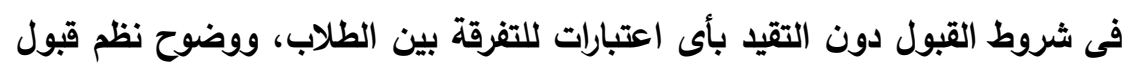

الطلاب وإعلانها، وعدم وجود امتيازات عنصرية أو طائفية أو مهنية، وإذا وُجِد

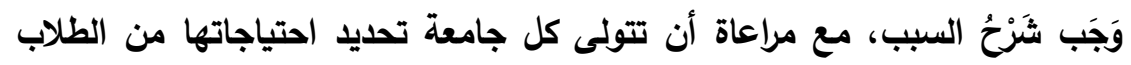

حسب الطاقة الاستيعابية لكلياتها وأقسامها المختلفة.

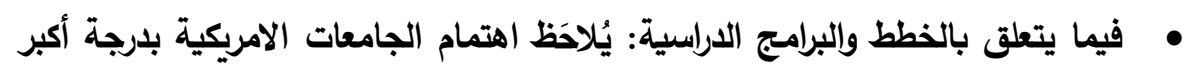

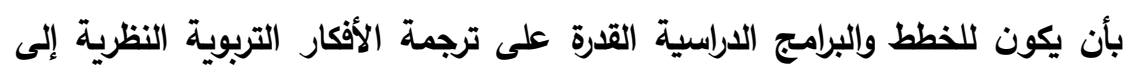
ممارسات أدائية أو إجرائية يمكن ملاحظتها فى سلوك المتعلمين حتى يتحقق معيار

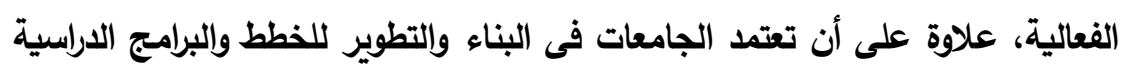
على مواصفات واضحة للخريج، مع تأكيا التوجيه المستقبلى فى الخطط والبرامج الاراسية، وأن يتوافر وصف تفصيلي للمقررات الدراسية لكل قسم علمى داخل كليات

الجامعة.

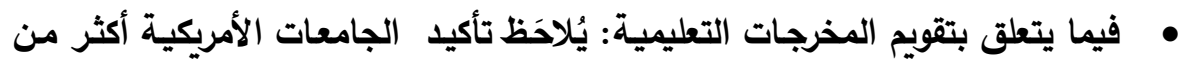

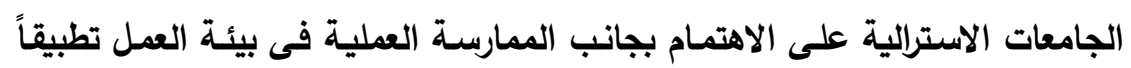

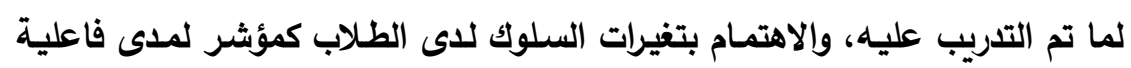

الأداء التعليمى للجامعة.

ب- المجال الثانى: الدور البحثى للمؤسسات الجامعية:

(1) اتفق نموذجا الجامعات الأمريكية مع نموذجى الجامعات الاسترالية فيما يتعلق بالدور

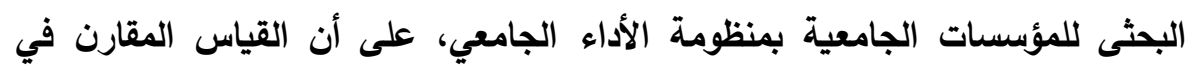

مجال البحث العلمي بالجامعات يتوجه نحو التأكيا على ما يلي:

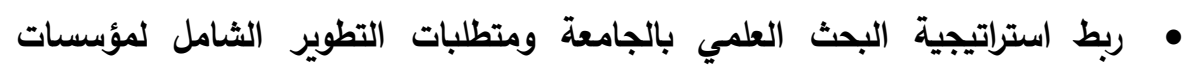


مجلة كلية التربية بالإسماعيلية - العدد الرابع والأربعون - مايو 9 م

المجتمع.

• تطبيق المؤسسات الجامعية للصيغة الاستشارية والمتمثلة في إنشاء بعض المراكز

الاستشارية بكل جامعة، مثل: (مراكز الدراسات والاستشارات الهندسية، ومراكز

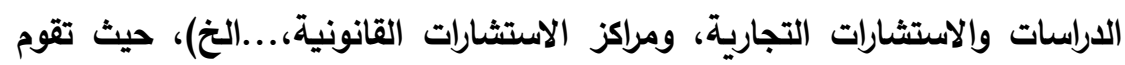

هذه المراكز بتقديم المشورة، وعمل الدراسات العلمية لبعض القطاعات الإنتاجية.

(Y) على الرغم من الاتفاق شبه التام بين نموذجى الجامعات الأمريكية مـع نموذجى الجامعات

الاسترالية فيما يتعلق بتقييم الاور البحثى للمؤسسات الجامعية، إلا إنه يُلاحَظ الاهتمام

من قبل الجامعات الامريكية بتطبيق صيغة المشروعات البحثية، بحيث يمكن للجامعة

تقديم المشروعات البحثية التي يتم تمويلها من جهات ومؤسسات محلية ودولية، التي

يهدف معظمها إلى حل بعض المشاكل البيئية والاقتصادية أو المتعلقة بتحسين الكفاءة

الإنتاجية في بعض المجالات.

ومن ناحية أخرى يُلاحظظ اتجاه الجامعات الاسترالية نحو دعم تمويل البحوث العلمية

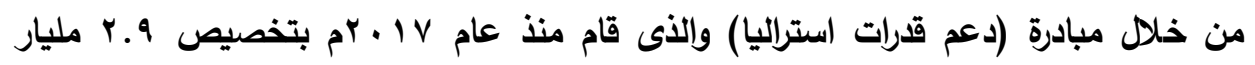

دولار استرالي (كميزانية لخمس سنوات تالية) لتمويل الأبحاث التي من شأنها دعم الابتكار

والإبداع في مجالي الاقتصاد والعلوم، وتستثمر استراليا ما يزيل عن ؛ ـ. مليون دولار

أسترالي لاستقدام باحثين عالميين إليها من خلال نظام زمالة الأبحاث الدارية.

ج- المجال الثالث: الاور المجتمعى للمؤسسات الجامعية:

(1) اتفق نموذجا الجامعات الأمريكية مع نموذجى الجامعات الاسترالية فيما يتعلق بالدور المجتمعى للمؤسسات الجامعية بمنظومة الأداء الجامعي، على أن القياس المقارن في مجال

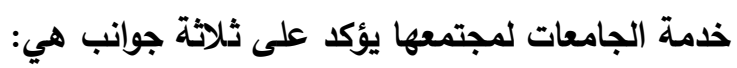
دعم التواصل بين الجامعة والمجتمع، وذلك من خلال: تقديم برامج ريادة الأعمال للطلاب،

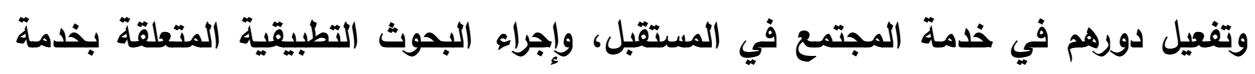
المجتمع ومشكلاته مثل مواجهة المخدرات والجريمة وغيرها، علاوة على تقديم برامج تدربية (اجتماعية وثقافية وتعليمية) لمجتمع الجامعة، والمساهمة في رفع وعي المجتمع تجاه

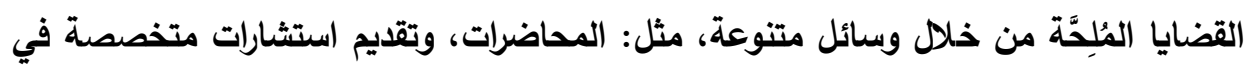
مجالات مختلفة تتعلق بقضايا المجتمع. 
بدائل مقترحة لتطوير منظومة تقييم أداء الجامعات --- د/ محمد ابراهيم عبد العزيز خاطر

• تقديم الخدمات الاجتماعية للمجتمع، وذلك من خلال الاهتمام ببرامج التعليم

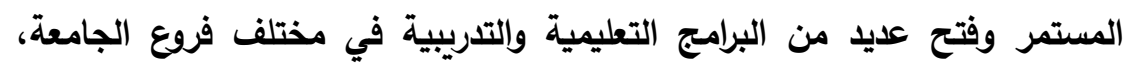
وإنثاء وحدات لنظم المعلومات والاستشعار عن بعد والمساهمة في دعم واتخاذ القرارات المتعلقة بالبيئة والمجتمع. •مساهمة الجامعة في الحد من المشكلات الاجتماعية، وذلك من خلال إقامة فعاليات

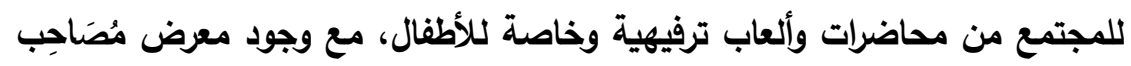

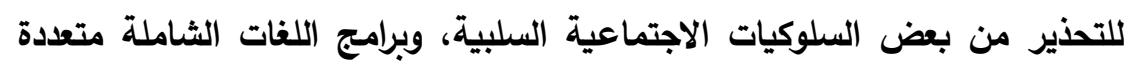
المستويات، علاوة على نشر الوعي البيئي والصحي من خلال القوافل الطبية، والندوات والاتفاقيات، والتعاون مع المستثفيات والمراكز الصحية المختلفة. (Y) على الرغم من الاتفاق بين الجامعات الأمربكية والجامعات الاسترالية في الجوانب الثلاثة

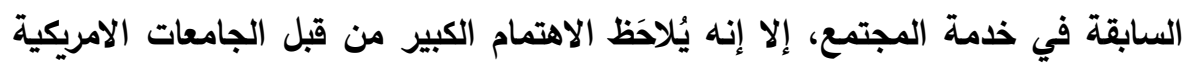

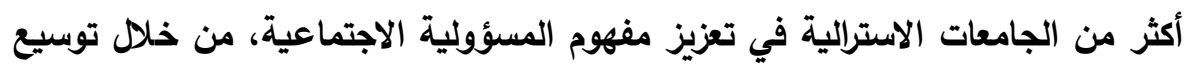

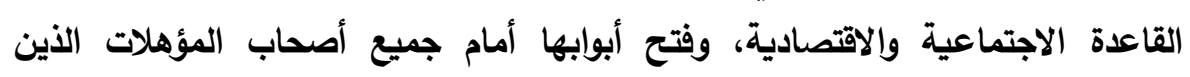

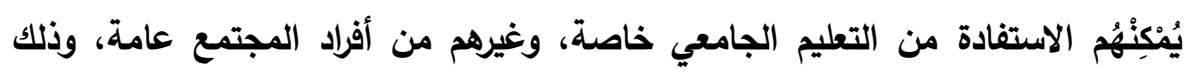

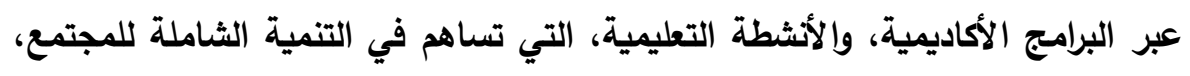

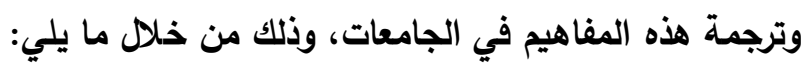

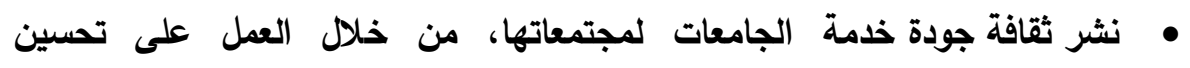
الخدمات التي تقدمها الجامعات للمجتمع، وإيجاد فرص عمل حقيقية، وتوفيرها لأفراد المجتمع، وتوفير المناخ الجامعي الأى يسمح بدرجة من التفاعل الاجتماعي بما ينعكس على معالجة مشكلات المجتمع وقضاياه محلياً وعالمياً. • نثر المفاهيم والقيم المرتبطة بخدمة المجتمع من خلال المؤتمرات والندوات والبرامج المجتمعية والاتفاقيات وورش العمل والحلقات النقاثية التي تعقدها الجامعة في مختلف مؤسسات المجتمع من مدارس ومستثفيات وغرف تجارية وغيرها.

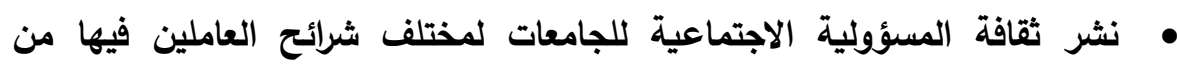
إدارين وأعضاء هيئة التدريس، وطلاب، وإصدار نشرات وتخصيص موقع إلكتروني 
مجلة كلية التربية بالإسماعيلية - العدد الرابع والأربعون - مايو 9 م ـ

• توافق التنمية المستدامة ورفاهية المجتمع، والأخذ في الاعتبار توقعات الأطراف

المعنية، وتكاملها داخل المؤسسات، والاختلاف والتنوع المجتمعي والبيئي والقانوني

والهيكلي، بالإضافة إلى الاختلافات الخاصة بالظروف الاقتصادية.

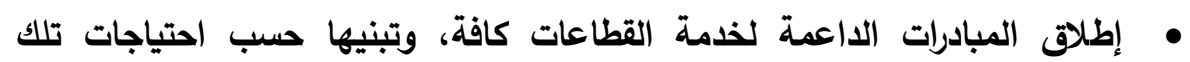

$$
\text { القطاعات وإمكانات المؤسسات. }
$$

• عقد مؤتمرات سنوية يثارك فيه أعضاء هيئة التدريس، وطلبة الدراسات العليا من

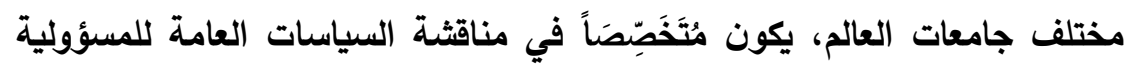
الاجتماعية في التعليم الجامعي، وضمان جودتها، وعرض التجارب الناجحة لتقويمها

وتطويرها، وتضمينها بما يُحَفِز الجامعات على الإبداع والتسابق في هذا الإطار .

ثالثاً: مخرجات القياس المقارن لتقييم الأداء بنماذج الجامعات العالمية:

تتمثل أوجه التثابه والاختلاف في مخرجات القياس المقارن لتقييم الأداء الجامعى،

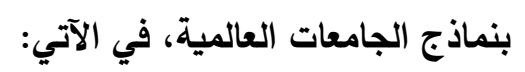

1- اتفق نموذجا الجامعات الأمريكية مع نموذجى الجامعات الاسترالية فيما يتعلق بمخرجات

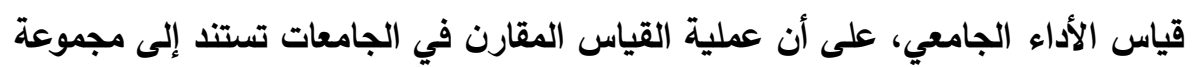

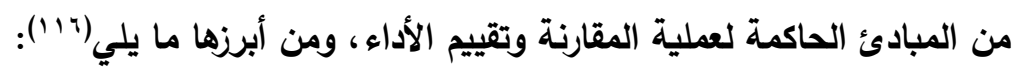

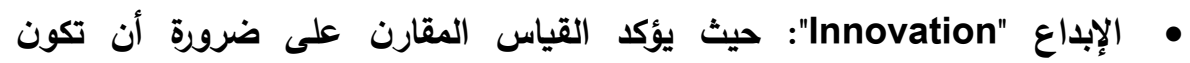
المؤسسات الجامعية مبدعة، لكي تكتسب القدرة على الاستجابة للعوامل الخارجية، وكذلك أهمية الإبداع في التدريس الجامعي والبحث العلمي بما يتفق مع المعايير القياسية العالمية. • التنوع والقابلية للمقارنة "Diversity \& Comparability": حيث إن الإبداع يؤدي إلى التنوع المتزايد في البرامج والمناهج، وخاصة إذا كانت على اتصال بالجامعات الأخرى، وليست معزولة عنها.

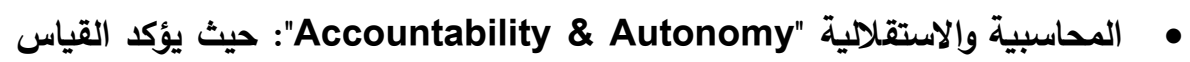
المقارن على الاستقلال الفكري والمالي والإداري في تحقيق جودة التعليم، ويهف تقييم أداء الجامعة إلى حماية قيمها الأساسية، وبخاصة أن تزايد توقعات الجامعة المرتبطة بادارة الميزانيات والتمويل يصاحبه تزايد الاهتمام بتطبيق نظم المحاسبية وآلياتها. 
بدائل مقترحة لتطوير منظومة تقييم أداء الجامعات --- د/ محمد ابراهيم عبد العزيز خاطر

• التركيز على الصالح العام "Focus on Public Good": فالجامعة يمكن النظر

إليها كجهة لتحقيق المصلحة العامة، وذلك من خلا الرؤية الحاكمة لنظام التعليم

الجامعي، ولذا تتطلب فعالية القياس المقارن تحقيق التوازن بين الصالح العام

والصالح الخاص.

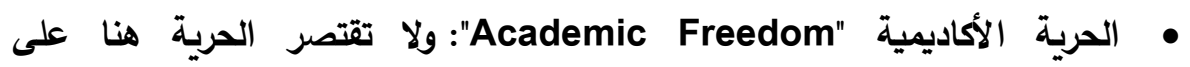

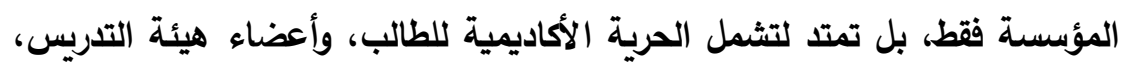
وهي تمثل في مجملها عاملاً مساعداً لتحقيق التعليم المتميز، وتحقيق الأهداف لافئهل

المؤسسية الاستراتيجية.

• الدقة والاتساق "Accuracy \& Consistency": أى تعكس تقارير القياس

المقارن المستويات التعليمية التى تحققت بالفعل، وتستتد إلى دلاتل مادية صادقة،

مع عرض البيانات والمعلومات فى صورة سهلة وبسيطة، وتمكن من الاستدلال على دلى دالى مدى فاعلية المدخلات والعمليات من خلال جودة المخرجات، بما يساعد متخذي مني القرار على الإحاطة بالمتطلبات اللازمة لتطوير منظومة الأداء الجامعي.

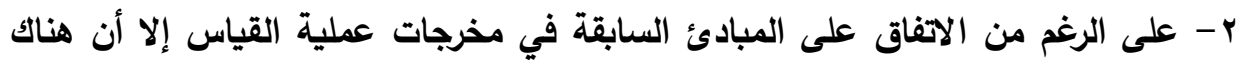

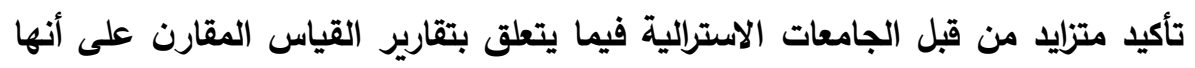
تسهم فى تنويع مصادر التفذية الراجعة مما ينعكس على مدخلات منظومة تقييم الأداء، وأن تثتمل تقارير القياس المقارن على معلومات تسهم فى اتخاذ قرارات لتطوير الأداء التعليمى للجامعات، مع الحث على المنافسة بين الجامعات، مع توكيد الجودة وتحسين

الإتتاجية التعليمية، بما يحقق زيادة كفاءة الجامعات وتحقيق فاعليتها.

المحور الرابع: أوجه الاستفادة من نماذج الجامعات الأمريكية والاسترالية في

القياس المقارن لمنظومة تقييم الأداء الجامعي:

يمكن الاستفادة من نماذج الجامعات الأمريكية والجامعات الاسترالية في توظيفها لأسلوب القياس المقارن لتقييم الأداء الجامعي من خلال استنباط بعض الاروس المستفادة،

والتي تتمثل فيما يلي:

التأكيد على مثاركة جميع أعضاء هيئة التدريس والأفراد العاملين بالمؤسسة

الجامعية، ممن يعرفون الممارسات التربوية والإدارية بها في عمليات القياس

$$
\text { المقارن. }
$$


مجلة كلية التربية بالإسماعيلية - العدد الرابع والأربعون - مايو 9 م ـ

توظيف القياس المقارن كأداة لاعم تطبيق المعايير المناسبة في مقابل الأطر

المرجعية الخارجية، ولإجراء مزيد من عمليات التحسين المستمر .

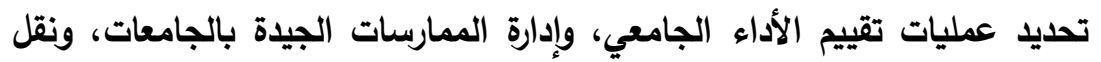

خبرات الجامعات الرائدة والاستفادة من تجاربها، وتطبيق الرؤى والمعايير القياسية

المرتبطة بعمليات تقييم المؤسسات الجامعية في مجالات الأداء المختلفة.

توافر القيادة الجامعية الفعالة، بحيث تكون قادرة على وضع الرؤى والأهداف

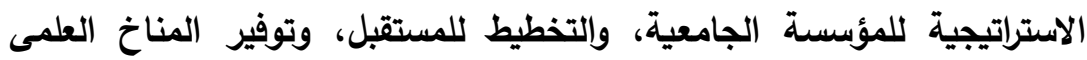

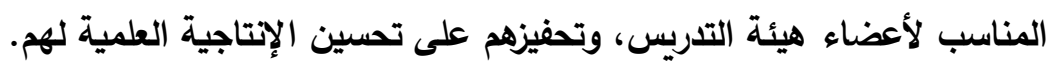

تطوير منظومة البحث العلمى، وذلك من خلا التنمية المتجدة للمهارات البحثية والمعرفية لأعضاء هيئة التدريس، والتوسع فى البعثات الخارجية واللاخلية، والإثراف المشترك، وبناء قاعدة معرفية للبحث العلمى، تتضمن البحوث التى تم نشرها، ووضع مواصفات موحدة ذات صبغة عالمية لإعداد بحوث الماجستير والاكتوراه.

توفير مصادر التمويل البديلة، وذلك من خلاه بناء قاعدة بيانات متكاملة عن

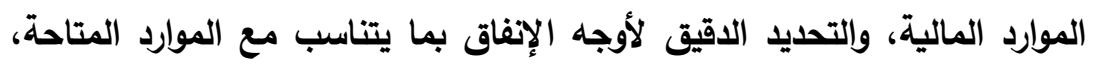
والبحث عن مصادر جديدة لزيادة الموارد المالية بالمؤسسات الجامعية.

تبنى منظور علمى لإزالـة الفواصل الجامدة بين الأقسام العلمية، تحقيقاً لوحدة المعرفة، والتفاعل بين التخصصات. عمل توصيف وظيفى للوظائف المختلفة بالجامعة وفقاً للتخصصات المطلوبة، والتطوير العلمى، بما يتوافق مع احتياجات الكليات والأقسام العلمية بالجامعة. توفير اللوائح والتشريعات التى تثجع على الثراكة بين الجامعة ومؤسسات المجتمع المدنى والمؤسسات الإتتاجية، وتوفير تكنولوجيا المعلومات التى تيسر الانصال بين الكلية ومؤسسات المجتمع. تفعيل مراكز ووحدات ضمان الجودة بالمؤسسات الجامعية، وذلك من خلال وضع العادئ الخطط اللازمة لتنمية ثقافة الجودة، وإنثاء وتوجيه الفرق الجرائ القيادية الأخرى للجودة، وتوفير الموارد المالية والبشرية لتحقيق ضمان الجودة بالجامعات. 
بدائل مقترحة لتطوير منظومة تقييم أداء الجامعات --- د/ محمد ابراهيم عبد العزيز خاطر

هنظومة تقييم أداء الجامعات المصرية (دراسة نظرية):

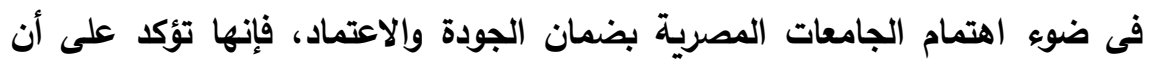

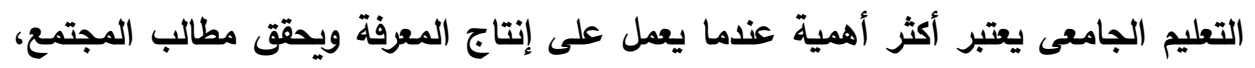

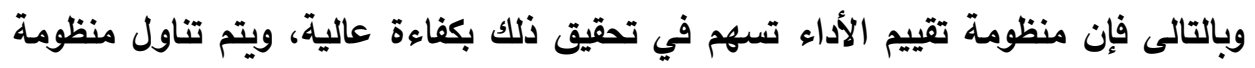
تقييم أداء الجامعات المصرية وفقاً للعناصر التالية: أولاً: مدخلات تقييم أداء الجامعات المصرية:

وتتضمن مدخلات تقييم الأداء بالجامعات المصرية ما ليلي: 1 - فلسفة تقييم أداء الجامعات المصرية وأهدافه:

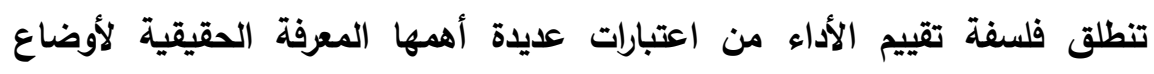

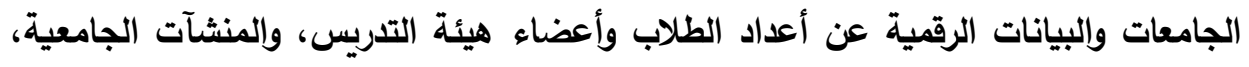

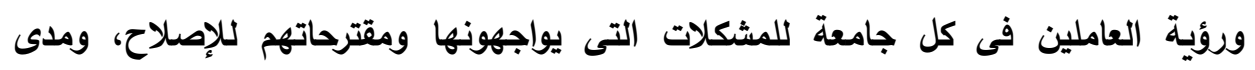

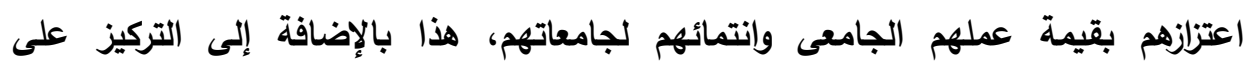
استقلالية الجامعات في والفكر والعلم والإدارة.

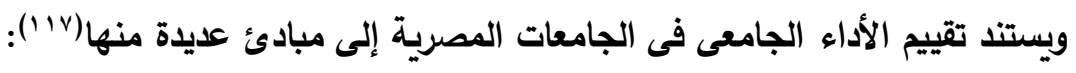

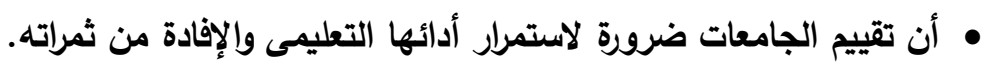

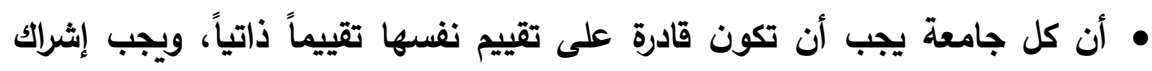

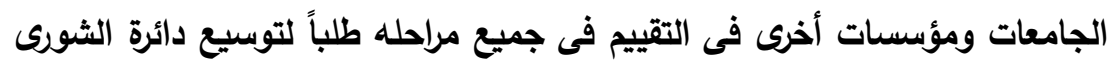
والإفادة من كل جديد ونافع. • إن التقييم هو فحص دقيق لواقع الحال بين المهتمين به، وتحديد مواطن القوة

$$
\text { ومواطن الضعف واقتراحات العلاج. }
$$

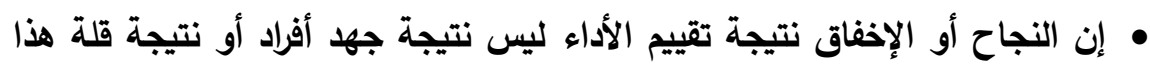

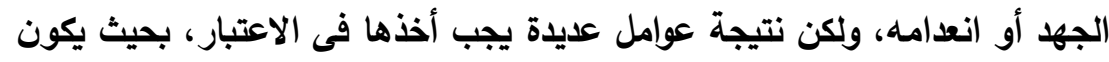

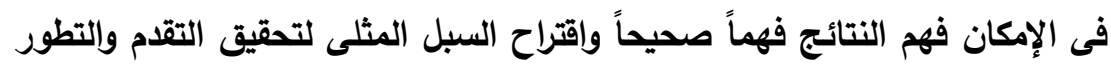

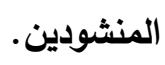
• إن التقييم لابد أن يمتد ليغطى أهداف الجامعة نفسها فيقرر ما إذا كانت ملاثمة

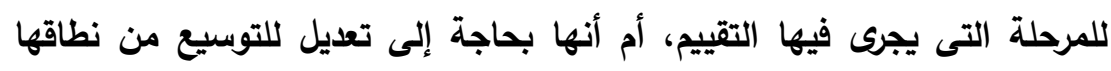

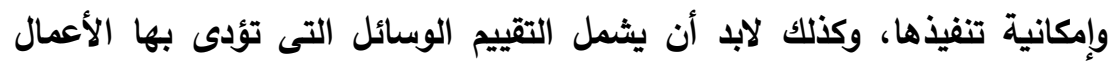


مجلة كلية التربية بالإسماعيلية - العدد الرابع والأربعون - مايو 9 م ـ r

الجامعية والأثخاص القائمين عليها، وكذلك يشمل النتائج التى يحققها خريجو

$$
\text { الجامعة فى الحياة العملية. }
$$

إن التقييم فى مجال التعليم الجامعى يضيف إلى معرفة مواطن القوة وزيادتها ومعرفة أوجه القصور وعلاجها؛ وتحقيق التطوير المستمر للخطط والبرامج الدراسية وسياسات القبول

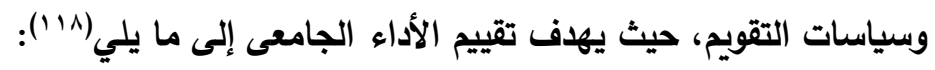
• تحديد الجامعات التى تتفق مع الحد الأدنى لمعايير المراجعة والتقييم والاعتماد. . • توفير دليل إرشادي لرفع مستوى الأداء التعليمي ووسائله. • تحفيز الجهود للتطوير المستمر للتعليم الجامعى.

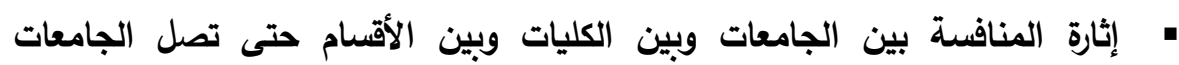
والكليات والأقشام إلى أعلى مرتبة فى الأداء التعليمى.

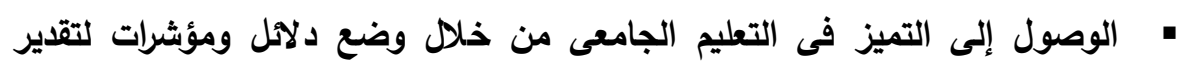
الفعالية التعليمية. • تشجيع استمرارية التحسين بالجامعات والبرامج التعليمية من خلال الدراسة الذاتية المستمرة والتخطيط. وعلى الرغم من أن التعليم الجامعى يهدف إلى إعداد إنسان له قدرة ذهنية وكفاءة مهنية يثارك فى بناء مجتمعه يحس مشاكله ويعمل على حلها، إلا أن الواقع يثير إلى أنه إنه

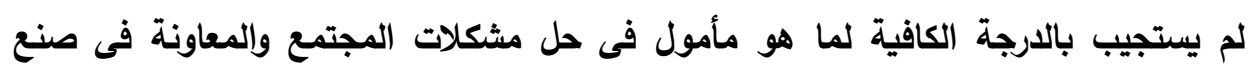

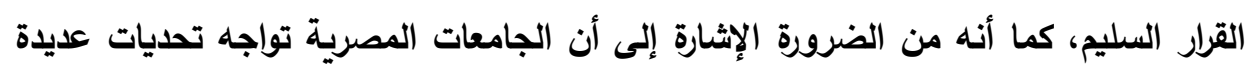

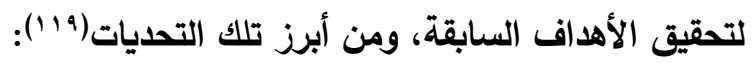
م زيادة الطلب على القوى العاملة التى تتميز بمستوى الجودة العالية والقدرة على القلى

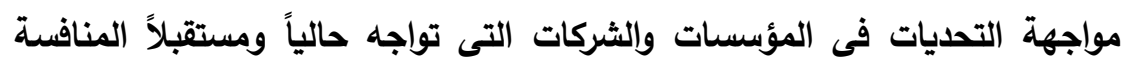
العالمية الحادة. م احتياجات المجتمع لنوعية متميزة من الخريجين والمتخصصين لمواجهة تحديات العصر والتقدم السربع فى نظم المعلومات والتكنولوجيا العالمية. م تطبيق برامج الإصلاح الاقتصادي، وتوسيع الملكية والمشروعات الجديدة الكبرى التى تتولاها الاولة. O الحاجة إلى التوسع فى التعليم الجامعى حتى تصل إلى المعدلات العالمية بنسبة عدد

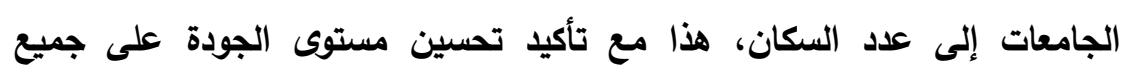
المستوبات. 
بدائل مقترحة لتطوير منظومة تقييم أداء الجامعات --- د/ محمد ابراهيم عبد العزيز خاطر

O الارتفاع المضطرد فى تكلفة العملية العلمية والبحثية بما لا يتوافق مع الموارد المالية المتاحة حالياً للجامعات.

r - الجهات المسؤولة عن تقييم أداء الجامعات المصرية: وتنقسم تلك الجهات إلى جهات خارجية وداخلية، وتتضح فيما يلي: أ- الجهات الخارجية:

وتتمثل في الجهات التالية(·rre):

المجلس الأعلى للجامعات: يقف المجلس الأعلى للجامعات على قمة المجالس التى تتولى الإشراف والرقابة على الجامعات، ويختص المجلس الأعلى للجامعات بأمور

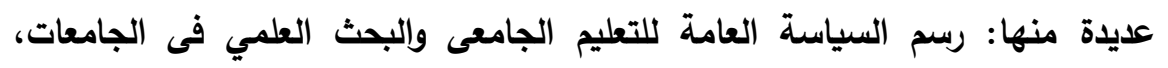
والعمل على توجيهها وتنسيقها بما يتفق مع حاجات البلاد وتيسير تحقيق الأهداف

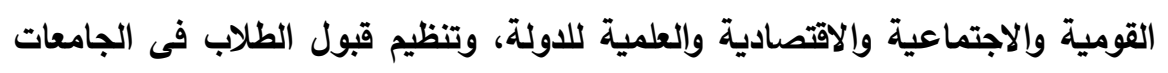
وتحديد أعدادهم، والمتابعة الدورية لتنفيذ سياساته وقراراته فى الجامعة، ووضع ولئه ولنظم الخاصة بتقويم وتطوير الأداء الجامعى، ويعتمد المجلس الأعلى للجامعات في أدائه لمهامه واختصاصاته على عدة مجالس تتبعه هي: المجلس الأعلى لثئون التعليم والطلاب، والمجلس الأعلى للاراسات العليا والبحوث، والمجلس الأعلى لخدمة المجتمع وتنمية البيئة. كما توجد جهات عديدة أخرى تمارس تقييم الأداء للجامعات المصرية، ومن هذه

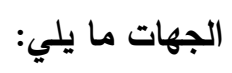

• الجهاز المركزي للمحاسبات: وتتمثل أدواره في الرقابة على تحقيق الموارد المتعددة

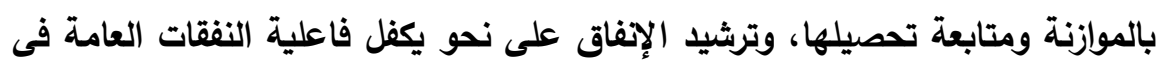

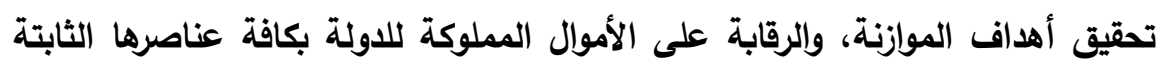

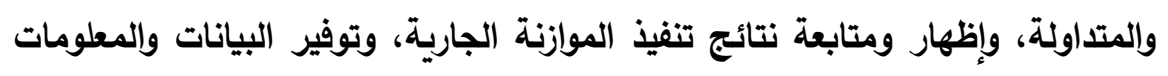

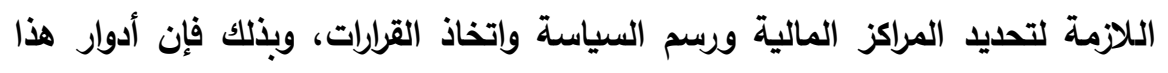
الجهاز تعتبر أدواراً عامة على كافة مؤسسات الدولة، ومن ضمنها الجها الجامعات وخاصة ولهات أن الجامعات تتلقى تمويلها من الحكومة وبالتالى تخضع لأجهزتها الرقابية المختلفة.

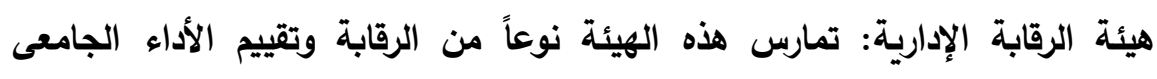

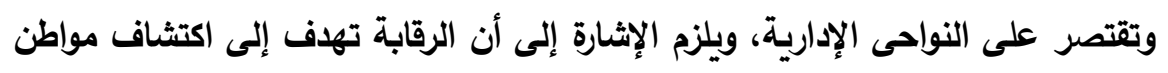

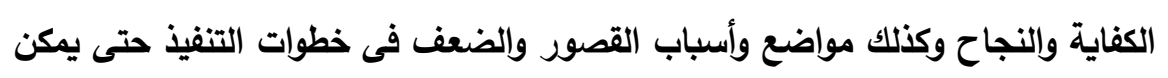


مجلة كلية التربية بالإسماعيلية - العدد الرابع والأربعون - مايو 9 م

علاجها فى الوقت المناسب، كما تهدف إلى إلخال أية تعديلات فى الخطة تستدعيها

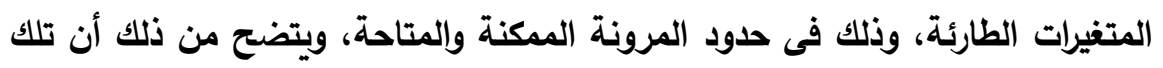

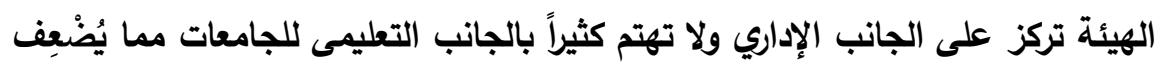
مساهمتها فى تقييم الأداء التعليمى للجامعات بمنظوره الثامل. • المجلس القومي للتعليم والبحث العلمي والتكنولوجيا: وهو أحد المجالس القومية المتخصصة وإلتى تسهم فى صنع السياسة العامة للدولة، بمعنى أن توجهها ليس وليس

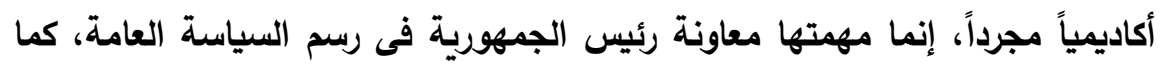
أنها تتبعه مباشرة، كما يختص المجلس القومي للتعليم والبحث العلمي وإلتكنولوجيا بلراسة واقتراح السياسات العامة لتنمية الإمكانيات القومية فى مجالات التعليم والبحث

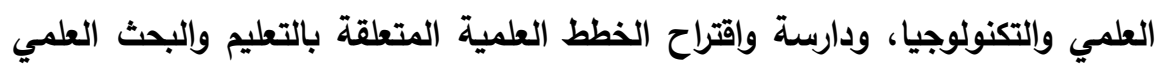
والتكنولوجيا والتبادل والتعاون الدولي فى هذه المجالات، والتنسيق بين السياسات المتعلقة فى مجالات عمل المجلس ومتابعة وتنفيذ الخطط وتقييمها بهدف تطوير السياسات المستقبلية فى ضوء الأهداف القومية. الهيئة القومية لضمان جودة التعليم والاعتماد: تعد الهيئة هي الجهة المسئولية عن نشر ثقافة الجودة في المؤسسات التعليمية والمجتمع، وعن تنمية المعايير القومية

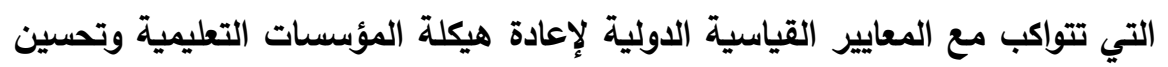
جودة عملياتها ومخرجاتها على النحو الذي يؤدى إلى كسب ثقة المجتمع فيها، وزيادة

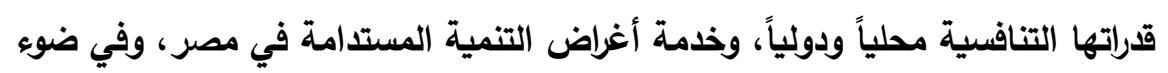

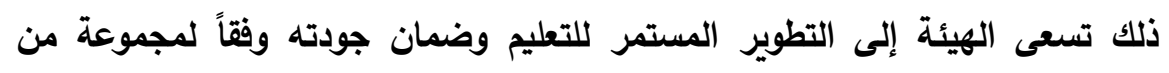
المبادئ والقيم التي تئكد الثفافية والموضوعية والعدالة والحرص على معاونة

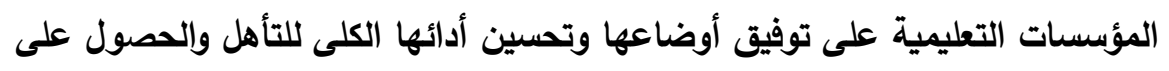

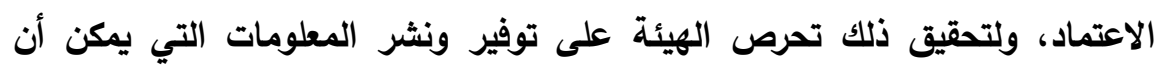

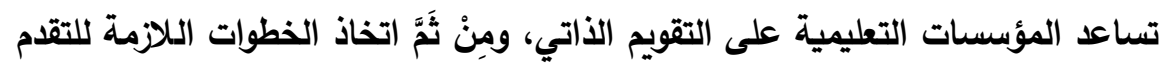

$$
\text { والحصول على الاعتماد. }
$$

ومن خلال ما سبق يمكن القول أن خضوع الجامعات لنظام الرقابة والمتابعة السائد فى الأجهزة الحكومية كان له أثراً كبيراً فى إعاقة استقلالها على الرغم من أن الجامعة هيئة

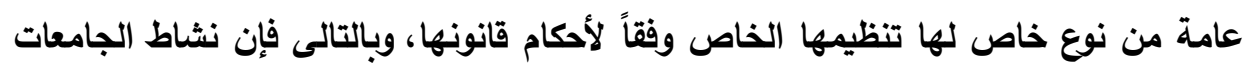
يختلف عن نشاط باقى الأجهزة الحكومية، كما تركز أغلب الأجهزة الخارجية على أساليب مراجعة وتقييم النتائج فقط دون الاهتمام بمراجعة وسائل تحقيق النتائج، هذا بجانب الاعتماد الاجن 
بدائل مقترحة لتطوير منظومة تقييم أداء الجامعات --- د/ محمد ابراهيم عبد العزيز خاطر على نتائج الأداء الملموس فقط والذى يمكن التعبير عنه رقمياً فقط، وعدم التركيز على الأداء غير الملموس والذى يمكن التعبير عنه وصفاً على نتائج الأداء بوجه عام. ب- الجهات الداخلية: وتتمثل هذه الجهات فيما يلي('rr'):

• مجلس الجامعة: لمجلس الجامعة دور فى تقييم الأداء وذلك من خلال اختصاصاته

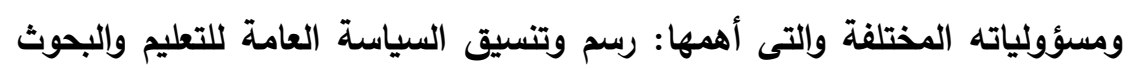

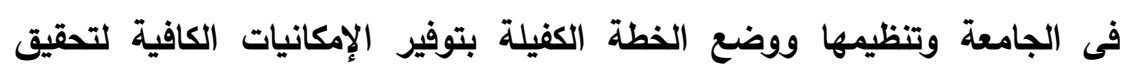
أهداف الجامعة، وتنظيم قبول الطلاب فى الجامعة وتحديد أعدادهم، ومناقثة تقارير

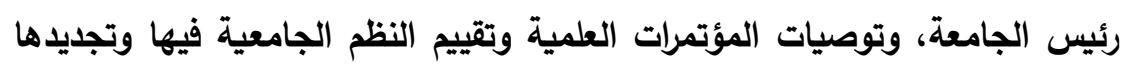
فى ضوء كل ذلك، وفى إطار التقدم العلمي والتعليمي ومطالب المجتمع وحاجاته

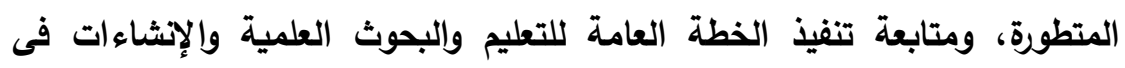
الجامعة.

•جلس الكلية: يلي مجلس الكلية مجلس الجامعة فى البناء التنظيمى لكل جامعة، وهو يتكون من عميد الكلية ووكلاء ورؤساء الأقسام وبعض الأساتذة والأساتذة

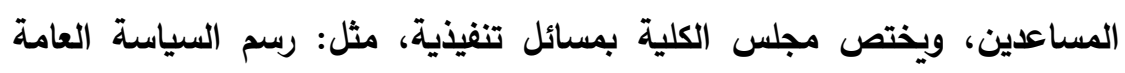
للتعليم والبحوث العلمية فى الكلية أو المعهد وتنسيقها بين الأقسام المختلفة، وإقرار المحتوى العلمى لمقررات الدراسة فى الكلية والتنسيق بينها فى الأقسام المختلفة، وتنظيم قبول الطلاب فى الكلية وتحديد أعدادهم، ومتابعة وتنفيذ السياسة العامة للتعليم والبحوث فى الكلية أو المعهد، ومناقثة التقرير السنوي للكلية أو المعهد وتقارير الأقسام وتوصيات المؤتمرات التعليمية للكلية وللأقسام، وتقييم نظم الدراسة ولتهات

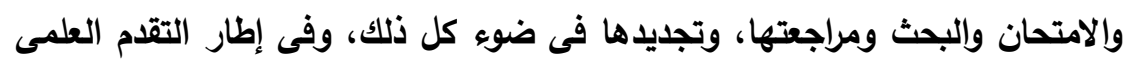
والتعليمى ومطالب المجتمع وحاجاته المتطورة، ومتابعة تنفيذ السياسة العامة للتعليم والبحوث فى الكلية أو المعهد. • مجلس القسم: ويختص مجلس القسم بأمور عديدة منها: رسم السياسة العامة للتعليم والبحث العلمى فى القسم، وتحديد المقررات الدراسية التى يتولى القسم

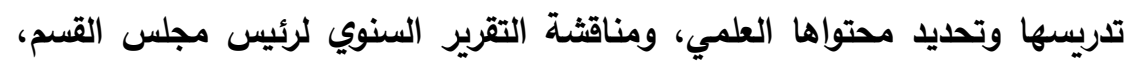
ومناقشة نتائج الامتحانات فى مواد القسم، وتقييم نظم الدراسة والامتحان وتحديدها 
مجلة كلية التربية بالإسماعيلية - العدد الرابع والأربعون - مايو 9 م ـ

فى ضوء التطور العلمى وفى ضوء مطالب المجتمع وفى إطار التقدم العلمى،

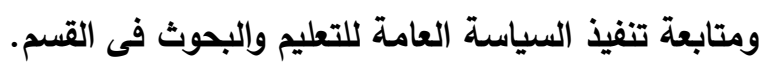
وعلى الرغم من تنوع وتعدد الجهات التى تمارس تقييم الأداء للجامعات واختلاف

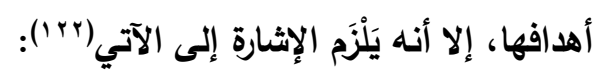

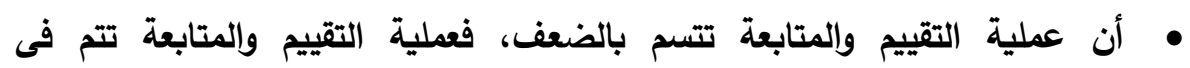

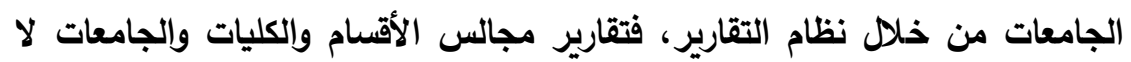

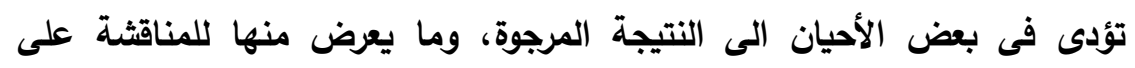

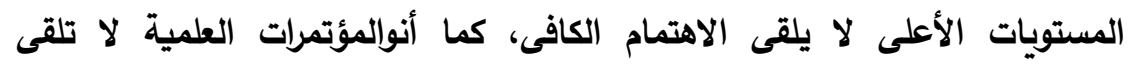
توصياتها تنفيذاً فعلياً فى كثير من الأحيان. • ضعف التعاون بين الجهات المختلفة التى تضطلع بقياس الأداء فى الجامعات، الأمر الذى يؤدى إلى ضعف مشاركتها فى تقييم الجامعات المصرية. ثانياً: عمليات تقييم أداء الجامعات المصريةة: يلزم لقياس أداء الجامعات المصرية دراسة عمليات هذا النظام، والتى تتمثل فيما

1 - التخطيط لتقييم الأداء الجامعى: يتم التخطيط لتقييم الأداء الجامعى من خلاء ما يلي:

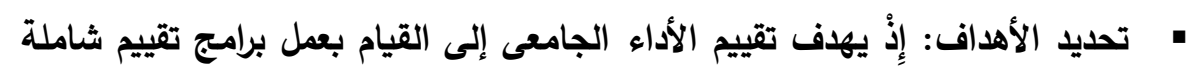

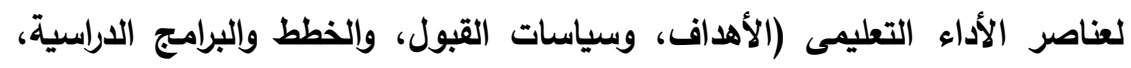
وتقويم الطلاب)، وتنظيمها والتي تؤدى إلى تطوير الأداء التعليمى للجامعات.

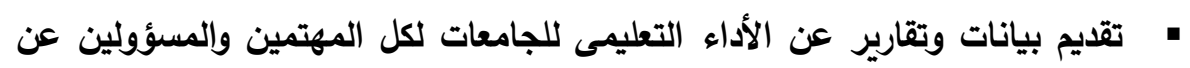
الجامعات، بتجميع البيانات واستطلاع رأى الجامعات. وعلى الرغم من الاهتمام بالتخطيط لقياس الأداء التعليمى للجامعات فى ضواء لجهات القرارات المراد اتخاذها إلا أن هناك قصوراً فى مراعاة التوجهات الرئيسة لتطوير الأداء التعليمى لأنى للجامعات، إذ تقتصر محاولات المجلس الأعلى للجامعات على رصد الوضع الراهن. r - التنظيم لتقييم الأداء الجامعى: تأتى مرحلة التظيم ليسهل إتمام عمليات تقييم الأداء، وفى ضوء التظيم لتقويم الأداء الجامعى بما فيه الأداء التعليمى للجامعات يتم تشكيل لجان فرعية لتقييم الأداء وقياسه 
بدائل مقترحة لتطوير منظومة تقييم أداء الجامعات --- د/ محمد ابراهيم عبد العزيز خاطر

تختص بكل مقوم من مقومات الأداء التعليمى للجامعات (الأهداف- سياسات القبول - الخطط

والبرامج الدراسية- سياسات التقويم). ب- تنفيذ أنشطة تقييم الأداء الجامعى: ويتم تنفيذ أنثطة تقييم الأداء الجامعى في المجالات التالية:

أ- المجال الأول: الدور التعليمى والتدريسى للمؤسسات الجامعية:

$$
\text { ويشتمل على ما يلي (أبان): }
$$

• الأهداف التعليمية: يهدف التعليم العالى فى مصر بصفة عامة والتعليم الجامعى

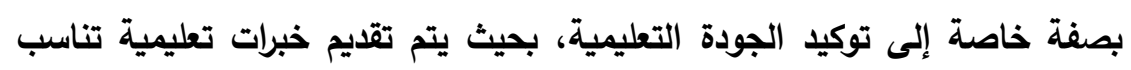

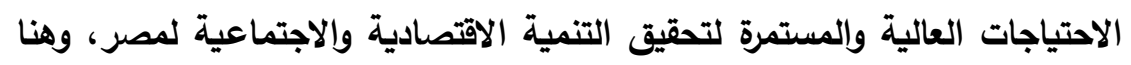
ينبغي الأخذ فى الاعتبار ما تتعرض لله الجامعات فى مصر من تحديات ترتبط بإمكانياتها وجودة مخرجاتها، وبخاصة مع المنافسة القادمة من الجامعات الأجنبية

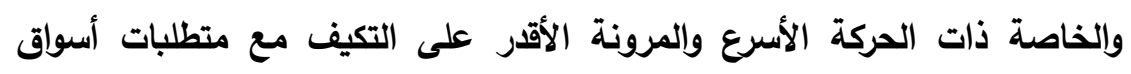
العمل من ناحية، وتطورات تقنيات التعليم من ناحية أخرى.

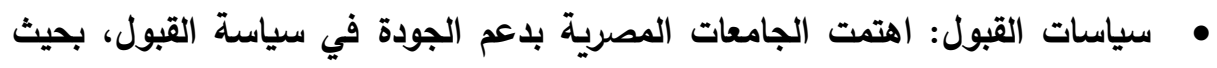

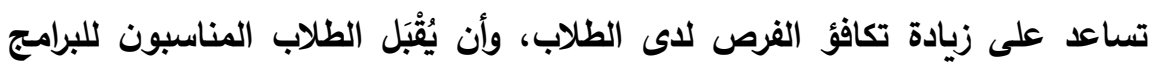

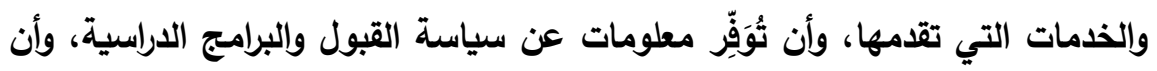

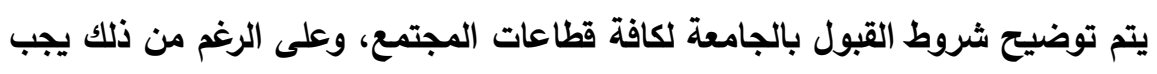

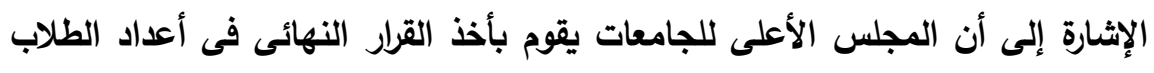

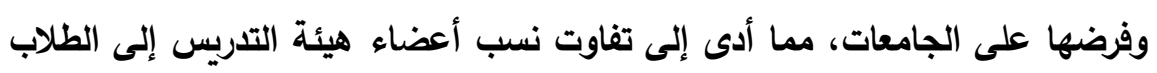

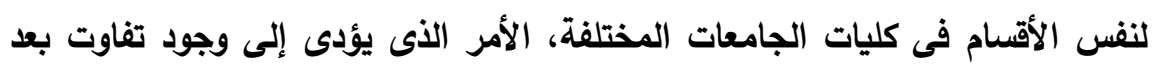

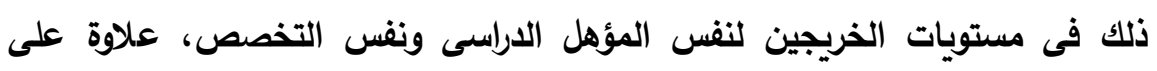
ضعف قدرة الكليات في التوصل إلى أدوات انتفاء موضوعية ومقنتة لاختيار أفضل

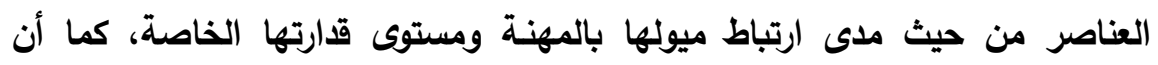
الطريقة التى يُعْقَد بها الامتحان الخاص بالكثف على آتلى قرات الطالب تفتقر إلى الدقة التي تسهم في إتاحة الفرصة الحقيقية للموهوبين.

• الخطط والبرامج الدراسية: اهتمت الجامعات المصرية -وبخاصة مع إنشاء الهيئة

القومية لضمان جودة التعليم والاعتماد- بضرورة تحديث البرامج والمقررات الاراسية، وضرورة عمل مصفوفات للبرامج التعليمية وطرح توصيفات للمقررات 
مجلة كلية التربية بالإسماعيلية - العدد الرابع والأربعون - مايو 9 م ـ

الاراسية، علاوة على التأكيد على أن تقوم الجامعة بتصميم وتنفيذ البرامج الخاصة

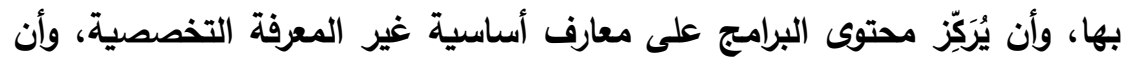
تتفق أساليب التدريس واستراتيجياته مع تحقيق أهداف البرامج، وأن تتوفر البنية

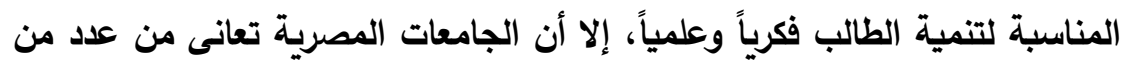

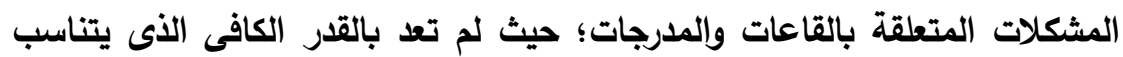
والأعداد الكبيرة والتخصصات والثعب المتعددة، كما تعانى الكثير من المعامل من نقص الأجهزة الحديثة والمواد الخام، كما أن طلاب بعض الكليات ينتقلون بين أكثر من كلية لحضور الاروس العملية لعدم وجود معامل بكلياتهم الأصلية مما يشتت جهود الطلاب، بالإضافة إلى الميل الواضح إلى التنميط فى المناهج والأساليب بين

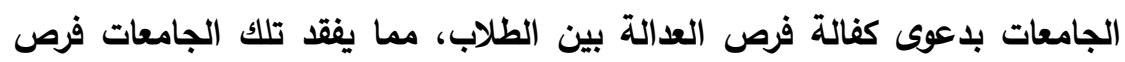

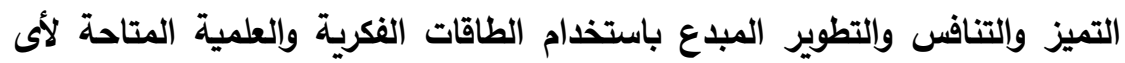
منها، علاوة على زيادة نسبة الطلاب والخريجين فى التخصصات النظرية والإنسانية

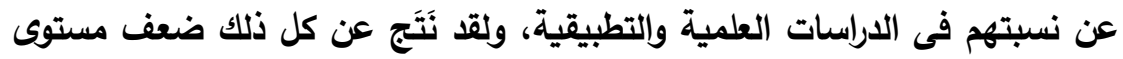
التعليم الجامعى حيث يعزز عن الوفاء بإعداد كوادر تكون قادرة على المساهمة فى في برامج التنمية الثاملة للدولة، أو حتى متطلبات القطاع الخاص. تقويم المخرجات التعليمية: مع انتثار ثقافة المعايير وضمان الجودة بالمؤسسات

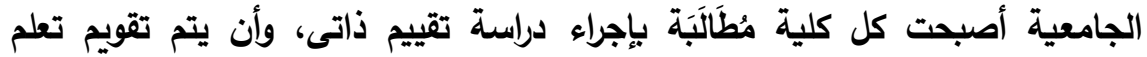
الطلاب وفق معايير أكاديمية محددة، وأن تتبع الجامعة نموذجاً ونظاماً واضحاً ومحدداً

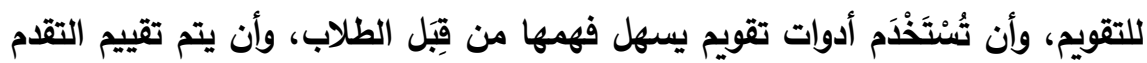

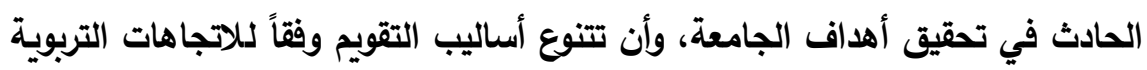
الحديثة، وأن يوجد بالجامعة لجنة خاصة بتقييم البرامج التي تقدمها، وأن يوجد نظام

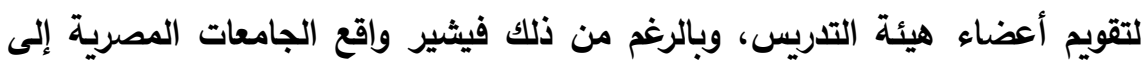
اقتصار عمليات التقويم فى الجامعات المصرية على تقويم معرفة المعلومات بصفة العيد رئيسة، وبرجة محدودة على الأداء العملي والتطبيقي، ولا يكاد أن يكون من الوارداد

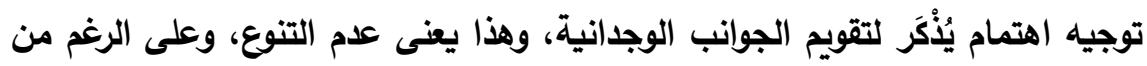

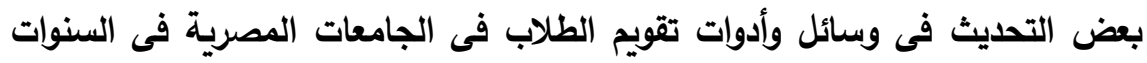

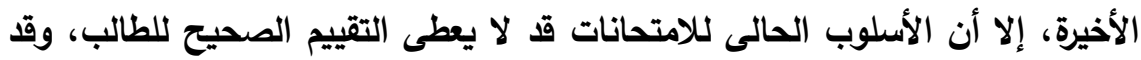

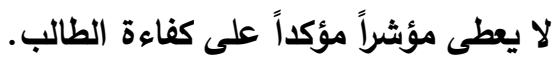


بدائل مقترحة لتطوير منظومة تقييم أداء الجامعات --- د/ محمد ابراهيم عبد العزيز خاطر

$$
\text { ب- المجال الثانى: الدور البحثى للمؤسسات الجامعية: }
$$

يمثل البحث العلمي البُعْد النوعي فى رسـالة أي جامعة لحل مشكلات المجتمع، لأنهـ يعنى التجديد والابتكار والتطوير على مـا هو مألوف ومعروف مـع التنقيب وإلتحري وإلتدقيق

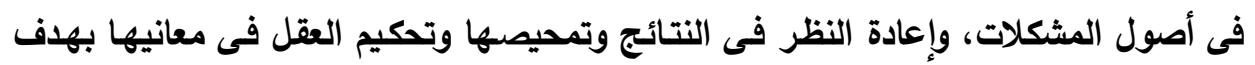
تطوير الواقع الذي نعيش فيه؛ فالبحث العلمي هو الذي يميز جامعة جادة فى حياة مجتمعها وجامعة تقليدية تعيش على إبداعات الآخرين وجهودهم. ونظراً لأن الجامعة هي المؤسسة التي يقع على عاتقها عبء إنتاج المعرفة وإنمائها

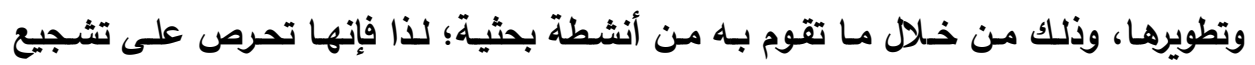

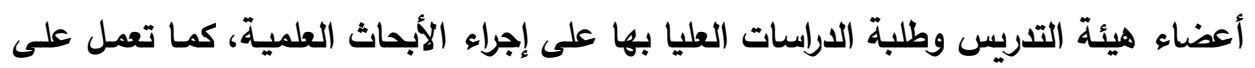
توفير المستلزمات الضروريـة لإجراء تلك الأبحاث من أجهزة وأدوات ومراجع علـمية وغيرها.

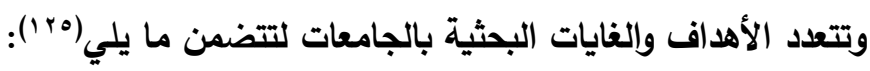

• تككين الباحثين من التعامل مع مثكلات واقعية ومحاولة إيجاد حلولاً لها.

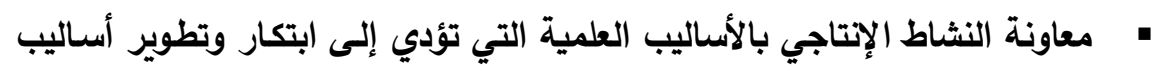
جديدة يترتب عليها وفرة الإتتاج وتحسينه.

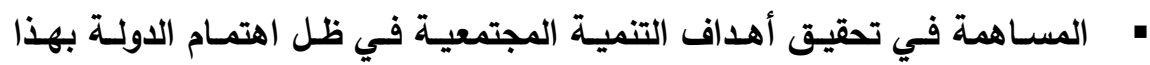

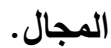
وفى ضوء ذلك، فإنه ينبغي نشر ثقافة التميز البحثي والمؤسسي للجامعات بالمجتمع باعتبارها سبيلاً لا بديل عنه للمنافسـة في عالم اليوم، وذلك بالاهتمـام بالجودة والكفاءة في لئي

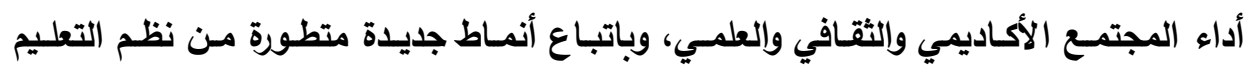

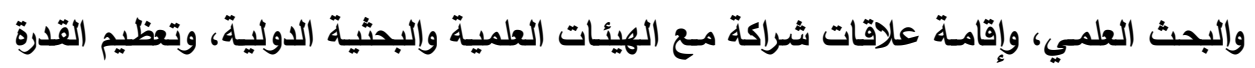

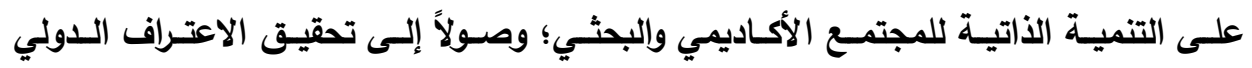
بالإنجازات العلمية على المستوى القومي وبالقدرة على المنافسة على المستوى الدولي. وتتنوع الأنشطة البحثية التى تجريها المؤسسات الجامعية والمراكز البحثية بالجامعات، حيث يتم طرح رسائل علمية (ماجستير ودكتوراه) وبحوث ترقية في مختلف المجالات الهدف الرئيسي لها إعداد وترقية أعضاء هيئة التدريس بالجامعات والباحثين بمراكز البحوث، وبالرغم

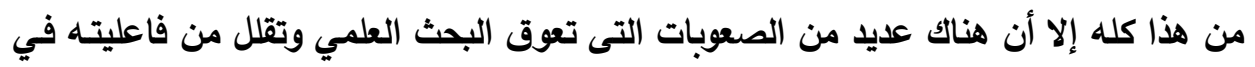

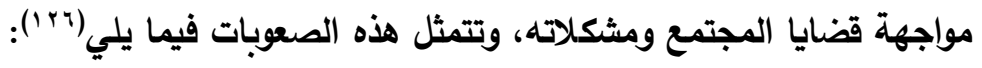


مجلة كلية التربية بالإسماعيلية - العدد الرابع والأربعون - مايو 9 م ـ

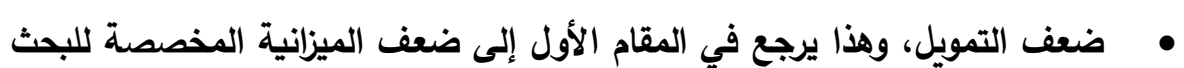

العلمي في ميزانية الدولة، وبالتالي يضطر الباحث إلى الإنفاق على ما يقوم باه من أبحاث من ماله الخاص، وهو الأمر الأي يدفعه إلى الاقتصاد في الإنفاق نظراً لضعف دخله أو الإحجام عن الإنفاق في بعض الأه الأحيان. • ضعف الصلة بين البحث العلمي ومشكلات المجتمع وقضاياه سواء على المستوى الإهيان القومي أو على مستوى الجامعات.

الافتقار إلى خطة لتشجيع المؤسسات والهيئات الإنتاجية على الاستثمار في البحث

العلمي.

• انحصار ثقافة البحوث البينية المشتركة، مما يحول دون تقديم حلول متكاملة

$$
\text { لبعض المشكلات. }
$$

• صعوبة النشر الدولي في المجالات العلمية العالمية وما يتطلبه من تكاليف باهظة،

إلى جانب صعوبة المشاركة في المؤتمرات العلمية العالمية.

•العفف الحوافز المادية والمعنوية لتشجيع العلماء والباحثين على البحث العلمي

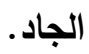

• ضعف الاستفادة من نتائج الأبحاث العلمية التي تجرى في الجامعات ومراكز

البحوث.

عدم وجود معايير لقياس وتقويم نوعية البحث العلمي ودوره في تحسين وتطوير

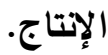

الافتقار إلى وجود آليات لربط الجامعات ومراكز البحوث بمؤسسات الإنتاج

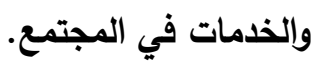

ج- المجال الثالث: الاور المجتمعى للمؤسسات الجامعية:

تتنوع المجالات التى يمكن للجامعات المصرية بكلياتها المختلفة العمل خلاكها لخدمة

$$
\text { مجتمعها في خمسة مجالات، هي كالتالي (rv (IV): }
$$

• مجال القيادة الفكرية للمجتمع: حيث تسهم الجامعة في بناء الحس القومي عند

الأفراد، وترسيخ القيم، ونشر الثقافة، والمحافظة على مكتسبات المجتمع وموارده. • مجال التعليم المستمر: وذلك بتقديم فرص تعليمية أو تدريبية للمواطنين الذين فاتهم مثل هذه الفرص من خلال التعليم النظامي، ويمكن للجامعة أن تقدم هذه 
بدائل مقترحة لتطوير منظومة تقييم أداء الجامعات --- د/ محمد ابراهيم عبد العزيز خاطر

الخدمة للمواطنين من خلال برامج الدراسات المسائية، والتعليم عن بعد، والدورات الفنية والمهنية للعمال والفنيين، والدورات العامة للراغبين والمهتمين. • مجال الاستشارات والدراسات: والتى يمكن أن تسهم في تطوير عمل كل مؤسسات الدولة، من خلال الدراسة، والتحليل، والتشخيص، وتقديم الاستشارة للإصلاح والتحديث.

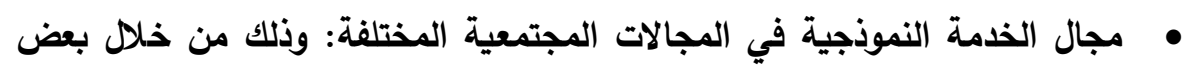
وحداتها ومراكزها مثل مستشفى الجامعة، وما يتبعه من مراكز وعيادات طبية،

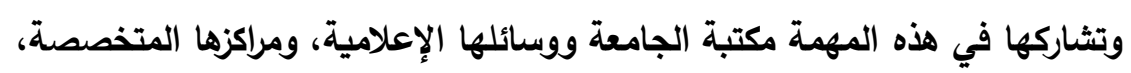
ومختبراتها، ومراكز الخدمات العامة فيها.

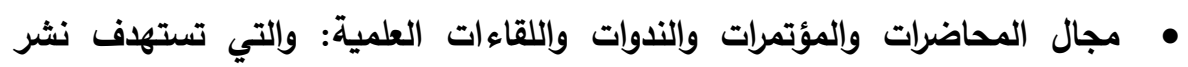
المعرفة، وتبادل الرأي والخبرة، وعرض الدراسات والبحوث في مجالات كثيرة، ومنها تحليل مشكلات المجتمع، وعرض وجهات النظر المختلفة للتصدي لها.

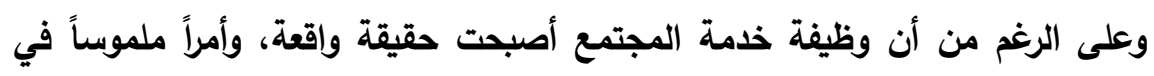
حياة الجامعات بعد أن أصبح لها هيكل تنظيمي، سواء في الجامعات أو الكليات، إلا أن أداء

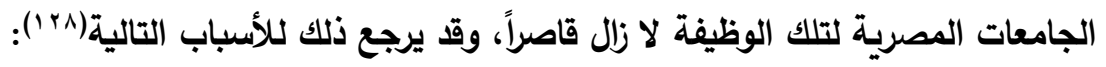

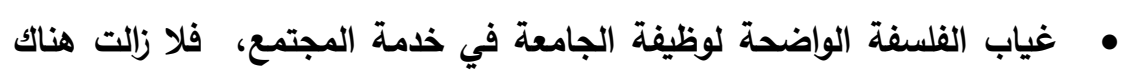
فواصل وتقسيم بين وظائف الجامعة الثلاث. • ضعف قنوات الاتصال بين الجامعات ومراكزها المتخصصة من جهة، وبين وائن المؤسسات واللهيئات الإنتاجية من جهة أخرى. • نقص التمويل اللازم والمناسب لتحقيق وظيفة الجامعة في خدمة المجتمع، علاوة على ضعف وجود الدافع لاى الطلاب وأعضاء هيئة التدريس والإداريين للعمل في خدمة المجتمع، حيث قد يرجع ذلك لضعف الحوافز والمكافآت.

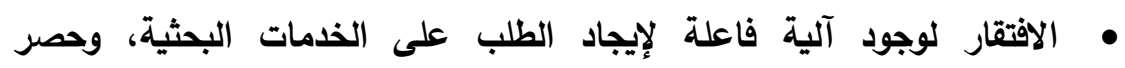
المشكلات الميدانية من القطاعات المختلفة، وتسويق النتائج البحثية لاى لإئاد

$$
\text { الفئات المستهدفة. }
$$

ثالثًاً: مخرجات تقييم أداء الجامعات المصريـة:

يرهاف تقييم الأداء إلى تقديم تقارير يتم فى ضوئها تطوير الأداء التعليمى للجامعات، وكذلك تحديد أوجه القوة والضعف وأسبابها، وقد هَذَف المجلس الأعلى للجامعات من تقويم 
مجلة كلية التربية بالإسماعيلية - العدد الرابع والأربعون - مايو 9 م ـ

الأداء الجامعى إلى وضع معايير ومعلات أساسية لتطوير الأداء الجامعى، ولذلك تجسدت المحاولات في هذا الإطار فى الاستبيانات الخاصة بالجامعات والكليات، دون صدور تقارير يتم

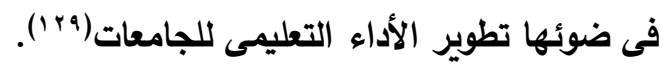

ويُعَ تقييم الأداء من أهم المتطلبات لتوكيد الجودة، بحيث يكون هناك مسؤولية لجميع

الأطراف أمام المجتمع، حيث يرجع السبب الرئيسى فى انخفاض مستوى مهارات وكفاءة أداء

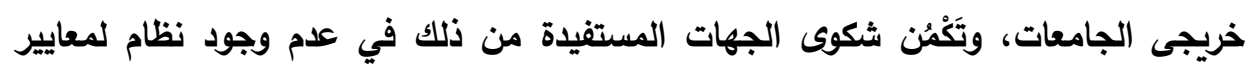
التقويم أو عدم تطبيقها بجدية، وانخفاض جودة الأداء وعدم وجود نظم للاعتماد وتوكيد الجودة.

وعلى الرغم مما تقدم، لازالت تعاني الجامعات المصرية من مشكلات عديدة تؤثر فى أفى

كفاءتها الداخلية والخارجية، ومن أهم تلك المشكلات "ضعف ملأممة مستوى تكوين الخريجين مع المستويات المطلوبة محلياً وعالمياً"، ولعل أسباب تلك المشكلة تَكْمُن في العوامل التالية: • ضعف تحديد مواصفات لخريجى كل تخصص وتطوير هذه المواصفات

بصفة دوريـة.

• ضعف المدخلات من الطلاب الحاصلين على الثانوية العامة.

• غياب معايير الأداء التى يمكن بها قياس الإنجازات والتحسين المستمر

فى مستوى الخريجين.

• غياب نظم وآليات فعالة لتقييم أداء الجامعات حيث لا تأثير لعوامل فئل

السوق وأحكام المستخدمين لمنتجاتها على ما يمكن أن تحصل عليه

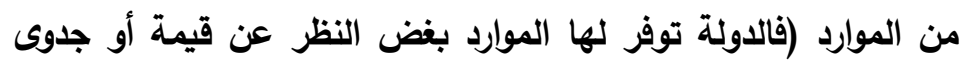

منتجاتها).

انحصار عمليات التقييم فى آليات داخلية هى أقرب إلى التقييم الذاتي المجامل الذى لا يأخذ فى الاعتبار تقييم العملاء (المجتمع).

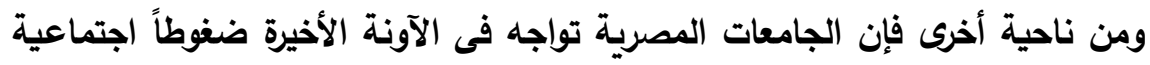

لقبول أعداد من الطلاب قد تفوق الطاقة الاستيعابية لها، وقد يرجع ذلك لعوامل عديدة

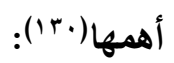

• اهتمام الاولة بالتعليم واعتباره قضية قومية والأخذ بسياسة التوسع فى

التعليم الجامعى.

• تطلع الثباب والأجيال الصاعدة إلى التعليم الجامعى باعتباره الطريق

الطبيعى والمضمون إلى تحقيق مستويات أفضل اقتصاديا واجتماعيا. 
بدائل مقترحة لتطوير منظومة تقييم أداء الجامعات --- د/ محمد ابراهيم عبد العزيز خاطر

• التوسع المطرد فى إنثاء الكليات بالمحافظات المختلفة، وإتاحة القبول

للراغبين فى الاتحاق بها دون أى تفرقة، وعلى أساس معيار موضوعى

$$
\text { واحد هو مجموع الطالب فى الثانوية العامة. }
$$

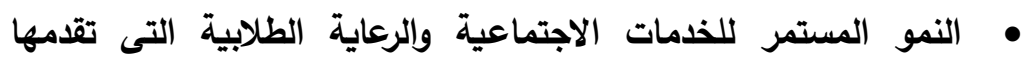

الجامعات (المدن الجامعية - صندوق التكافل الاجتماعي - دعم

$$
\text { (المكتبات الجامعية). }
$$

الإطار المُقْتَرَح للادراسية:

يَتَتََّّل الإطار المُْْتَرَح للاراسة في "بدائل مقترحة لتطوير منظومة تقييم أداء الجامعات

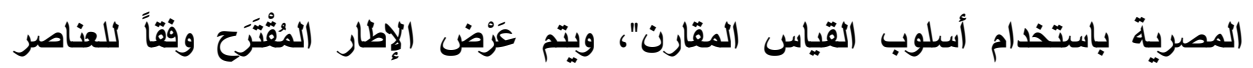

أهداف الإطار المُقْتَرَح:

تتمثل أهداف الإطار المُقْتَرح فيما يلي:

- - اقتراح ثلاثة بدائل لتطبيق أسلوب القياس المقارن فى منظومة تقييم الأداء الجامعى

$$
\text { بالجامعات المصرية. }
$$

r - تطبيق عدد من المعايير للمفاضلة والموازنة بين البدائل الثلاثة المقترحة.

r- الخروج بأكثر البدائل المقترحة مناسبة للسياق الثقافى والبيئى للجامعات المصرية.

منطلقات الإطار المُقْتَرَح:

يسير الإطـار المُقْتَرَح أو البدائل المقترحة لتوظيف القياس المقـارن بمنظومـة تقيِيم

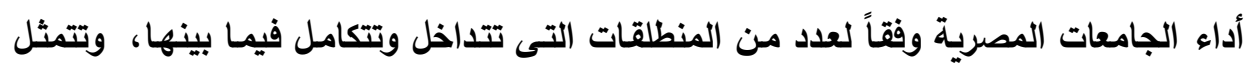

$$
\text { أهم هذه المنطلقات فيما يلي: }
$$

• يساعد قياس الأداء المقارن في تحديد ما إذا كانت المؤسسة الجامعية تحقق احتياجات

المستفيدين أم لا، مع فهم العمليات التي تقوم بها المؤسسة لتلبية تلك الاحتياجات.

• يحدد القياس المقارن وبدقة أي الأماكن أو القطاعات في المؤسسة تحتاج إلى إجراء

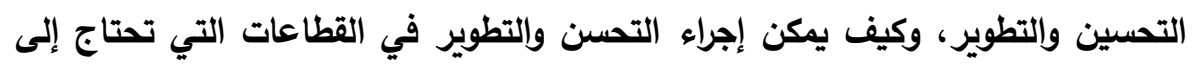

• يُنْهُمُ قياس الأداء المقارن في التأكد من أن التحسين والتطوير الذي تم التخطيط له قد حدث بالفعل، بالإضافة إلى أنه يعطينا إجابة عن سؤال هام يتعلق بتطوير الأداء

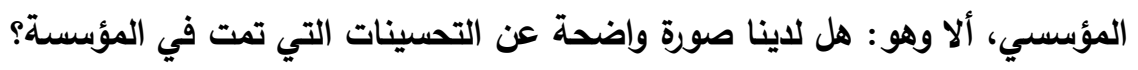


مجلة كلية التربية بالإسماعيلية - العدد الرابع والأربعون - مايو 9 م ـ r

• يعتبر القياس المقارن من أهم الأساليب التي يمكن أن تعتمـ عليها المؤسسـات

$$
\text { الخدميـة في قياس وتحسين الجـودة. }
$$

• أن هناك شبه اتفاق وإجماع على أن القياس المقارن أداة وطريقة إدارية متمثلة في

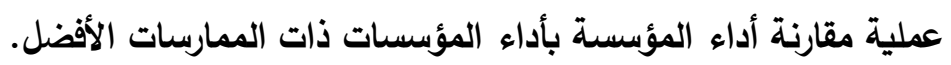

• يمثل القياس المقارن عملية مستمرة للبحث عن أفضل الممارسات، يتضمن جانباً للتعلم من الآخرين بهدف التطوير، والبحث وراء الأداء المتميز.

• أن القياس المقارن يسهم في التعلم من أفضل تطبيقات المنظمات الرائدة من أي مكان

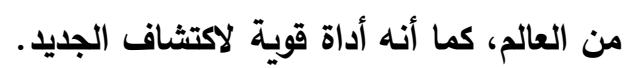

• يُنِِْ القياس المقارن فى توفير المناخ الملانم والمساعدة فى تحديد العمليات الحرجة وإعطائها الاهتمام اللازم والأولوية في التنفيذ.

تزود المؤسسة الجامعية بالوسائل التي تمكنها من أن تبني وتحسن، في ذات الوقت

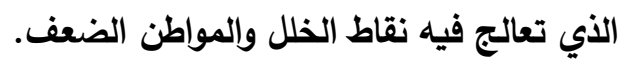

• أن التركيز الخارجي لأسلوب القياس المقارن يُسنهِه في صياغة مقاييس تنافسية

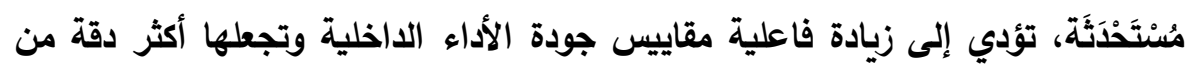
ناحية، وتجعل المؤسسات الجامعية أكثر التزاماً بها من ناحية أخرى.

البدائل المُقْتَرَح لتطوير منظومة تقييم أداء الجامعات المصرية باستخدام أسلوب القياس المقارن: - (القان

تتمثل البدائل المقترحة فى ثلاثة بدائل، يمكن تناولها كما يلي:

البليل الأول: القياس المقارن الخارجى لمنظومة تقييم أداء الجامعات المصرية: وهو قياس الأداء الذى يسير على ضوء المعلومات المُجَمَّعَة من الجامعات التي يُنْظَر إليها على أنها جامعات رائدة ولها السَبْق ولها مراكز تنافسية في المسابقات أو التصنيفات الاولية، ويعتبر هذا النوع من المقارنات ذا قيمة عالية في صناعة القرار، وهي عملية تتم بواسطة جهات إداريـة عُلْيَا ومحايدة من أجل ضمان الحفاظ على سرية المعلومات المتبادلة.

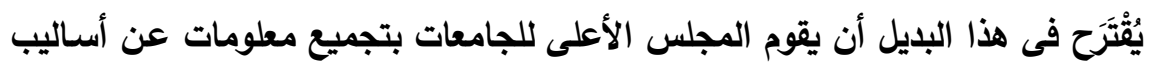

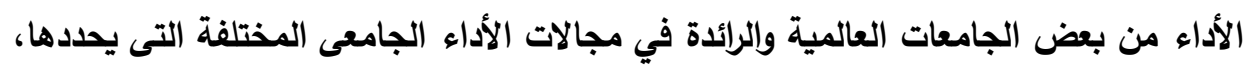
ولا يُشْتَرَطُ في ذلك الرجوع إلى الجامعات المصرية، باعتبار المجلس الأعلى للجامعات هيئة 
بدائل مقترحة لتطوير منظومة تقييم أداء الجامعات --- د/ محمد ابراهيم عبد العزيز خاطر

للتنسيق بين الجامعات المصرية، وتنمية أثكال التعاون وإلتكامل فيمـا بينها، كمـا أنـه يُعْتَبر الجهة المنوط بها تطبيق نظم تقييم الأداء الجامعى وتقويمه. ووفقاً للقياس المقارن يَخَرُج المجلس الأعلى للجامعات بقائمة من المعايير والمؤشرات

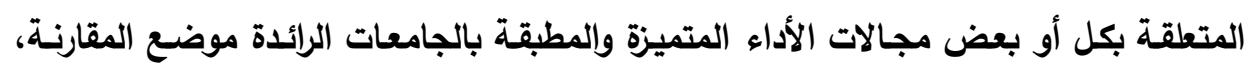
ومِن ثِّم يطرحها؛ لكي يتم تعميمها على الجامعات المصرية للأخذ بها والعمل على تطبيقها. ويمكن تقديم هذا البديل المقترح وفقاً للعناصر التالية: أولاً: مدخلات القياس المقارن الخارجى لتقييم أداء الجامعات المصريةة: وتتضمن ما يلى:

1- فلسفة القياس المقارن الخارجى لتقييم أداء الجامعات المصرية وأهد(فه: وتنطلق فلسفة هذا البديل من الملامح التالية: تحديد معالم التنافس بين الجامعـات المصرية والجامعـات الرائدة في مجـالات الأداء الجامعى المختلفة. إتاحـة الفرص للجامعات لتطوير أدائها في ضويء توجيهات وتقارير القياس المقارن التى تَوَصَّل إليها المجلس الأعلى للجامعات. تعميم مقاييس ومؤشرات واحدة فى القياس المقارن للجامعات، وبالتالى ضمان الإعى مستوى أداء مناسب لكل الجامعات. وتتحدد أهداف القياس المقارن، وفقاً لهذا البديل فما يلي: إثارة المنافسة بين الجامعات لتحقيق مستويات إنجاز أعلى. • تقييم الأداء التعليمى للجامعات فى ضوه مقاييس ومؤشرات الجامعات الرائدة.

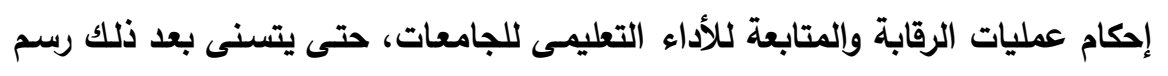
السياسات التعليمية الخاصة بالجامعات. r - الجهات المسؤولة عـن القيـاس المقـارن الخـارجى لتقيـيم أداء الجامعـات

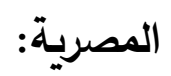
وفقاً لهذا البديل فِإن المجلس الأعلى للجامعات يُعْبََر الجهـة العليـا المسؤولة عن ممارسة القياس المقارن الخارجى للجامعات، ولتحقيق ذلك يلزم ما يلي: إنشاء قواعد البيانات الخاصة بكل جامعة بالمجلس الأعلى للجامعات يتم فى ضئئها القياس المقارن للجامعات، وتوفير معلومـات وخصائص تساعد على رسم السياسـات بلات

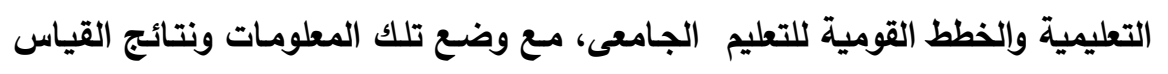


مجلة كلية التربية بالإسماعيلية - العدد الرابع والأربعون - مايو 9 م ـ

المقارن فى متــاول مجالس الجامعـات للاسترثــاد بها فـى وضـع خططها التعليمية

التالية.

تنشيط دور لجان قطاعات التعليم الجامعى المختلفة التابعة للمجلس الأعلى للجامعات

$$
\text { والتى تعمل كلجان استشارية }
$$

لتحديد الأعداد اللازمسة من الخريجين فى التخصصـات المختلفة، وذلك بالاشتراك مـع الهيئات والأجهزة المعنية، وتحديد المستوى المطلوب توافره فـى الخريجين في ضوهي

التقدم العلمي واحتياجات خطط التنمية فى مجتمعها.

ثانياً: عمليات القياس المقارن الخارجى لتقييم أداء الجامعات المصرية: وتتمثل هذه العمليات فيما يلي:

1 - تخطيط القياس المقارن الخارجى لتقييم الأداء الجامعى:

ويـتم التخطيط بقيـام المجلس الأعلى للجامعـات بالقيـاس المقـارن لأداء الجامعـات

الرائدة، وذلك للوقوف على مقومات الأداء التعليمس وفحص نظم القبول فى الكليات والأقسام وكذلك الخطط والبرامج الدراسية، وأيضاً تقويم الطلاب ومـا يتبعه من تغذيـة راجعة، مـع الأخذ فـ الاعتبار مراجعة المعـايير القياسـية مـن آن لأخر، عـلاوة على تعديـ الأداء البحثى

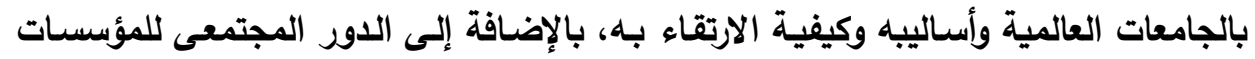
الجامعية وكيفية توسعها في خدمة مجتمعها بالثكل المتميز. ץ - تنظيم القياس المقارن الخارجى لتقييم الأداء الجامعى: يتم تنظيم القياس المقارن وفقاً للخطوات التالية: • طلب البيانـات والمعلومـات مـن الجامعـات العالميـة وخاصـة المتعلقـة بمقومـات الأداء

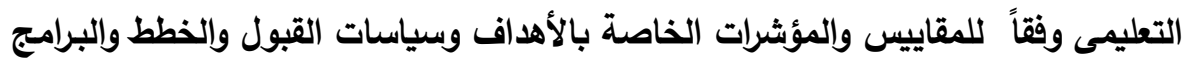
الاراسية وتقويم الطلاب، إلى جانب الجانب البحثى والمجتمعى والخدمى.

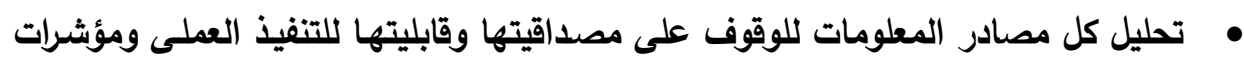
نجاح هذا التفيذ بالجامعات الرائدة.

r- تنفيذ أنشطة القياس المقارن الخارجى لتقييم الأداء الجامعى: فى ضوء هذا البديل يكون المجلس الأعلى للجامعات مسؤولاً عن وضـع مقاييس الأداء المقارن الخارجى، في المجالات التالية: أ- المجال الأول: الدور التعليمى والتدريسى للمؤسسات الجامعية: ويتمثل في الجوانب التالية: 
بدائل مقترحة لتطوير منظومة تقييم أداء الجامعات --- د/ محمد ابراهيم عبد العزيز خاطر

• الأهداف التعليمية: لما كانت الجامعات المصرية تعمل وفقاً لقانون تنظيم الجامعات الذى يحدد أهدافها، فإن المجلس الأعلى للجامعات يمكنه تطبيق القياس المقارن لأهداف الجامعات الـواردة فى القانون، مـع مراعاة الأهداف التعليمية التى قد تختلف باختلاف

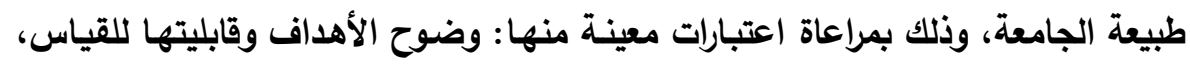

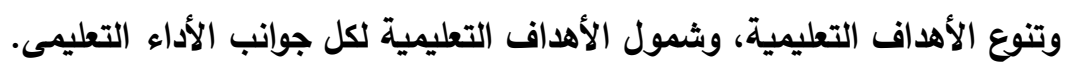

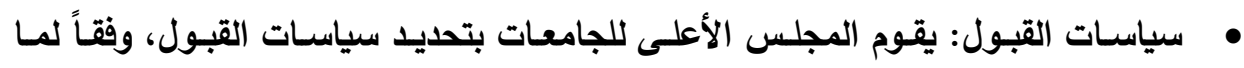
أسفرت عنـه عمليات القياس المقارن الخـارجى، وذلك بمراعاة: الحياديـة فـى سياسـات القبول، والتنوع فى شروط القبول، وتعدد القائمين على رسم وتنفيذ سياسات القبول.

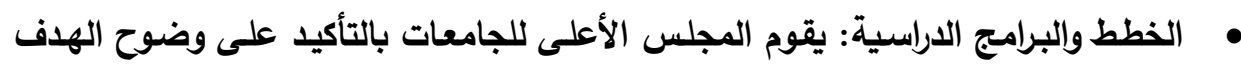
من المقرر، وصلة المقرر بالبرنامج العام، وتوافر المصادر والمراجع، والأدوات المناسبة

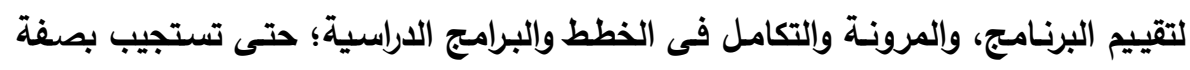
دائمة للتغيرات العالمية والمجتمعية لتحقيق أهدافها، والتميز والتنوع فى الخطط والبرامج الاراسية، وحريـة الاختيار للطلاب فحى الخطط والبرامج الدراسية، والمواءمـة بين الخطط والبرامج الدراسية وبين متطلبات التنمية.

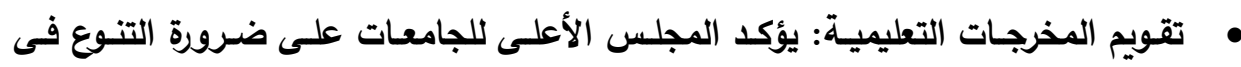
أسـاليب تقويم الطلاب، والتعدد فى أسـاليب التقويم، والتغذيـة الراجعـة المرتبطة بنتـائج التقويم، والاستمرارية فى تقويم الطلاب، وشمول أساليب التقويم حتى تحقق أهدافها. ب- المجال الثاني: الدور البحثى للمؤسسات الجامعية: ويتمثل دور المجلس الأعلى للجامعـات وفقـاً لنتـائج القياس المقـارن الخـارجى مـع

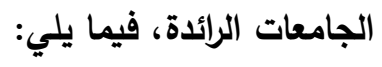
• زيادة عدد البعثات الخارجية للجامعات ومراكز البحوث وقطاعات الإنتاج. • إنشاء مراكز بالجامعات لتبادل الخبرات والاحتكاك العلمى والتواصل التكنولوجي.

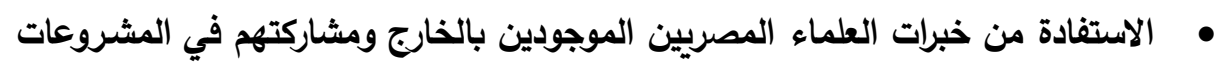
البحثية وبرامج التربب لثباب الباحثين. عقد اتفاقيات لإجراء بحوث مشتركة بين الجامعات المصرية وجامعات في دول متقدمة مشهود لها بالسمعة العلمية الطيبة. 
مجلة كلية التربية بالإسماعيلية - العدد الرابع والأربعون - مايو 9 م

ج- المجال الثالث: الدور المجتمعى للمؤسسات الجامعية:

ويتمثل دور المجلس الأعلى للجامعات في مجال خدمة المؤسسة الجامعية، وفقاً لما

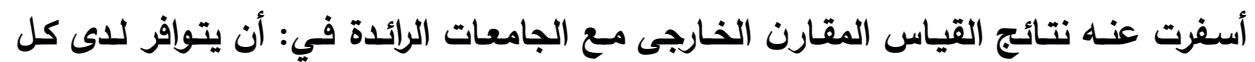
مؤسسة جامعية مراكز تعليم ومصادر متتوعة للمعرفة، وأن تقدم الخدمات المعلوماتية للطلبة

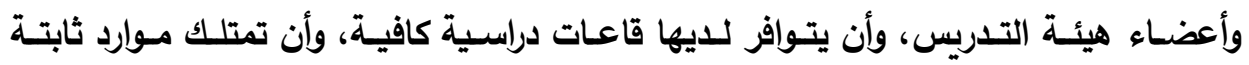
ومستمرة تـعم محساولات تطويرهـا، وأن تسعى إلى تـوفير المـوارد والخدمات اللازمسة للتعلم الفعال، وأن تستخدم المصادر المتاحة في العملية التعليمية، وأن توفر الداعم المالي الـلازم لتطوير وحدات وكليات الجامعة، حيث يعتبر توزيع الموارد على البرامج الدراسية مؤشراً لأداء

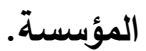

ثالثثاً: مخرجات القياس المقارن الخارجى لتقييم أداء الجامعات المصرية:

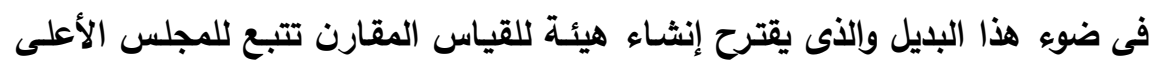

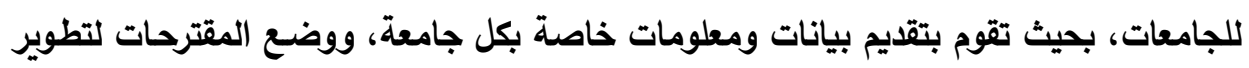

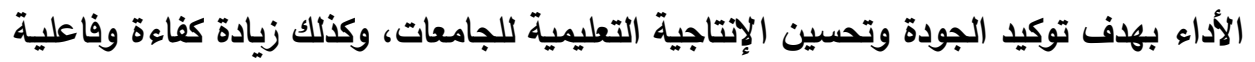

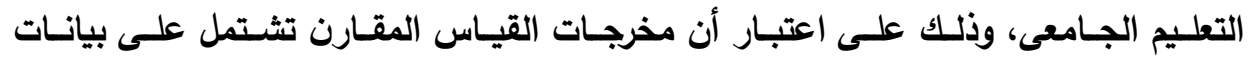
ومعلومات لجوانب القوة وجوانب الضعف للأداء التعليمي.

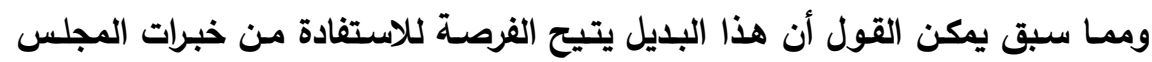

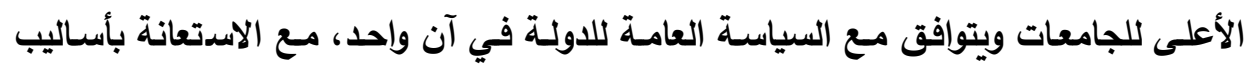

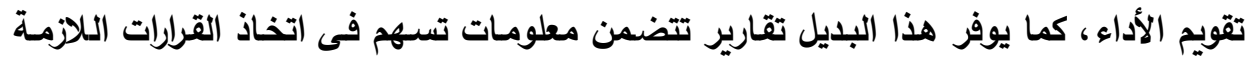
لكل القضايا الاقتصادية والاجتماعية المتعلقة بالجامعات.

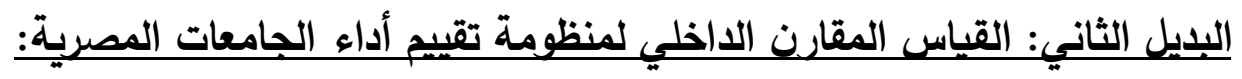

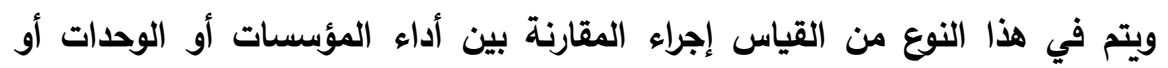

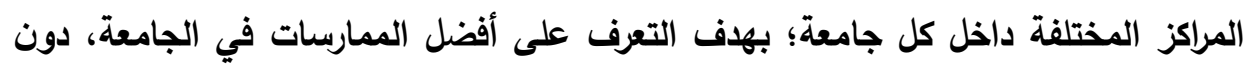

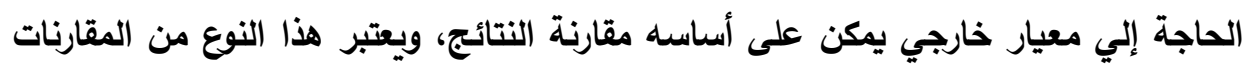
ملاثم للجامعات عالية المستوى. وينطلق هذا البديل من افتراض أن القياس المقارن يتم من خـلال الجامعة والمجالس واللجان التابعة لها وليس من خارجها، وبالتالى فإن هذا البديل يسهم فى تدعيم استقلالية

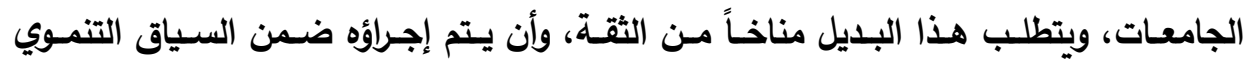


بدائل مقترحة لتطوير منظومة تقييم أداء الجامعات --- د/ محمد ابراهيم عبد العزيز خاطر

للجامعـة، كمـا أنـه يستلزم استخدام مقـاييس ومؤشـرات، ووســائل وأسـاليب للقيـاس عاليـة الكفاءة وسهلة التطبيق. ويمكن أن يتيح هذا البديل الفرصة لاستخدام الإككانات داخل كل جامعة، مثل مجهودات مركز القياس والتقويم ومركز تطوير التعليم الملحق بكل جامعة وعلاقات هذه المراكز بكليات ومعاهد الجامعة، وفى ضوء هذا البديل يجب أن ينتهى دور المجلس الأعلى للجامعات كسلطة

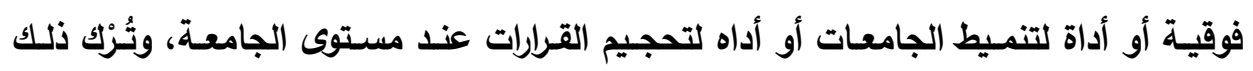
للمجالس الجامعية باعتبارها كيانات أساسية فى الهيكل الجامعى لها صـلاحياتها، كما أنها

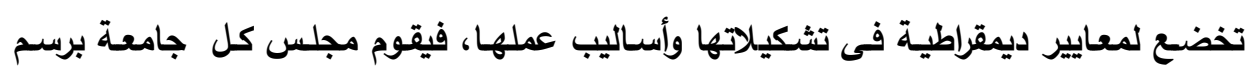

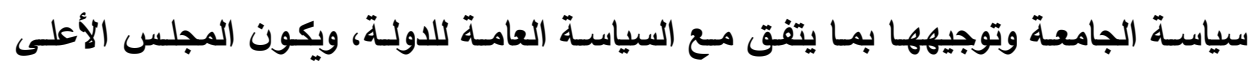

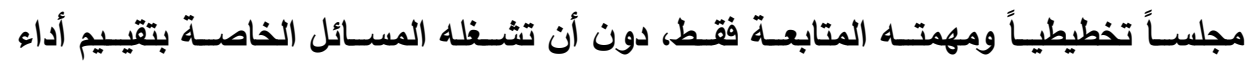
الجامعات.

وينطلق هذا البديل من أمور عديدة أهمها:

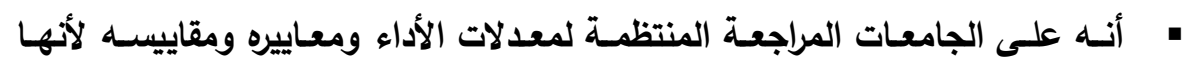
بطبيعتها نسبية ومتغيرة ومتطورة، ومن حق المجتمع أن يطمئن إلى مستوى الأداء

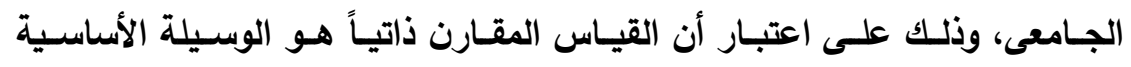
للتطوير، وهى الأداة للحكم على معدلات الكيف فى الأداء التعليمى للجامعات لأنها تنطلق من داخل الجامعات.

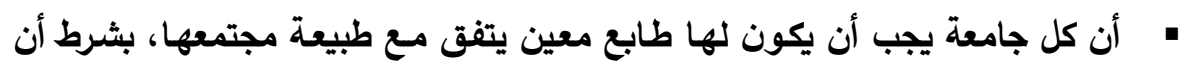
تتميز فيه لجذب هذا المجتمع إليها وإلى مخرجاتها وخدماتها.

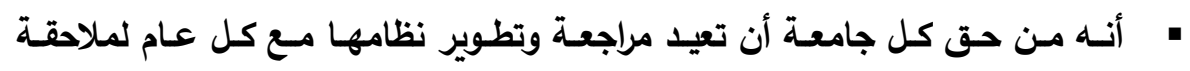
متطلبات المجتمع. ويمكن تقديم هذا البديل على النحو التالي :

أولاً: مدخلات القياس المقارن الداخلى لتقييم أداء الجامعات المصرية: وتتضمن ما يلي:

1 - فلسفة القياس المقارن الداخلي لتقييم أداء الجامعات المصرية وأهدافه:

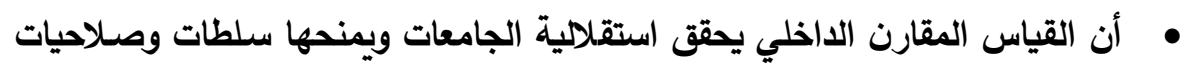
أكبر، عن طريق تحديد أهدافها ومستويات أداء الطلاب والخطط والبرامج الدراسية وأساليب تقويم الطلاب، ووضع استراتيجيات تحقيق ذلك لضمئ لضمان مراجعات الجامعة 
مجلة كلية التربية بالإسماعيلية - العدد الرابع والأربعون - مايو 9 م ـ

لكل مقوماتها التعليمية، وبـلك تصبح الجامعة مسؤولية عن شؤونها، مسن خـلال

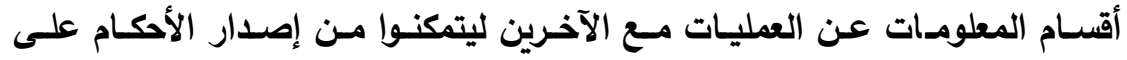

الجامعة فى ضوء السياسات والأولويات المحددة وتوقعات المجتمع.

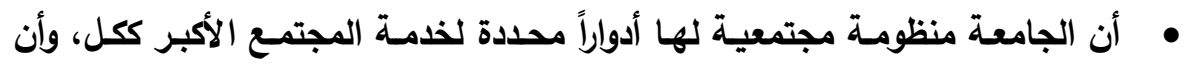

المجتمع يفوضها فى ذلك.

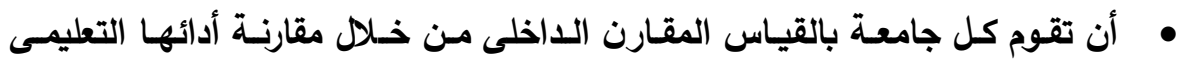

بالأهداف المحددة سلفاً.

• أن تتبنى كل جامعة مقاييس ومؤشرات خاصـة بها، وكذلك أدوات للقياس المقارن

حسب طبيعة كل كلية أو قسم علمي.

وتتحدد أهداف القياس المقارن الداخلى للجامعات المصرية، فيما يلي:

• إعداد تقـارير تفصيلية عـن كل مقومـات الأداء التعليمسى للجامعـة، وذلـك لاتخـاذ

القرارات وإلتخطيط على مستوى الجامعة.

• تقديم معلومات عن الأداء التعليمى للجامعة لكل المهتمين بالأداء التعليمى للجامعة

حتى تحظى بالدعم الاجتماعي.

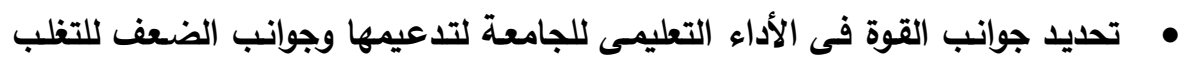

عليها وذلك لتوكيد الجودة وتحسين الإتتاجيـة التعليمية وزيـادة الكفـاءة والفاعليـة

التعليمية للجامعة.

• إيجاد الحلول لبعض الصعوبات الناشئة والتغلب عليها.

r - الجهـات المسؤولة عـن القيـاس المقـارن الـداخلى لتقيـيم أداء الجامعـات

المصريـة: - (المية

وفقاً لهذا البديل تتعدد الجهات التى تمارس القياس المقارن الداخلى فى الجامعات

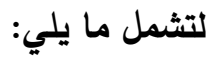

• إنثاء مجلس فى كل جامعة يضم بعض الكفاءات العلمية والثخصيات العامـة ذوى

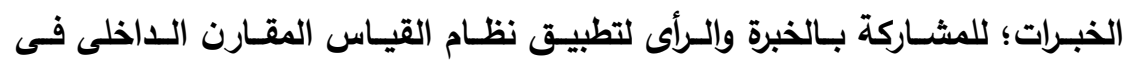

الجامعة.

• تشكيل لجنة عليا على مستوى الجامعة من أفضل العقول والخبرات فيها، ويعهد

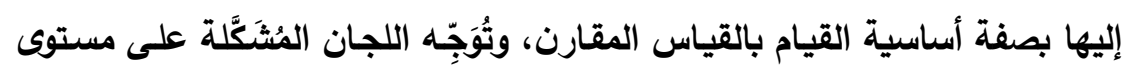

كل كلية، وتتعاون معها فى تنفيذ عمليات القياس المقارن. 
بدائل مقترحة لتطوير منظومة تقييم أداء الجامعات --- د/ محمد ابراهيم عبد العزيز خاطر

• تثكيل لجنة على مستوى القسم الأكاديمي يتولى المحاسبية التعليمية على مستوى

القسم الأكاديمي.

إنشـاء أجهزة للمتابعة والرقابـة فى كل جامعة يلخخل فى تخصصها قياس مدى مـا

حققته الجامعة من أهداف.

• تثكيل ورش عمل لبحث ودراسة الأبعاد التنفيذية للقياس المقارن ذاتياً.

• تشكيل لجنة على مستوى كل كلية أو معهد تابع للجامعة تتولى قياس الأداء على على

مستوى الكلية.

ثانياً: عمليات القياس المقارن الداخلي لتقييم أداء الجامعات المصريةة:

1- تخطيط القياس المقارن الداخلي لتقييم الأداء الجامعى:

فى ضوء هذا البديل يتم تخطيط القياس المقارن من خلال الجهات التابعة للجامعة،

وذلك من خلال المراحل التالية:

• إعداد بيانـات ومعلومـات عن جوانب الأداء التعليمى ومقوماتـه بكل مؤسســة

جامعية.

• عمل مقابلات مع المهتمين بمستويات الأداء بالكليات داخل الجامعة.

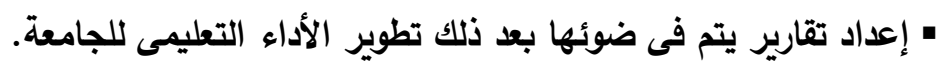

r - تنظيم القياس المقارن الداخلي لتقييم الأداء الجامعى:

وفقاً لهذا البديل يتم القياس المقارن من خلال رصد كل ما يتعلق بالأداء التعليمى من

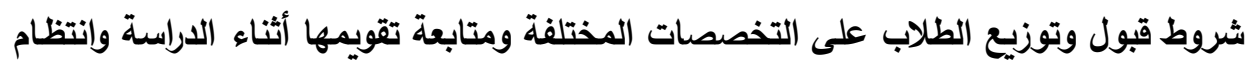

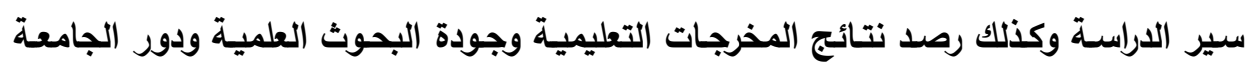

ومؤسساتها في خدمة المجتمع.

وحتى تتمكن الجامعات من تحقيق المنافسة فيما بينها فى ضوء هذا البديل المقترح،

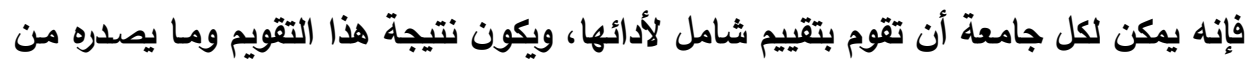

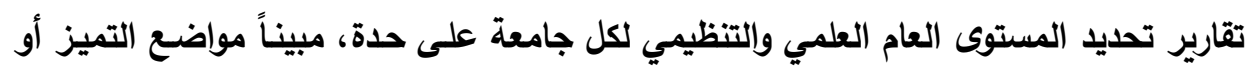
القصسور فى كل جامعـة، ووضـع نظـام لترتيبها علـى قائمسة الجـودة والأداء وتنميـة التمـايز والتفوق بين الجامعات. r - تنفيذ أنشطة القياس المقارن الداخلي لتقييم الأداء الجامعى: 
مجلة كلية التربية بالإسماعيلية - العدد الرابع والأربعون - مايو 9 م ـ

فى هذا البديل يتم القياس المقارن الداخلي وذلك بالاستعانة بوسائل القياس المختلفة،

مثل: المقابلات الشخصية والزيارات الميدانية والاستفتاءات والاختبارات المتنوعة، وكذلك يمكن

اتباع أساليب أخرى للقياس، ومنها:

• الملاحظات أثناء تأدية المؤسسات الجامعية لعملها وتحديد القصور فى الأداء.

• الرجوع الى توصيف وظائف كل مؤسسة جامعية ودراسـة مهامها والأداء الـلازم لكل فل الاءل

مهمة بنجاح.

• الاطـلاع علـى تقـارير الأداء حيث يمكن التعرف علـى مـاطن الضـف فـى الأداء

التعليمى للجامعة والتركيز عليها لتلافى القصور وكذلك معرفة مواطن القوة لتعزيزها.

ويـتم تنفيـذ القيـاس المقـارن الـاخلي لتقيـيم أداء الجامعـات المصرية في المجـالات

أ- المجال الأول: الدور التعليمى والتدريسى للمؤسسات الجامعية:

• الأهداف التعليمية: فى ضوء هذا البديل لابد أن يكون لأيـة جامعة هدف عام تتبثق

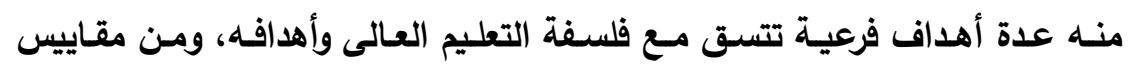

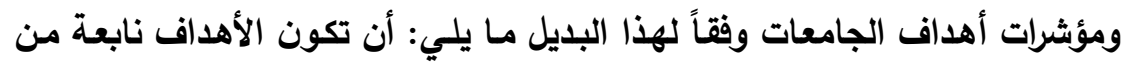

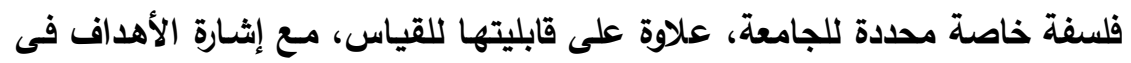

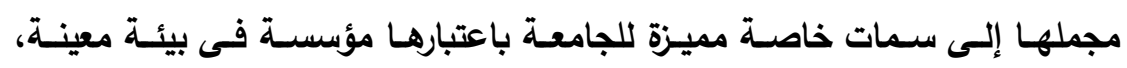

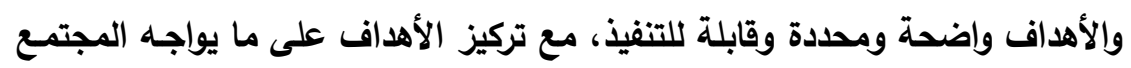
من مشكلات فى مختلف المجالات، وتؤكد الأهداف على مواكبة الخريجين للعصر الأنى سيعيشون فيه.

• سياسات القبول: فحى ضوء هذا البديل يَلْزَم أن تعدد كل جامعة عدد الأمـاكن المتاحة بها فى كل قسم من أقسام كلياتها أو كل كلية حسب إمكاناتها ومتطلبات الدراسـة فيها، كما يَلْزَم إضافة بعض المعايير الأخرى لتقوية نظام القبول بالجامعة مثل إجراء

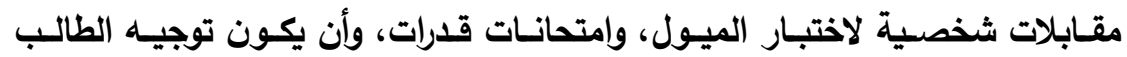
للتخصص الذى يلانمه مبنياً على هذا الأسـاس، وكذلك ضرورة تطبيق نظم توجيه وإرشـاد تربـوي مهنـي بوسـائل متعددة لضـمان اختيـار الطالب المناسب للتخصص فيس المناسب، مـع مراعاة الحياديـة، وتنوع أسـاليب القبول، ووضوح نظم قبول الطلاب لئبل 
بدائل مقترحة لتطوير منظومة تقييم أداء الجامعات --- د/ محمد ابراهيم عبد العزيز خاطر

وإعلاتها، واشثتراك الأقسـام العلمية مـع الكليات فى رسـم وتطبيق سياسـات القبول للطلاب.

الخطط والبرامج الدراسية: فى ضوء هذا البديل يلزم توصيف المقررات الجامعيـة، إذ يتم تكليف الأقسام العلمية بكليات الجامعة ومعاهدها بإعداد ملف المقرر وتوصيف المقرر، وذلك لجميـع المقـررات التـى تقـوم هذه الأقسـام بتدريسها كـل فـى مجـال

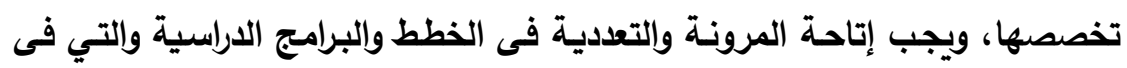
ضوئها ثُتَّاح الحرية للطالب للاختيار من بينها، والتتوع فى الخطط والبرامج الدراسية

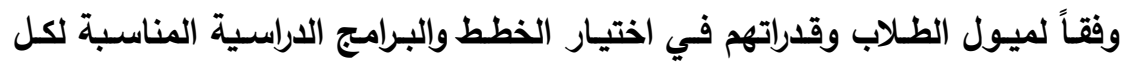
منهم، وتناسب الخطط والبرامج الدراسية مع أهداف الجامعة. • تقويم المخرجات التعليمية: فى ضوء هذا البديل يلزم إنشاء مكتب للاختبار والتقويم التباء

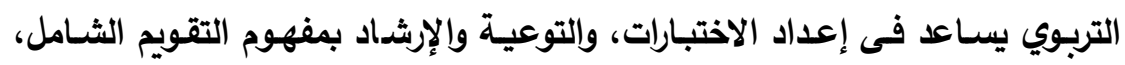

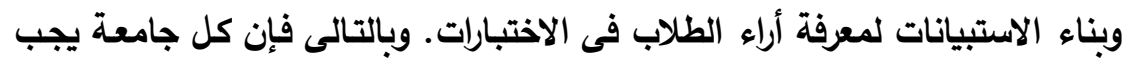

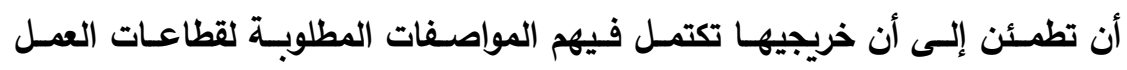

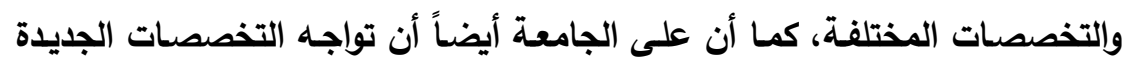

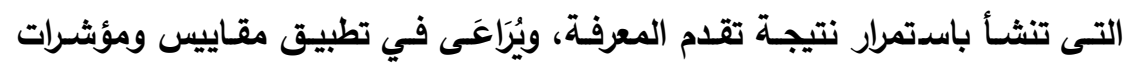

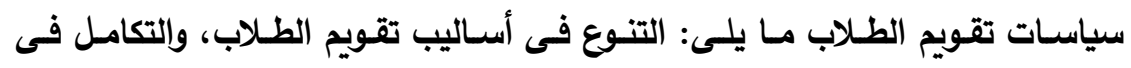
أساليب التقويم وإتسامها بالموضوعية، والثمول فى تقويم الطلاب ليشمل النواحى

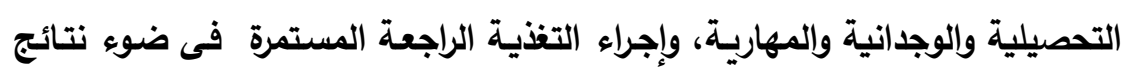
تقوبم الطلاب. ب- المجال الثانى: الاور البحثى للمؤسسات الجامعية: وفقاً للقياس المقارن الداخلى فإن على كل جامعـة أن تحدد وبدقة القوى البشرية البحثية وكفاءتها ونوعيتها، والإمكانيات البحثية والمعملية وأماكنها وتمويلها، كما أن على كل

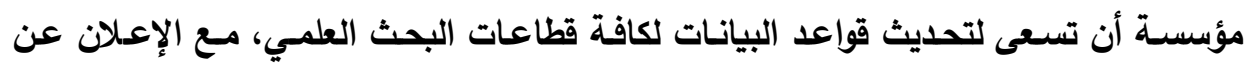

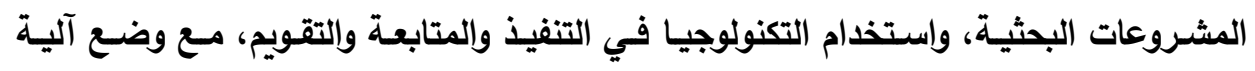
للحوافز المادية والمعنوية؛ لتشجيع الباحثين وتحفيزهم للقيام ببحوث هادفة مرتبطة بمشكلات المجتمع وتطوير قطاعاته.

ج- المجال الثالث: الدور المجتمعى للمؤسسات الجامعية: يمكن إجراء القياس المقارن الاخلى فى مجالات خدمة المجتمع في المجالات التالية: 
مجلة كلية التربية بالإسماعيلية - العدد الرابع والأربعون - مايو 9 م ـ

• مجال التعليم المستمر والتعلم مدى الحياة والبرامج الارشادية والتتموية التي تقدمها

كليات الجامعة لمجتمعها.

• مجال الاستشارات والدراسات التي يقدمها الأساتذة في كليات الجامعة المختلفة. • مجال المرافق والتسهيلات الجامعية مثل: الملاعب الرياضية بأنواعها، وقاعات الاجتماعات والاحتفالات.

• مجال الندوات والمؤتمرات والمحاضرات العامة والخاصة التي تلتقي فيها قيادات فكرية واقتصادية واجتماعية، يُتَاح للمشاركين فيها فرص تبادل الخبرات والمعارف.

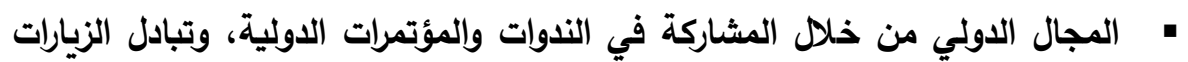
بين الطلبة والأساتذة في الجامعات.

ثالثاً: مخرجات القياس المقارن الداخلي لتقييم أداء الجامعات المصريـة: وفى هذا البديل المُقْتَرَح يعمل القياس المقارن بالجامعات على إنتاج تقارير تتضمن معلومـات تسـهم بقـدر كبير فـى تطوير الأداء التعليمسى للجامعـة، مـن خـلال توكيــ الجـودة

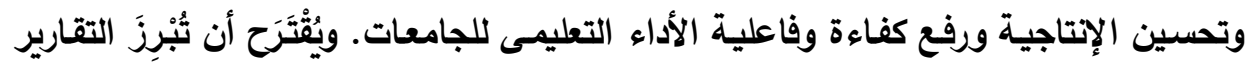
نواحى القصور من أجل تقديم مقترحات بثأن ذلك، ومن تلك المقترحات ما يلي:

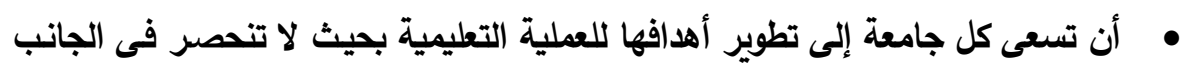

المعرفي، وإنما تمتد إلى الجوانب المهارية وتتمية الثخصية فى صورة متكاملة.

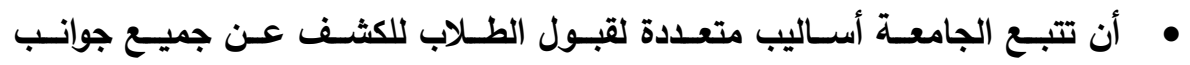
شخصياتهم، واتباع أساليب الإششاد التربوى والمهني عند توزيعهم على التخصصات المختلفة، مع مراعاة تحقيق التوازن بين أعداد الطلاب والإمكانات المختلفة بداخلها.

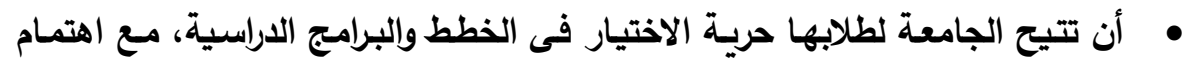
الجامعـة بنشر تلك الخطط والبرامج وتحديد أهدافها؛ حتى يتحقق للطالب الرؤيـة الواضحة التى تمكنه من الاختيار.

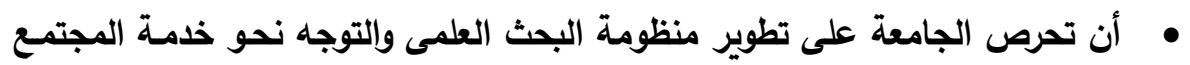
وتنمية البيئة.

وفى ضـوء هذا البـديل المقترح تقوم كل جامعـة بنشـر تقريرهـا السنوى توضـح فيـه برنامجها وأعمالها خلال العام الدراسى متضمناً تقرير منفصل عن القياس المقارن، يتم فيه توضيح مدى التقدم فى تحقيق الأهداف وإنجازها فى الوقت المناسب المُتَّفَق عليه، كما يتم 
بائل مقترحة لتطوير منظومة تقييم أداء الجامعات --- د/ محمد ابراهيم عبد العزيز خاطر

نشر التقارير وتزويد الكليات التابعة للجامعة بصور من هذه التقارير؛ لأخذ ما جاء بها بعين الاعتبار عند إعادة التخطيط للسياسات التعليمية وطرق تنفيذها.

البــديل الثالــث: القيـاس المقــارن التثــاركي لمنظومــة تقيـيم أداء الجامعـات

المصريـة

ترتبط المقارنة التشاركية بالنوعين السابقين (القياس المقارن الخارجي والقياس

المقارن الداخلي)، حيث تتم مشاركة مجموعة من الجامعات في نشاط معين لتحقيق الاستفادة الجماعيـة، هذا إلى جانب قيـام كل جامسعة بقياس أدائها داخليـاً. ويُقْتَرَح فحى هذا البديل أن يقوم المجلس الأعلى للجامعات بالتعاون مـع مجلس كل

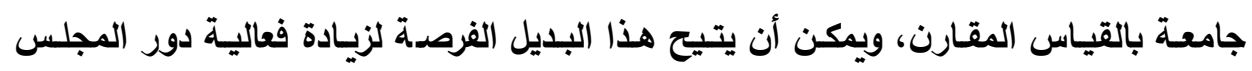

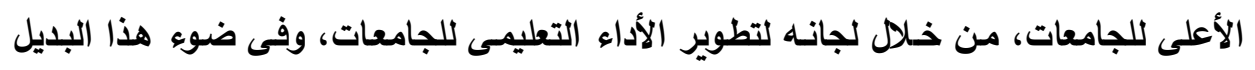

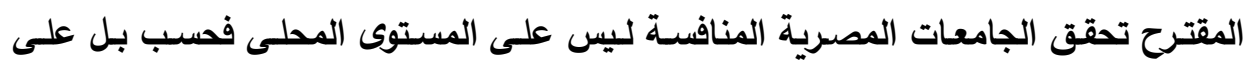
المستوى العالمى أيضـاً، مـع العمل على مواجهة التحديات التحى تلقى بظلالها على التعليم الجامعى. ويمكن تقديم هذا البديل على النحو التالي: أولاً: مدخلات القياس المقارن التشاركى لتقييم أداء الجامعات المصريـة:

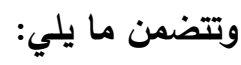

ا - فلسفة القياس المقارن التشاركى لتقييم أداء الجامعات المصرية وأهدافه: تنطلق فلسفة هذا البديل مـن مسـاهته فحى تحسين قدرة كل جامعـة على مواجهة

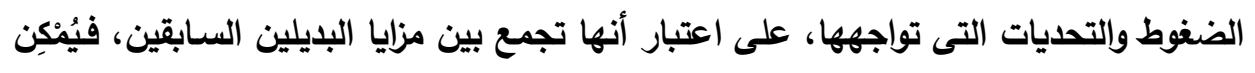

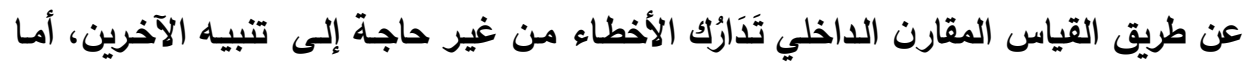
عن طريق القياس المقارن الخارجى يمكن تحقيق المنافسـة ويمكن عن طريقها أيضاً ضمان تصحيح المسار وتحقيق الأهداف فى إطار المنافسة. وهذا البديل تتحقق فيه شروط الملاءمـة بين أغراض القياس المقارن من الجهات الجهات

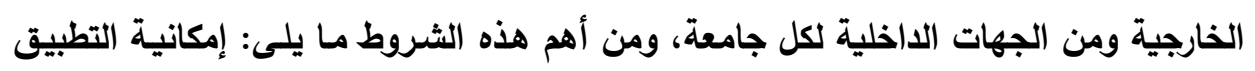

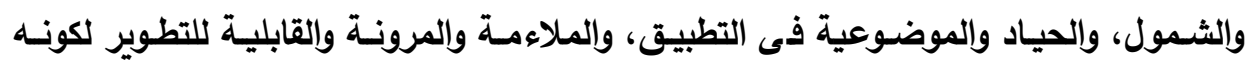
يراعى ظروف كل جامعة، ويهدف هذا البديل إلى تحقيق ما يأتي: 
مجلة كلية التربية بالإسماعيلية - العدد الرابع والأربعون - مايو 9 م

• التقييم الذاتى للأداء الجامعى بما يفيد فى تطوير هذا الأداء من خلا تدعيم جوانب

القوة وعلاج جوانب الضعف.

• السماح للجامعات بالاطلاع على جوانب القوة وجوانب الضعف فى الأداء التعليمى

للجامعات الأخرى، وبالتالى تنمية روح المنافسة بين الجامعات.

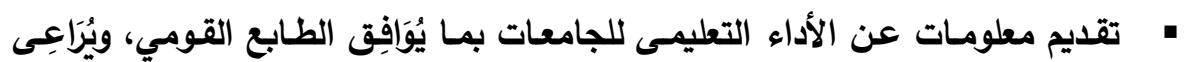

أيضاً مواصفات التنافسية العالمية للجامعات ذات الريادة.

r - الجهات المسؤولة عن القيـاس المقـارن التشـاركي لتقيـيم أداء الجامعات

المصريـة:

فى ضوء هذا البديل يتم التأكيد على تحقيق مبدأ الاستقلالية الجامعية، ولهذا تتعدد

الجهات التى تمارس القياس المقارن فى الجامعات لتشمل عدد من وحدات القياس المقارن،

ترتبط بوحدات فرعية داخل كل كلية من كليات الجامعة، وترتبط أيضـا بالوحدات المشابهة في في وهي

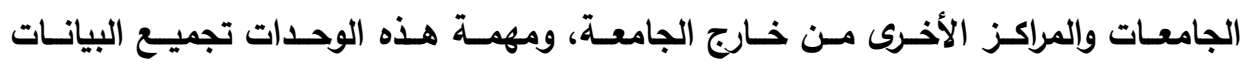

والإحصاءات والتخطيط والتقويم وإدارة عمليات القياس المقارن فى الجامعة وكلياتها.

وفى ضوء مـا سبق يَلْزَم إعادة النظر في وظائف المجلس الأعلى للجامعـات؛ بحيث

يمثل حلقة وصل بين الجامعة والدولة، ويتحول من كَوْنَه هيئة مركزية تتولى مسؤولية تخطيط السياسة العامة للتعليم الجامعى، والتنسيق بين الجامعات وتنظيم قبول الطلاب فى الجامعات وتحديد أعدادهم وفقاً لسياسـة الدولـة فقط، إلى مجلس وسيط بين الجين الجامعة والدولـة، ويأخذ أيضاً بآراء الجامعات ويستجيب لتطلعاتها، وكذلك اشتراك القيادات التنفيذية فى قطاعات العمل والإنتاج فى عضوية هذه المجالس، على أن تتولى مـع القيادات الجامعية صياغة الخطط والبرامج التى تتفق والاحتياجات الفعلية لهذه القطاعات.

ثانياً: عمليات القياس المقارن التثاركي لتقييم أداء الجامعات المصرية: فح ضوء هذا البديل يقوم المجلس الأعلى للجامعات بإنشاء مركز للقياس المقارن فى جميع الجامعات، وينبثق عن هذا المركز عدد من اللجان الفرعية (لجان القياس المقارن في

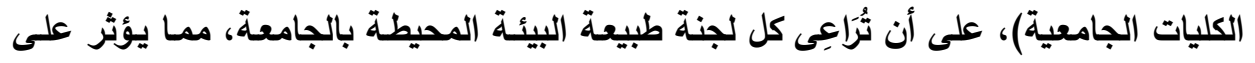

$$
\text { طبيعة الاراسة بها والتخصصات التى تحتويها. }
$$

1- تخطيط القياس المقارن التثاركي لتقييم الأداء الجامعى:

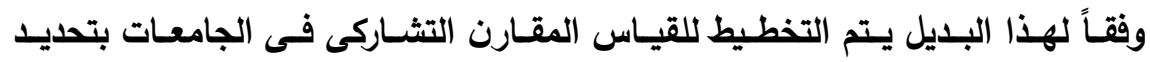

المستويات المطلوب تحقيقها أو تنميتها والارتقاء بها للشيء المراد عن طريق خطة تنفيذية 
بدائل مقترحة لتطوير منظومة تقييم أداء الجامعات --- د/ محمد ابراهيم عبد العزيز خاطر

معينة، إلى جانب تحديد المقاييس والمؤشرات التى يمكن عن طريقها قياس الجوانب المطلوب تقيمها.

r - تنظيم القياس المقارن التشاركي لتقييم الأداء الجامعى: يَلْزَم تنظيم القياس المقارن التشاركى فى الجامعات قيام كل جامعة بعملية تقييم ذاتي

للأداء التعليمى بها، وتقدم للجان القياس المقارن تقريراً مفصلاً عن مستوى الأداء التعليمي بها مـع التقريـر، وتقوم لجـان القياس المقـارن التشـاركى بزيـارة الجامعات تبعاً لنظام تقويم الأداء ومعاييره المختلفة، وتكتب بعدها اللجنة تقريراً عن مستوى الأداء بالجامعة، وفى نهاية

التقرير تقدم اللجنة مجموعة من المقترحات والتوصيات التي ينبغي على الجامعة اتباعها. r- تنفيذ أنشطة القياس المقارن التشاركي لتقييم الأداء الجامعى: وفقـاً لهـا البـديل يـتم القيـاس المقـارن التشـاركى مـن خـلال الاعتمـاد على التقـارير

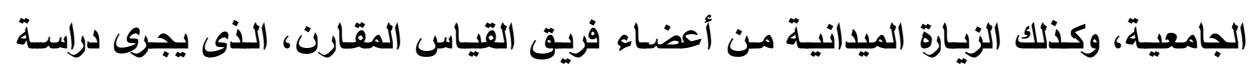
شاملة ثم يقوم بمناقشة نتائجها مع مجلس الجامعة، وذلك عقب الانتهاء من عمليات القياس

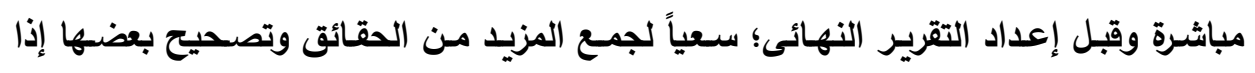
تَطَّبَ الأمسر ذلك، ومـن المسـائل العامـة التى يتم مناقشتها خطـة العمـل والإصـلاح والجدول

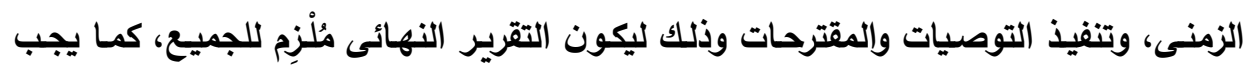
متابعـة التقرير للحكم على مدى الاتتزام بها، وحتى يستطيع فريق القياس المقـارن الزائر للجامعة إصدار الأحكام لابد من الاستناد إلى عديد من المصادر لتجميع الأدلة على الأداء التعليمى، ويشمل ذلك ما يلي:

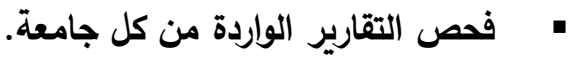

• المناقشة المفتوحة والحرة مـع بعض الطلاب وهيئات التدريس؛ للتعرف على آرائهم

فحى مقومات الأداء التعليمى للجامعة.

• فحص نتائج الامتحانات بعد تحليلها.

• ملاحظة مباشـرة لبعض الخطط والبرامج الدراسية وتقـارير تقويم الأداء للأقسـام

العلمية.

ويتم تنفيذ القياس المقارن التشـاركي لتقييم أداء الجامعات المصرية في المجالات 
مجلة كلية التربية بالإسماعيلية - العدد الرابع والأربعون - مايو 9 م ـ

أ- المجال الأول: الدور التعليمى والتدربسى للمؤسسات الجامعية:

• الأهداف التعليمية: يُرَاعِى هذا البديل في الأهداف التعليمية أن تكون واقعية وإجرائية

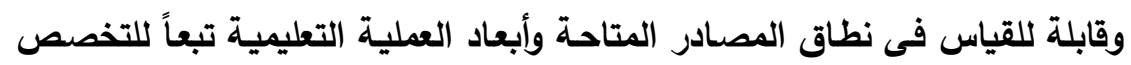

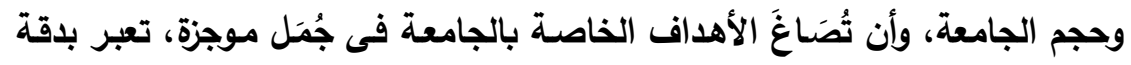
عن طبيتها وطبيعة الجمهور الذى تتطع لخدمته، ولذلك يجب أن تكون للجامعة الجية أهداف واضحة ومُعْلَنَة للجمهور الخارجى. • سياسات القبول: فى ضوء هذا البديل يتم تحديد سياسات القبول باشتراك الجامعات الجات

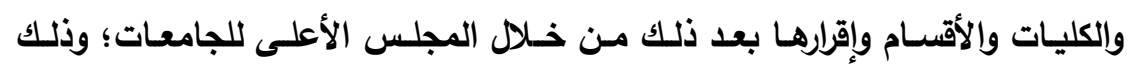

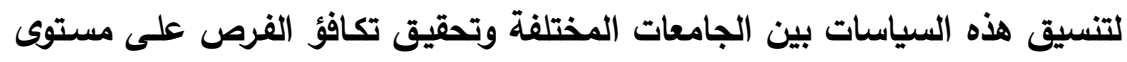

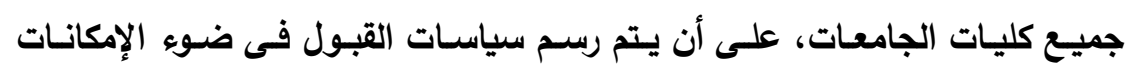

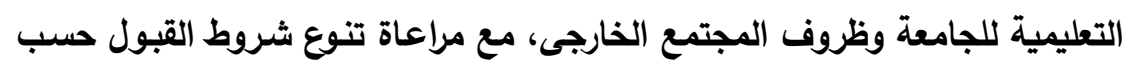

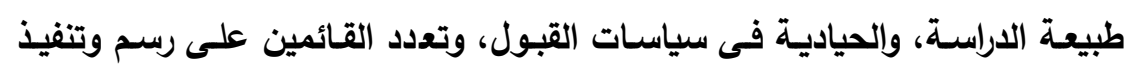
سياسات القبول. الخطط والبرامج الدراسية: وفى ظل هذا البديل تُشْنَفْدَمُ مقاييس ومؤشرات عديدة

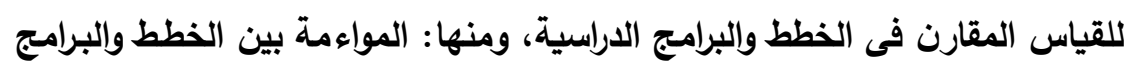

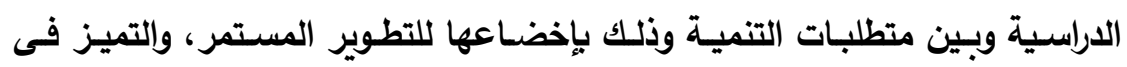

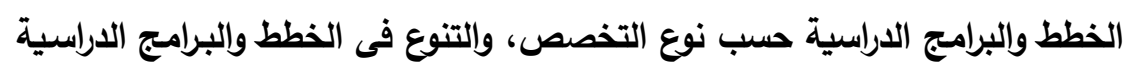

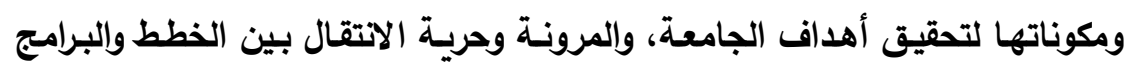

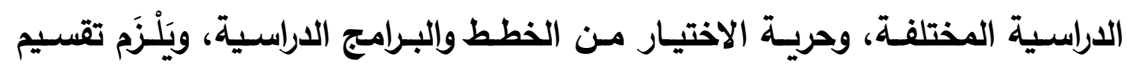

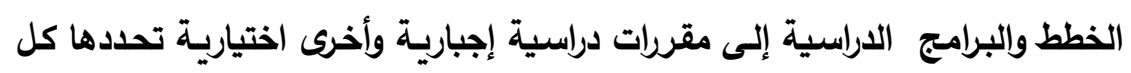
كليـة حسب اهتماماتها، كمـا يجب تحقيـق مبدأ التكامـل والتـوازن بقدار الإمكسان

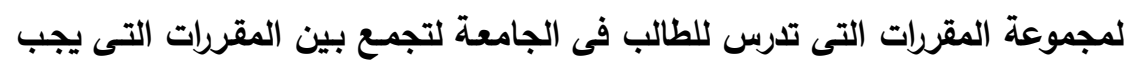

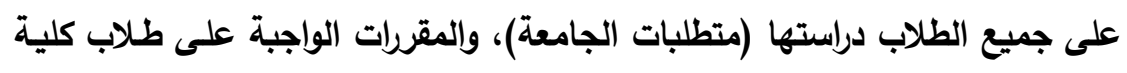

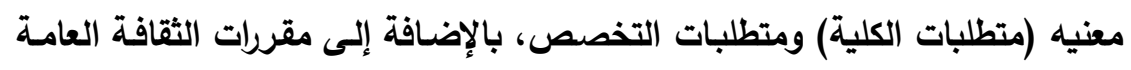

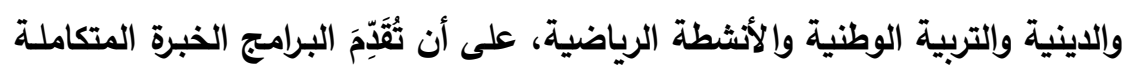

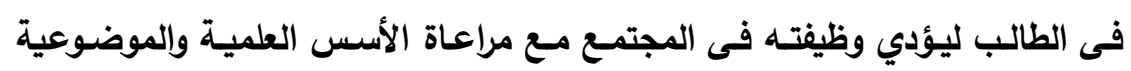
لمسايرة التقدم العلمي ورَكْبِ التطور. • تقويم المخرجات التعليميـة: فى ضوئ هذا لتطور، البديل تحدد الجامعة معايير أكاديميـة 
بدائل مقترحة لتطوير منظومة تقييم أداء الجامعات --- د/ محمد ابراهيم عبد العزيز خاطر

لعملية تقويم الطلاب، والمشـاركة فى عملية التقويم وإجراءات الامتحانـات، وكذلك اشتراك الهيئات المهنية المتخصصة فى عمليات التقويم حتى تتمكن الجامعة من الحفـاظ على مستوى الخريج للوفاء باحتياجـات سـوق العمل، ويتم تطبيق أسـاليب

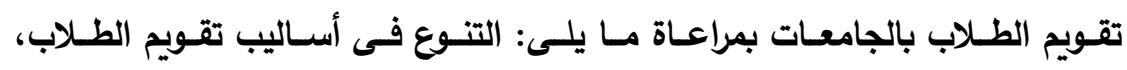

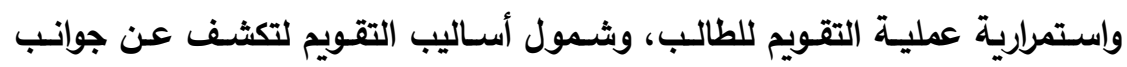
شخصية الطالب، واستعانة الجامعة بآليات لاستخدام نتائج تقويم الطلاب، وبالتالى وئى الاستفادة من هذه النتائج فى عملية التخطيط المستقبلي بها، والوقوف على أسباب التهاب القصور والضعف وتطوير الأداء بها. ب- المجال الثانى: الدور البحثى للمؤسسات الجامعية: يستند البديل المُقْتَرَح في هذا المجال على تحديد معايير لقياس وتقويم كفاءة البحث العلمي بالجامعات، على أن تتضمن ما يلي: البلي:

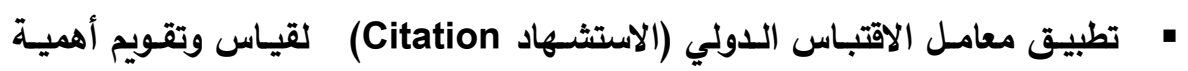
البحوث المنشورة في مختلف المجالات التخصصية بالمؤسسات الجامعية.

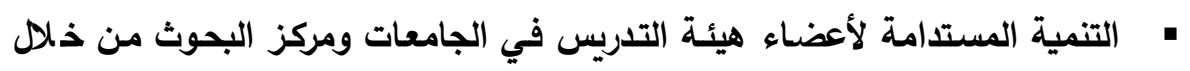

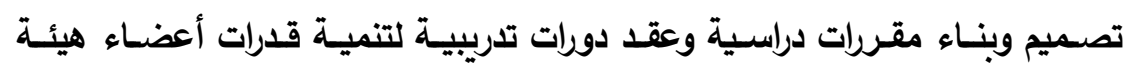
التدريس في جدارات البحث العلمي مثل: (الاستثمار في البحث العلمي، استراتيجية

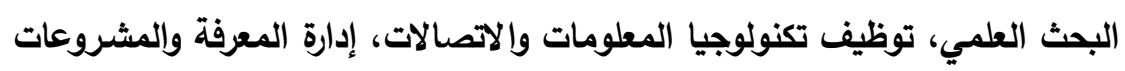

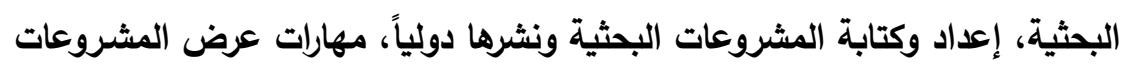

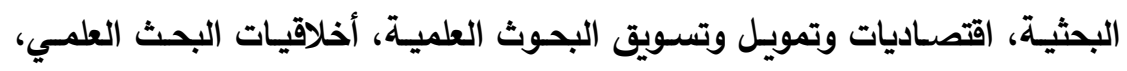
وأخلاقيات وآداب المهنة).

ج- المجال الثالث: الاور المجتمعى للمؤسسات الجامعية: وبنعكس هذا البديل فيما يلي: • اتباع كل جامعة لسياسات واضحة فى تنظيم شؤونها المتعلقة بالمجتمع الخارجى ومؤسساته، مع وضع رؤى استراتيجية مستقبلية لزيادة مصادر التمويل الذاتية. • امتلاك الجامعة قاعدة بيانات متكاملة عن الشركات والهيئات والجمعيات المستفيدة من خدماتها في المجتمع، وأن تعمل على تقديم برامج لخدمة المجتمع كمصدر

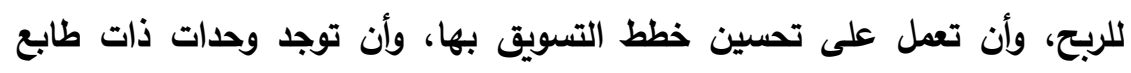


مجلة كلية التربية بالإسماعيلية - العدد الرابع والأربعون - مايو 9 م ـ

خاص عديدة بالجامعة، وأن توفر التمويل اللازم للمشروعات البحثية التطبيقية

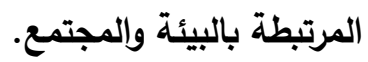

• طرح المجلس الأعلى للجامعات لمبادرة وطنية للمسؤولية الاجتماعية، تشمل برامج

وندوات تثقيفية إلى كافة شرائح المجتمع، وتوضح لهم أهمية المسؤولية الاجتماعية، والدور الذي يمكن أن تؤديه في تحقيق التعاون والتكافل الاجتماعي

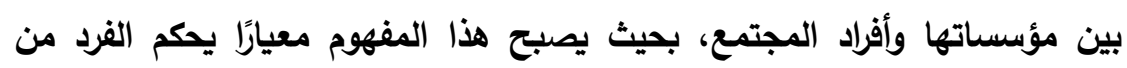
خلاله على أداء هذه المؤسسات التابعة لها.

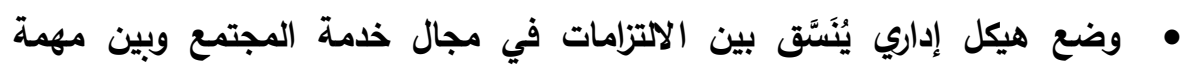

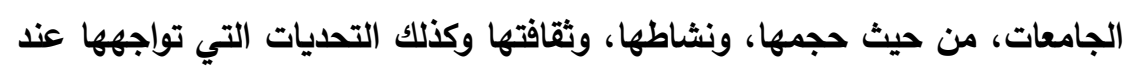
القيام بعملية تخطيط جودة خدمة المجتمع على المدى البعيد، وتصبح المسؤولية الاجتماعية جزياً رئيساً من أنشطة الجامعات تتم متابعتها.

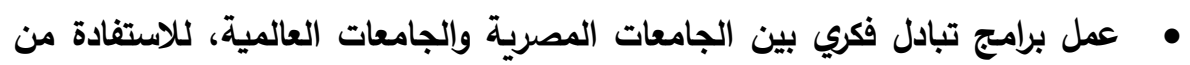
تجارب تلك الجامعات الأخرى في كل ما هو جديد في برامج المسؤولية الاجتماعية للتعليم الجامعي. • متابعة المجلس الأعلى للجامعات لكل جامعة لتوفير البنية التحتية اللازمة لأداء

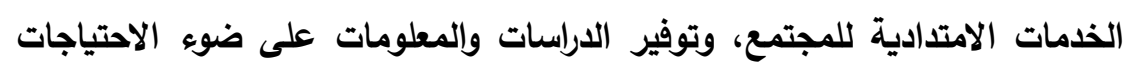
الفعلية للمجتمع.

ثالثاً: مخرجات القياس المقارن التشاركي لتقييم أداء الجامعات المصرية: يعمل هذا البديل على إنتاج تقارير القياس التى تتضمن معايير تساعد على تطوير الأداء التعليمى، من خلال توكيد الجودة وتحسين الإنتاجية التعليمية للجامعات ورفع الكفاءة

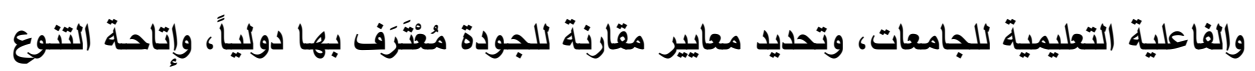
تفادى الأنماط الموحدة بين الجامعات، وإشراك كل أصحاب الثأن كأطراف فى عملية تقييم

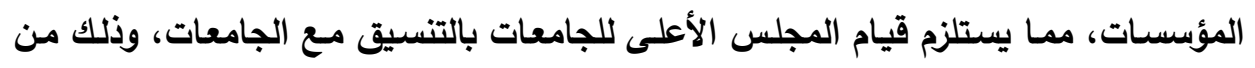
خلال سلسلة متصلة من الإجراءات التى تبدأ من الأقسام العلمية والكليات والجامعات. الموازنة بين البدائل المقترحة: تهـدف الموازنـة بين البـائل المقترحسة إلى التعرف على مـدى ملاءمسة هذه البدائل

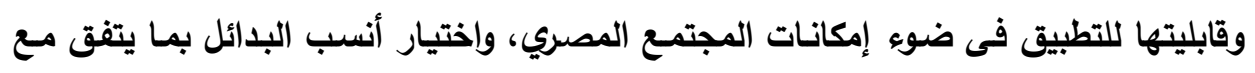
ظروف وإمكانات المؤسسات الجامعية المصرية، ومن معايير الموازنة بين البدائل المقترحة ما لمائ 
بدائل مقترحة لتطوير منظومة تقييم أداء الجامعات --- د/ محمد ابراهيم عبد العزيز خاطر يلي:

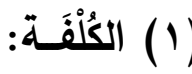

يُقْصَد بالكلفة في هذا السياق التكلفة المادية التى يتطلبها تنفيذ البديل، وهنا يشترط تحقيق أقل تكلفة ممكنة فى البديل المقترح. وتتفق جميع البدائل المقترحة فى مقابلة الإمكانات المتاحة والتمويل الـلازم للتطبيق،

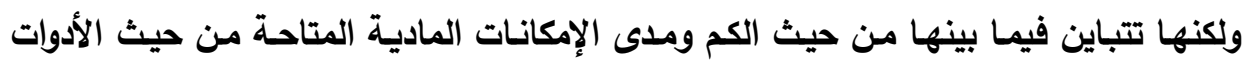
وقرة النظام على تمويل ذاته بالاشتراك مع وزارة التعليم العالى حيث إن إن:

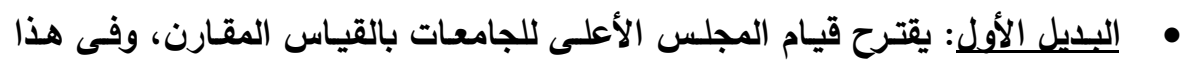

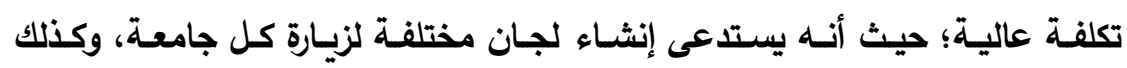
الحصول على بيانات مختلفة من كل جامعة من الجامعات الرائدة المختارة لاراسة الجاء مقومات الأداء المتميز بهذه الجامعة. • البديل الثانى: يقترح قيام مجلس كل جامعة بالقياس المقارن الداخلى، وفى هذاء

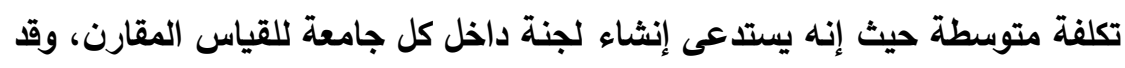
يتطلب ذلك تفرغ أعضاء هذه اللجنة لهذا الغرض.

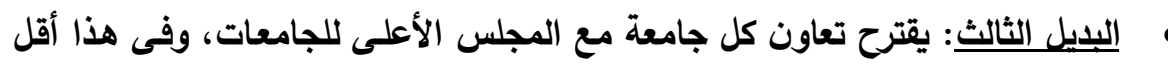

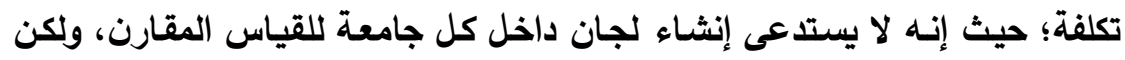
تضمين مسؤولية مجلس الجامعة عن القياس المقارن من خلال مجلس التعليم

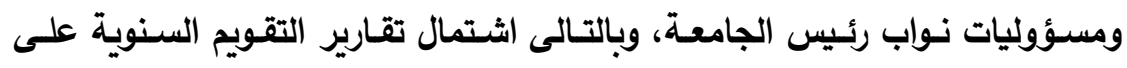

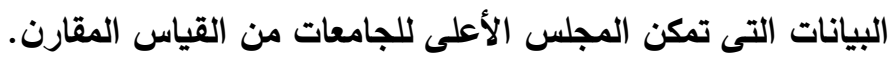
وبالتالى يعتبر البديل الثالث أقل تكلفة بالمقارنة بالبديلين الآخرين.

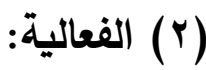

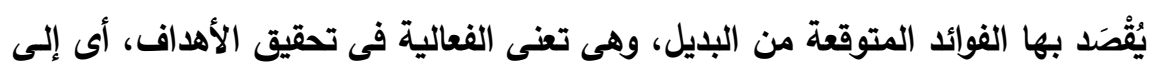

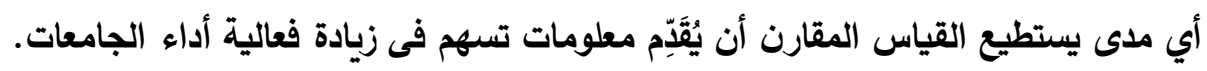

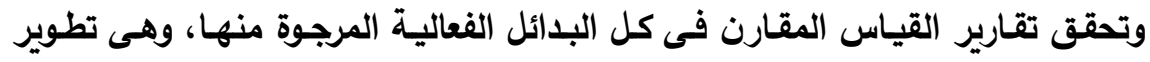

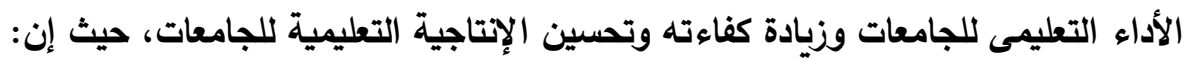

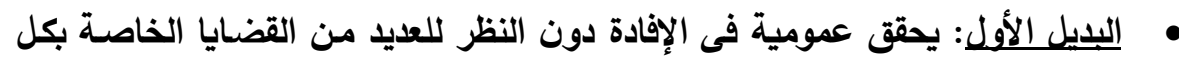

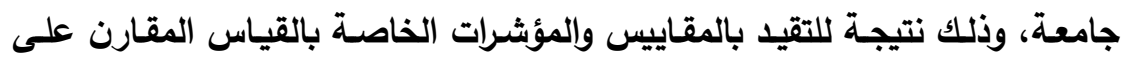

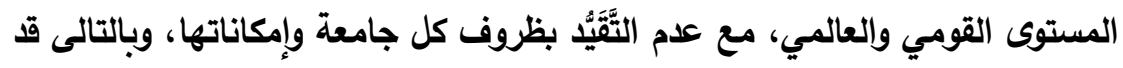


مجلة كلية التربية بالإسماعيلية - العدد الرابع والأربعون - مايو 9 م ـ

يحقق هذا البديل فعالية عالية فى جامعة معينة وفعالية منخفضة فى جامعة أخرى. • البديل الثاني: يركز على كل جامعة على حدة دون الأخذ فى الاعتبار المنافسـة بين الجامعات، وق ينتج عن ذلك تفاوت الأداء التعليمى لكل جامعة عن الأخرى، الأمر

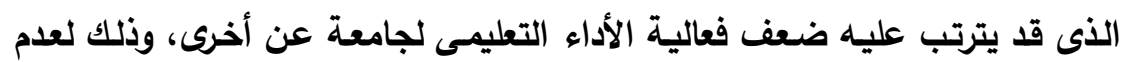

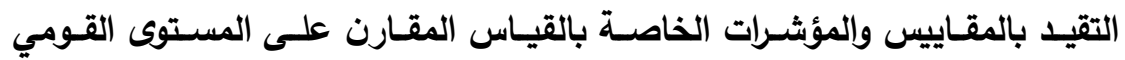
والعالمي. البليل الثالث: يركز على تعاون كل جامعة مع المجلس الأعلى للجامعات فى القياس

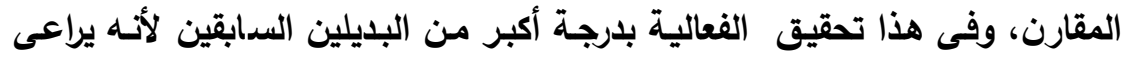

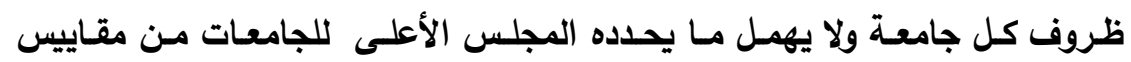
ومؤشرات للقياس المقارن على المستوى القومى والعالمى، وبالتالى فإن هذا البديل هو الأنسب.

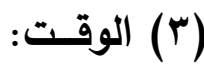

يُقْصَد به الفترة الزمنية الذى يستغرقها تنفيذ البديل، بمعنى الوقت المناسب الذى يعالج الحل المختار المشكلة، فى إطارها الحالى وليس بعد حدوث المثكلة. وتتفق البدائل كلها فى تخصيص الوقت الـلازم للقياس المقارن، ولكنها تختلف فى لـ طول هذا الوقت، حيث إن: • البديل الأول: يقترح أن يتم القياس المقارن الخارجى سنوياً، ووفقاً لهذا يتم اتخاذ إجراءات التطوير العام التالى، ولعل ذلك يؤدى إلى ضياع جزء من الوقت فى قيام الجامعة بأداء تعليمى قد يكون في بعض الأحيان قليل الفائدة.

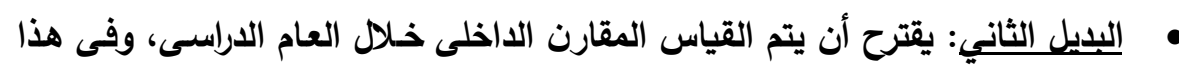
البديل، قد يحدث ضياع للوقت فى تجميع معلومات قد تكون غير مفيدة نظراً لأن هئ

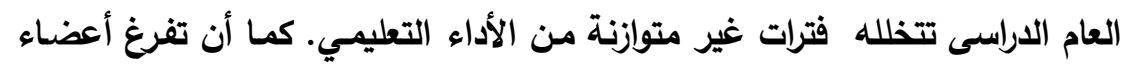

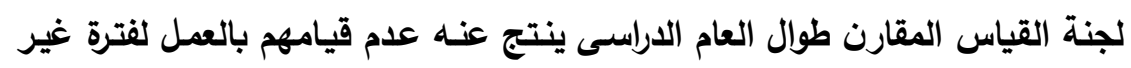
قليلة من العام الاراسي لعدم وجود بيانات للقياس سوى دراسـة مدى انتظام تدريس المحاضرات. • اللبديل الثالث: يُقْتَرَح أن يتم القياس المقارن التثاركى خلال مراحل الأداء التعليمس، وذلك قبل بداية العام الدراسـى ونهاية الفصل الدراسـ الأول ونهاية الفصل الدراسى الثانى، وفي هذا عدم ضياع للوقت، بل الاستفادة القصوى من الوقت، وبالتالى فإن 
بدائل مقترحة لتطوير منظومة تقييم أداء الجامعات --- د/ محمد ابراهيم عبد العزيز خاطر

هذا البديل هو الأفضل حيث أن الوقت المستغرق فى التنفيذ يتناسب حسب طبيعة الأداء التعليمى لكل جامعة، ولا يتم ضياع الوقت فى قيام الجامعة بأداء تعليمى غير

$$
\text { الاقتصاد فرغوب فيه. الجها: }
$$

ويعنى ذلك أنه يُفَضَّل البديل الذى يعطى أفضل النتائج بأقل جها ممكن، وتتفق جميع

البدائل المقترحة فى بذل الجهر للتففيذ، ولكنها تتباين فى الاقتصاد فى هذا الجها، ديث إنها:

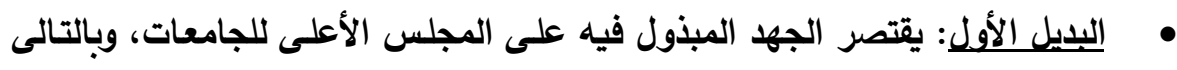
قد لا يكون ذلك دافعاً للاهتمام بتقارير القياس المقارن الخارجى من قبل الجامعات.

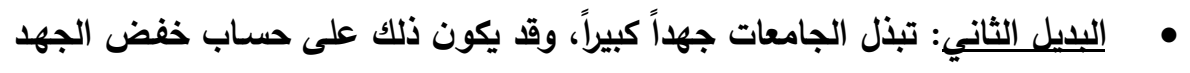

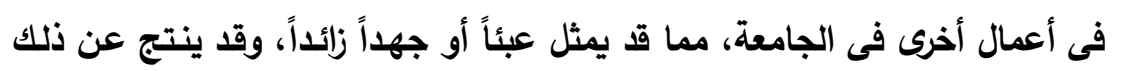
انخفاض كفاءة تنفيذ هذا البديل. البديل الثالث: الجهد المبذول فيـه يتم توزيعـه بين المجلس الأعلى للجامعات، هوهات ومجالس الجامعات، وبالتالى فإن هذا البديل هو الأفضل.

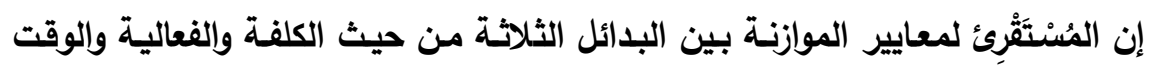

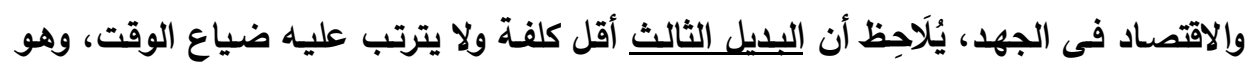

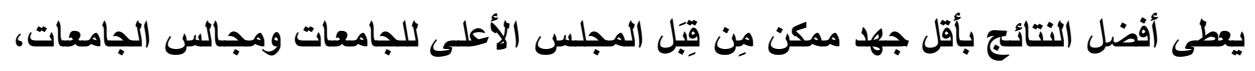
وبالتالى فهو أفضل بديل بالمقارنة بالبديلين السابقين.

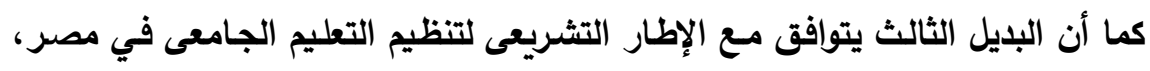
حيث يجمع ما بين المركزية والللامركزية في إدارة المؤسسات الجامعية وتقييمها. متطلبات نجاح القياس المقارن لمنظومة تقييم أداء الجامعات المصرية: من الضرورى الإسراع في إعداد وتنفيذ عمليات القياس المقارن؛ نظراً للتغيرات التي قد تحدث في البيئة الداخلية والبيئة الخارجية للمؤسسات الجامعية، فالأهداف التي تتم المقارنة معها هي أيضاً أهداف متحركة ومتطورة باستمرار، وعلى ذلك يتطلب نجاحُ الموات المؤسسات الجامعية المصرية لتنفيذ القياس المقارن بأعلى قدر من الدقة، توافرَ المتطلبات التالية:

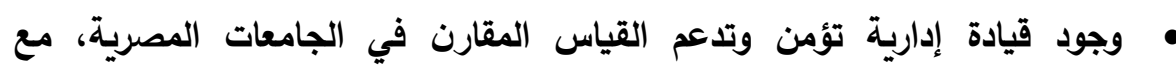
الاختيار الدقيق والسليم لشركاء المقارنة، وتهيئة المناخ الثقافي المناسب في 
مجلة كلية التربية بالإسماعيلية - العدد الرابع والأربعون - مايو 9 م

المؤسسات الجامعية، مع اختيار فرق العمل ممن تتوافر فيها الخبرة الجيدة في القياس والمقارنة وإعداد خرائط العمليات ومخططات السبب والمردود. • استخدام أساليب القياس المناسبة للتعرف على الأداء الحالي للمؤسسة، وتحديد العمليات المراد تحسينها بثكل دقيق قبل البدء في إجراء الاتصالات مع شركاء المقارنة، ممن تتوفر لايهم الرغبة الصادقة في تبادل المعلومات والخبرات. القياس المباثر المبنى على المعلومات، وبخاصة فى الأنثطة التعليمية والبحثية والخدمية، مع استخدام طرق التحسين المختلفة، والتي تعني التغيير الجديد لعمليات المؤسسة وأفرادها كي تصبح أكثر كفاءة وفاعلية، وإعادة هندسة العمليات، وتوفير أنظمة جيدة للمعلومات والبيانات. • استطلاع آراء واقتراحات وإنطباعات الأفراد والهيئات ذات الاتصال المباشر بالجامعة واليات

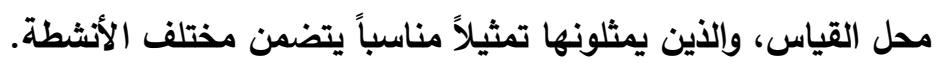

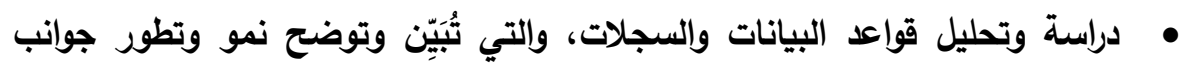
الأداء المختلفة، حيث إن هذه القواعد تمكن من الحصول على بيانات هامة، مثل: أعداد الطلاب وطريقة اختيارهم وتوزيعهم على تخصصات الجامعة، والخطط والبرامج الاراسية، وأساليب تقويم الطلاب، علاوة على الرصد الدورى للعملية التعليمية والمؤثرات عليها داخلياً وخارجياً. • تصميم استبيانات تجمع بين الجوانب الكمية والكيفية، لتجمع البيانات من أعضاء واءئاء هيئة التدريس والإداريين والفنيين المساعدين والطلاب، إلى جانب كافة المستفيدين من منظومة الأداء الجامعى. مالادرين • الزيارة الميدانية، وهى تتم بناءً على أداة الملاحظة المقننة، التى يمكن أن تُظْهِر مؤشرات التعليم الجامعى، ويقوم بها فنيون قادرون على هذا العمل، ثم تُجْمَعُ بيانات

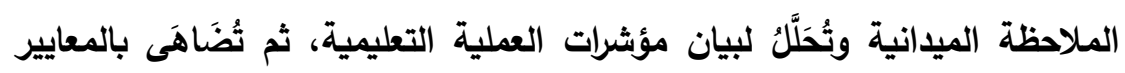
الموضوعية، وتهاف الزيارة الميدانية إلى تقييم العوامل التى يصعب تحديدها بوضوح فى الاستبيان، فمثلاً هناك المناخ الفكرى للطلاب، وهو يعبر عن العوامل الكيفية، ويُعْتَبر غير ملموس ويصعب تحديده فى بيان كتابى، وتسهم الزيارة الميدانية فى مساعدة المؤسسة الجامعية على تحديد نقاط الضعف ونقاط القوة فى وئ البرنامـج موضوع التقييم. 
بدائل مقترحة لتطوير منظومة تقييم أداء الجامعات --- د/ محمد ابراهيم عبد العزيز خاطر

\section{المراجع}

1- هاني رزق عبدالجواد الألفي، "دراسة مقارنة لنظم الحوكمة المؤسسية للجامعات بكل من إنجلترا وكندا وإمكانية الإفادة منها فى مصر"، مستقبل التربية العربية: تصدر عن المركز

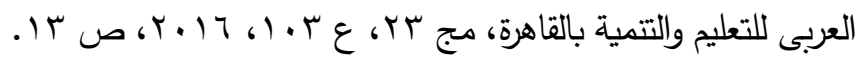

r- منال بنت حسين الحميدي، "واقع تطبيق الحوكمة الرشيدة ومعوقاتها بجامعة الطائف من

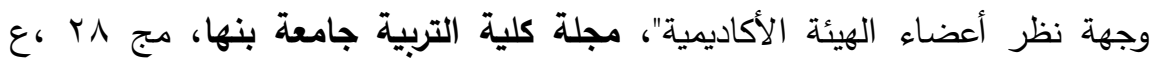

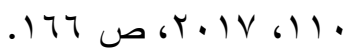

r- عبدالوهاب شرقاوي، "بالقياس المقارن يمكن لمصر الاستفادة والتعلم من تجربة التعليم

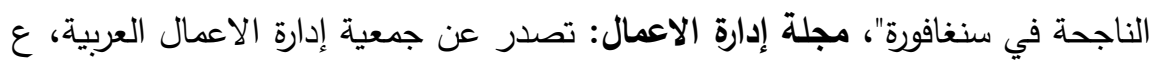

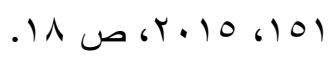

Stadler, C. , "The four principles of enduring success", Harvard - $-\varepsilon$ Business Review, Vol. 85, No. 4, 2017, p. 72.

Committee on Science, Engineering, and Public policy, -0 Experiments in International Benchmarking of U.S. Research

Fields, National Academies Press, Washington D.c, 2018, p. 68. Weeks, Patricia, "Benchmarking in Higher Education: An Australian - Case Study", Innovations in Education and Training International, Vol.37, No. 1, 2017, p. 21. - V أحمد إبراهيم أحمد، وآخرون، "تقويم أداء الجامعات المصرية باستخدام بطاقة الأداء

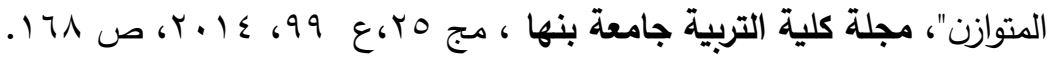
1- - رانيا حسن محروس، تفعيل الحوكمة الأكاديمية التثاركية بالجامعات المصرية: دراسة

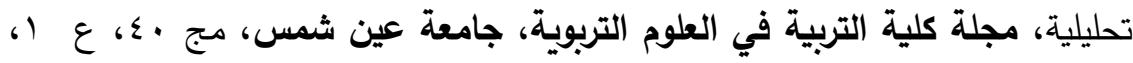

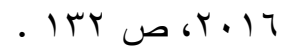

9- حسام حمدي عبدالحميد، "قياس الفجوة بين الإدراكات والتوقعات في جودة الخدمة التعليمية بالجامعات المصرية باستخدام مقياس Servqual مقارنة ببعض الجامعات

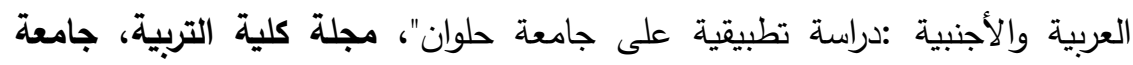

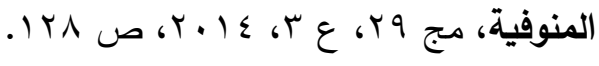


مجلة كلية التربية بالإسماعيلية - العدد الرابع والأربعون - مايو 9 م

• 1- سهير على الجيار، "القيادة الريادية مدخلاً لتحقيق متطلبات مجتمع المعرفة بالجامعات

المصرية"، من أوراق عمل المؤتمر العلمي السنوي الخامس والعشرين للجمعية

المصرية للتربية المقارنة والإدارة التعليمية :نظم التعليم ومجتمع المعرفة، فى الفترة من

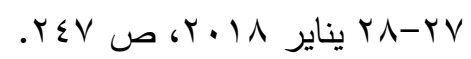

1 - 1 - محمد حسنين السيد طه، "قياس جودة الخدمة التعليمية المقدمة من الجامعات المصرية :

مدخل القياس المقارن"، المجلة العلمية للدراسات التجارية والبيئية، جامعة قناة

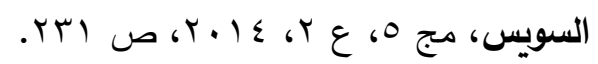

Bray, Mark \& et.al., Comparative Education Research: -1 r

Approaches and Methods, Library of Congress, New York, 2014,

ب ا- المنظمة العربية للتمية الإدارية، معجم المصطلحات الإدارية، المنظمة العربية للتمية

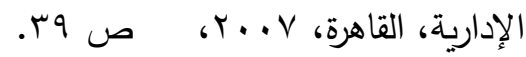

ع ا - لمياء محمد أحمد السيد ، "تقييم أداء الجامعات الحكومية في ج • م. ع باستخدام بطاقة

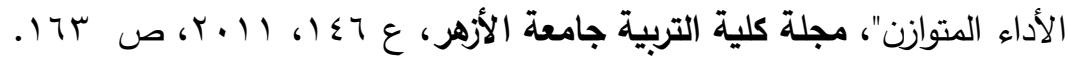
10-سعاد بوعناقة جديدي، "قياس الأداء من خلال تقنية القياس المقارن Benchmarking: دراسة في المفاهيم وآليات التطبيق"، المؤتمر الخامس والعشرون :جودة الأداء في المكتبات ومراكز المعلومات والأرشيف، الاتحاد العربي للمكتبات والمعلومات (أعلم)،

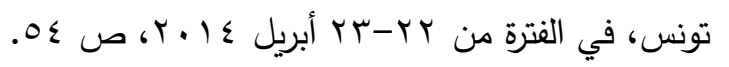

7 ا - محمد رفعت حسنين، "نماذج تطبيقية لأسلوب القياس المقارن بالأفضل لتحسين أداء

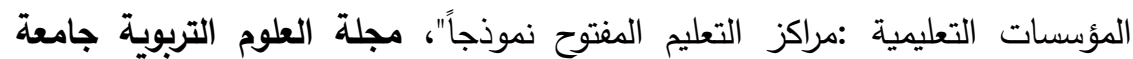

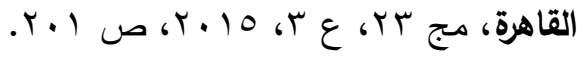

IV - ادية يوسف جمال الدين، "المقارنة المرجعية كمخل لتحسين الأداء"، مجلة العلوم

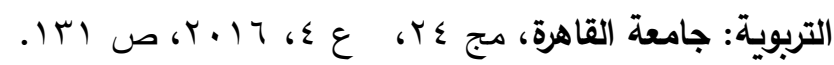

Weeks, Patricia, op.cit., p. 16. - I^

Cambridge Business English Dictionary, "Benchmarking" , Cambridge -19 University Press, available at:

https://dictionary.cambridge.org/dictionary/english/benchmarking, accessed: 6/3/2019. 
بدائل مقترحة لتطوير منظومة تقييم أداء الجامعات --- د/ محمد ابراهيم عبد العزيز خاطر

Garg, R.K. \& Ma, J. , "Benchmarking culture and performance in $-r$.

Chinese organizations", Benchmarking: An International

Journal, Vol. 12, No.3, 2019, p.118.

ا Y- عمار فتحي موسى إسماعيل، "معوقات تطبيق مدخل إدارة المعرفة في مؤسسات التعليم

العالي في مصر : مدخل القياس المقارن"، المؤتمر العلمي السنوي العربي الرابع :إدارة المعرفة وإدارة رأس المال الفكري في مؤسسات التعليم العالي في مصر والوطن العربي:

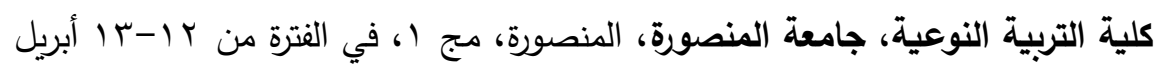

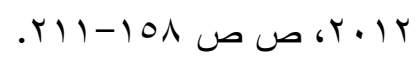

El-Hefnawy, Mohamed Rashad M, El-Bastawissy, Ali Hamed \& - Y Y Kadry, Mona Ahmed, "Benchmarking the Higher Education Institutions in Egypt using Composite Index Model", International Journal of Advanced Computer Science and Applications, Special Issue on Extended Papers from Science and Information Conference, 11-12 January 2014, pp.1-16. Al-Khalifa, Lobna Ali, "Benchmarking as a means to gauge and - r improve academic standards in higher education within the Arab Region", The Business and Management Review, Vol. 6 , No. 5, September 2015, pp. 308-321.

צץ- جبل حامد علي حسن ، "المقارنات المرجعية مدخل لدعم صناعة القرار الجامعي"،

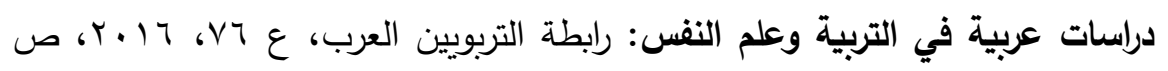
ص.

هץ - فؤاد أحمد حلمي، "المقارنة المرجعية Benchmarking"، المؤتمر العلمي السنوي الرابع والعشرين :قيادة التعليم وإدارته في الوطن العربي : الواقع والرؤى المستقبلية، الجمعية

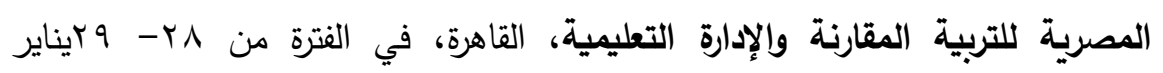

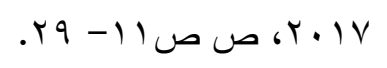

Weeks, Patricia, op.cit., pp. 1-26. - ז 
مجلة كلية التربية بالإسماعيلية - العدد الرابع والأربعون - مايو 9 م ـ

TV رتيبة بوهالى ومبارك بلالطة، "نموذج مقترح للمقارنة المرجعية في الجودة للجامعات

العربية : دراسة مقارنة بين جامعة جيجل الجزائرية والجامعة الأردنية"، المجلة العربية

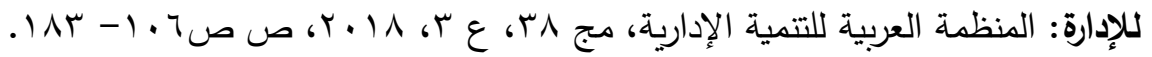

^ץ- التهامي محمد إبراهيم متولي، "تطوير أداء مركز ضمان الجودة والتدريب بجامعة الأزهر

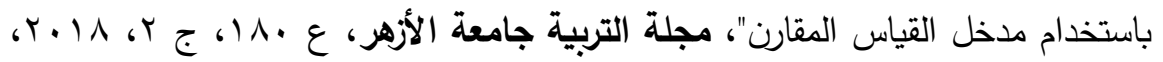

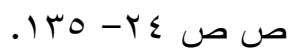

Resnick, Lauren B., "Benchmarking Education Standards", - $q$

Educational Evaluation and Policy Analysis, Vol. 17, No. 4,

$$
\text { 2019, pp. 438- } 461
$$

• ץ-فاطمة علي السعيد جمعة، "تقييم أعضاء هيئة التدريس لمشروع الجودة الثاملة

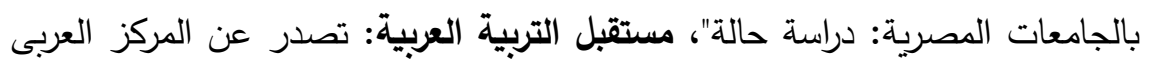

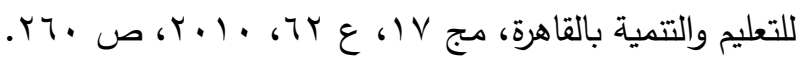

اب- عاليه عبدالحميد عارف، "معايير متابعة و قياس الأداء في المنظمات العامة بالتركيز

على استخدام النموذج الأوروبي للجودة EFQM"، مجلة الإدارة: تصدر عن اتحاد

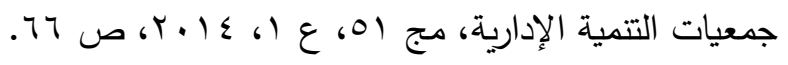

ץ ب-أسامة محمود قرني، "تصور مقترح لتطبيق مدخل الأداء المتوازن في إدارة الجامعات

المصرية"، مجلة التربية: تصدر عن الجمعية المصرية للتربية المقارنة والإدارة التعليمية،

$$
\text { مج }
$$

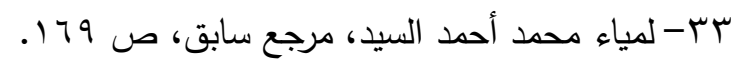

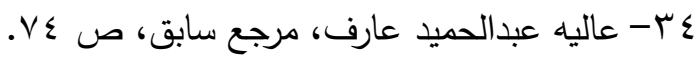

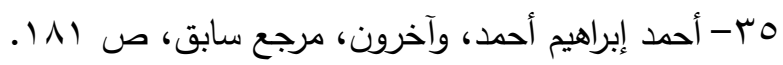

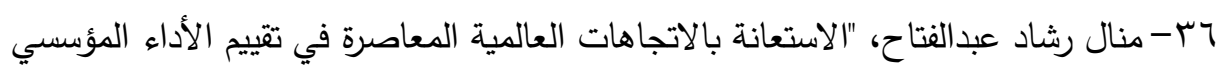

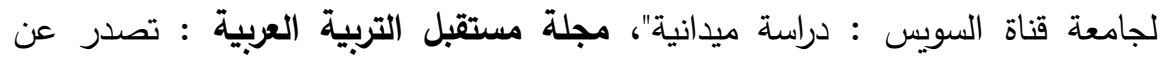

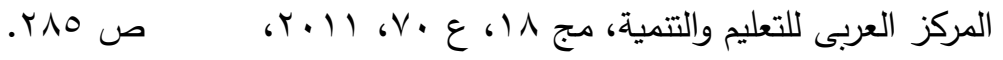

$$
\begin{aligned}
& \text { rV }
\end{aligned}
$$

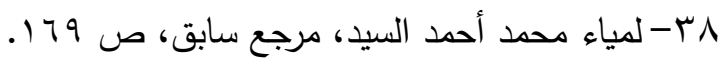


بدائل مقترحة لتطوير منظومة تقييم أداء الجامعات --- د/ محمد ابراهيم عبد العزيز خاطر

q ب-محد علي الثباطات، "مفهوم حوكمة الجامعات وأثره في تعزيز معايير الثفافية

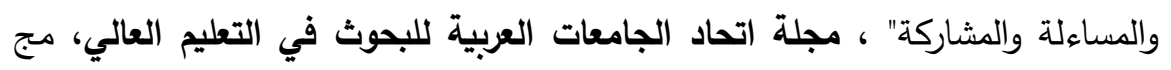

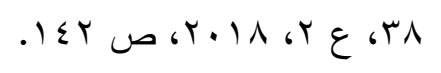

• ع - أحمد سعيد بامخرمة ومحمد عمر باطويح، "تطبيق مفهوم الحوسبة في الجامعات العربية

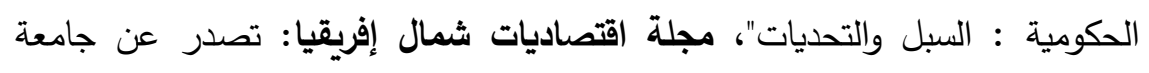

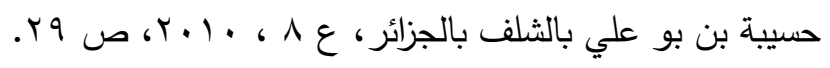

اء-نرجس صفو، "أهمية الحوكمة لضمان جودة التعليم العالي"، أعمال ملتقى الأمانة

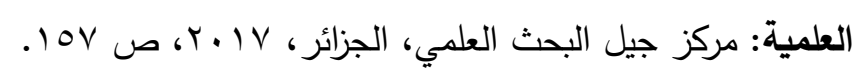

Y Y - رانيا عبد المعز الجمال، "دراسة مقارنة لحوكمة الجامعات في كل من جامعتي ماسترخت وفيينا وإمكانية الإفادة منها في الجامعات المصرية"، مجلة التربية: تصدر عن الجية الجمعية

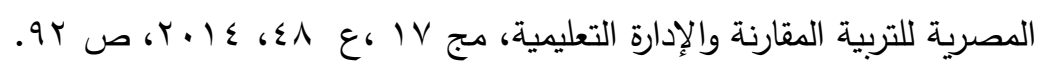
بـ-مديحة فخري محمود، "دراسة تحليلية لـفهوم الحوكمة الرشيدة ومتطلبات تطبيقه في الجامعات المصرية"، مجلة مستقبل التربية العربية: تصدر عن المركز العربى للتعليم

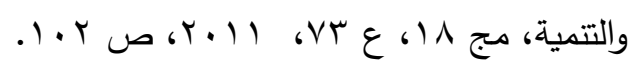

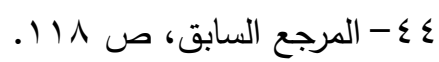

هـ - هالة فوزي محمد ، "تطوير الأداء الإداري بالجامعات السعودية بالاستفادة من أبرز نماذج العادي

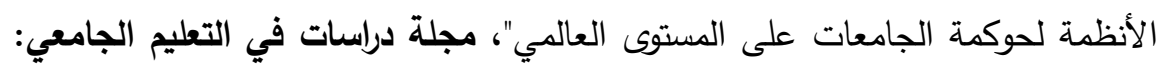

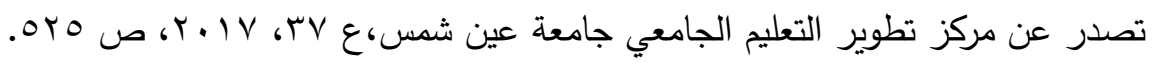
7 צـ-رمزى عطية محمد مزهر ، "دور التخطيط الاستراتيجي في تحقيق جودة الخدمات التعليمية والبحثية: دراسة ميدانية مقارنة بين الجامعات العربية والأجنبية"، المجلة العلمية دولية

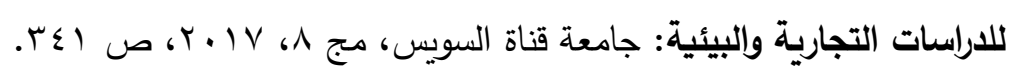
乏V التعليم العالي"، المؤتمر القومي السنوي الثامن عثر بعنوان: تطوير منظومة الأداء في الجامعات العربية في ضوء المتغيرات العالمية، جامعة عين شمس مركز تطوير التعليم

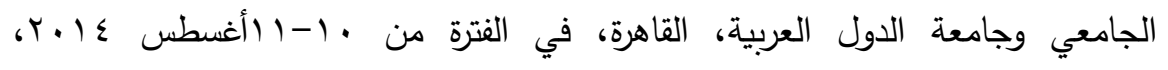
ص إl 
مجلة كلية التربية بالإسماعيلية - العدد الرابع والأربعون - مايو 9 م ـ

- وإنظر أيضاً:

علي عبدالله النودل، "حوكمة أنثطة البحوث العلمية: دراسة نقدية لممارسات برامج

الكراسي البحثية في الجامعات السعودية كنموذج"، من بحوث مؤتمر بعنوان: الرؤيا

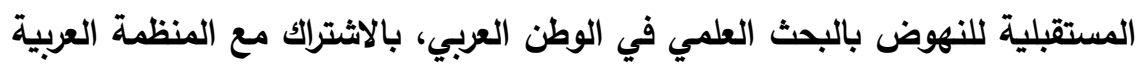

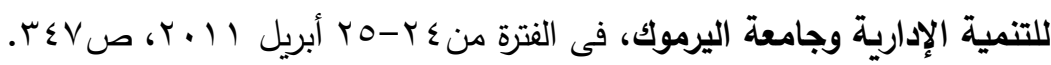

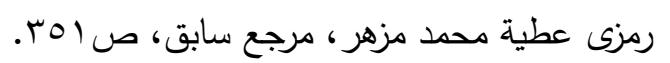

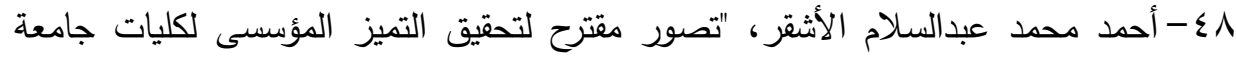

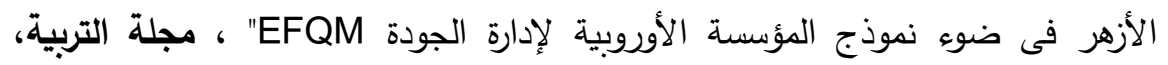

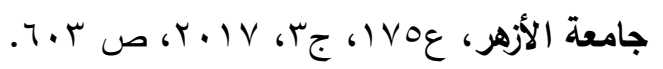

9 ؟ - وزارة التعليم العالي، الوظيفة الثالثة للجامعات، وكالة الوزارة للتخطيط والمعلومات، الإدارة

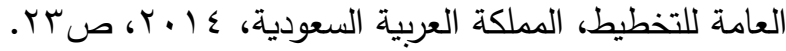

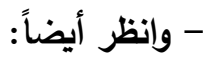

قاسم بن عائل الحربي، " دور جامعة جازان فى تتمية وخذمة المجتمع المحلى: دراسة

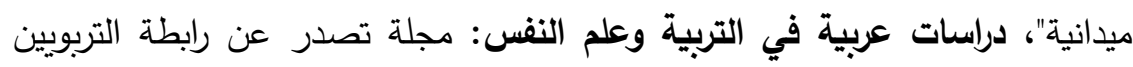

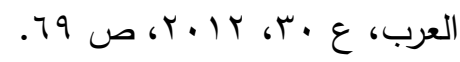

•- هيلة بنت عبدالله سليمان الفايز، "نموذج متترح لمعايير حوكمة الجامعات الحكومية

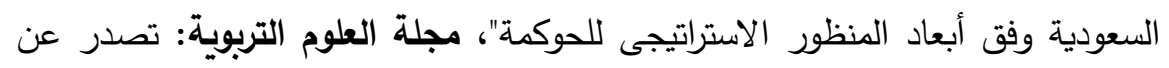

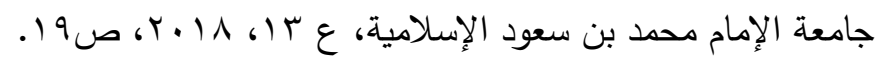

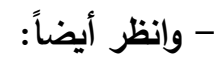

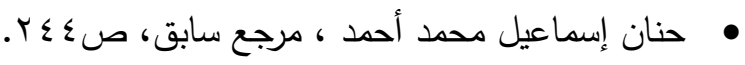

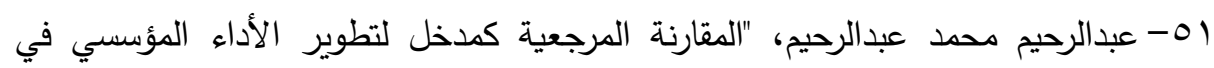

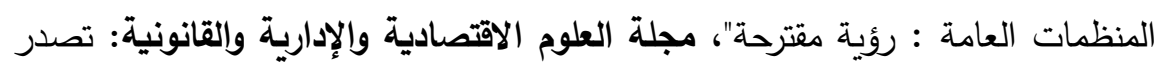

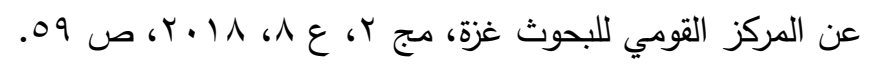

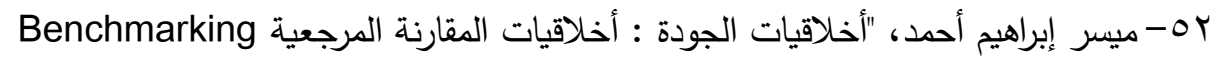

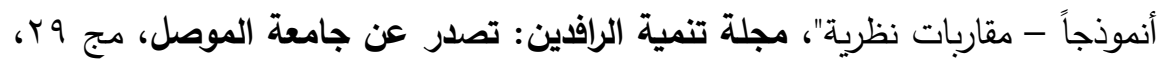

$$
\text { . IV^ }
$$


بدائل مقترحة لتطوير منظومة تقييم أداء الجامعات --- د/ محمد ابراهيم عبد العزيز خاطر

به- أحمد جميل وميلود زيد الخير، "مدخل المقارنة المرجعية من خلال الأدلة الإرشادية

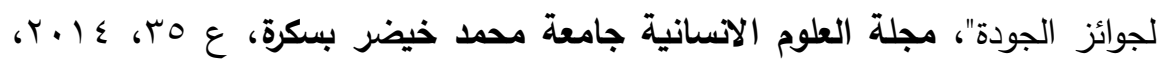

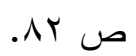

Kovacic, A. , "Benchmarking the Slovenian competitiveness by -0 纟 system of indicators", Benchmarking: An International Journal,

Vol.14, No.5, 2017, p. 504.

00- جيسون سول، "المقارنة المرجعية للمؤسسات غير الربحية : كيف تقيس وتدير وتطور الأداء؟"، مجلة مداد لدراسات العمل الخيري: المركز الدولي للأبحاث والدراسات، ع ع بات، ror 2 r. II

4ه- زرزار العياشي وكريمة غياد، "الإطار المفاهيمى لتطبيق المقارنة المرجعية وأهميتها

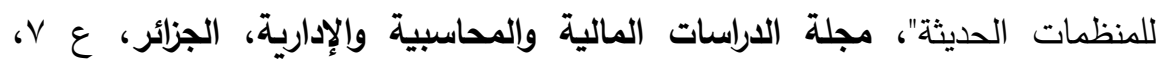
$.11906 .1 V$

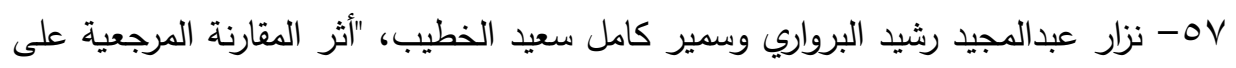
الأداء المنظمي : دراسة حالة مع نموذج مقترح"، مجلة التعاون الصناعي في الخليج

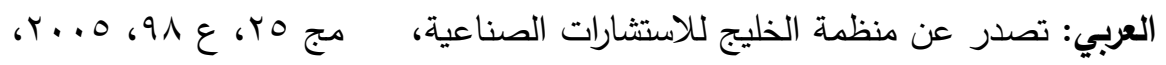
ص 1.

A- ميسر إبراهيم أحمد الجبوري، وأحمد هاني محمد النعيمي، "بناء بيت الجودة باستخدام

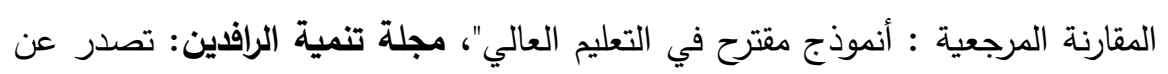

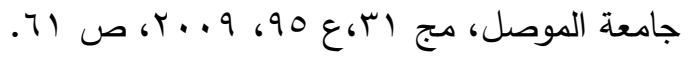
- وانظر أيضاً:

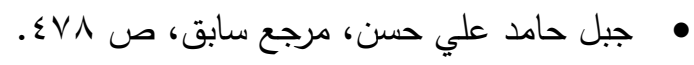

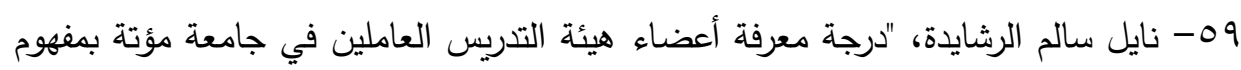
القياس المقارن ودرجة ممارستهم لله"، مجلة مؤتة للبحوث واللاراسات، سلسلة العلوم

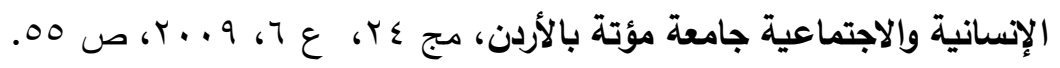

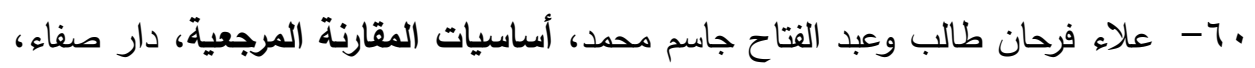

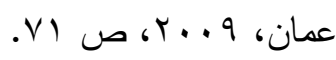

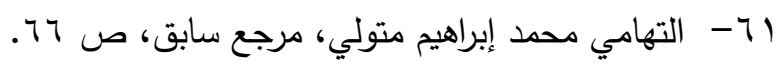
Al-Khalifa, Lobna Ali, op.cit., p.315. - - r 
با7- عاطف كامل عطا الله، "تأثير استخدام نظام القياس المقارن على فعالية تحديد

الاحتياجات التدريبية:دراسة تطبيقية على مشروع تطوير قدرات أعضاء هيئة التدريس

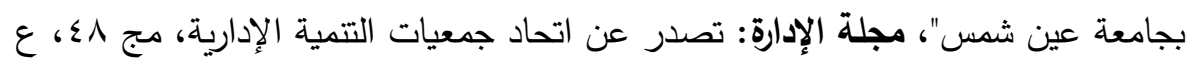

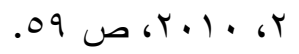

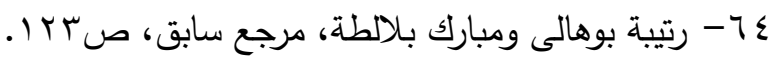

Committee on Science, Engineering, and Public policy, op.cit., - 70

p.78

Stadler, C., op.cit., p.83.-7

Harvard University, Mission, Vision, and History, available at: - $7 \mathrm{~V}$ https://college.harvard.edu/about/mission-and-vision, accessed:

$1 / 4 / 2019$.

Harvard University, About Harvard, available at: -71 http://www.harvard.edu/about-harvard, accessed: 29/3/2019.

Harvard University, Admissions \& Aid, available at: -79 http://www.harvard.edu/admissions-aid, accessed: 2/4/2019.

Harvard University, Harvard's President \& Leadership, $-\vee$. http://www.harvard.edu/about-harvard/harvards- available at: president-leadership, accessed: 13/3/2019.

Harvard University, Administrative Offices, available at: $-v$ ) https://www.harvard.edu/about-harvard/administrative-offices, accessed: 21/3/2019.

Harvard university, "Green Revolving Funds in Action: Case Study - - $r$ Series", available at: http://greenbillion.org/wpcontent/uploads/2011/10/Harvard.pdf , accessed: 2/3/2019

Seltzer, Margo, et.al., "The Case for Application-Specific $-\vee r$ Benchmarking; Harvard University", available at: http://www.eecs.harvard.edu/ margo/papers/hotos99-2/paper.pdf, accessed: 2/3/2019.

available at: Harvard university, "The Harvard system", - - $\varepsilon$ http://www.uefap.com/writing/referenc/harvard.pdf, $: 2 / 4 / 2019$

Committee on Science, Engineering, and Public policy, op.cit., -vo p.78 Seltzer, Margo, et.al., op.cit. $\quad-\vee\urcorner$ 
بدائل مقترحة لتطوير منظومة تقييم أداء الجامعات --- د/ محمد ابراهيم عبد العزيز خاطر

Harvard university, "Benchmark Best Practices: Mentoring, $-\mathrm{V} \vee$ Appreciation \& Recognition", available at:

https://coache.gse.harvard.edu/files/gse-coache/files/coachementoring.pdf, accessed : 4/3/2019.

Ibid. $-\vee \wedge$

The university of Pennsylvania, "A Comprehensive Evaluation and - - 9 Benchmarking", available

at:

http://equity.psu.edu/workshop/assets/pdf/fall13/penn-statecomprehensive-evaluation-benchmarking, accessed: 12/4/2019.

The university of Pennsylvania, "Examples of Benchmarking $-\wedge$. Reports in Higher Education", available at: http:/www.planning.salford.ac.uk/ data/assets/pdf file/0020/2065 7/Examples-of-Benchmarking-Reports-in-Higher-EducationMembership.pdf, accessed: 12/4/2019

The university of Pennsylvania, " Powering Philadelphia and $-\wedge$ ) Pennsylvania", http://www.evp.upenn.edu/pdf/Penn_Economic Impact Powering PHL_PA.pdf, accessed: 29/3/2019.

Winning\& et.al., "Benchmarking learning and teaching: $-\wedge r$ developing a method", Quality Assurance in Education, Vol.14, No. 2, 2006, p. 133.

Miguel, P.A. \& Carnevalli, J.A., "Benchmarking practices of $-\wedge r$ quality function deployment: results from a field study", Benchmarking: An International Journal, Vol. 15 No. 6, 2008, p. 657.

Timothy O., Daniel W.M., "Development of a benchmarking -^₹ model for BIM implementation in developing countries", Benchmarking: An International Journal, Vol. 26, Issue, 4, 2019, pp. 1210-1211.

Saunders, M., Mann, R. and Smith, R., "Benchmarking -^o strategy deployment practices", Benchmarking: An International Journal, Vol. 14, No. 5, 2007, pp. 605-606 Maqsood, Ahmad, Tareq, Zayed \& Wikström, Kim , -ᄉ "Benchmarking the strategic roles of the project management office (PMO) when developing business ecosystems", Benchmarking:

An International Journal, Vol. 26, Issue: 2, 2019, pp. 452-453.

Xing, Zhou, \& Holger, Kohl, "High-performance benchmarking of - $-\wedge \mathrm{V}$ manufacturing processes with object-based modeling", 


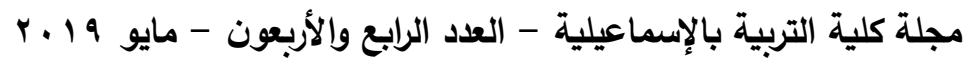

Benchmarking: An International Journal, Vol. 24, Issue 7, 2017, pp. 2063-2064.

OECD, Benchmarking higher education system performance: $-\wedge \wedge$

Conceptual framework and data; Enhancing Higher Education

System Performance, OECD, Paris, 2017, pp.12-15.

Spendolini, M J, The Benchmarking, American management $-\wedge q$ association communications (AMACOM), New York, 2010, p. 79.

$$
\text { Ibid, p.89. }-9 \text {. }
$$

Stella, A., \& Woodhouse, D. "Benchmarking in Australian higher - 9 ) education", available at:

http://pandora.nla.gov.au/pan/127066/201108260004/www.auqa.ed u.au/files/publications/benchmarking final text website.pdf. accessed: 21/3/2019.

The Association of Commonwealth Universities, "Benchmarking - 9 r archaeology degrees in Australian universities", available at:

http://www.acu.ac.uk/member_services/benchmarking_programme/ benchmarking programme, accessed: 12/2/2019.

The Association of Commonwealth Universities, "What is benchmarking?", available at: http://www.acu.ac.uk/member_services/benchmarking programme/ what is benchmarking, accessed: 5/3/2019

Wilson, A., Pitman, L., \& Trahn, I. , "Guidelines for the -9 ร application of best practice in Australian university", international benchmarks, Department of Education, Training and Youth Affairs, Canberra, 2010, pp. 44-45

Department of Education, Training and Youth Affairs, -90 Benchmarking A manual for Australian Universities, Commonwealth of Australia 2012, p. 124.

The European Commission (Programme: Tempus IV), -97 Benchmarking of Quality Assurance in Higher Education: Experiences from the FOCUS Project, University of Alicante International Project Management Office, 2013, p. 60.

Mok, Ka Ho, \& Chan, Ying, "International Benchmarking with the $-9 \mathrm{~V}$ Best Universities: Policy and Practice in Mainland China and Taiwan", Higher Education Policy, 2008, p. 469.

The UNESCO European Centre for Higher Education (UNESCO - - $-\wedge$ CEPES), A Practical Guide Benchmarking in European Higher Education, the European Commission, 2008, pp. 168-169. 
بدائل مقترحة لتطوير منظومة تقييم أداء الجامعات --- د/ محمد ابراهيم عبد العزيز خاطر

Rezić, Snježana \& et.al., Benchmarking; Handbook for the -99 Universities of BIH, Benchmarking AS A Tool for Improvement of Higher Education Performance, The publication is produced within the implementation of the TEMPUS Project, 2014, pp.88-89.

Steve, Garlick \& Langworthy, Anne, "Benchmarking University -1.. Community Engagement: Developing a National Approach in Australia", Higher Education Management and Policy ,Vol. 20, Issue 2, 2018, p. 40.

Achim, Moise Ioan \& et.al., "on the Role of Benchmarking in The $-1 \cdot 1$ Higher Education quality assessment", Annales Universitatis Apulensis Series Oeconomica, Vol.11, No.2, 2009, p. 124.

Shafer, B.S.\& Coate, L.E." Benchmarking in Higher Education: A - - • r Tool for Improving Quality and Reducing Cost, Business Officer, Vol.26, No.5, 2012, pp.28-29.

Resnick, L. B., Nolan, K. J.\& Resnick, D. P., "Benchmarking -1.r Education Standards", Educational Evaluation and Policy Analysis Winter, Vol. 17, No. 4, 2009, pp. 438-439.

Booth, Sara, "Higher Education Pacific Quality; Benchmarking - - . Project 2017: Benchmarking teaching quality, reward and recognition, programme quality, and student voice", A report prepared for University of Tasmania, 2017, p. 77.

Booth, S. , "Utilising benchmarking to inform decision-making at -1.0 the institutional level: A research informed process", Journal of

Institutional Research, Vol.18, No.1, 2012, p. 8.

Longden, B., \& Yorke, M., "Institutional research. Perspectives", - 1 · 7 Policy and Practice in Higher Education, Vol.13, No.3, 2009, p.

66.

Epper, R. M.," Applying benchmarking to higher education: Some - - •V lessons from experience", Change, Vol.31, No.6, 2011, p. 17.

Australasian Council on Open Distance and e-Learning, -1.1 "Benchmarks for e-learning in universities and guidelines for use, available at: http://www.acode.edu.au/resources/acodebmguideline0607.pdf, accessed: $1 / 2 / 2019$

Council of Australian directors of academic development (cadad), - 1 . 9 Benchmarking Performance of academic development Units in Australian Universities, 2011, p. 256. 
مجلة كلية التربية بالإسماعيلية - العدد الرابع والأربعون - مايو 9 م ـ

Ibid, pp. 128-129. -11

Levy G. \& Ronco S, "How Benchmarking and Higher Education -111 Came Together?", New Directions for Institutional Research, 2012, pp. 13-15.

Penelope, S. , "Benchmarking Academic Research Output in $-11 \mathrm{r}$ Australia", Journal Assessment \& Evaluation in Higher Vol. 20, Issue 1, 2011, p.7. Education,

Freeman, Brigid, "Benchmarking Australian and New Zealand - 11 r university meta-policy in an increasingly regulated tertiary environment", Journal of Higher Education Policy and Management, Vol. 36, Issue 1, 2014, p. 167.

Anderson , D.\& et. al., "Quality Assurance and accreditation in -11 \& Australian Higher Education: An assessment of Australian and International practice", Center of continuing Education, Australian National University, Australia, 2012, pp. 12-13.

Shafer, B.S.\& Coate, op.cit., p. 32. -110

OECD, op.cit., p. 42. -117 - I IV

11 1 - اسماعيل سراج الدين وآخران، حوكمة الجامعات وتعزيز قدرات منظومة التعليم العالي

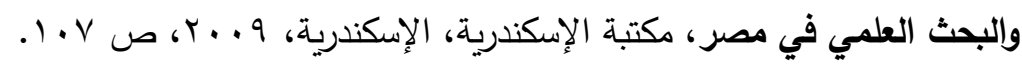

9 11 1-وزارة التعليم العالي بمصر، "أفاق تطوير التعليم العالي"، مجلة تصدر عن المجلس مصله

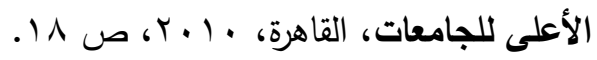

• Y ا-فاروق جعفر عبدالحكيم، "حوكمة الجامعات : مدخل لتطوير الإدارة من خلال

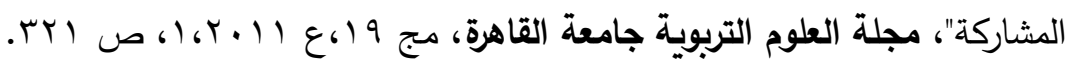

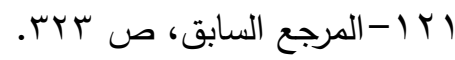

r Y -مجدي عبد الوهاب قاسم وفاطمة الزهراء سالم، مستقبل جودة التعليم (التدويل وريادة

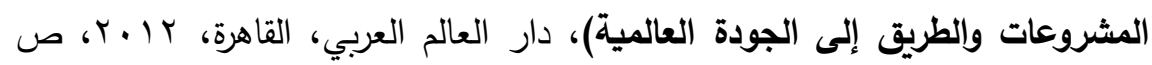
.177

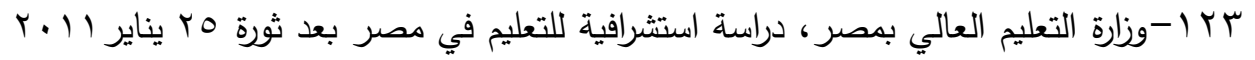

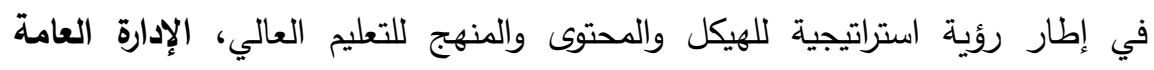

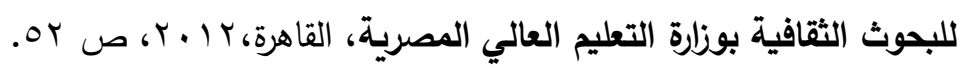
ع I T أسامة محمود قرني، مرجع سابق، ص AV. 
بدائل مقترحة لتطوير منظومة تقييم أداء الجامعات --- د/ محمد ابراهيم عبد العزيز خاطر

0 ا أماني محمد شريف عبدالسلام، "الجودة البحثية فى الجامعات المصرية : المؤشرات

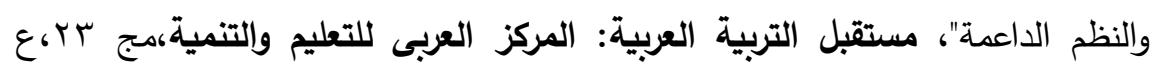

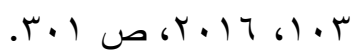

ד Y - بائشة عبد الفتاح مغاورى، "تصور مفترح لتدويل التعليم الجامعي المصري في ضوء

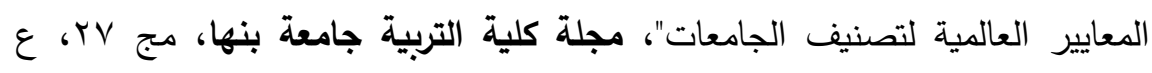

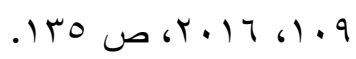

I IV V -طارق عبد الرووف عامر ، الجامعة وخدمة المجتمع: توجهات عالمية معاصرة، مؤسسة

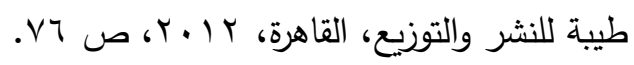

^ץ ا -محمد ريحان حسين، "طبيعة الوحدات ذات الطابع الخاص وأهميتها في تتمية الموارد

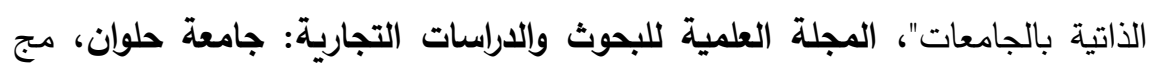
r r 100 ص 9 ا ا-عزة مختار إبراهيم عبدالرحمن البنا، "تطبيق Six Sigma في التعليم العالي"، المؤتمر القومي السنوي الثامن عشر : تطوير منظومة الأداء في الجامعات العزبية في ضوء المتغيرات العالمية المعاصرة، جامعة عين شمس - مركز تطوير التعليم الجامعي

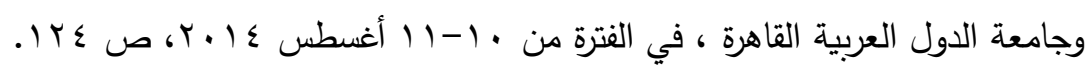
• با ا-منظمة التتمية الاقتصادية والتعاون بالاشتراك مع البنك الدولي، مراجعة لسياسات التعليم

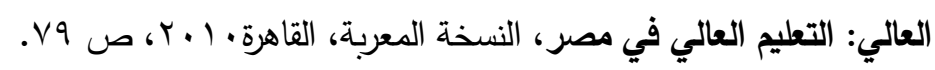


مجلة كلية التربية بالإسماعيلية - العدد الرابع والأربعون - مايو 19 ب P

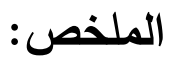

سعت الاراسـة إلى توظيف أسلوب القياس المقارن في تطوير منظومـة تقييم الأداء

الجامعية بما تثمله من مدخلات وعمليات ومخرجات، ولتحقيق هذا الهلف اعتمدت الدراسـة على أسلوب تحليل النظم (Systems Analysis approach)؛ وذلك لتحليل مكونـات

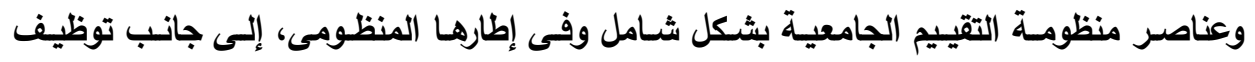

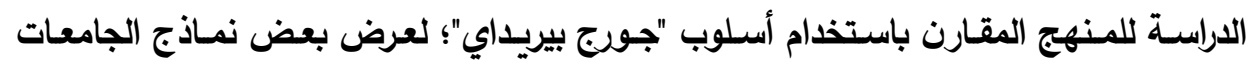

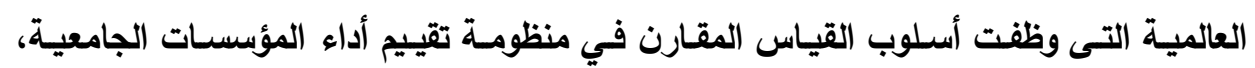

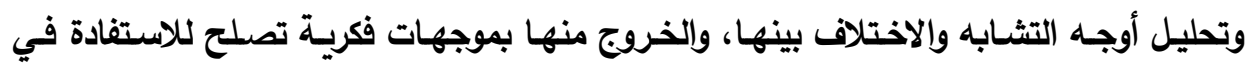
تطوير منظومـة تقييم الأداء بالجامعات المصرية. ولقد توصلت الاراستة إلى تقديم ثلاثلة بدائل الئل

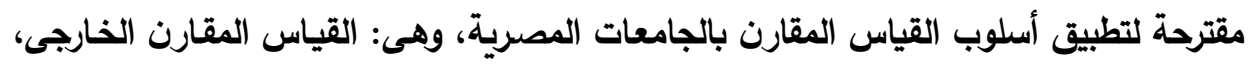
والقياس المقارن الداخلى، والقياس المقارن التثاركى، ثم تمت المفاضلة بين هذه البدائل البدائل؛ لتحديد البديل الأكثر مناسبة للسياق التشريعى والتنظيمى بالجامعات المصرية.

Suggested Alternatives for Developing Performance Evaluation System of Egyptian Universities Using the Benchmarking Approach Abstract:

The study amid at using benchmarking approach for developing university performance evaluation system including inputs, processes and outputs. To achieve this objective, the study used systems analysis approach to analyze the components of university evaluation system in a comprehensive and systemic framework. Also, the study used the comparative method through employing "George Bereday" approach to present some models of international universities that implement benchmarking approach in performance evaluation system of university institutions, analyze the similarities and differences between them, and extract suitable intellectual guides to benefit from them for developing the performance evaluation system at Egyptian universities. The study presented three suggested alternatives to implement benchmarking approach at Egyptian universities. These alternatives are represented in the external benchmarking, the internal benchmarking, and the participatory benchmarking. Moreover, a comparison was held between these alternatives in order to identify the most appropriate alternative to the legislative and regulatory context of Egyptian universities. 